\title{
Population Genetics of New Zealand Nemadactylus macropterus (tarakihi) and Characterisation of their Mitochondrial Genome
}

\section{By \\ Alexander Graham Halliwell}

A thesis submitted to Victoria University of Wellington in partial fulfilment of the requirements for the degree of Master of Science in Marine Biology.

Victoria University of Wellington

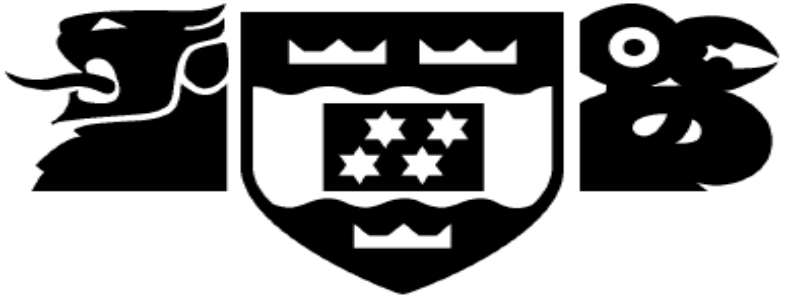

2019 



\section{Abstract}

Nemadactylus macropterus, commonly known as tarakihi in New Zealand is highly regarded by commercial and recreational fishers and considered a taonga by iwi and customary fisheries. For many years N. macropterus was New Zealand's second most important commercial catch and is currently the third most valuable inshore commercial finfish fishery in which $90 \%$ is consumed by the domestic market. However, despite the apparent importance, relatively little is known about the population structure of the N. macropterus. In 2017 the first fully quantitative stock assessment was conducted on the east coast $N$. macropterus fisheries as one stock. Alarmingly, the east coast fishery was estimated to be $15.9 \%$ of the unexploited spawning biomass and predicted to have been declining for the past thirty years. In an effort to rebuild the fishery, several rebuild plans have been purposed and commercial catch limits have been reduced. In order to rebuild and successfully manage a viable future $N$. macropterus fishery, an understanding of demographic connectivity and genetic connectivity among $N$. macropterus populations is essential.

The overall goal of this thesis research was to investigate the population genetic structure, genetic diversity and demographic history of $N$. macropterus using fish sampled from around New Zealand. This was achieved by analysing hyper variable region one of mitochondrial DNA for $370 \mathrm{~N}$. macropterus collected from 14 locations. No genetic differentiation was observed among the 14 locations, an indication that $N$. macropterus have a panmictic genetic structure. Furthermore, N. macropterus display a relatively high level of genetic diversity and appear to have a large stable population with a long evolutionary history. The Bayesian skyline analysis indicates the $N$. macropterus historic population has gone through two expansions. The mostly likely cause of this is an expansion before and after the last glacial maximum.

The genetic diversity and demographic history of $N$. $s p$ was also studied using samples collected from around the Three Kings Islands of New Zealand. The complete mitochondrial genome of $N$. macropterus was reconstructed from bulk DNA sequencing data and a set of specific mtDNA primers were developed to amplify hyper variable region one. The DNA sequencing data provided by these primers with the addition of published control region sequences was used to reconstruct the Nemadactylus phylogeny. 


\section{$\underline{\text { Acknowledgements }}$}

Firstly, I would like to thank my supervisor Dr Peter Ritchie for his continued guidance and support over the last two years and for giving me the opportunity to study my most feared topic - genetics. Thank you for always keeping an open door and willingness to help, you're a good sort Pete.

Next I would like to thank Yvan for spending countless days by my side processing tarakihi samples. Your great banter and Swiss humour made the days fly by. I would also like to thank you for taking me under your wing and providing guidance throughout this thesis.

A massive thank you must go to the Ritchie lab group - Amber, Leah, Tom and Yvan for great yarns, plenty of discussion and lots of laughs. Throughout my thesis it has been awesome getting to know you, hanging out at conferences and group pot luck dinners at Leah's house.

A special mention must go to Levi as he convinced me that I was capable of doing a mountain bike jump that resulted in a four month suspension of this thesis due to two broken elbows. Thank you for always believing in me.

A huge thank you to Dr Mark Morrison, Cameron Walsh and Jono (Cook Strait fishing charters) who organised the collection of tarakihi samples required for this thesis. Thank you to Mark Fenwick, Rob Stewart, Dean Stotter and John Van der Sman for providing the wet lab space necessary for processing the tarakihi samples. Thank you Ben Knight and Rob Wilson for providing underwater images of tarakihi.

Patrice, thank you for always being there for me. You have stuck with me the whole way through this thesis providing a constant source of support and encouragement.

Lastly but not least, I would like to thank my family, especially mum and dad. Without whom I would never have been given this opportunity. You've always supported me no matter what I've chosen to do in life and provided constant encouragement in pursuing my goals and dreams. For that I am eternally grateful, thank you. 


\section{$\underline{\text { Table of Contents }}$}

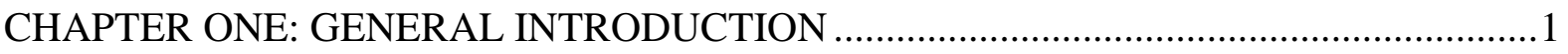

1.1: Population CONNECTIVITY \& Genetic STRUCTURE .....................................................

1.2: NEW ZEALAND's MARINE ENVIRONMENT AND GENETIC CONNECTIVITY ........................

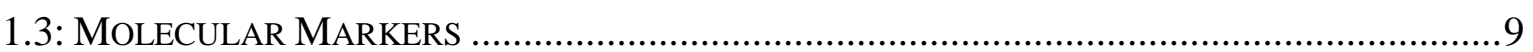

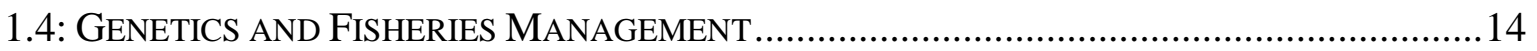

1.5: STUDY SPECIES: NEMADACTYLUS MACROPTERUS (TARAKIHI) AND NEMADACTYLUS SP

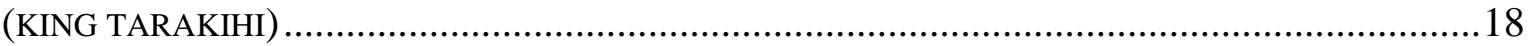

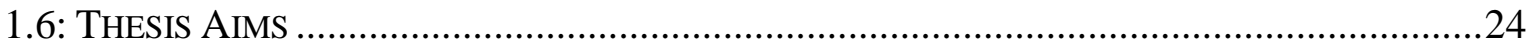

CHAPTER TWO: THE MITOCHONDRIAL GENOME OF NEMADACTYLUS

MACROPTERUS, DEVELOPMENT OF HYPER VARIABLE REGION ONE PRIMERS

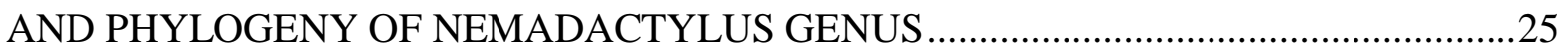

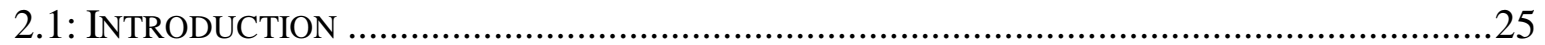

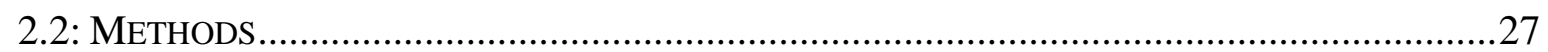

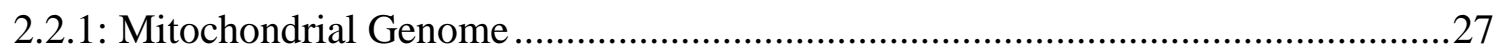

2.2.2: Hyper Variable Region One Primer Design .......................................................29

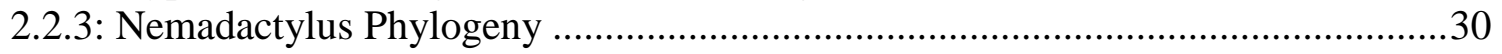

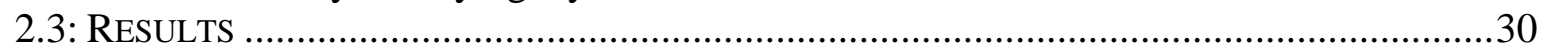

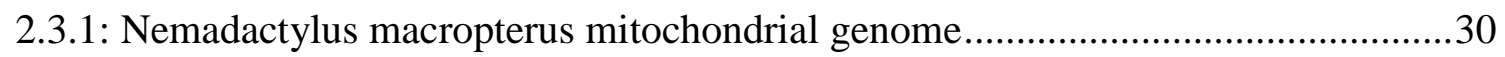

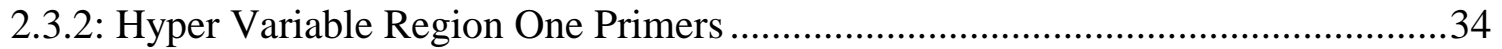

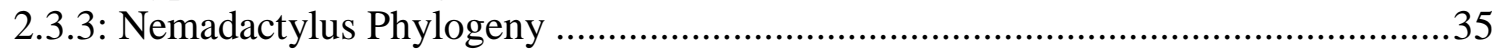

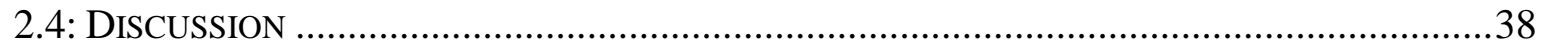

CHAPTER THREE: POPULATION GENETIC STRUCTURE OF N. MACROPTERUS AND DEMOGRAPHIC HISTORY/GENETIC DIVERSITY OF N. MACROPTERUS AND

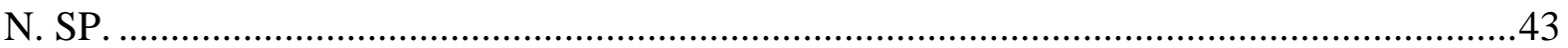

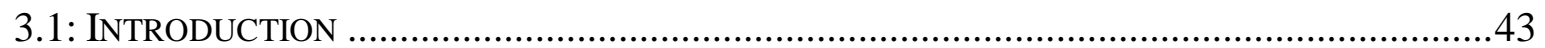

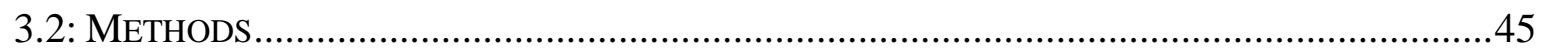

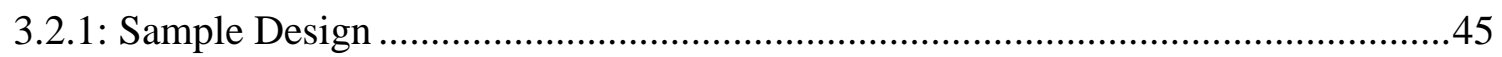

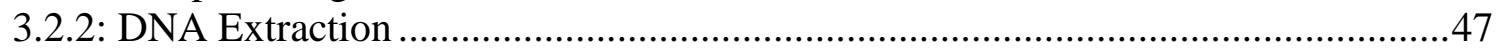

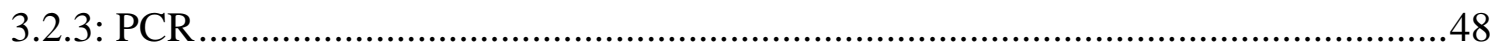

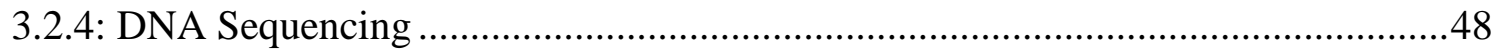

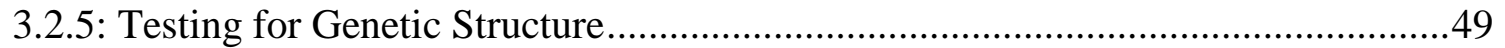

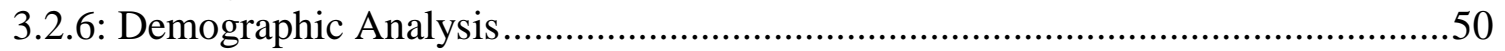

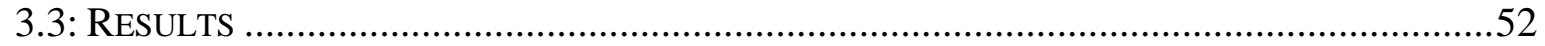

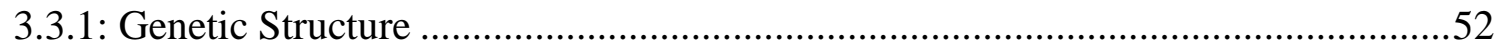

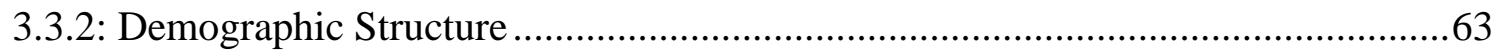

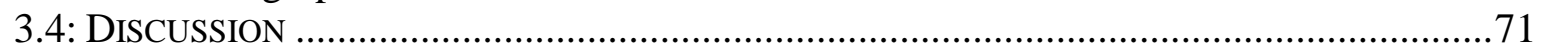

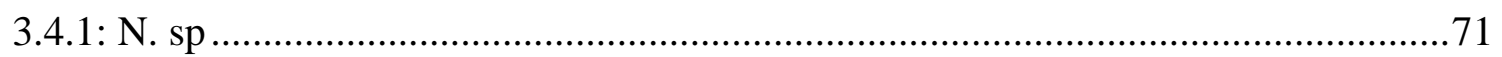

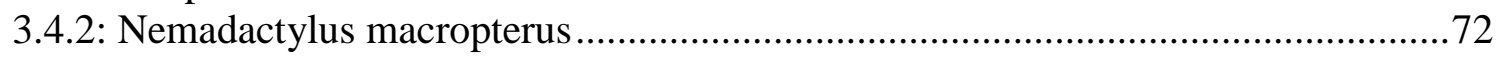

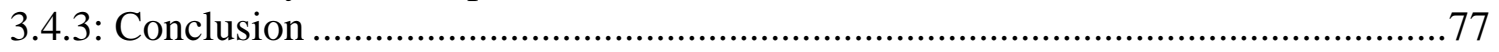

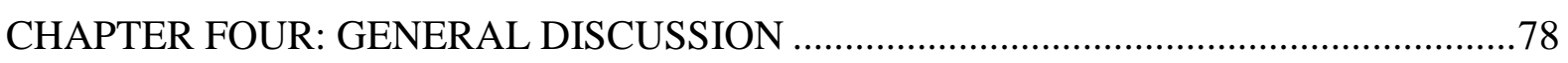

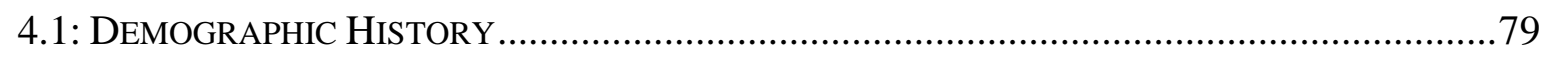

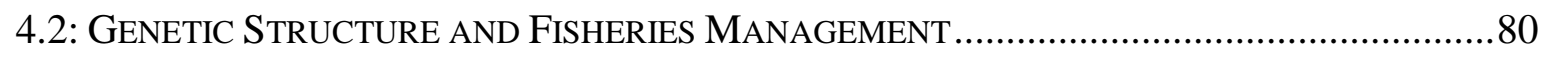




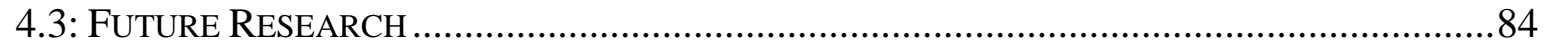

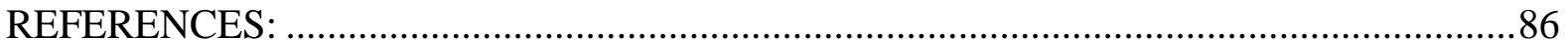

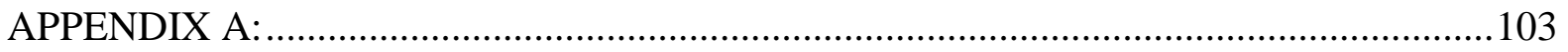

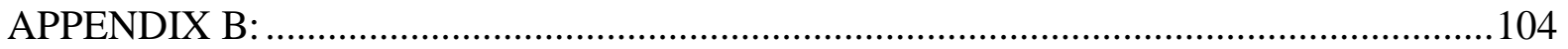




\section{List of Figures}

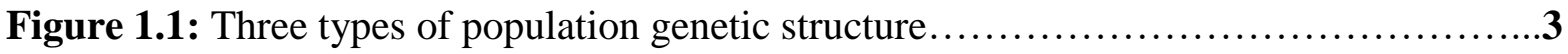

Figure 1.2: Major ocean currents surrounding New Zealand............................5

Figure 1.3: Typical teleost mitochondrial genome.................................

Figure 1.4: Nemadactylus macropterus (tarakihi).................................19

Figure 1.5: $N$. macropterus quota management areas...............................21

Figure 1.6: Nemadactylus $s p$ (king tarakihi)........................................23

Figure 2.1: $N$. macropterus mitochondrial genome...............................31

Figure 2.2: Hyper variable region one primer binding sites............................34

Figure 2.3: Nemadactylus species...............................................

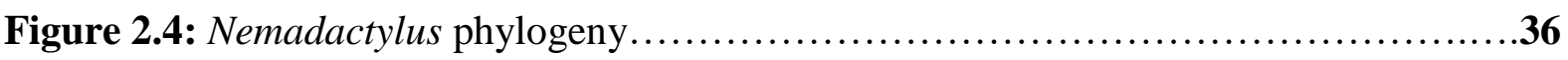

Figure 2.5: Nemadactylus phylogeny sample locations...............................37

Figure 2.6: Possible introgressive hybridization ...............................40

Figure 3.1: Map of $N$. macropterus and $N$. $s p$ sampling locations......................46

Figure 3.2: Rarefaction curve of HVR1 haplotype frequency of $N$. $s p \ldots \ldots \ldots \ldots \ldots \ldots \ldots . . \ldots 56$

Figure 3.3: Rarefaction curve of HVR1 haplotype frequency of $N$. macropterus............56

Figure 3.4: Principal component analysis for all samples..............................60

Figure 3.5: Principal component analysis for non-spawning samples..................60

Figure 3.6: Principal component analysis for spawning samples.......................61

Figure 3.7: Principal component analysis for spawning sizes.........................61

Figure 3.8: Isolation by distance plot for all samples...............................62

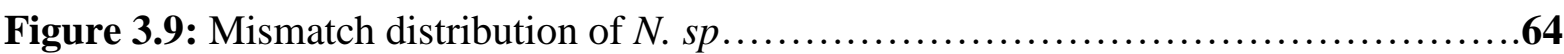

Figure 3.10: Mismatch distribution of $N$. macropterus ...............................65

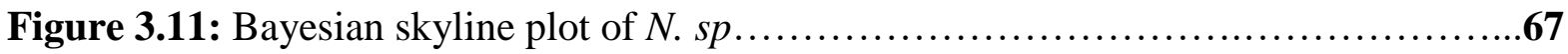

Figure 3.12: Bayesian skyline plot of $N$. macropterus...............................67

Figure 4.1: TAR QMA part of the 2017 east coast stock assessment....................81

Figure 4.2: Trends in N. macropterus east coast stock spawning biomass.................82

\section{$\underline{\text { List of Tables }}$}

Table 2.1: Summary statistics of mitochondrial genome re-construction..................32

Table 2.2: Characterization of $N$. macropterus mitochondrial genome....................33

Table 3.1: Summary statistics of genetic diversity .......................................

Table 3.2: Shared haplotypes..............................................5.555

Table 3.3: Pairwise $\phi \mathrm{ST}$ for $N$. macropterus and $N$. $s p$...............................58

Table 3.4: AMOVA for $N$. macropterus and $N$. $s p$...................................59

Table 3.5: Neutrality and goodness of fit summary statistics........................63

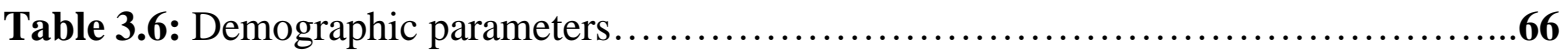




\section{Chapter One: General Introduction}

\section{1: Population Connectivity \& Genetic Structure}

The population is the unit of evolution and therefore an important part of understanding how the evolutionary process works (Luck et al., 2003). A population is defined as a group of conspecific individuals that exist in the same geographic region and display random mating and reproductive continuity (Waples \& Gaggiotti, 2006). Understanding the degree of connectivity between and among populations in the marine ecosystem is a key part in fisheries stock assessments and conservation of species (Ward, 2000). Connectivity occurs via two main mechanisms, demographic connectivity and genetic connectivity (Cowen et al., 2007). Demographic connectivity is the relative contribution of dispersal to population dynamics (Carson et al., 2011). Population dynamics is how biological and environmental factors affect the overall population size (Pulliam, 1988). Changes in population size are due to the increase (natality and immigration) and decrease (mortality and emigration) of individuals within a population (Pulliam, 1988). As the population size changes this also causes change in the population structure (age variation, density, distribution and sex ratio) (Pulliam, 1988). The size of a population does not increase indefinitely because it is limited by density-dependent and density-independent factors (Hixon \& Jones, 2005). Density-dependent factors such as finite resources, competition or habitat availability enforce a limit on the size of a population (Hixon \& Jones, 2005). Density-independent factors are stochastic events such as a natural disaster that dramatically affect population size and structure (Hixon \& Jones, 2005). Dispersal is when a species leaves the home range of its birth population and is the main mechanism driving demographic connectivity (Cowen \& Sponaugle, 2009).

The dispersal potential of a species is largely affected by their life history traits (Bradbury et al., 2008). Marine organisms have a diverse range of life histories but can be divided into two general categories; organisms that have a larval development phase and those that do not (Leis, 2006). The adult stages of marine organisms that do not have a larval phase are often highly dispersive, and their success in mating contributes to demographic connectivity (Selkoe et al., 2016). Organisms that do have a larval stage develop pelagically in the plankton and have the potential for their larvae to disperse somewhat passively with currents and tides (Shanks, 2009). Pelagic larval duration (PLD) is the amount of time larvae spends developing in the plankton (Shanks, 2009). PLD varies between taxa ranging from a short duration of hours or 
days (Haliotis iris, Stephens et al., 2006), moderate 2 - 4 weeks (Perna canaliculus, Apte \& Gardner, 2002) and long 12-18 months (Jasus edwardsii, Thomas \& Bell, 2013). The duration has been suggested to affect the dispersal potential of the larvae and an important determinant of demographic connectivity (Selkoe \& Toonen, 2011). However, despite many marine organisms having highly dispersive life histories, many populations are often not connected and mainly sustained by self-recruitment (eg. coral reef fish, Jones et al., 2005).

Gene flow is a measure of genetic connectivity that is determined by individuals that successfully move among and between populations, and reproduce (Slatkin, 1987). Lower levels of gene flow are expected in species that have a limited power of migration/dispersal (Slatkin, 1987). This is expected to be more common in fragmented habitats, when population size is small, and due to behavioural characteristics such as natal return or assortative mating (Vrijenhoek, 1997). High levels of migration/dispersal increase gene flow and typically results in low levels of genetic differentiation and homogeneity among populations (Lenormand, 2002). If the rate of gene flow is high enough between populations it may result in equivalent allele frequencies, and then they are considered a single population (Bohonak, 1999). An absence of gene flow will increase the level of genetic differentiation between populations and evolutionary forces such as genetic drift will begin to operate independently within each group resulting in genetic heterogeneity among locations (Petit \& Excoffier, 2009). Additional evolutionary processes such as mutation, inbreeding, and selection can influence the patterns of genetic variation within each population independently (Morjan \& Rieseberg, 2004). Overall the level of genetic differentiation among populations is primarily due to the balance between the opposing forces of gene flow and genetic drift. If populations persist in isolation for a long period of time, they may become reproductively incompatible, which will most likely result in speciation. However, the magnitude in which each of the evolutionary forces act upon a population is dependent on the populations size and distribution (Charlesworth, 2009). For example, genetic differentiation may remain low between large populations because genetic drift will be a weak force in that setting.

Laikre et al. (2005) described three generalised patterns of genetic population structure within a species (Figure 1.1), referring to these as: "distinct populations" (Figure 1.1C), "continuous change" (also known as "isolation by distance") (Figure 1.1B), and "no differentiation" (also known as "panmixia") (Figure 1.1A). "No differentiation" or "panmixia" refers to a lack of genetic structure throughout a given part of a species distribution. This pattern occurs when 
there is a high level of gene flow and random mating throughout the geographic range of a population. "Continuous change" or "isolation by distance" describes a gradient of genetic differences across a geographic distance. This occurs when the level of gene flow is higher among nearby areas and lower between more distant locations (Wright, 1943; Laikre et al., 2005). Genetically "distinct populations" form when there is little or no gene flow between populations. When this occurs, evolutionary forces act independently upon each population and if the populations remain in genetic isolation for long enough, speciation can occur. A species genetic structure may fit any of these models, however levels of gene flow can vary throughout their geographic range. This can result in a species fitting a combination of genetic structures, making the distinction between patterns difficult to determine (Laikre et al., 2005).
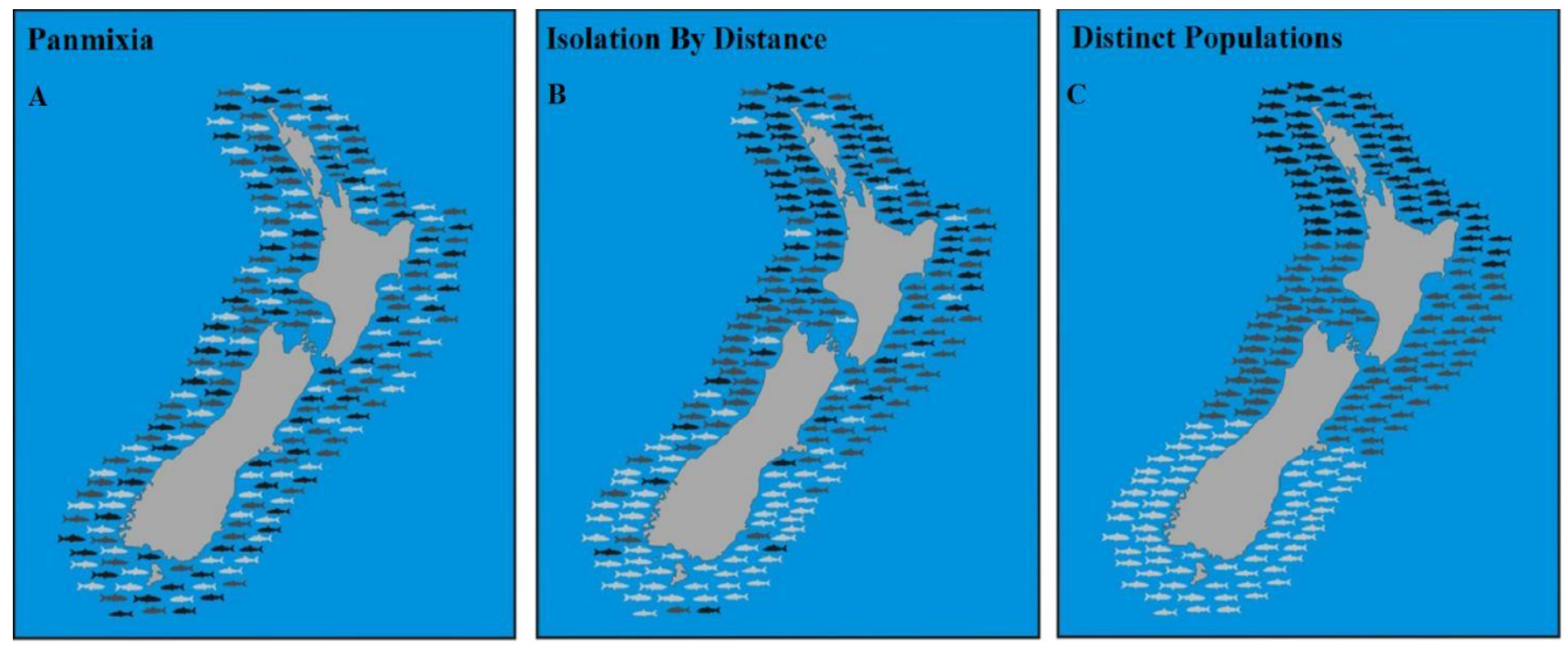

Figure 1.1: Three forms of population structure as defined by Laikre et al. (2005) A: Panmixia where populations display high levels of gene flow and random mating occurs. B: Isolation by Distance or "continuous change" where nearby populations display high levels of gene flow; but low levels of gene flow occur between geographically separate populations. C: Distinct Populations where low levels of gene flow occur between each population and they are not genetically connected. Figure adapted from Smith (2012)

An important consideration is that genetically connected populations do not necessarily mean that they are also demographically connected. Demographic connectivity is measured as the proportion of migrants exchanged in relation to the overall population size (Lowe \& Allendorf, 2010). The proportion required may change depending on taxa, however, generally a minimal threshold of $10 \%$ of the overall population size migrating to a recipient population is considered demographically connected (Lowe \& Allendorf, 2010; Ovenden, 2013). In contrast, genetic connectivity is measured by an absolute number of individuals migrating between populations, and is independent from the total population size (Lowe \& Allendorf, 2010). Only a few 
individuals are required to migrate between populations to achieve low levels of gene flow (Lowe \& Allendorf, 2010). A "rule of thumb" of one migrant per generation is required to prevent populations from diverging (Wright, 1949). However, in some cases dispersal may be high enough to meet the threshold for genetic connectivity but too low to meet the threshold of demographic connectivity, this can lead to a 'crinkled pattern' of connectivity (Ovenden, 2013).

In theory, species with a long PLD are highly migratory/dispersive adults, would exhibit lower levels of genetic divergence and would most likely fit a "panmixia" or "isolation by distance" genetic pattern. The same would be true for species with a shorter PLD or adults with low mobility such as sessile or sedentary species, or those that exhibit site fidelity. They would display a higher level of genetic divergence and most likely fit an "isolation by distance" or "distinct population" genetic structure. However, it seems there is no "one size fits all" answer to the question of which factors contribute to population connectivity due to variations in life history and environmental conditions. Because of this a holistic approach is required that encompasses both demographic connectivity and genetic connectivity to completely understand population connectivity.

\section{2: New Zealand's Marine Environment and Genetic Connectivity}

New Zealand (Aotearoa) is an archipelago of approximately 600 islands that lie on the submerged continental crust of Zealandia. The archipelago stretches from the Subantarctic Auckland (Maungahuka) and Campbell (Moutere Ihupuku) Islands in the south, to the Subtropical Kermadec Islands (Rangitahua) in the north, and Chatham Island (Rēkohu) in the east, creating a region that spans over $2700 \mathrm{~km}$. The North Island (Ikaroa-a-Māui) and South Island (Waipounamu) make up the majority of land mass and are separated by Cook Strait (Raukawa Moana). The third largest island, Stewart Island (Rakiura) is located to the south of the South Island and is separated by Foveaux Strait (Ara-a-Kiwa). 


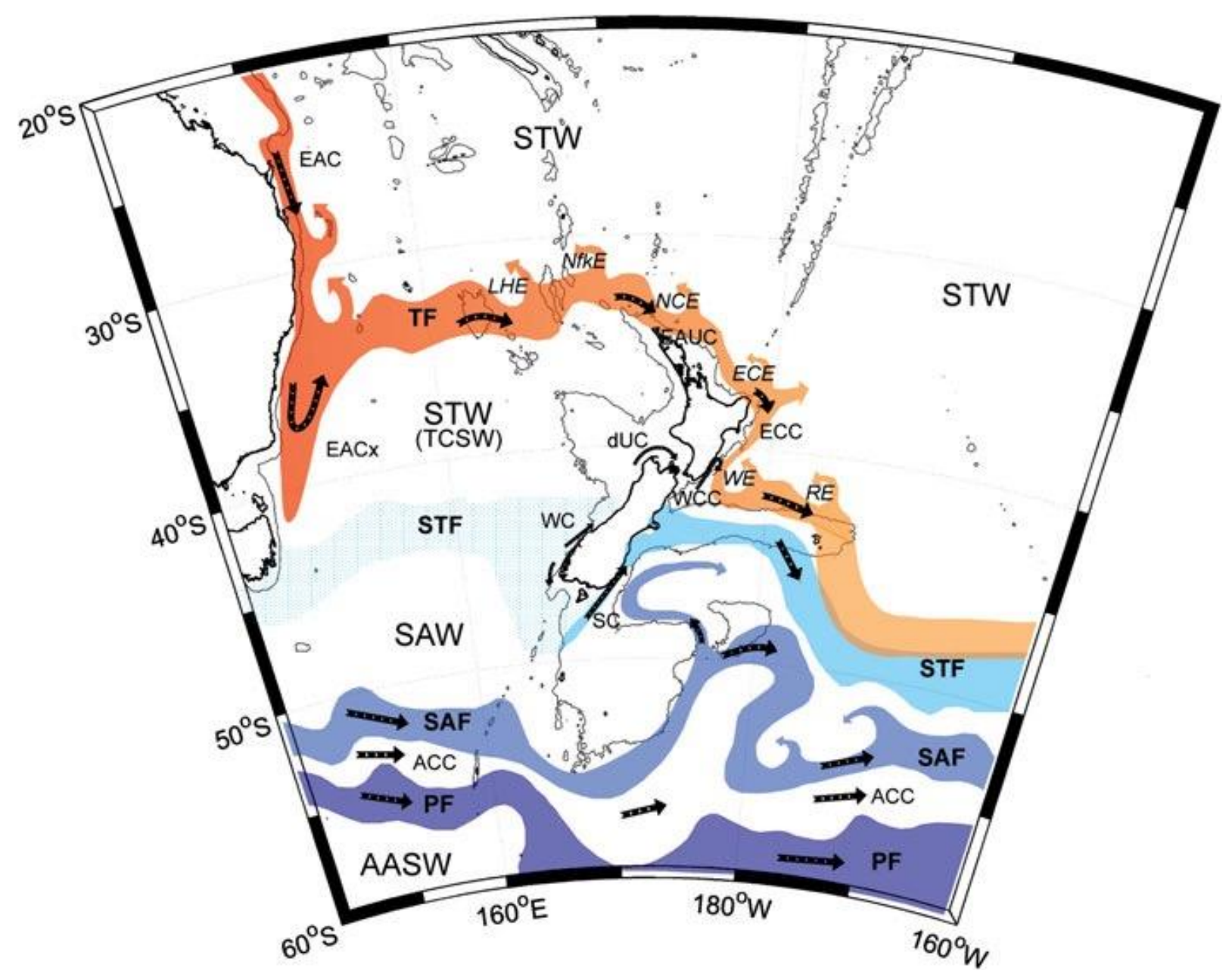

Figure 1.2: The major surface currents surrounding New Zealand are represented by the coloured regions; colour denotes temperature with the red colouration indicating warmer water, whilst blue colours indicate cooler water. Water masses: Subtropical Water (STW), Tasman Sea Central Water (TSCW), Subantarctic Water (SAW) and Antarctic Surface Water (AASW). Ocean fronts: Tasman Front (TF), Subtropical Front (STF), Subantarctic Front (SAF) and Polar Front (PF). Ocean currents: East Australia Current (EAC), East Australia Current extension (EACx), East Auckland Current (EAUC), East Cape Current (ECC), d'Urville Current (dUC), Wairarapa Coastal Current (WCC), Westland Current (WC), Southland Current (SC) and Antarctic Circumpolar Current (ACC). Eddies: Lord Howe Eddy (LHE), Norfolk Eddy (NfkE), North Cape Eddy (NCE), East Cape Eddy (ECE), Wairarapa Eddy (WE) and Rekohu Eddy (RE). Figure retrieved from Chiswell et al. (2015).

The physical oceanography of New Zealand (Figure 1.2) is influenced by two major currents, Subtropical and Subantarctic, that arrive from the west (Chiswell et al., 2015). Subtropical currents arrive at Cape Reinga via the East Australian current and Tasman front. The Tasman front flows around North Cape and then down the east coast of the North Island creating the East Auckland and East Cape currents. The East Cape current extends south around the East Cape where the East Cape Eddie splits off and the current becomes the Wairarapa coastal current. The Wairarapa coastal current then diverges east along the northern side of the Chatham rise, creating the Wairarapa, Hikurangi and Rēkohu Eddies (Chiswell et al., 2015; Stevens et al., 2019). From the south, the Subantarctic front and Southland current flow north 
up the east side of the South Island. The current then diverges east along the southern side of the Chatham rise. Subtropical and Subantarctic currents converge along the Chatham rise creating the subtropical front that flows east past the Chatham islands into the Pacific Ocean. Cook Strait connects the Eastern Tasman sea to the Western Pacific Ocean. Currents within Cook Strait are primarily tidal due to the two seas being on separate tide cycles. The d'Urville current creates a slight westerly net flow as it moves through Cook Strait where it meets up with the southward extension of the Wairarapa and Hikurangi Eddy (Chiswell et al., 2015; Stevens et al., 2019).

Historically the marine environment was viewed as being demographically open, however, there are an increasing amount of genetic studies that challenge this view (Roughgarden et al., (1985). Currently it is widely accepted that marine taxa exhibit varying genetic structures and this can be influenced by oceanographic processes, habitat availability and life history requirements (Cowen et al., 2006). A panmixia describes when there is no significant genetic subdivision (Laikre et al., 2005). Species with this pattern suggest that gene flow is high (longer PLD or high mobility), barriers to dispersal are absent, and that populations can be considered as part of a single interbreeding unit. Reisser et al. (2014) conducted a study on Nerita melanotragus (black nerite) genetic connectivity between northern New Zealand and the Kermadec Islands. They found that $N$. melanotragus were genetically similar between sampling locations indicating that the realised dispersal is at least $750 \mathrm{~km}$. Furthermore, oceanic currents, moderate PLD (5-6 months) and larvae phenotypic plasticity allow N. melanotragus to successfully settle in different environmental conditions, and this facilitates their panmixia. A panmictic genetic structure can also be detected in a number of New Zealand marine taxa from varying habitats, examples of these are Macruronus novaezelandiae (hoki, Takeshima et al., 2011), Seriola lalandi (yellow tail kingfish, Miller et al., 2011), Coscinasterias muricata (eleven arm starfish, Waters \& Roy, 2003), Austrovenus stutchburyi (common cockle, Lidgard, 2001) and Mustelus lenticulatus, rig shark (Hendry, 2004). Having a longer PLD does not benefit connectivity if the surrounding ocean currents are not favourable. Jasus edwardsii (red rock lobster) have a somewhat panmictic population that encompasses New Zealand, however the Stewart Island population is genetically distinct (Thomas \& Bell, 2013). This is a result of a long PLD that lasts approximately 12-18 months. Larvae are transported from Stewart Island up the east coast of the South Island via the Southland current and then carried away from New Zealand into the Pacific Ocean via the Subtropical front, removing larvae from the system entirely (Thomas \& Bell, 2013). Different life history traits of species that live in the same 
environment can produce contrasting genetic structure. Bors et al. (2012) conducted a study on the genetic connectivity of Munida gracilis (squat lobster) and the Hyalinoecia longibranchiata (quill worm) that were sampled from continental slope, seamount, and offshore rise habitats on the Chatham Rise, Hikurangi Margin, and Challenger Plateau. They found that $M$. gracilis showed panmictic genetic structure between sites, however, $H$. longibranchiata displayed distinct levels of genetic structure between sampling sites indicating an isolation by distance genetic structure. The difference in genetic structure between $M$. gracilis and $H$. longibranchiata is likely due to $M$. gracilis having longer PLD and higher mobility.

Isolation by distance (IBD) is an observed latitudinal cline in genetic structure across the range of a species (Wright, 1943). This is caused by an increase in the independence of genetic drift as distance increases among groups of individuals and is often the result of more frequent localised dispersal when compared to long-distance dispersal (Laikre et al., 2005). Populations that exist closer together may display greater genetic similarity than populations that are more distant, producing a gradient pattern of genetic differences. This is assumed because it is easier for larvae or adults to disperse between closer populations, especially if those species have no/short PLD or have low mobility. Species that have a wide thermal tolerance may also display IBD genetic structure as they can potentially move easily across a greater range if they are not restricted by habitat requirements (Sunday et al., 2012). Examples of these include Pinnotheres atrinicola (pea crab, Stevens, 1991), Actinia tenebrosa (waratah anemone, Veale, 2007), Forsterygion lapillum (common triplefin, Hickey et al., 2009), Bellapiscis medius (twister, Hickey et al., 2009) and Madrepora oculata (zigzag coral, Zeng et al., 2017). A similar genetic pattern can be the result of isolation by depth instead of distance due to different currents and water densities. Zeng et al. (2017) conducted a study on stony corals Goniocorella dumosa \& Madrepora oculata collected from the Chatham Rise and Kermadec Ridge. Both species displayed a pattern of isolation-by-depth between samples taken from 300-600m and 700-1200m at each sampling location. Species that display an isolation by distance genetic structure are more vulnerable to changes in gene flow as a barrier could cause one population to become isolated. This has influenced the population structure of Hectors dolphin (Cephalorhynchus hectori), an endemic dolphin to New Zealand that is confined to three populations; west and east coast of the South Island, and west coast of the North Island (Hamner et al., 2014). South Island populations display IBD genetic structure due to the South Island acting as a physical barrier limiting gene flow. Gene flow to the North Island population 
is severely limited, and this has resulted in a distinct North Island population becoming a subspecies commonly known as Māui dolphin (Cephalorhynchus hectori maui).

Distinct populations form when there is little or no gene flow between populations resulting in a significant level of genetic differentiation (Laikre et al., 2005). This is often caused by species that display high levels of self-recruitment and/or large geographic distances between populations caused by specific habitat requirements. Examples of this can be seen in estuarine species such as Paracorophium lucasi (amphipod, Stevens \& Hogg, 2004) and Grahamina nigripenne (estuarine triplefin, Hickey et al., 2009) that display distinct genetic differences between the North and South Islands, and between east and west coasts of both islands. Deep sea habitats are often geographically isolated and form distinct populations, examples of this can be seen in species such as Genypterus blacodes (ling, Smith \& Paulin, 2003), Polyprion oxygeneios (hāpuku, Lane et al., 2016) and Solenosmilia variabilis (stony coral, Zeng et al., 2017). Furthermore, stony coral species have also shown to have high levels of selfrecruitment. Distinct populations may form relatively close to one another as a result of geological barriers such as fiords reducing gene flow between populations. Fiords create unique hydrological environments often creating closed populations (Stanton, 1986). Significant genetic differences between and within fiords have been reported in species such as Antipathes fiordensis (black coral, Miller, 1997; Miller, 1998) and Errina novaezealandiae (red coral, Miller et al., 2004). Perhaps the most contrasting example of this occurs in New Zealand's endemic sea urchin, commonly known as kina (Evechinus chloroticus). E. chloroticus have a panmictic population genetic structure that encompasses New Zealand, however there is one genetically distinct population that occurs in the Doubtful Sound fiord in Fiordland (Mladenov et al., 1997).

One of the more notable breaks in population genetic structure observed in many New Zealand marine species occurs near Cook Strait at a latitude of approximately $42^{\circ} \mathrm{S}$ (Ayers \& Waters, 2005). Golden Bay, Tasman Bay, Marlborough Sounds and the North Island form the northern group and south of $42^{\circ} \mathrm{S}$ forms the southern group. The reason for this break is not clear however it is thought to be a combination of the d'Urville current and upwelling that cause a significant barrier to larval dispersal. Cook Strait formed approximately 6000 - 16000 years ago due to post-ice age rising sea levels (Chiswell et al., 2015). During the Last Glacial Maximum (LGM) a land bridge connected the North and South Island together, creating a physical barrier to gene flow between eastern and western populations. East and west coast 
genetic differences have been documented (Ross et al., 2009), however, this finding is most likely a relic of historic founding populations, or populations that have become fragmented due to the significant geological changes New Zealand has undergone over the last 65 million years (Cooper \& Milliener, 1993). Changes to environmental conditions can also create a barrier to gene flow and fragment populations. Pecten novaezelandiae (scallop) are particularly sensitive to reduced salinity and sedimentations. Increased sediment in waterways that discharge over P. novaezelandiae beds have been shown to create a barrier to gene flow among populations (Silva \& Gardner, 2015).

\section{3: Molecular Markers}

As the field of molecular ecology has progressed, a range of molecular markers have been developed to determine the levels of genetic diversity within populations, and to estimate the level of connectivity between them. The first study that used molecular methods and successfully addressed population structure was undertaken by Vrooman, (1964). C-positive blood group frequencies were used to detect three genetically distinct subpopulations of Sardinops caerulea (pacific sardine) off the coast of California. A few years later the first studies to use multiple loci to describe genetic variation was published (Harris, 1966; Lewontin \& Hubby, 1966) using protein electrophoresis that was later described as an allozyme (Prakash et al., 1969). Allozymes are variant forms of an enzyme (protein) that differ structurally but not functionally, and are coded by different alleles at the same locus. Allozyme variation soon became a popular molecular tool as it could be applied to fresh tissue from multiple taxonomic groups including animals, plants and bacteria (Allendorf, 2017). By 1984 genetic variation using allozymes had been described in approximately 1100 species of animals and 75 species of plants with a mean of 23 loci used (Nevo et al. 1984). Restriction fragment length polymorphisms was the next innovation in molecular techniques to describe genetic variation in natural populations (Avise et al., 1979; Brown \& Wright, 1979). They are created using restriction endonuclease (enzyme) to cut deoxyribonucleic acid (DNA - chloroplast, mitochondrial or nuclear) into fragments at specific restriction sites (Allendorf, 2017). Mutations in the DNA fragments result in varying sizes that can be compared with gel electrophoresis. Restriction fragment length polymorphisms marked a major shift from analyzing the variation in enzymes to directly comparing the variation of the underlying DNA. 
The invention of polymerase chain reaction (PCR) in 1983 by Mullis (1994) was a huge turning point in molecular biology. Previous techniques required large samples of tissue to yield a sufficient quantity of enzymes or DNA to be analyzed (Allendorf, 2017). PCR offers exponential amplification yielding approximately one billion copies of the template DNA after 30 cycles. Because PCR can operate sufficiently with very little DNA, non-lethal sampling methods were able to be used, such as analyzing scatt or taking fin-clips from fish (Lench et al., 1988). Primers are short, synthesized, single stranded segments of DNA that can be designed for PCR to specifically target (20-25 bp in length) a section of DNA such as a gene, or shorter generic primers ( $10 \mathrm{bp}$ in length) can be used to randomly amplify multiple loci across the genome (Dieffenbach et al., 1993). PCR provided the foundations for the further development of new molecular markers such as randomly amplified polymorphic DNA (Hadrys et al., 1992), amplified fragment length polymorphisms (Vos et al., 1995), and singlestrand conformation polymorphisms (Orita et al., 1989).

At a similar time, another major milestone was reached in molecular ecology when first generation DNA sequencing (sanger sequencing) was developed by Fredrick Sanger and his colleges in 1977 (Sanger et al., 1997). Similar sized DNA/PCR fragments that had sequence variations were previously indistinguishable from one another. Sanger DNA sequencing revealed the underlying DNA/PCR product nucleotide sequences and could be used to detect single nucleotide polymorphisms (SNPs). The coupling of PCR and sanger sequencing lead to microsatellites being one of the most widely used molecular markers to investigate population genetic structure, especially in fisheries stocks (Cuellar-Pinzon et al., 2016). Microsatellites are non-coding sections of DNA characterised by short motifs (1-6bp) that repeat in tandem and can be found in multiple locations throughout the genome (Chambers \& MacAvoy, 2000; Selkoe \& Toonen, 2006). Because microsatellites are non-coding they have a high degree of polymorphism due to a mutational process known as replication slippage that can cause the gain or loss of entire repeats (Bhargava \& Fuentes, 2010). Specific PCR primers can be designed to target the flanking regions of a microsatellite so they can be amplified and then sequenced. The variation in microsatellites between individuals can then be genotyped and analysed.

Increased computing power and the development of next (second) generation sequencing (NGS) technologies have advanced the field of molecular ecology considerably. NGS techniques are a shift from analysing SNPs from a few loci to analysing SNPs from thousands 
of loci, effectively obtaining a large sample of the genome (Allendorf, 2017). One approach is known as reduced-representation genome sequencing and includes methods such as genotyping-by-sequencing (Elshire et al., 2011), Restriction site Associated DNA Sequencing (RAD-Seq, Miller et al., 2007) and double digest RADseq. Furthermore, NGS technologies such as illumina and nanopore sequencing have made whole genome sequencing (WGS) more accessible. WGS makes it possible to detect hundreds of thousands of SNPs from neutral and adaptive genomic regions (Jones et al., 2012). This provides new insight into how the forces of evolution and harvesting affect population genetic structure and function with its environment ((Diopere et al., 2018; Jones et al., 2012; Pavey et al., 2015; Sandoval-Castillo, Robinson, Hart, Strain, \& Beheregaray, 2018). Funk et al. (2012) noted that the coupling of neutral and adaptive markers can delineate more fine scale genetic structure and provide more comprehensive management advice (Bernatchez et al., 2017; Nielsen, Hemmer-Hansen, Larsen, \& Bekkevold, 2009; Russello, Kirk, Frazer, \& Askey, 2011). However, currently WGS is relatively costly and is computationally intensive, making it impractical to use on large collections of samples or preliminary studies. Traditional molecular markers such as microsatellites or specific genes and regions of mitochondrial DNA still have their merits. They are relatively inexpensive to apply to a sample set and have high enough resolution to detect patterns in population genetic structure. NGS methods can then be used to follow up on those findings to detect the finer scale genetic structuring. (e.g. Dammannagoda et al., 2011)

The mitochondria is an intracellular organelle that contains its own genome and is responsible for the production of cellular energy in eukaryotes (Xinhong et al., 2004). Mitochondria have a high copy number $(10$ - 10,000) per cell depending on tissue type, however, this can result in heteroplasmy. The mutation rate of mitochondrial DNA (mtDNA) is typically 5-10 times higher than that of nuclear DNA (Brown, 2008). This is due to mitochondria lacking histones and mtDNA repair mechanisms that would correct mutations caused from oxidative damage during cellular respiration. The mitochondrial genome is a double stranded circular molecule approximately $16,500 \mathrm{bp}$ in teleost fish containing 37 genes ( 2 rRNAs, 22 tRNA and 13 proteins), (Brown, 2008). One protein coding gene that is commonly used in phylogenetic studies is Cytochrome c oxidase subunit one (CO1), (Strüder-Kypke \& Lynn, 2010). Because $\mathrm{CO} 1$ is protein coding it is more conserved than other regions of the mitochondrial genome and displays lower levels of variation within species. This is what makes CO1 a good molecular marker for comparing species and is often used as a barcoding gene to distinguish cryptic species and taxonomic classification (Ward et al., 2009). Smith et al. (2008) used a set of 
generic CO1 primers designed by Ivanova et al. (2007) to barcode New Zealand commercially important fish species and create the first phylogeny.

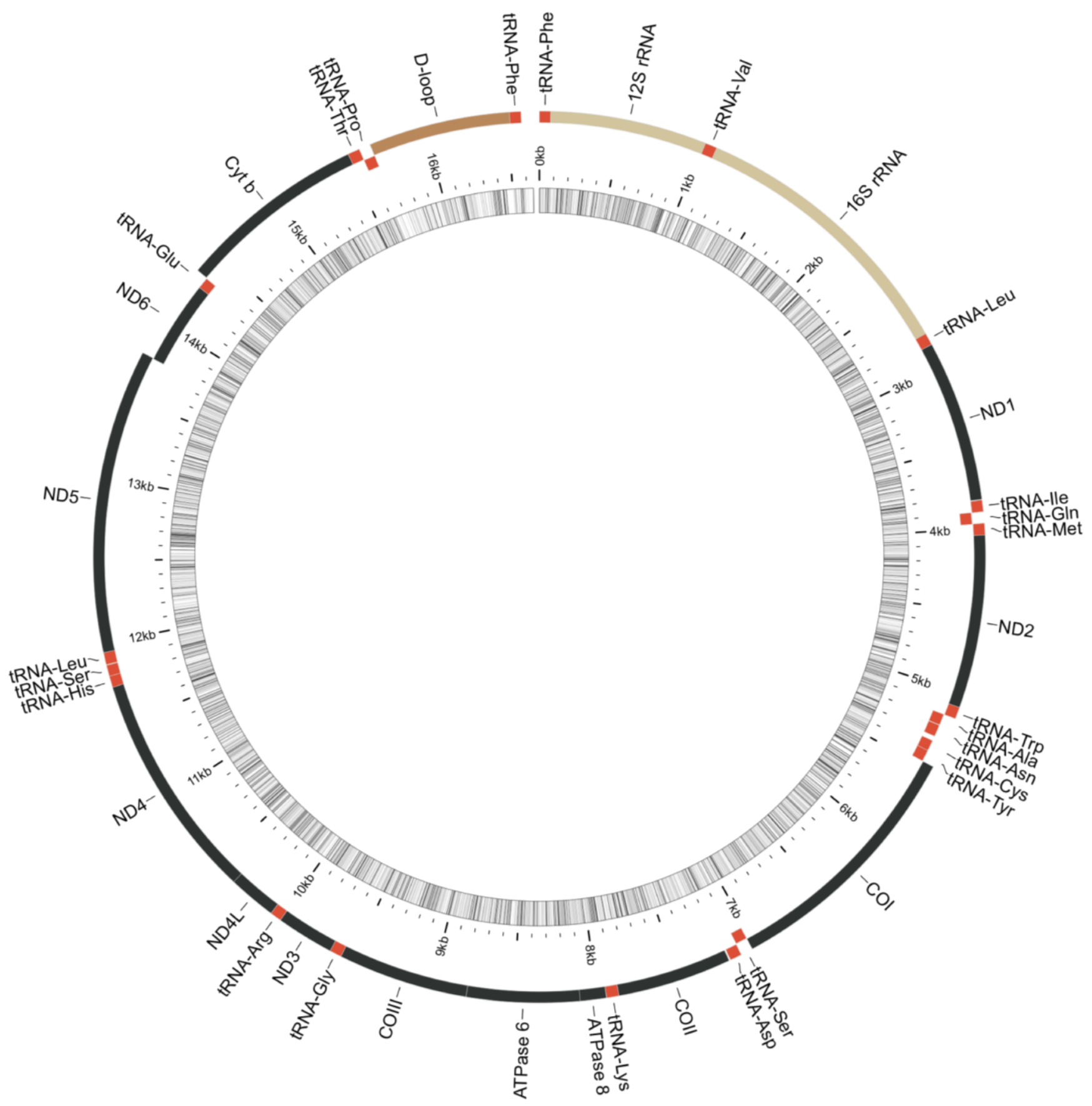

Figure 1.3: Vertebrate mitochondrial genome. Typical gene arrangement of most teleosts. Indented genes denote transcription occurs on the internal, light strand. Protein coding genes colored black, tRNAs are red, rRNAs are beige and control region is brown. Figure generated using MitoFish (Iwasaki et al., 2013).

The control region (CR) is a non-coding region of mtDNA that mutates at a faster rate than other areas and is often responsible for the variation in mitochondrial genome size (Billington 
\& Hebert, 1991; Lee et al., 1995). The CR region is approximately $1 \mathrm{~kb}$ in length flanked by tRNA-Pro at the 5' end, and tRNA-Phe at the 3' end. In teleost fish the 5' and 3' ends are the most variable areas of the CR, known as hypervariable region one (HVR1) and hypervariable region two (HVR2), (Lee et al., 1995). Between these two regions is a conserved area known as the conserved central domain (CCD) and is where the displacement loop (D-loop, site of mitochondrial replication) is located. HVR1 is thought to be the more variable region of the two and is often used for population genetic studies (Pourkazemi et al., 1999; Ovenden et al., 2002; Aboim et al., 2005; Xiao et al., 2009).

A unique feature of mitochondria is that it is typically maternally inherited as a haploid genome from the mother (Hutchison et al., 1974). Furthermore, mtDNA does not undergo recombination, making it a powerful molecular marker for tracking ancestry through matrilineages. However, because mtDNA is maternally inherited this results in a smaller effective population size $(N e)$ proportional to the number of females (Nef) within the population (Birky et al., 1989 ). Overall, the high mutation rate, maternal inheritance, and lack of recombination make mtDNA unique in use for determining population genetic history and structure. The smaller effective population size increases the sensitivity of mitochondrial sequences as a marker for detecting population genetic subdivisions.

Sampling design is an important consideration when undertaking a population genetic study. A data set must be robust enough to detect a suitable level of statistical resolution as variation may be widespread depending on demographic features of the sampled populations. Chakraborty (1992) determines that a sample size of at least 50 individuals should be obtained from each location, however, 100 individuals are preferable to obtain reasonable statistical resolution. Molecular markers differ in their rate of mutation and mode of inheritance offering variable genetic resolution. An example of this is the inconsistent results obtained from studies attempting to determine the population genetic structure of Hoplostethus atlanticus (orange roughy). H. atlanticus are long lived ( 100 years), slow maturing ( 20-30 years) deep sea fish (700 - 1500m), thought to have low levels of dispersal (Elliott et al., 1995; Francis \& Clark, 1998), and are distributed throughout most major ocean basins in both the northern and southern hemisphere (Smith et al., 1995). Initial genetic studies by Smith (1986, allozymes), Baker et al. (1992, DNA finger printing) and Baker et al. (1995, mtDNA seq - cytb) all detected a panmictic genetic structure. A latter study by Smith and Benson (1997) used a different set of allozymes to analyse 11 loci and found an isolation-by-distance genetic structure. Further 
conflicting results came from Smith et al. (1997 allozymes + RAPD + mtDNA) and Smith et al. (2002 allozymes + microsatellites + mtDNA) who determined distinct population genetic structures. The most recent studies conducted by Varela et al. (2012 mtDNA seq (COI+cytb)) and Varela et al. (2013 microsat) have brought the current population structure full circle and H. atlanticus are considered to be panmictic.

\section{4: Genetics and Fisheries Management}

"I believe then that the cod fishery, the herring fishery, the pilchard fishery, the mackerel fishery and probably all the great sea fisheries are inexhaustible: that is to say that nothing we do seriously affects the numbers of fish. And any attempt to regulate these fisheries seems consequently from the nature of the case to be useless." (Huxley 1884).

In 1884 Thomas Huxley believed that it was not necessary or possible to manage fisheries resources. Almost 135 years later, sadly this has now been well recognized as not the case (Thurstan et al., 2010). Prior to the industrial revolution, fishing was undertaken by individual fishing households. Artisanal fishing was small-scale with the goal to provide seafood to meet the local demand. By 1950's fishing was quickly becoming commercialized operating at an industrial scale. Catch was surplus to local demand and soon became a valuable export. By the late 1980's Thomas Huxley's message was shown to be demonstrably wrong based on global catch records, which began to report a significant drop in stock sizes (Mullon et al., 2005). Increased fishing pressure from industrial-scale fleets have made overfishing achievable, collapsing many of the world's fisheries, including cod, herring, pilchard and mackerel fisheries (Pauly et al., 2002). In order to develop a management strategy, harvesting has to align with the fisheries levels of productivity to prevent further overexploitation.

The goal of the maximum sustainable yield (MSY) concept is to identify the point of balance between exploitation and natural stock replenishment (Maunder, 2002). It is a key component in many stock assessment models. MSY is the maximum level at which a fisheries resource can be routinely exploited without long-term depletion. This is achieved by maintaining a fisheries biomass at a level where growth rate from recruits is highest. MSY estimates are a fundamental component in stock assessments, that provide total allowable catch (TAC) limits 
for a stock, and quota for the fishers. However, stock assessment estimates rely on an accurate description of stock structure and its vital rates. The term "stock" has several definitions in fisheries management, but usually refers to a particular biological unit of conspecifics (population) more or less isolated from other stocks and large enough to be self-recruiting (Hilborn \& Walters, 1992). Analysing the genetic structure for a metapopulation (multiple stocks) provides crucial information about how many stocks are in a particular fishery and information about their connectivity (Watson et al., 2012).

However, the management boundaries of a stock may not reflect the natural population boundaries (Botsford et al., 1997). Typically, a fishery is divided into management areas that are usually determined by the boundaries of a regional authority or geographic features such as a cape. Stocks may straddle multiple management areas or alternatively a single management area may encompass multiple stocks. Large panmictic stocks may be divided into sub-stocks based on management areas such as an island or bathymetric features such as rise/ridges, knolls, plateau and trenches.

The key to long term successful management of a fisheries is to conserve the natural genetic diversity within its gene pool (Ward, 2000). Genetic diversity in wild populations are constantly changing as a result of the four evolutionary forces (gene flow, genetic drift, mutation and selection). Large natural populations usually have a high degree of genetic diversity, which is the basis of long-term evolutionary resilience. This allows natural selection to favour advantageous alleles, which results in adaptation to challenges in the environment. When populations have no connectivity and are considered distinct for one another, they are known as evolutionary significant units (Palsboll et al., 2007). Evolutionary forces differentiate isolated populations, which can result in local adaptation and/or generate unique reservoirs of genetic variants.

At an industrial scale, fishing-induced mortality has the potential to overcome recruitment, therefore, reducing the overall stock levels (Pauly et al., 2002). The size-selective method of fishing combined with the overall scale of mortality has the potential to impose a new force known as "fishing-induced evolution" (Enberg et al., 2012). Specific size limits, gear restrictions or market demand generate a target size range for most fisheries. As a result of this, larger individuals are typically targeted as they maximise the commercial return of a catch. Size-selective fishing unintentionally improves the chances of reproductive success for fish 
with particular traits such as, weight-at-age, length-at-age, age-at-maturity, length-at-maturity, spawning season, number of eggs and size of eggs. This has two consequences: 1 . it removes "big old fat fecund female fish" from the stock (Hsieh et al., 2010); and 2. it selects for individuals that reproduce early and at a smaller size (slow growth), which decreases the average size of fish in the stock (Enberg et al., 2012).

However, if a fishery is not properly regulated and fishing mortality remains consistently higher than recruitment levels, then there is a significant risk of overfishing the stock (Scheffer et al., 2005). A declining stock size increases the strength of genetic drift, a process that eliminates polymorphism from a population. This causes a reduction of evolutionary potential and the loss of unique alleles from evolutionary significant units. Stocks become more vulnerable to new challenges in the environment, disease and parasite outbreaks. Furthermore, reduced stock size can cause inbreeding depression as recessive deleterious alleles are more likely to form homozygotes, further reducing the stocks viability. Overfishing has also been linked to increased heterozygosity as it disrupts connectivity between stocks, altering the overall structure and potentially forming fewer large populations as smaller populations collapse and join neighbouring populations (Pinsky \& Palumbi, 2014). Overfishing causes stock size to shrink and go through a genetic bottleneck. Stocks can be rebuilt by reducing or eliminating fishing pressure, but eliminated alleles will take tens of thousands of years to reaccumulate (Willi et al., 2018). The minimum viable population size to maintain a level of genetic diversity that will limit the risk of extinction has been debated. Harmon and Braude, (2010) purposed that a minimum of 50 individuals were needed to negate the effects of inbreeding and 500 individuals are required to overcome genetic drift. However, Reed et al. (2003) estimated that a minimum effective population size of 7000 is required. This highlights the importance of having a well-informed fisheries management system in place to avoid the undesirable outcomes from overfishing.

Since the arrival of foreign trawl fleets in the 1950's, there has been concern for a number of New Zealand's fisheries (Gibbs, 2008). Collapses have been documented in both inshore fin and shell fish fisheries and offshore orange roughy fisheries. In an attempt to gain better control and implement a management system, the New Zealand government established its exclusive economic zone (EEZ) in 1977 that extends 200 nautical miles from shore (Gibbs, 2008). New Zealand claims the fifth largest exclusive economic zone in the world $\left(4,300,000 \mathrm{~km}^{2}\right)$ approximately 15 times larger than its land area. In 1986 the New Zealand government 
implemented the quota management system (QMS) under the Fisheries Act (1996) and the Treaty of Waitangi Settlement Act.

The QMS uses an individual transferable quota (ITQ) system as the central mechanism for distributing sustainable harvesting levels for each fishery within the commercial fishing industry (Gibbs, 2008; Batstone \& Sharp, 1999). The QMS recognises separate MA within the EEZ as quota management area (QMA) for each fishery species. QMS determines the total allowable catch (TAC) for each QMA. TAC is divided into four portions; commercial catch, customary catch, recreational catch and other source of mortality. The total allowable commercial catch (TACC) is the proportion of the TAC that determines the maximum combined commercial catch for a given QMA. ITQ system allows TACC to be divided into shares that can be purchased by commercial fishers. Every year each commercial fisher receives an annual catch entitlement (ACE) that is determined by the number of shares they own for that quota. Each commercial fisher must own enough shares in a given quota to have enough ACE to cover the QMS species they catch during the year. The ITQ system allows commercial fishers to buy and sell their quota shares between themselves to cover the species they are catching, however, ownership cannot go to foreign fisheries. To prevent individual fishery companies from monopolising the fisheries, aggregation limits prevent quota owners from owning over a certain percentage of shares in a quota for any stock and species.

Fishery managers use a feedback loop of information to update annual TAC.

Commercial fishers must report catch, effort, landing returns for each fishing trip and monthly harvest returns. Licensed fish receivers (LFR) must report monthly amounts and type of fishery species received and the fishers who supplied them. Cross checking between LFR and commercial fishers is used to validate the accuracy of their reportings. Fishery surveys are conducted by researchers independently from the direct fishery data to provide information about abundance, biological characteristics, catch levels, and demographic and genetic structure for a given species. All this information is used to inform stock assessment models that provide TAC estimates for a fisheries, which can be used to adjust the ACE.

Stock assessments are carried out periodically on fisheries to analyse their performance and estimate how many adult fish are within the stock known as spawning biomass. The goal is to estimate how much TAC can be taken from the fishery for a given fishing year whilst maintaining the spawning biomass at a MSY, usually $40 \%$ of the historic unfished/virgin 
biomass (SB0). As a safety net there is a soft limit (20\% SB0) and a hard limit (10\% SB0) implemented to protect the stock from overexploitation. If the spawning biomass of a stock falls below the $20 \%$ SB0 soft limit, the stock is considered to be overfished or depleted and needs to be actively rebuilt. One way of doing this is by reducing the TACC. If the spawning biomass of a stock falls below the $10 \%$ SB 0 hard limit, the stock is considered to have collapsed and the fisheries may need to be closed in order to restore the spawning biomass at the fastest possible rate.

Currently New Zealand has 98 species managed under the QMS that are divided into 642 separate stocks. TACC for all 98 species combined is $604,487,437 \mathrm{~kg}$, making fisheries New Zealand's fifth largest export that is worth between $\$ 1.8$ billion per annum (Seafood New Zealand). The 2018 report on the status of New Zealand's fisheries reported that of assessed fisheries $95.0 \%$ were above the hard limit, $77.6 \%$ were below the overfishing threshold and $75.9 \%$ were above their management targets (Stock status).

\section{5: Study Species: Nemadactylus macropterus (tarakihi) and Nemadactylus sp (king tarakihi)}

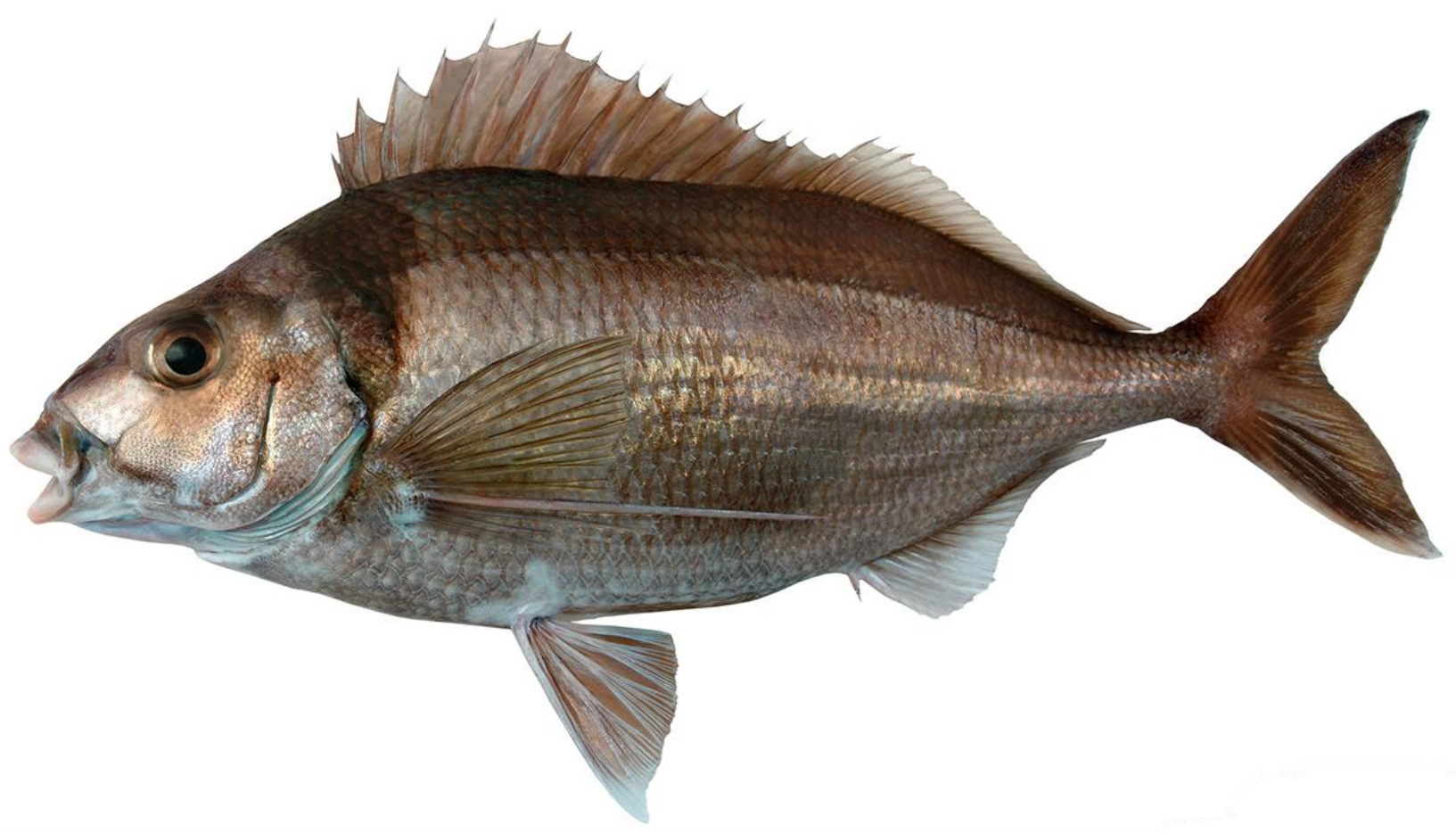

Figure 1.4: Nemadactylus macropterus or commonly known as tarakihi in New Zealand. Photo by Hann (2013.a). 
Nemadactylus macropterus (tarakihi), also known as Jackass morwong in Australia, is a demersal marine fish belonging to the Cheilodactylidae family. N. macropterus can be distinguished from other morwong species by their black crescent shaped band across its nape to the pectoral fin base (Burridge, 1999). Morwong species belong to the genus Nemadactylus that translates to filament finger, hence morwong species are characterised by their elongated pectoral fin ray. $N$. macropterus are widely distributed throughout inshore areas of New Zealand and are found in all QMAs (Annala, 1987).

N. macropterus are also distributed along the southern coast of Australia, including Tasmania (Jordan, 2001). Occurrences have also been documented in the Indian Ocean Islands of Amsterdam and St. Paul, and off the Argentinian coast in South America. However, these may have been misidentifications of close relative species N. monodactylus and N. bergi (Burridge, 1999). N. macropterus are broadcast spawners that form serial spawning aggregations during summer and autumn (Tong \& Vooren, 1972). Three spawning aggregations have been documented in New Zealand; East Cape of the North Island, Pegasus Bay to Cape Campbell along the east coast of the South Island and the lower west coast of the South Island near Jackson Bay (Robertson, 1978). The extent of the spawning grounds is not known as they have been identified from observations of eggs or ripe, running ripe and spent fish (Morrison et al., 2014; Mckenzie et al., 2017). N. macropterus have a larval development phase directly after spawning that lasts approximately 9-10 months (Annala, 1987). Ocean currents disperse larvae over long distances and mixing of larvae from different sources is thought to occur (Annala, 1987). After 10 months, larvae go through metamorphosis and settle in shallow nursery grounds (10-50m) at a size of 7-9cm (Vooren, 1972). Juvenile $N$. macropterus have been found in numerous locations around New Zealand, however, there seem to be an abundance of juveniles caught in Golden Bay, Tasman Bay, Pegasus Bay and Canterbury Bight suggesting these areas could be nursery grounds (Vooren, 1975; Hurst et al., 2000). Juvenile $N$. macropterus reach maturity at $25-35 \mathrm{~cm}$ or $4-6$ years and can grow to lengths of $60 \mathrm{~cm}$ and live over 30 years (Beentjes et al., 2012). Adult N. macropterus are typically found in schools over open seafloors in depths ranging from 50-250 meters where they feed on invertebrates such as worms, crabs, brittlestars and shellfish (Annala, 1987). N. macropterus are thought to be highly mobile throughout their life and disperse large distances from their nursery habitats. $N$. macropterus have been documented to migrate seasonally in latitude and depth, typically found shallower during winter months (Annala, 1987). Tagging data found $N$. macropterus have the 
potential to migrate over $320 \mathrm{~km}$, as adults tagged off Kaikoura were recaptured from the Wairarapa coast and Kaipara harbour (McKenzie, 1961; Annala, 1987).

Following the arrival of foreign trawl fleets in the 1950's, N. macropterus catches increased substantially from about 2000 T (1940's), to over 6000 T annually (Hanchet \& Field, n.d.). Catch remained high until the introduction of New Zealand's EEZ in 1977 and QMS in 1986. N. macropterus fisheries were divided into 8 QMA (TAR 1, TAR 2, TAR 3, TAR 4, TAR 5, TAR 7, TAR 8, and TAR 10) (Figure 1.5) supporting a nation scale fishery averaging 4000$5000 \mathrm{~T}$ per year, making it the third most valued inshore commercial finfish fishery (Hanchet $\&$ Field, n.d.). A fork length of $25 \mathrm{~cm}$ is set as the minimum size limit for recreational and commercial fishers. Recreational fishers are restricted to a maximum "bag limit" of 20-30 N. macropterus depending on the region and a minimum net mesh size of $100 \mathrm{~mm}$. The number of $N$. macropterus (measured in tonnes) commercial fishers are allowed to catch depends on the size of the quota they possess. Currently TAR 10 is unfished as it became part of the Kermadec ocean sanctuary established in 2012 (mfe.govt, 2019). N. macropterus are the target species for the majority of commercial catches, however, a portion of $N$. macropterus are caught as bycatch from other fisheries such as snapper, john dory, gurnard and gemfish (fs.fish, 2019).

The main source of commercial $N$. macropterus catch comes from QMA TAR 1, 2, 3 and 7 via bottom trawling (Figure 1.5) in depth ranges of 50-200m (Langley, 2018). There is also a small set net fishery operating out of Kaikoura (Langley, 2017). Because of this, most stock assessments have been carried out on the east coast fishery (TAR 1, 2 and 3, Figure 1.5) indicating a degree of connectivity among them. Catch-per-unit-effort indices, age compositions and tagging data all indicate a net northwards movement of $N$. macropterus from the east coast South Island nursery ground (Langley, 2017). The current stock hypothesis is; "Canterbury Bight/Pegasus Bay area represents the main nursery area for the eastern stock unit. At the onset of maturity, a proportion of the fish migrate northwards to recruit to the East Cape area and, subsequently, the Bay of Plenty and east Northland areas" (Langley, 2018). Very little information is known about the connectivity among the west coast fishery, and if there is a connection to the east coast fishery. However, differences in growth rates from TAR 1 may indicate a lack of connectivity between east and west Northland (Langley, 2018). Furthermore, tagged $N$. macropterus have migrated from Kaikoura to the west coast of the North Island (Kaipara harbour), (McKenzie, 1961; Annala, 1987). 


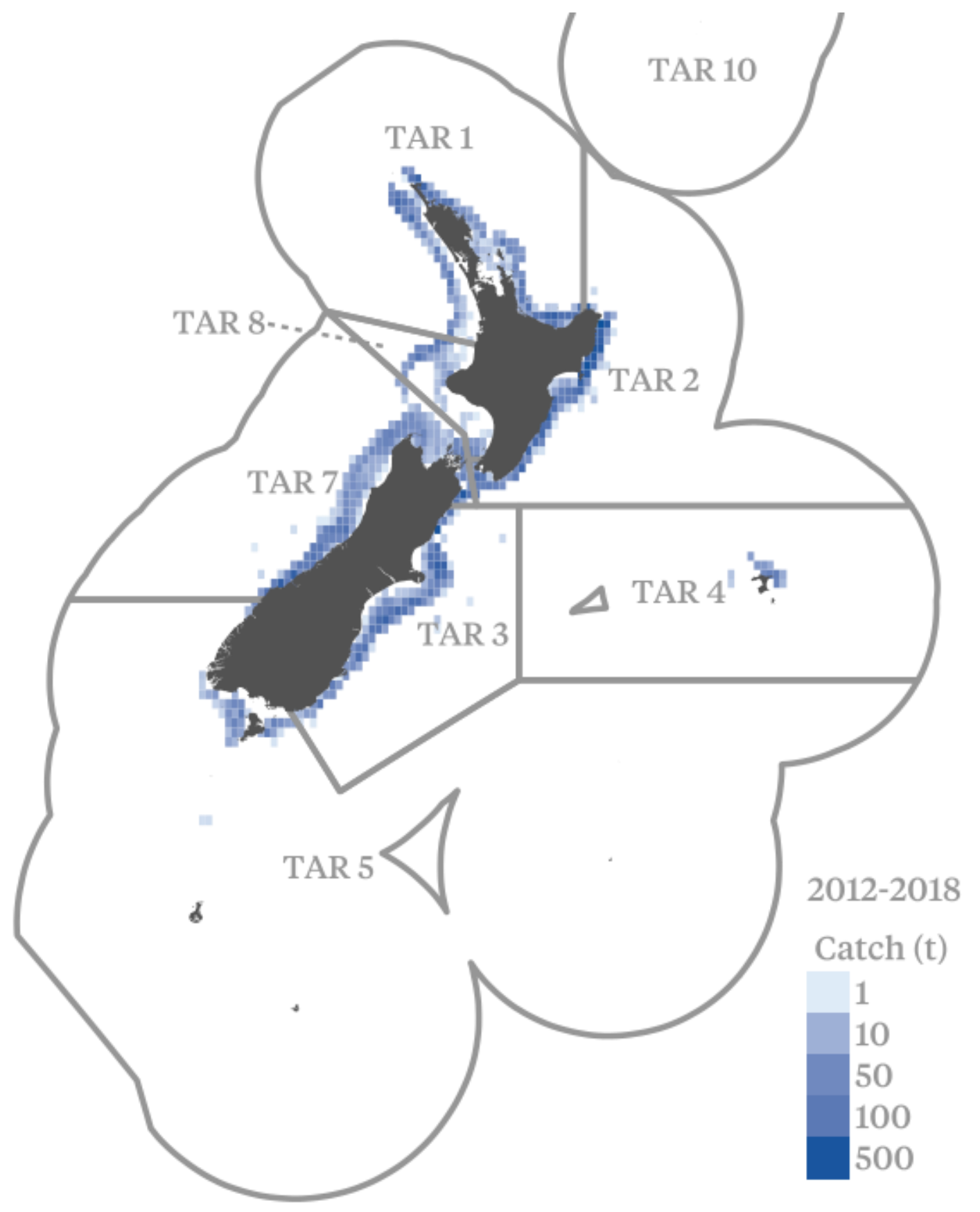

Figure 1.5: Tarakihi quota management areas of New Zealand's exclusive economic zone. Commercial catch data collected from 2012-2018 is displayed. Light blue denotes low catch and dark blue denotes high catch. Retrieved from Openseas, 2019.

A recent stock assessment of the east coast fisheries raised concern as the spawning biomass was estimated to be below 20\% (soft limit) of its non-fished size since the mid-2000s (Langley, 2018). Once a stock falls below its soft limit it is considered to be overfished or depleted and needs to be actively rebuilt. Multiple scenarios in TAC reductions have been purposed to aid in rebuilding the fishery. So far TACC has been reduced from 6,439,173 $\mathrm{kg}$ (2018) to 5,383,200 $\mathrm{kg}$ for the 2019 fishing season (fs.fish, 2019). 
N. macropterus are relatively long lived (>30 years) and have the potential to migrate and disperse over large distances, thus promoting gene flow. Because of this, studies attempting to resolve the genetic structure of $N$. macropterus stocks have produced conflicting results. Vooren \& Tracey (1976) was the first study attempting to dispute this model by comparing parasite faunas of $N$. macropterus from East Cape, Tasman Bay and Chatham Islands. The parasites from each location differed from one another, however, due to the spatial scale Vooren \& Tracey (1976) could not determine where the population boundaries occur. Gauldie \& Nathan (1977) successfully segregated N. macropterus populations into three groups (north, centre, south) based on variation in otolith iron content. However, Gauldie et al. (1980) postulated that the differences in iron content could be the result of sea temperature or heredity. Gauldie \& Johnston (1980) compared allozyme frequencies for one polymorphic site from samples collected all around New Zealand. Initial results suggested several discrete populations existed, however, these differences were most likely due to environmental selection as the variation corelated with a north-south temperature gradient. Further studies utilizing allozymes and mitochondrial RFLPs comparing N. macropterus samples from Australia and one New Zealand location (Richardson, 1982: 5 enzyme loci, Elliott \& Ward, 1994: 33 enzyme loci, Grewe et al., 1994: 3 restriction enzymes) did not detect any structure among Australian stocks, and found a weak but significant genetic disjunction between Australia and New Zealand. However, a later study conducted by Burridge \& Smolenski (2003) using microsatellite DNA markers did not detect significant divergence among Australian samples, or between Australian and New Zealand samples. Modern molecular markers and DNA sequencing have yet to be used to examine $N$. macropterus stock structure around New Zealand. The current hypothesis is that the North and South Islands consist of a single population and Chatham Island are treated as a separate population due to geographic distance.

Nemadactylus sp (king tarakihi) are demersal marine fish that belong to the Cheilodactylidae family (Burridge, 1999). N. sp can be distinguished from N. macropterus as the black band across their nape is typically less prominent and the tips of their pectoral fins have distinct black margins (Figure 1.6). N. $s p$ are generally found near offshore reefs adjacent to deep water in northern New Zealand locations such as the Ranfurly Banks, Three Kings Islands, Kermadec Islands as well as Norfolk Island and Lord Howe Island. Furthermore, reports from recreational fishers indicate that $N$. $s p$ also occur down the west coast of the North Island as far south as Taranaki. N. sp grow considerably larger than $N$. macropterus reaching upwards of $6 \mathrm{~kg}$ and 
$70 \mathrm{~cm}$ fork length. Because of this, historic catches were often referred to as large old $N$. macropterus from far northern waters (Ayling \& Cox 1982).

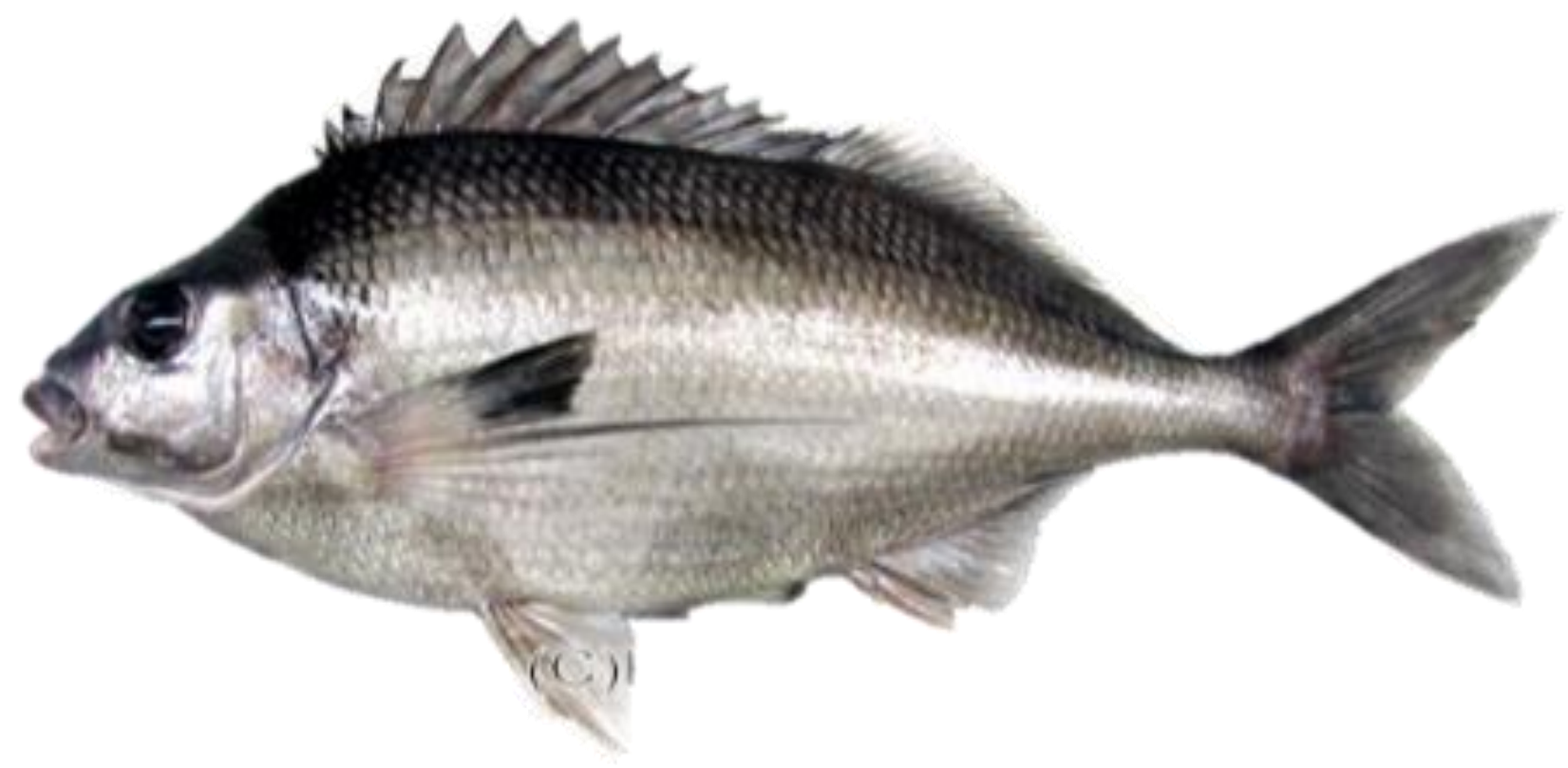

Figure 1.6: Nemadactylus sp commonly known as king tarakihi in New Zealand. Retrieved from Bray (2019.a).

N. $s p$ currently have no assigned species name, although, Smith et al., (1996) have purposed $N$. rex as a candidate, rex meaning "king". Currently N. rex is considered invalid (Roberts et al., 2017) despite studies using allozymes, RAPD (Smith et al.,1996) and mitochondrial CO1 barcoding confirming $N . s p$ and $N$. macropterus are genetically distinct. Furthermore $N$. $s p$ is recognised as a separate species from $N$. macropterus under the QMS and prior to 2001, $N$. $s p$ and $N$. macropterus catches had to be reported separately. However, due to concerns that some $N$. macropterus catches were being misreported, $N$. $s p$ was included within the species definition of the N. macropterus QMS fish stocks (under Fisheries (Commercial Fishing) Regulations 2001).

A phylogenetic study of Nemadactylus and Acantholatris families conducted by (Burridge, 1999) determined that $N$. $s p$ are more closely related to $N$. gayi from west of South America than N. macropterus, deeming them transoceanic sister taxa. The phylogeny was constructed using the control region and cytochrome $b$ mitochondrial markers. 


\section{6: Thesis Aims}

The overall aim of this thesis research is to investigate the population genetic structure, genetic diversity and demographic history of $N$. macropterus using fish sampled from around New Zealand. In addition to that, the genetic diversity and demographic history of $N$. $s p$ will also be analysed using samples collected from around the Three Kings Islands of New Zealand. This will be achieved by analysing hyper variable region one of mitochondrial DNA. The complete mitochondrial genome of $N$. macropterus will also be reconstructed from bulk DNA sequencing data and a set of specific mtDNA primers will be developed to amplify hyper variable region one. The DNA sequencing data provided by these primers with the addition of published control region sequences will be used to reconstruct the Nemadactylus phylogeny. 


\section{Chapter Two: The Mitochondrial Genome of Nemadactylus macropterus, Development of Hyper Variable Region One Primers and Phylogeny of Nemadactylus genus}

\section{1: Introduction}

The simplicity of mtDNA as a genetic marker has made it a common choice for many phylogenetic and population genetic studies. Characteristics such as maternal inheritance and high mutation rate compared to nuclear DNA and lack of recombination, make mtDNA a relatively useful molecule for addressing population and phylogenetic issues (Brown, 2008). MtDNA marker choice has expanded from using a single gene to comparing multiple genes such as cytochrome oxidase subunit 1 (CO1), cytochrome- b (Cyt-b) and the Control region (CR) that all show different levels of variability (Allendorf, 2017). Analysing multiple locus offers a combined data set with sequences of differing levels of genetic resolution that can be used to determine the genetic structure within a species or be used to reconstruct phylogenetic relationships among species (Allendorf, 2017). The first documented mitochondrial genome from a fish was produced from Crossostoma lacustre (freshwater loach) by Tzeng et al. (1992). Traditionally, mitochondrial genome sequences were produced de novo from 500-700 bp length reads determined using Sanger chain-termination sequencing methods (Sanger et al., 1977). Now the availability of high-throughput next-generation sequencing technologies have made it possible to produce large volumes of sequences that cover almost all of an organism's genome (Allendorf, 2017). Sequences from the genome of mitochondria are also generated from whole genome sequencing methods. The high mtDNA copy number per cell make it relatively easy to find in this type of bulk sequence data. The mapped sequences form contigs that overlap one another, which means the identity of each nucleotide will be determined more than once (Mascher et al., 2013). The number of times a nucleotide position has been sequenced is called its depth of coverage and the DNA sequences of regions with a high depth of coverage are considered more accurate. Currently there are over 2700 published mitochondrial genomes that have been reported for fish species alone (Iwasaki et al., 2013). Complete mitochondrial genomes are often used to reconstruct phylogenies. These have been especially useful for identifying cryptic species or for obtaining primer-site information for a species in which PCR generic primer sequences have been unsuccessful (Shen et al., 2016). Furthermore, having an ever growing abundance of published mitochondrial genomes has 
improved the understanding of mitochondrial genome structure and gene organisation (Pereira, 2000; Satoh et al., 2016). In particular, significant re-organisation of tRNAs in the IQM (located between ND1 and ND2 genes) and WANCY (located between CO1 and ND2 genes) regions have been documented (Kong et al., 2009).

Improvement to the reliability of PCR primers has been possible when the whole mitochondrial genome of a closely related species can be used as a reference for binding sites to target a particular locus. The most common mitochondrial locus used for analysing population-level diversity and differentiation is the CR (Satoh et al., 2016). The CR is a non-coding region of mitochondrial DNA that accumulates mutations at a higher rate than any other mitochondrial gene (Satoh et al., 2016). The CR region is approximately $1 \mathrm{kbp}$ in length flanked by tRNAPro at the 5' end, and tRNA-Phe at the 3' end (Satoh et al., 2016). In teleost fish the 5' and 3' ends are the most variable areas of the CR, known as hypervariable region one (HVR1) and hypervariable region two (HVR2) (Satoh et al., 2016). Between these two regions is a conserved area known as the conserved central domain (CCD) and is where the D-loop (site of mitochondrial replication) is located (Satoh et al., 2016). HVR1 is thought to be the more variable region of the two and is often targeted for analysing population genetic structure within a species (Chiang et al., 2008). HVR1 is also a useful marker for reconstructing phylogenies for closely related or recently diverged species when the traditional markers, such as CO1, have not had the time for mutations to accumulate (Zhu et al., 1994).

Nemadactylus is a genus of marine perciform species located in the southern hemisphere inhabiting the South Pacific, South Atlantic and South Indian Oceans (Figure 2.5) (Burridge, 1999). It currently contains seven recognised species, Nemadactylus macropterus (tarakihi/jackass morwong), Nemadactylus bergi (castaneta), Nemadactylus douglasii (grey morwong), Nemadactylus gayi (breca), Nemadactylus monodactylus (St. Paul's fingerfin), Nemadactylus valenciennesi (blue morwong) and Nemadactylus vemae (Figure 2.3). An eighth species Nemadactylus rex (king tarakihi) has been proposed but has yet to be formally accepted, and is currently recognised as Nemadactylus sp (Smith et al., 1996). All species are characterised by possessing a "filament finger" created by their elongated pectoral fin ray. Furthermore, all species except $N$. valenciennesi and $N$. douglasii have a prominent black saddle across their nape (Burridge, 1999). There is very little published data regarding $N$. vemae, however $N$. vemae is known to inhabit Vema Seamount, located in the South Atlantic Ocean and have similar morphology to N. monodactylus (Penrith, 1967; Lamb, 1990). N. 
monodactylus inhabits small islands (Saint Paul Island, Amsterdam Island, Gough Island, Tristan da Cunha Island) and sea mounts in the Southern Atlantic and Indian Ocean. N. valenciennesi inhabits the waters of south Australia. N. douglasii, N. macropterus and N. sp inhabit the waters of south Australia and New Zealand. N. bergi (Argentina) and N. gayi (Chile) inhabit the waters of South America. Nemadactylus species are thought have radiated recently, with estimates of divergence times of 0.6-2.6 million years before present (Burridge, 1999).

The overall aim for this chapter is: firstly, to assemble, annotate and describe the complete mitochondrial genome of $N$. macropterus; secondly, to develop a set of CR primers that can successfully amplify HVR1 of Nemadactylus species; and lastly, to reconstruct the phylogeny of the Nemadactylus genus using CR sequences.

\section{2: Methods}

\subsection{1: Mitochondrial Genome}

The reference mitochondrial genome was assembled from DNA sequences obtained for a whole-genome sequencing project that aims to produce a high quality nuclear genome reference for $N$. macropterus. Fin-clips were taken from the specimen that was chosen as the reference for N. macropterus (provided by Plant and Food Research in Nelson, New Zealand). The rapid Salt-extraction protocol adapted from Aljanabi and Martinez (1997) was used to extract the DNA. The samples were treated with RNAse following the initial digestion of proteins using Proteinase-K during the DNA extraction protocol. The purified DNA was sent to BGI genomics (China) for whole genome library preparation and sequencing. The initial library produced $350 \mathrm{bp}$ fragments that were sequenced using Illumina HiSeq technologies, which produced 150 bp paired-end reads with an estimated 60 times genome coverage. FastQC was used to analyze the quality of sequencing data. Kraken v.2.0.7-beta (Kraken, RRID:SCR 005484) was used to detect and filter contamination from archaea, bacteria, viral and human sequences based on the MiniKraken2 v2 8 GB database. After quality control 367,760,592 150 bp paired-end reads were kept with a total number of 55,164,088,800 ( 55 GB) bases.

The paired-end read sequence files were imported into Geneious Prime v2019.0.4 (http://www.geneious.com) in order to extract the mitochondrial genome. The only available 
CR sequence for $N$. macropterus was downloaded from GenBank $^{\circledR}$ (www.ncbi.nlm.nih.gov/genbank/) into Geneious Prime (accession: AF067101.1). A blast search of the CR sequence was performed using Geneious Prime to determine the closest related species with a complete mitochondrial genome sequence available. Cheilodactylus variegatus (accession: KP704218.1) was the closest species with a complete mitochondrial genome. The paired-end reads of the reference $N$. macropterus were mapped to the $C$. variegatus mitochondrial genome using the default Geneious mapper set to highest sensitivity and 5 iterations. The consensus sequence was extracted from the resulting contig using the highest quality threshold creating the draft mitochondrial genome. The paired-end reads were then mapped to the first draft $N$. macropterus mitochondrial genome that was produced, using the default Geneious mapper set to highest sensitivity and 10 iterations to increase the overall coverage produced by the contigs. The consensus sequence was extracted from the resulting contig using the highest quality threshold to create the reference $N$. macropterus mitochondrial genome.

N. macropterus mitochondrial genome was then uploaded to MitoFish (http://mitofish.aori.utokyo.ac.jp/) (Iwasaki et al., 2013) and the web based MitoAnnotator pipeline was used to extract 13 protein-coding genes, 22 tRNA genes, 2 rRNA genes, and CR. These sequences were downloaded into Geneious Prime and mapped back to the N. macropterus mitochondrial genome to determine the start and stop position of each gene. The start and stop codons were assessed before Geneious Prime was used to annotate each gene and set the read direction.

The structure and characteristics of $N$. macropterus mitochondrial genome was analyzed by extracting 27 mitochondrial genomes from preliminary low coverage whole genome sequence data obtained from an ongoing N. macropterus genomic project. The 27 N. macropterus samples were caught from multiple geographic regions around New Zealand's continental shelf. Rapid Salt-extraction protocol adapted from Aljanabi and Martinez (1997) was used to extract the DNA with an additional RNAase digest following the initial sample digestion. DNA from the 27 samples was sent to AGRF (Melbourne, Australia) for whole genome library preparation and sequencing. The initial library preparation produced $350 \mathrm{bp}$ fragments that were sequenced using Illumina Novaseq 6000 technology producing 150 bp paired-end reads with $10 \mathrm{x}$ genome coverage. FastQC was used to analyze the quality of sequencing data. After removing the low quality sequences an average of 60 million, 150 bp paired-end reads, which totalled to $9 \mathrm{~GB}$ of sequencing data, were retained for each sample. The paired-end reads for 
the 27 samples were imported into Geneious Prime and mapped "one at a time" to the reference $N$. macropterus mitochondrial genome using the default setting in the Geneious mapper, set to highest sensitivity level and 10 iterations. The consensus sequence for each sample was determined from the resulting contigs using the highest quality threshold to create each mitochondrial genome. The 27 mitochondrial genomes were aligned using Geneious MUSCLE algorithm so the gene annotations could be transferred from the reference $N$. macropterus mitochondrial genome. The alignment of 27 mitochondrial genomes was exported into DNAsp v6.12.03 (Rozas et al., 2017) to characterise the genetic diversity of each gene by using the start and stop position to separate the alignment into deems.

\subsection{2: Hyper Variable Region One Primer Design}

N. macropterus reference mitochondrial genome was used as a template to design CR primers to target HVR1. HVR1 primers were designed using Geneious Prime. To achieve this, the light strand (forward) primer was designed to bind in the conserved tRNA-Thr at the 5' end of the CR. Designing the primer to bind in this region also allows the amplification of the conserved tRNA-Pro that can be used to aid the alignment of HVR1 sequences. The heavy strand (reverse) primer was designed to bind to the $3^{\prime}$ end of the conserved central domain. Both primers were designed to bind in the most conservative locations available to improve the chances of successful amplification between varying samples. Allowing space on either side of HVR1 gives the sequencer enough burn period in which the poor quality sequenced nucleotides can be discarded without effecting the sequences of the targeted loci. $\mathrm{R}$ package adegenet 2.0.0 was used to create a graph of SNPs from the 5' end of tRNA-Thr to the 3' end of the CR. In order to assess if the designed HVR1 primers could be used on several Nemadactylus species, DNA was extracted, amplified and sequenced from the muscle tissue of 10 N. macropterus samples and 10 N. sp samples (full protocol discussed in chapter 3). Each sample was sequenced with the forward and reverse primer to determine which primer produced the better quality DNA sequencing results. 


\subsection{3: Nemadactylus Phylogeny}

The Nemadactylus phylogeny was reconstructed using CR mtDNA sequences. Seven CR sequences were used from $N$. macropterus and $N$. $s p$ that were amplified using the HVR1 primers designed above. CR sequences for the remaining Nemadactylus species were downloaded from GenBank (Appendix. A). The only species in which there was no published CR mtDNA sequences available was $N$. vemae. All sequences were mapped to the $N$. macropterus mitochondrial genome using Geneious Prime. Aligned sequences were trimmed to the largest overlap between aligned sequences. The resulting $300 \mathrm{bp}$ mtDNA fragment is located at the 5' end of HVR1. PhyML v2.2 plugin for Geneious Prime was used to compute a maximum likelihood phylogenetic tree with 500 bootstraps using the HKY 85 model. Geneious Prime consensus tree builder was used to construct the final phylogeny.

\section{3: Results}

\subsection{1: Nemadactylus macropterus mitochondrial genome}

The reference $N$. macropterus mitochondrial genome (Figure 2.1) sequence is $16,650 \mathrm{bp}$ in length and was constructed from 1,805,987 paired-end reads with a 16,193 mean depth of coverage (Appendix. B). The minimum coverage is 10,017 times and maximum 18,492 pairedend reads. The mitochondrial genome consists 13 protein-coding genes, two rRNA genes, 22 tRNA genes and a non-coding CR. Twenty eight of the genes and CR are located on the heavy (outside) strand and the remaining nine genes are located on the light (inside) strand. All protein-coding genes had ATG as the start codon apart from CO1 that had GTG. All proteincoding genes apart from ND1 (TAG), COII (CCT), ND3 (AAT), ND4 and Cyt-b (CTT) had TAA as the stop codon. The mitochondrial genome has asymmetric base frequencies $\mathrm{A}=26.9 \%$, $\mathrm{C}=28.9 \%, \mathrm{G}=17.4 \%, \mathrm{~T}=26.9 \%$, and $\mathrm{GC}=46.3 \%$. 


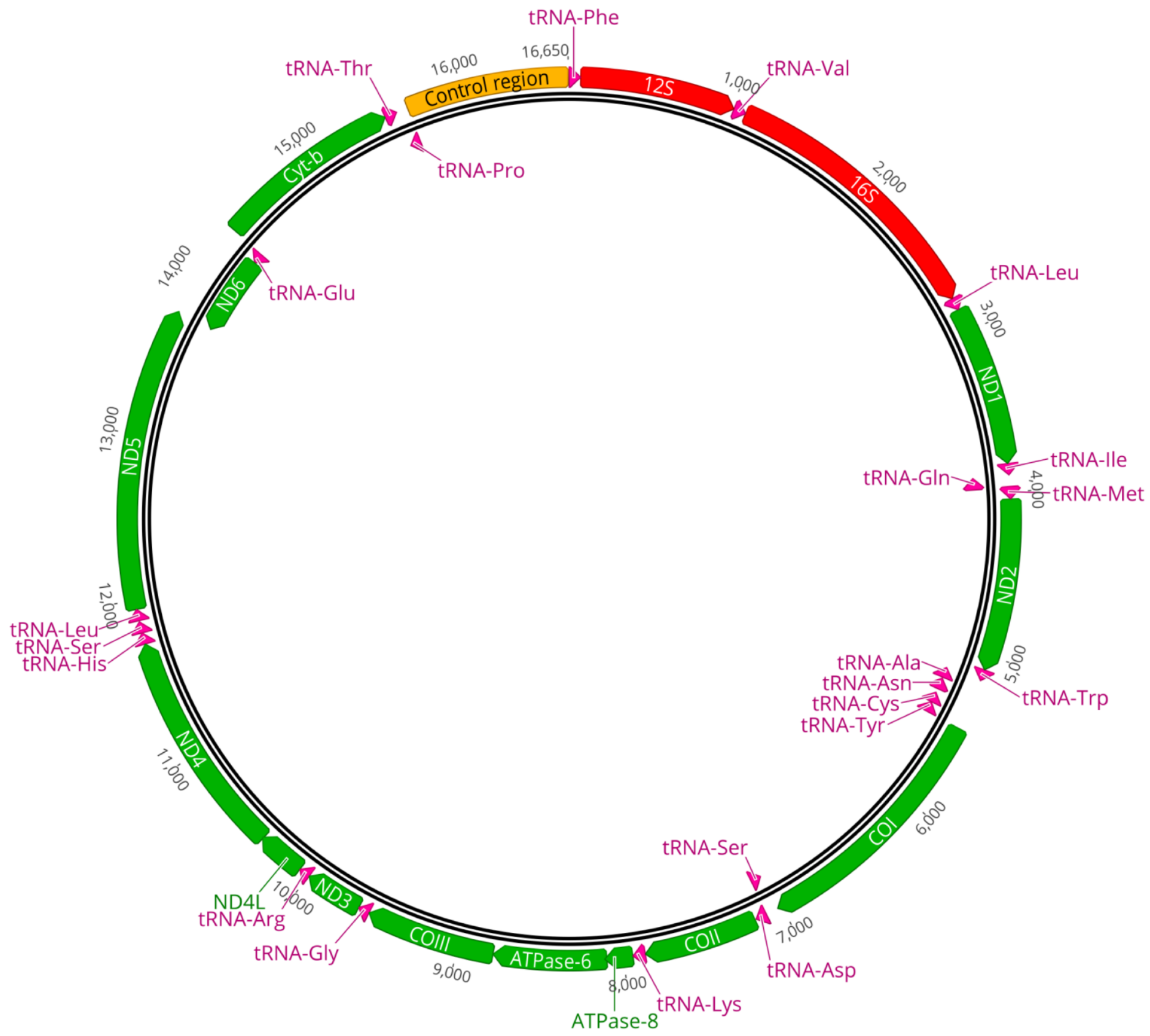

Figure 2.1: Complete mitochondrial genome of $N$. macropterus, 16,650 bp in length. Protein-coding genes are coloured green, rRNA genes are red, tRNA genes are pink and a non-coding control region is orange. Arrows indicate the transcription direction of each gene. Indented genes are located on the light strand and the remaining genes are located on the heavy strand.

The additional twenty seven mitochondrial genomes constructed (Table 2.1) were on average $16,650 \mathrm{bp}$ in length constructed from 268,403 paired-end reads with a 2,419 mean depth of coverage. The smallest mitochondrial genome was $16,647 \mathrm{bp}$ in length and the largest 16,651bp. The difference in mitochondrial genome sizes was due to indels within the CR. Samples WAI054 had an A inserted at position 15,818 and SPWCSI006 had an A inserted at position 15,832. Deletions of a single nucleotide occurred at position 15,665 (SPGB010, 
SPWCSI023, SPEC027, SPCC040, SPWCSI036 \& SPWCSI059), 15,823 (SPWCSO059 \&

WGTN025), 16,385 (SPCC008, SPGB006 \& FRDL015), 16,402 (WGTN025) and 16,440

(WGTN025 \& SPCC008).

Table 2.1: Summarises the coverage and length of the reference $N$. macropterus mitochondrial genome compared to the additional 27 N. macropterus mitochondrial genomes reconstructed using low coverage sequence data.

\begin{tabular}{|c|c|c|c|c|c|c|c|c|}
\hline \multirow[b]{2}{*}{ Location } & \multirow[b]{2}{*}{ Sample } & \multicolumn{2}{|c|}{ Sequencing } & \multirow{2}{*}{$\begin{array}{c}\text { Contig } \\
\text { Reads Mapped } \\
\end{array}$} & \multicolumn{3}{|c|}{ Coverage } & \multirow[b]{2}{*}{ Mitogenome Length } \\
\hline & & Total paired end reads & Total Bases (Gb) & & Mean & Maximum & Minimum & \\
\hline P\&FR - Nelson & Refference & $367,760,592$ & 55.16 & $1,805,997$ & 16193.2 & 18492 & 10017 & 16,650 \\
\hline North Taranaki & NT17031 & $70,057,992$ & 10.58 & 517,039 & 4659.2 & 11703 & 1764 & 16650 \\
\hline North Taranaki & NT17033 & $63,623,900$ & 9.61 & 549,510 & 4951.6 & 8717 & 2935 & 16650 \\
\hline North Taranaki & NT17049 & $49,378,610$ & 7.46 & 315,654 & 2855.7 & 10440 & 1166 & 16650 \\
\hline East Northland & ENLD035 & $65,706,242$ & 9.92 & 164,108 & 1478 & 3263 & 753 & 16650 \\
\hline Wellington & WGTN025 & $74,952,314$ & 11.32 & $1,106,368$ & 9986 & 21807 & 4953 & 16647 \\
\hline Fiordland & FRDL015 & $68,602,714$ & 10.36 & 200,160 & 1801.5 & 3603 & 1088 & 16649 \\
\hline Wairarapa & WAI050 & $65,627,474$ & 9.91 & 339,680 & 3059.4 & 4870 & 1590 & 16650 \\
\hline Wairarapa & WAI054 & $62,896,190$ & 9.5 & 327,480 & 2951.9 & 8352 & 1255 & 16651 \\
\hline Wairarapa & WAI056 & $58,244,866$ & 8.79 & 75,956 & 684 & 998 & 250 & 16650 \\
\hline East Cape & SPGB006 & $56,391,498$ & 8.52 & 240,296 & 2164.2 & 4633 & 972 & 16649 \\
\hline East Cape & SPGB010 & $52,580,500$ & 7.94 & 260,231 & 2344.2 & 5215 & 1110 & 16649 \\
\hline East Cape & SPEC027 & $69,169,898$ & 10.44 & 187,825 & 1691 & 2670 & 837 & 16649 \\
\hline East Cape & SPEC029 & $60,552,246$ & 9.14 & 381,373 & 3451.1 & 14245 & 1187 & 16650 \\
\hline Cape Campbel & SPCC008 & $62,279,204$ & 9.4 & 147,112 & 1324.8 & 2157 & 709 & 16648 \\
\hline Cape Campbel & SPCC022 & $69,935,722$ & 10.56 & 183,232 & 1650.5 & 4291 & 767 & 16650 \\
\hline Cape Campbel & SPCC031 & $74,241,620$ & 11.21 & 155,151 & 1396.5 & 3034 & 704 & 16650 \\
\hline Cape Campbel & SPCC037 & $67,627,990$ & 10.21 & 90,445 & 814.5 & 1512 & 405 & 16650 \\
\hline Cape Campbel & SPCC040 & $67,888,898$ & 10.25 & 162,776 & 1465.4 & 2283 & 625 & 16649 \\
\hline West Coast South Island & SPWCSI006 & $67,575,600$ & 10.2 & 158,538 & 1427.4 & 2088 & 656 & 16651 \\
\hline West Coast South Island & SPWCSI010 & $59,837,774$ & 9.04 & 154,370 & 1390.1 & 3402 & 688 & 16650 \\
\hline West Coast South Island & SPWCSI023 & $63,471,424$ & 9.58 & 202,203 & 1820.4 & 2757 & 955 & 16649 \\
\hline West Coast South Island & SPWCSI036 & $52,380,326$ & 7.91 & 326,347 & 2937.3 & 4127 & 1449 & 16649 \\
\hline West Coast South Island & SPWCSI051 & $64,063,782$ & 9.67 & 159,931 & 1439.6 & 1934 & 645 & 16650 \\
\hline West Coast South Island & SPWCSI054 & $59,933,536$ & 9.05 & 226,665 & 2040.1 & 3301 & 1126 & 16650 \\
\hline West Coast South Island & SPWCSI056 & $75,483,210$ & 11.4 & 128,042 & 1153 & 1665 & 514 & 16650 \\
\hline West Coast South Island & SPWCSI059 & $64,651,748$ & 9.76 & 261,414 & 2353.3 & 3790 & 1228 & 16648 \\
\hline West Coast South Island & SPWCSI060 & $50,976,214$ & 7.7 & 224,985 & 2025.4 & 3172 & 1049 & 16650 \\
\hline
\end{tabular}

The organization of the thirteen protein-coding genes, two rRNA genes, twenty two tRNA genes and a non-coding CR did not change between samples (Table 2.2). Furthermore, there was no difference in organization between the mitochondrial genome of $N$. macropterus and C.variegatus. The tRNA genes are the shortest gene within the mitochondrial genome with an average length of 70bp. The shortest was tRNA-Ser (66 bp) and the longest tRNA-Lys (73 bp). One segregating site (S) was found in tRNA-Asp, tRNA-Gly and tRNA-His and no variation was found in the remaining tRNA genes. This makes the tRNA genes the most conserved mitochondrial genes. 16SrRNA was larger (1692 bp) than 12S rRNA (945 bp), however, 12S rRNA was the more variable rRNA with a haplotype diversity $(\mathrm{Hd})$ of $0.843(\mathrm{~S}=15)$ compared to $16 \mathrm{~S}$ rRNA $(\mathrm{Hd}=0.8060, \mathrm{~S}=12)$. The least variable protein-coding gene is $\mathrm{ND} 4 \mathrm{~L}$ ( $\mathrm{Hd}=0.3420, \mathrm{~S}=5$ and the most variable protein-coding gene is ND4 ( $\mathrm{Hd}=1, \mathrm{~S}=69)$. The most 
variable area of the mitochondrial genome is the CR with a haplotype diversity of 1 and 130 segregation sites. All variable genes had a negative Tajima D statistic, however, only ND4L, CO1, COIII and ND2 were significant at $\mathrm{p}<0.05$ and COII was significant at $\mathrm{p}<0.01$. Furthermore, Fu's Fs statistic were also negative for all variable genes.

Table 2.2: Characterization of $N$. macropterus genome. Gene diversity calculated from 28 N. macropterus mitochondrial genomes.

\begin{tabular}{|c|c|c|c|c|c|c|c|c|c|c|}
\hline Gene / Region & Start & Stop & Strand & Size & $\mathbf{S}$ & Hap & Hd & $\mathbf{P i}$ & TajimaD & FuFs \\
\hline tRNA-Phe & 1 & 68 & $\mathrm{H}$ & 68 & 0 & 1 & 0 & 0 & - & - \\
\hline $12 \mathrm{~S}$ rRNA & 69 & 1014 & $\mathrm{H}$ & 945 & 12 & 12 & 0.8430 & 0.0017 & -1.6034 & -7.4260 \\
\hline tRNA-Val & 1015 & 1086 & $\mathrm{H}$ & 71 & 0 & 1 & 0 & 0 & - & - \\
\hline 16S rRNA & 1087 & 2779 & $\mathrm{H}$ & 1692 & 17 & 14 & 0.8060 & 0.0014 & -1.6847 & -8.0710 \\
\hline tRNA-Leu & 2780 & 2853 & $\mathrm{H}$ & 73 & 0 & 1 & 0 & 0 & - & - \\
\hline ND1 & 2854 & 3828 & $\mathrm{H}$ & 974 & 42 & 23 & 0.9890 & 0.0075 & -1.3133 & -13.2440 \\
\hline tRNA-Ile & 3833 & 3902 & $\mathrm{H}$ & 69 & 0 & 1 & 0 & 0 & - & - \\
\hline tRNA-Gln & 3902 & 3972 & $\mathrm{~L}$ & 70 & 0 & 1 & 0 & 0 & - & - \\
\hline tRNA-Met & 3972 & 4042 & $\mathrm{H}$ & 70 & 0 & 1 & 0 & 0 & - & - \\
\hline ND2 & 4043 & 5088 & $\mathrm{H}$ & 1045 & 48 & 24 & 0.9890 & 0.0061 & -1.8913 & -17.2780 \\
\hline tRNA-Trp & 5089 & 5159 & $\mathrm{H}$ & 70 & 0 & 1 & 0 & 0 & - & - \\
\hline tRNA-Ala & 5161 & 5229 & $\mathrm{~L}$ & 68 & 0 & 1 & 0 & 0 & - & - \\
\hline tRNA-Asn & 5233 & 5305 & $\mathrm{~L}$ & 72 & 0 & 1 & 0 & 0 & - & - \\
\hline tRNA-Cys & 5336 & 5402 & $\mathrm{~L}$ & 66 & 0 & 1 & 0 & 0 & - & - \\
\hline tRNA-Tys & 5403 & 5473 & $\mathrm{~L}$ & 70 & 0 & 1 & 0 & 0 & - & - \\
\hline $\mathrm{COI}$ & 5475 & 7025 & $\mathrm{H}$ & 1550 & 49 & 24 & 0.9890 & 0.0037 & -2.0690 & -18.5870 \\
\hline tRNA-Ser & 7026 & 7096 & $\mathrm{~L}$ & 70 & 0 & 1 & 0 & 0 & - & - \\
\hline tRNA-Asp & 7100 & 7170 & $\mathrm{H}$ & 70 & 1 & 2 & 0.0740 & 0.0010 & -1.1535 & -1.1250 \\
\hline COII & 7180 & 7870 & $\mathrm{H}$ & 690 & 9 & 9 & 0.5130 & 0.0010 & -2.2754 & -7.9900 \\
\hline tRNA-Lys & 7871 & 7944 & $\mathrm{H}$ & 73 & 0 & 1 & 0 & 0 & - & - \\
\hline ATPase- 8 & 7946 & 8113 & $\mathrm{H}$ & 167 & 5 & 6 & 0.4960 & 0.0033 & -1.5975 & -3.6990 \\
\hline ATPase-6 & 8104 & 8786 & $\mathrm{H}$ & 682 & 30 & 20 & 0.9520 & 0.0065 & -1.5778 & -12.4900 \\
\hline COIII & 8787 & 9571 & $\mathrm{H}$ & 784 & 26 & 18 & 0.9150 & 0.0044 & -1.8534 & -11.3000 \\
\hline tRNA-Gly & 9572 & 9643 & $\mathrm{H}$ & 71 & 1 & 2 & 0.0740 & 0.0010 & -1.1535 & -1.1250 \\
\hline ND3 & 9644 & 9992 & $\mathrm{H}$ & 348 & 11 & 12 & 0.8600 & 0.0048 & -1.5423 & -7.1830 \\
\hline tRNA-Arg & 9993 & 10061 & $\mathrm{H}$ & 68 & 0 & 1 & 0 & 0 & - & - \\
\hline ND4L & 10062 & 10358 & $\mathrm{H}$ & 296 & 5 & 6 & 0.3420 & 0.0015 & -1.8562 & -4.5820 \\
\hline ND4 & 10352 & 11732 & $\mathrm{H}$ & 1380 & 69 & 27 & 1 & 0.0078 & -1.6024 & -19.7810 \\
\hline tRNA-His & 11733 & 11801 & $\mathrm{H}$ & 68 & 1 & 2 & 0.1420 & 0.0021 & -0.7280 & -0.3490 \\
\hline tRNA-Ser & 11802 & 11868 & $\mathrm{H}$ & 66 & 0 & 1 & 0 & 0 & - & - \\
\hline tRNA-Leu & 11873 & 11945 & $\mathrm{H}$ & 72 & 0 & 1 & 0 & 0 & - & - \\
\hline ND5 & 11946 & 13784 & $\mathrm{H}$ & 1838 & 88 & 26 & 0.9970 & 0.0076 & -1.5495 & -13.2400 \\
\hline ND6 & 13781 & 14302 & $\mathrm{~L}$ & 521 & 28 & 17 & 0.8690 & 0.0077 & -1.7775 & -8.1370 \\
\hline tRNA-Glu & 14303 & 14371 & $\mathrm{~L}$ & 68 & 0 & 1 & 0 & 0 & - & - \\
\hline Cyt-b & 14376 & 15516 & $\mathrm{H}$ & 1140 & 42 & 21 & 0.9540 & 0.0053 & -1.6714 & -11.1370 \\
\hline tRNA-Thr & 15517 & 15588 & $\mathrm{H}$ & 71 & 0 & 1 & 0 & 0 & - & - \\
\hline tRNA-Pro & 15589 & 15658 & $\mathrm{~L}$ & 69 & 0 & 1 & 0 & 0 & - & - \\
\hline Control region & 15659 & 16650 & $\mathrm{H}$ & 991 & 130 & 27 & 1 & 0.0250 & -1.2191 & -10.8350 \\
\hline
\end{tabular}




\subsection{2: Hyper Variable Region One Primers}

The following two primers were designed to target and amplify a 817 bp (913 bp including primers) section of the CR and more specifically, HVR1 (Figure 2.2). Both primers were designed to have the same length and GC content so melting and annealing temperatures would be similar. L-tRNA-Thr_Tar $=\left(5^{\prime}\right.$ GGTCTTGTAAACCGGATGTCG 3') is the forward primer designed to bind within tRNA-Thr at the 5' end of the CR to the L strand and amplify the $\mathrm{H}$ strand. L-tRNA-Thr_Tar is 21 bp in length with a GC content of 52.4\% (A:19.0\%, C:19.0\%, G: $33.3 \%$, T: 28.6\%). H-CCD_Tar (5' GGGGTCTTTTCTGTTTACGGG 3') is the reverse primer designed to bind to the 3 ' end of CCD within the CR to the $\mathrm{H}$ strand amplifying the L strand. H-CCD_Tar is 21 bp in length with a GC content of $52.4 \%$ (A: $4.8 \%, \mathbf{C}: 14.3 \%$, G: $38.1 \%$, T: $42.9 \%$ ). Both primers have a $\mathrm{G}$ and $\mathrm{C}$ on the 3' end to aid in annealing during PCR cycles. Furthermore, both primers are not self-complementarity. H-CCD_Tar and tRNAThr_Tar successfully amplified HVR1 of ten $N$. macropterus samples and $N$. $s p$. The amplified fragment was 913 bp in length. After comparing mtDNA sequence data, H-CCD_Tar produced the higher quality sequences.
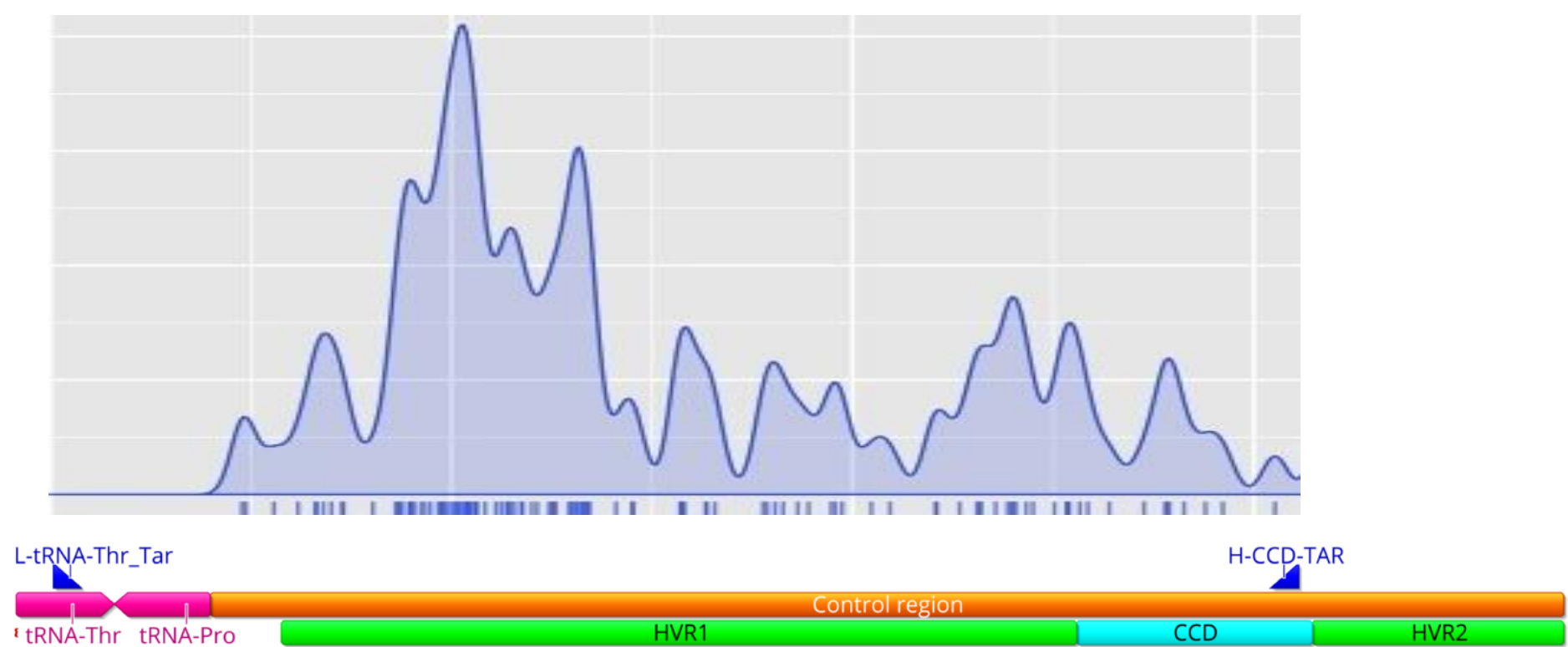

Figure 2.2: HVR1 forward (L-tRNA-Thr_Tar) and reverse (H-CCD-TAR) primer binding sites. Primers are coloured dark blue, control region is orange, tRNAs are pink, hyper variable region one (HVR1) and two (HVR2) are green and conserved central domain is light blue. Above is the abundance of single nucleotide polymorphisms distributed across the amplified fragment of the control region. 


\subsection{3: Nemadactylus Phylogeny}

The maximum likelihood phylogenetic tree was constructed using CR mtDNA sequences for seven Nemadactylus species as no sequences were available for $N$. vemae (Figure 2.3).

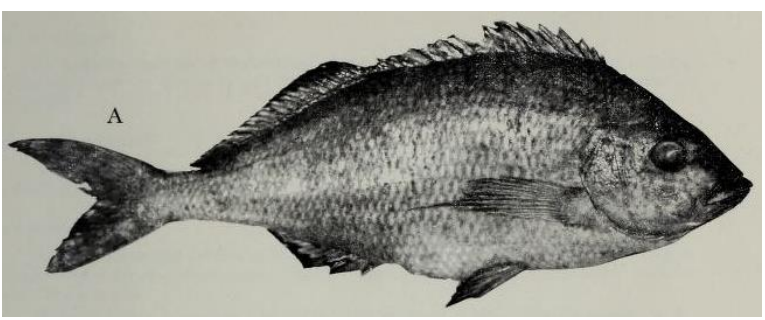

Nemadactylus Vemae

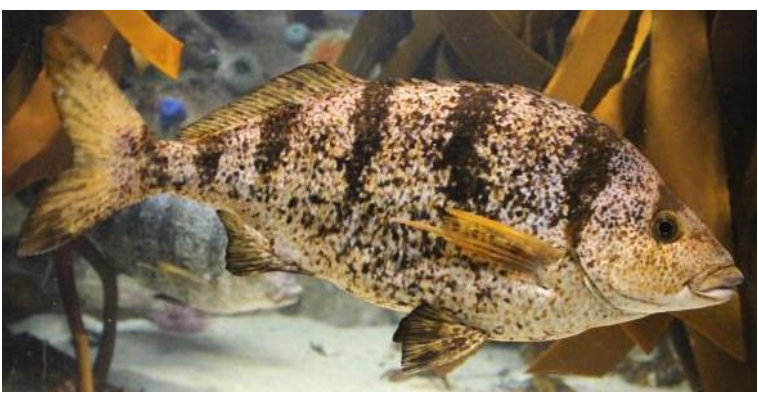

Nemadactylus monodactylus (St. Paul's fingerfin)

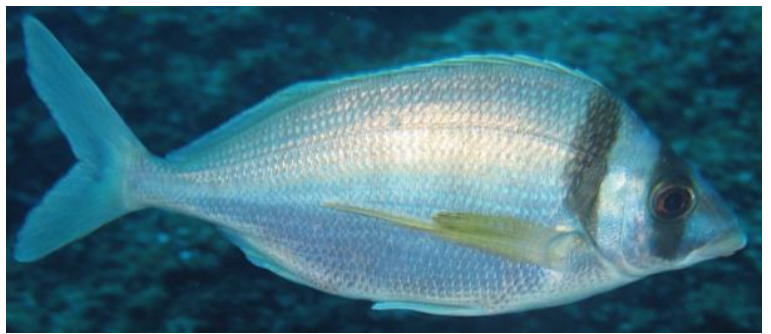

Nemadactylus gayi (breca)

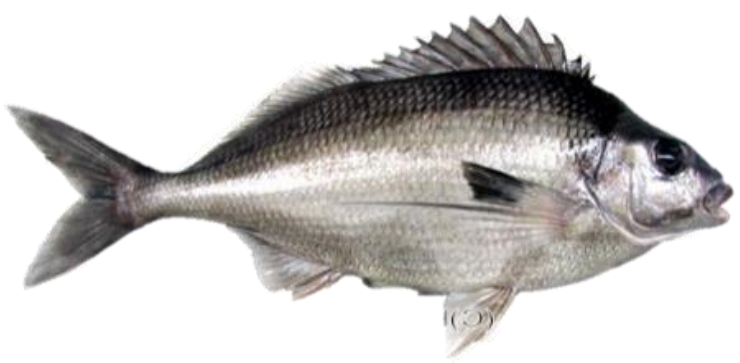

Nemadactylus sp (king tarakihi)

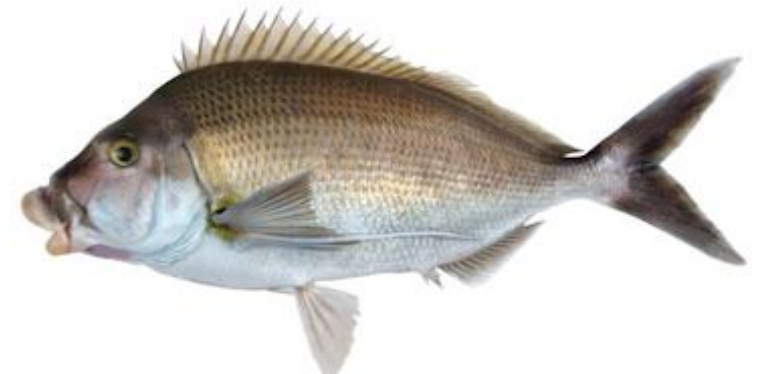

Nemsdactylus douglasii (porae/grey morwong)

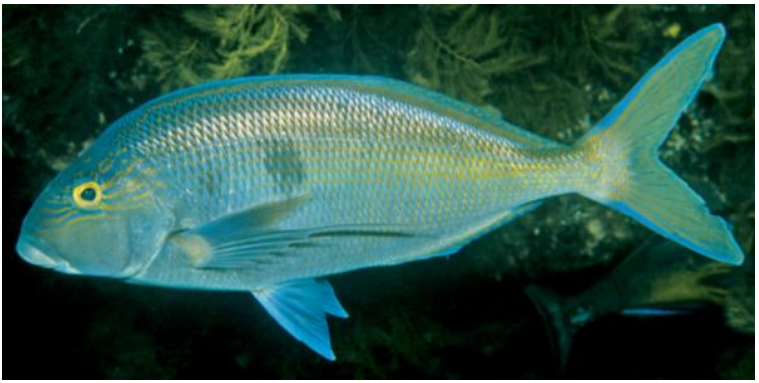

Nemadactylus valenciennesi (blue morwong)

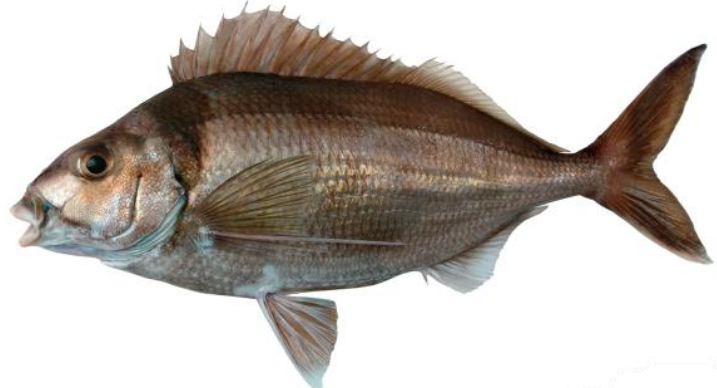

Nemadactylus macropterus (tarakihi/jackass morwong)

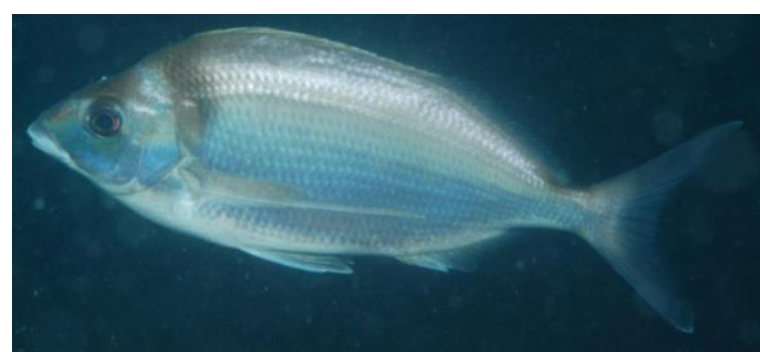

Nemadactylus bergi (Castaneta)

Figure 2.3: Species of Nemadactylus. N. vemae (Cape Town Museum, 1891), N. douglasii (Hann, 2013.b), N. monodactylus (Two Oceans Aquarium, 2019), N. valenciennesi (Bray, 2019.b), N. gayi (vision oceanica, 2019), N. macropterus (Hann, 2013.a), N. sp (Bray, 2019.a) and N. bergi (Reef Life Survey, 2019). 


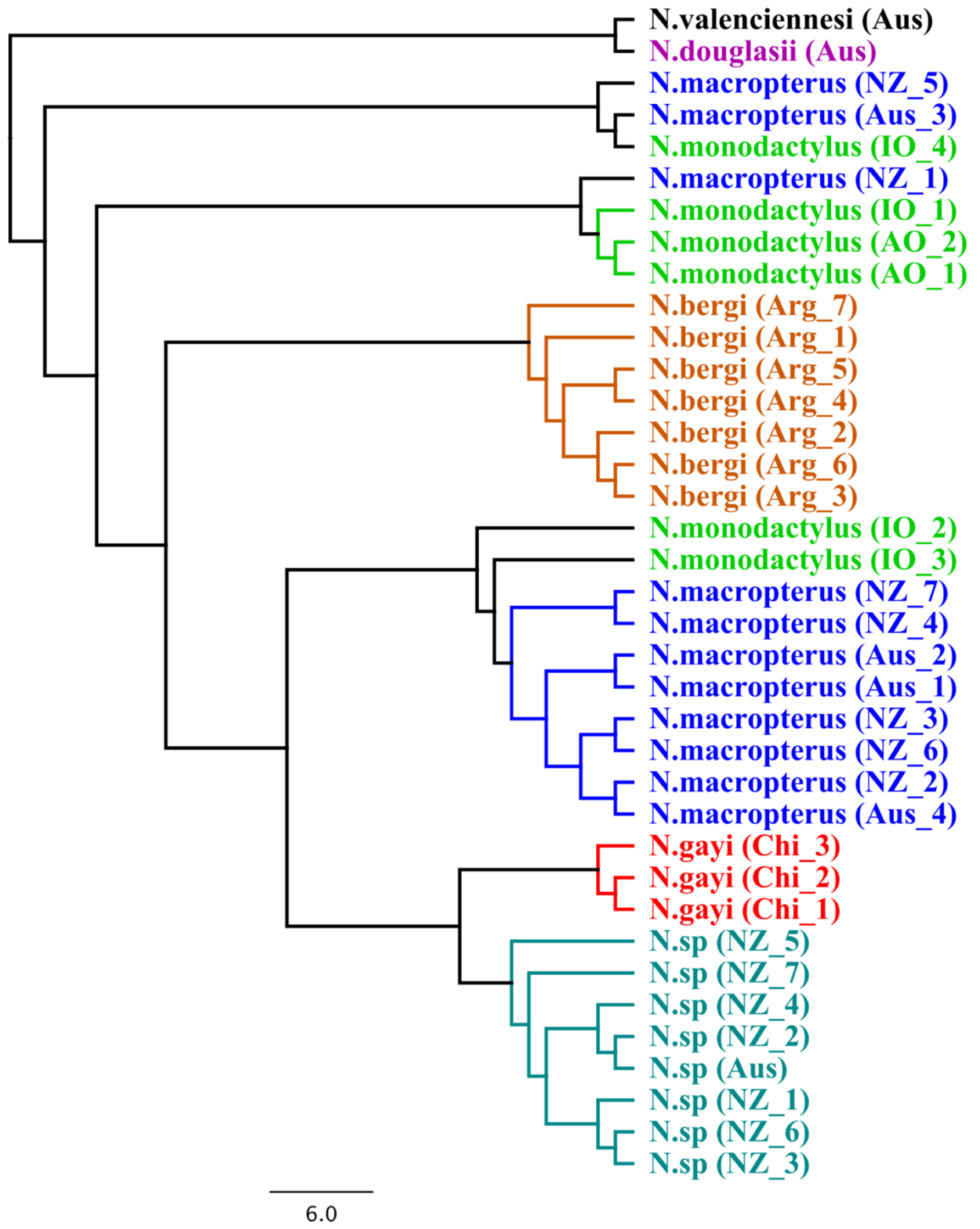

Figure 2.4: Reconstructed phylogeny of Nemadactylus species. Each species is assigned its own colour. 


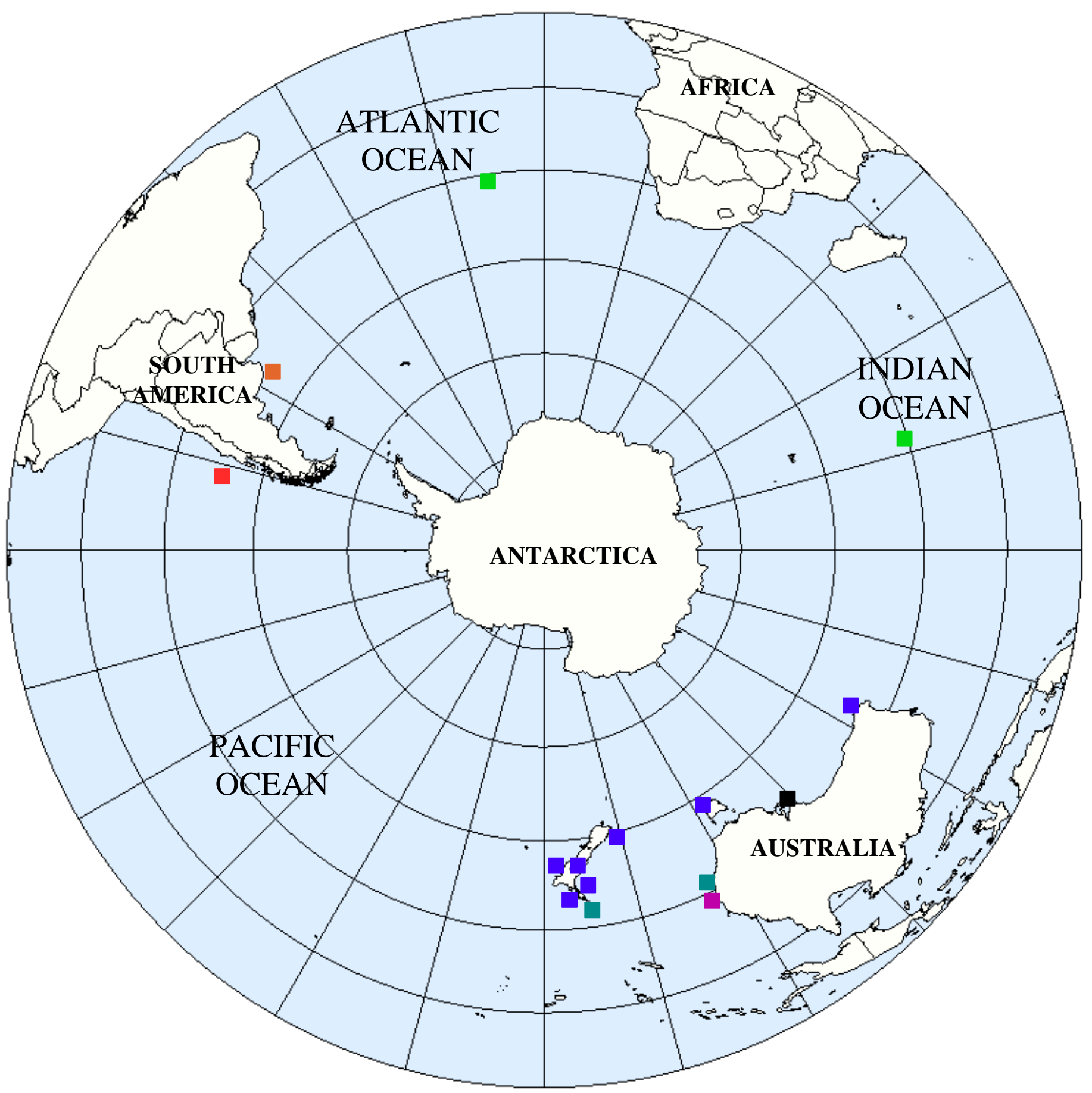

Figure 2.5: Location of samples used to create Nemadactylus phylogeny. Blue - N. macropterus, purple - N. douglasii, green - N. monodactylus, black - N. valenciennesi, red - N. gayi, aqua - N. sp and orange - N. bergi. Map adapted from - Southern Hemisphere, Wikipedia. Further information about sample location and GenBank accession numbers can be found in appendix A.

The maximum likelihood phylogenetic tree can be divided into two distinct clades (Figure 2.4). The first clade contains N. valenciennesi and N. douglasii, the second clade contains the remaining Nemadactylus species. The second clade consists of six smaller clades, three are monophyletic and three are polyphyletic. $N . s p$ and $N$. gayi form a monophyletic sister clade separate from the remaining Nemadactylus species. Australian and New Zealand N. sp 
samples form a monophyletic clade. $N$. bergi formed the final monophyletic clade nested among polyphyletic clades of $N$. monodactylus and $N$. macropterus. The largest polyphyletic clade contained $N$. macropterus samples from New Zealand and Australia grouping with $N$. monodactylus samples from the Southern Indian Ocean (Amsterdam Island). The same clustering of samples make up the polyphyletic clade closest to $N$. valenciennesi and $N$. douglasii. The final polyphyletic clade (next to $N$. bergi) contains one $N$. macropterus sample from New Zealand and N. monodactylus samples from the Southern Indian and Atlantic (Gough Island and Tristan da Cunha Island) Oceans (Figure 2.5).

\section{4: Discussion}

This is the first known mitochondrial genome constructed for the Nemadactylus genus. The complete mitochondrial genome of $N$. macropterus is $16,650 \mathrm{bp}$ in length, consisting of 13 protein-coding genes, 22 tRNAs, 2 rRNAs, and the non-coding CR. There was no evidence of reorganization within tRNA gene cluster regions (IQM and WANCY) detected among $N$. macropterus or between $C$. variegatus and $N$. macropterus genomes. The gene arrangement of N. macropterus is consistent with the standard vertebrate mitochondrial gene arrangement and similar to many other teleost fish species (Satoh et al., 2016). Mitochondrial tRNA genes were the most conserved genes within the mitochondrial genome. One possible reason for this is that tRNA genes are sensitive to mutations as they often are deleterious, preventing the tRNA from forming their typical clover leaf structure and deeming them dysfunctional (Abbott et al., 2014). In contrast, the CR was the least conserved area of the mitochondrial genome and displayed over twice the level of nucleotide diversity of the most variable protein coding gene (ND5). This is due to the CR region being non-coding, meaning it does not transcribe a protein so the persistence of a mutation that arise within the CR is less likely to impact on the phenotype and be under as many constrains (Satoh et al., 2016). Because mitochondria have a high copy number per cell, mitochondrial heteroplasmy is often seen in CR sequences (Satoh et al., 2016). However, one area of the CR that is more conserved was the CCD as this is the location for mitochondrial replication and transcription (Satoh et al., 2016).

Mitochondrial genes are thought to be selectively neutral (Ballard \& Kreitman, 1995). However, the genome undergoes a rolling circle type of replication, which might expose 
strands to an asymmetric mutational pressure (Satoh et al., 2016). Negative Tajima D and Fu's Fs statistics from all variable genes validates this as a negative value implies the population is undergoing an expansion. If positive values were detected, that would suggest selection. If there was a mix of positive and negative values that would indicate there is selection pressure operating on specific genes. As the $\mathrm{CR}$ appears to be selectively neutral and highly polymorphic, developing primers to specifically target HVR1 should provide sequences that contain enough variability to provide the resolution required for inferences about population genetic structure (Chapter 3). The complete mitochondrial genome provides a valuable template for designing primers to target additional loci.

The Nemadactylus phylogeny was successfully reconstructed using maximum likelihood methods with CR sequence data for all species apart from $N$. vemae as sequences were not available. Nemadactylus phylogeny formed two distinct clades, one of which contained $N$. douglasii and $N$. valenciennesi that formed a divergent sister clade from the remaining Nemadactylus species. Phenotypically, N. douglasii and N. valenciennesi look more similar to one another and are the only two species that do not have a distinct black saddle across their nape. The ancestors of species in the genus Nemadactylus have been estimated to have dispersed and radiated during the last 0.6-2.6 million years (Burridge, 1999). Due to the divergence between the two clades, the last common ancestor of $N$. douglasii and $N$. valenciennesi would have most likely been the first to diverge closer to 2.6 million years ago. The remaining Nemadactylus species have diverged more recently as their lineages are relatively shallow. $N$. $s p$ form a monophyletic clade that contains samples from New Zealand and Australia. The Australia sample is nested amongst the New Zealand samples indicating that the two populations may not be reproductively isolated and some degree of gene flow across the Tasman sea could be facilitating this genetic similarity (Bruce et al., 2001). Another possibility is allopatric speciation may have recently begun, however, the divergence period has not been long enough to detect any genetic differences of reproductive isolation. The same rationale could also be used to explain why Australian and New Zealand N. macropterus samples group together in the polyphyletic clades. $N$. gayi also form a monophyletic clade that is sister to $N$. sp. Before the initial discovery of this by Burridge (1999), $N$. $s p$ was thought to have been a sister species to $N$. macropterus that had undergone sympatric speciation. However, Burridge (1999) suggests that N. sp and N. gayi are "transoceanic sister taxa" possibly linking species radiation between New Zealand and Chile. Furthermore, $N$. $s p$ and $N$. gayi share the same number of anal fin ray counts (Lamb, 1990; Roberts, 1993). N. bergi forms 
the final monophyletic clade nestled among polyphyletic clades of $N$. macropterus and $N$. monodactylus. $N$. bergi and $N$. macropterus look morphologically similar, however, slight differences in the width of the supra-cleithrum relative to the diameter of the eye, the relative lengths of their thickened pectoral fin rays, and lateral line scale counts distinguish these two species (Norman, 1937; Lamb, 1990). However, due to almost phenotypic similarity and $N$. bergi nested among $N$. macropterus suggest $N$. bergi and $N$. macropterus are more closely related than N. macropterus is to N. sp. Furthermore, Burridge (1999) analysed the genetic diversity between $N$. macropterus and $N$. bergi concluding that $N$. bergi has a reduced genetic diversity compared to that of $N$. macropterus. This could possibly indicate a founding event between these two species or may have been a result of overfishing during the 1960's (Burridge, 1999). N. macropterus form three polyphyletic clades with N. monodactylus samples from the South Atlantic and Indian Oceans. Burridge (1999) suggest that either introgressive hybridization (Figure 2.6) or incomplete lineage sorting may be causing the polytypic structure.

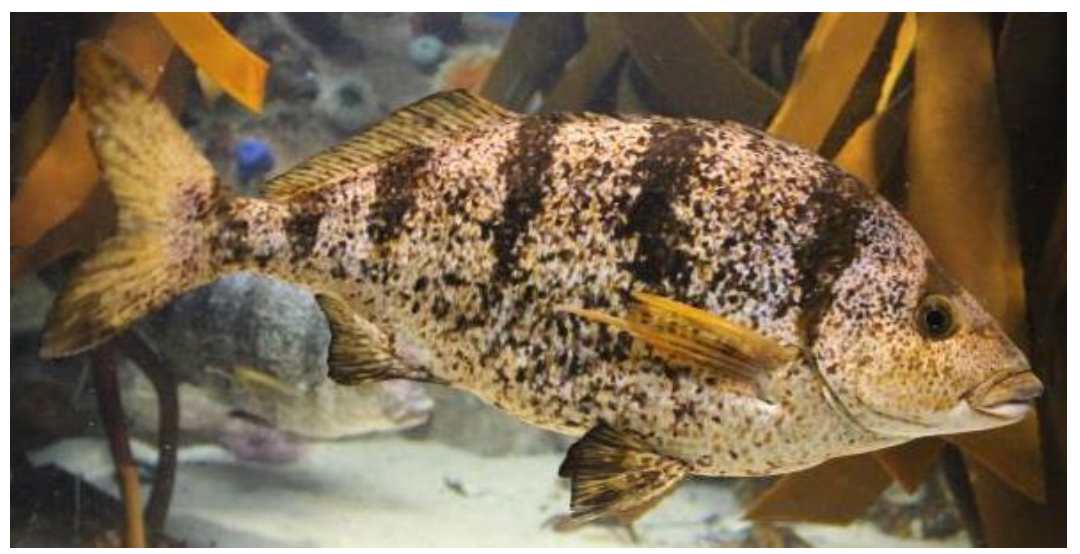

N. monodactylus (St Paul's fingerfin)

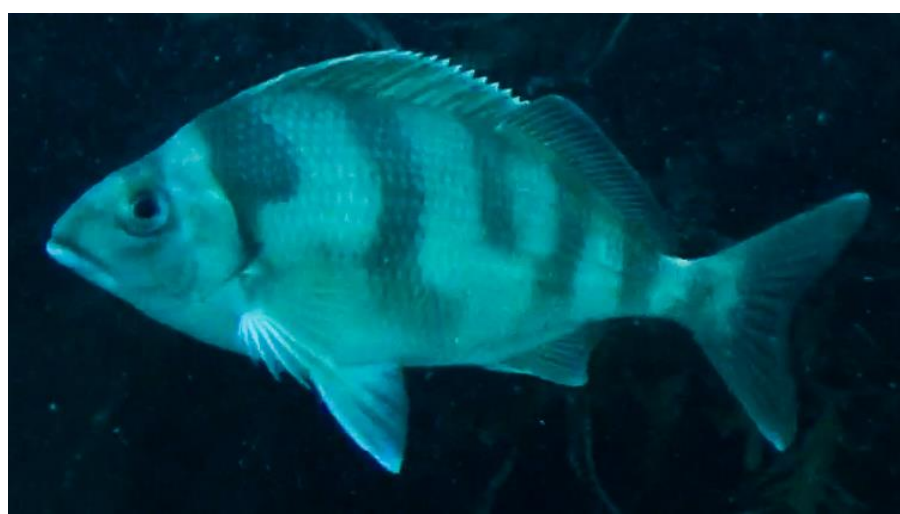

"Banded N. macropterus"

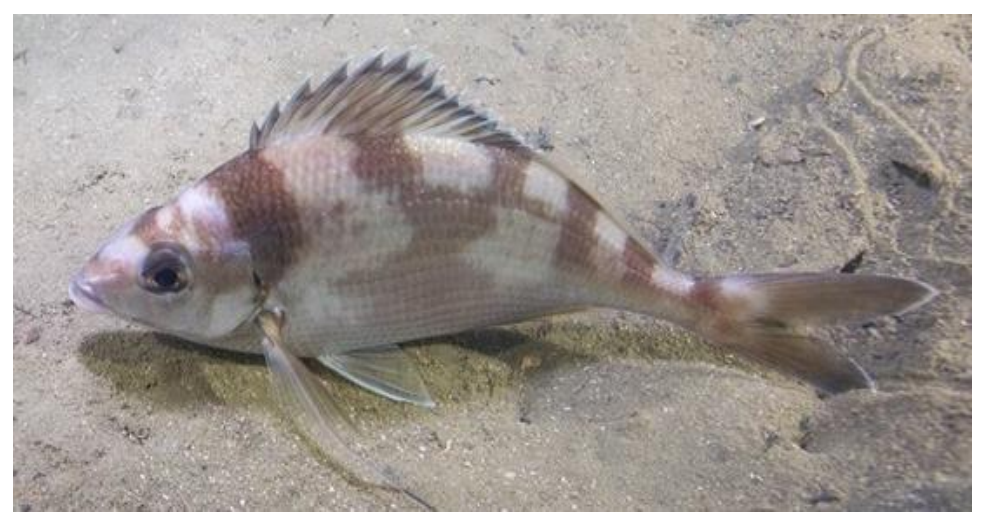

N. macropterus (tarakihi)

Figure 2.6: Possible evidence of introgressive hybridization between N. monodactylus and N. macropterus. Photo of "banded N. macropterus" taken by Ben Knight in the Kapiti marine reserve, 2018. Photo of N. macropterus displaying a banding pattern at night taken by Rob Wilson in Wellington harbour, 2018). 
Nemadactylus species have relatively long PLD of 7-12 months making oceanic travel of larvae possible if the conditions are favourable. Furthermore, the spawning periods of $N$. macropterus and N. monodactylus overlap (Annala, 1987; Andrew et al., 1995). But these species appear to be phenotypically different as $N$. monodactylus is the only Nemadactylus species to have several dark markings along its dorsal. However, photos captured of $N$. macropterus at night reveal several dark markings along their dorsal as well. Furthermore, a sighting of a "dark banded N. macropterus" was captured in the Kapiti Island marine reserve during the day time. The similarities in phenotypes between $N$. macropterus and $N$. monodactylus may provide evidence that introgressive hybridization is occurring. Another possibility is that $N$. macropterus and N. monodactylus both possess the genotype to display the phenotypic banding. The banding may have been advantageous to $N$. monodactylus within its environment, resulting in the banding becoming fixated among the population via natural selection. However, it has also been noted that the "banded N. macropterus" may be a previously undescribed species or a possible hybridization with another species such as Cheilodactylus spectabilis (red moki) (RNZ, 2018). The most likely explanation behind the formation of the polyphyletic clades is incomplete lineage sorting. The common ancestral population of $N$. macropterus and N. monodactylus, is thought to have been relatively large with a high level of genetic diversity. Due to the recent divergence, $N$. macropterus and $N$. monodactylus most likely retain some of the ancestral haplotypes. This creates a discordance between the gene and species phylogenetic tree resulting in the formation of polytypic clades.

N. macropterus (jackass morwong) is the only species within the Nemadactylus genus that has had research done to identify their population genetic structure around South Australia (Burridge \& Smolenski, 2003). As very little is currently known about the genetic population structure of New Zealand's $N$. macropterus fishery, the development of primers capable to target HVR1 will provide a useful tool for an initial genetic survey. Furthermore, the HVR1 primers can be used to clarify taxonomic differences between $N . s p$ and $N$. macropterus and potentially within the Nemadactylus genus (Smith et al., 1996; Burridge 1999). The newly designed HVR1 primers can amplify $~ 900 \mathrm{bp}$ fragment of the control region. This is much larger than the only other published CR primers that have been used on Nemadactylus genus ( 300 bp) (Burridge 1999). Due to the successful amplification of N. macropterus and N. $s p$ mtDNA, HVR1 primers would most likely be capable of amplifying this region for most Nemadactylus species as they appear to have radiated recently. This could be particularly useful for analysing the population structure of $N$. bergi as they are commercially fished in Argentina 
(Venerus \& Cedrola, 2017). However, further testing is required to confirm this for N. douglasii and $N$. valenciennesi due to their divergence from other Nemadactylus species. 


\section{Chapter Three: Population genetic structure of N. macropterus and demographic history/genetic diversity of N. macropterus and N. sp.}

\section{1: Introduction}

Understanding the patterns of connectivity and stock boundaries for a commercially exploited species is essential for effective management. The primary goal for fishery managers is to maintain a sustainable harvesting level that fluctuate around a MSY (Maunder, 2002). In order to prevent over harvesting, the factors of fishing pressure and methods, and the location of the harvesting, must be monitored and controlled at a level that fishing mortality is not higher than recruitment and emigration of fish away from the stock area (Pinsky \& Palumbi 2014). Recruitment into the fishery typically occurs via reproduction or immigration (Methot \& Wetzel, 2013). In order to regulate fishing-induced mortality, fisheries are typically split into manageable units or stocks (Methot \& Wetzel, 2013). To best manage a stock, it must align to the natural patterns of genetic and demographic structuring (Carvalho \& Hauser, 1995). If the genetic structure of a stock is poorly defined, excessive fishing induced mortality increases the risk of fishing reducing the population size which will erode genetic diversity (Carvalho \& Hauser, 1995). If the intensity is high enough it could also alter genetic structure and hinder gene flow. A declining stock size causes stronger genetic drift (Carvalho \& Hauser, 1995). This means erratic allele frequency changes and a high chance that low frequency (rare) alleles will be lost (Pinsky \& Palumbi, 2014). Stocks with lower levels of genetic diversity are less adaptable, which makes them more vulnerable to environmental changes and disease outbreaks (Pinsky \& Palumbi, 2014). Furthermore, reduced stocks are more likely to be exposed to inbreeding depression as recessive deleterious alleles become more prevalent in the homozygote form, further reducing the stocks viability (Pinsky \& Palumbi, 2014). However, identifying independent reproductive units and determining stock boundaries can be difficult (Laikre et al., 2005). Marine species have a diverse range of life history characteristics that can either facilitate gene flow among populations or be the cause of genetic subdivision (Endler, 1979). Populations that seem somewhat isolated from one another may migrate to form spawning aggregations periodically (Endler, 1979). In contrast, many sessile and sedentary species are broad cast spawners relying on currents to disperse their larvae (Gaines \& Bertness, 
1992). Difference in PLD also effect the distance in which the larvae can disperse, potentially connecting unexpected populations or maintaining self-recruitment (Shanks, 2009). Other species can be highly dispersive during their adult phase (Hogan et al., 2014). The longevity for highly dispersive species can affect the distance in which they may travel during their lifetime (Hogan et al., 2014).

DNA-based approaches are used to estimate levels of connectivity and effective population size. Mitochondrial DNA is more sensitive to changes in the effective population size compared to nuclear DNA (Brown, 2008). This is because mtDNA is maternally inherited which has a smaller effective population size $\left(N_{e f}\right)$ that is proportional to the number of females within the population. (Birky et al., 1989). The smaller effective population size is argued to increase its sensitivity for detecting population genetic subdivisions (Birky et al., 1989). Overall, the high mutation rate, maternal inheritance, and lack of recombination make mtDNA a unique marker for understanding the contemporary and historic population patterns and processes (Brown, 2008).

N. macropterus are widely distributed around New Zealand and are found in all QMA (Annala, 1987). N. macropterus also occur around south Australia and Tasmania where they are commonly known as jackass morwong (Burridge \& Smolenski, 2003). N. macropterus are relatively long lived (>30 years), have a PLD of approximately 10 months and the potential to disperse over large distances (Annala, 1987). Due to these life history characteristics, $N$. macropterus populations inhabiting south Australian waters display a panmictic genetic structure (Burridge \& Smolenski, 2003). Attempts to compare Australian and New Zealand populations using microsatellites indicate a lack of genetic difference (Burridge \& Smolenski, 2003). This could provide evidence that trans-Tasman dispersal may be occurring, increasing N. macropterus larval dispersal ability to exceed 1000km (Bruce et al., 2001).

Very little is currently known about the connectivity and genetic structure of $N$. macropterus within New Zealand. The majority of genetic studies utilizing N. macropterus DNA have been used to produce phylogenies or make comparisons between New Zealand and Australian samples (Burridge, 1999; Burridge \& Smolenski, 2003). Initial studies using a combination of parasites, iron content within otoliths, allozymes and RFLP comparisons, did not provide any clear indication of population structure (Vooren \& Tracey, 1976); Gauldie \& Nathan, 1977); Gauldie et al., 1980); Gauldie \& Johnston, 1980). Modern molecular markers and DNA 
sequencing have yet to be used to examine the population structure around New Zealand. The current estimate of population structure and connectivity of $N$. macropterus is derived from observations of catch data from the fishing industry and stock assessments (Langley, 2018). Differences in growth rates between east and west Northland may indicate a lack of connectivity between coasts (Langley, 2018). However, tagged N. macropterus have migrated from Kaikoura to the west coast of the North Island (Kaipara harbour) (McKenzie, 1961; Annala, 1987). The current stock hypothesis is; "Canterbury Bight/Pegasus Bay area represents the main nursery area for the eastern stock unit. At the onset of maturity, a proportion of the fish migrate northwards to recruit to the East Cape area and, subsequently, the Bay of Plenty and east Northland areas" (Langley, 2018).

In this study a 500bp mtDNA sequence of the control region that spans across HVR1 was used to address three aims. The first aim of this study is investigate the genetic structure and demographic history of $N$. macropterus populations surrounding New Zealand. The second aim is to investigate the genetic diversity and historic demography of $N$. $s p$. The third aim is to investigate the genetic relationship between $N$. macropterus and $N$. $s p$.

\section{2: Methods}

\subsection{1: Sample Design}

N. macropterus samples were collected from all quota management areas within New Zealand's EEZ that are currently being fished (Figure 3.1). N. macropterus samples were provided from the commercial fishing industry and from a charter fishing boat in Fiordland as there was no current commercial N. macropterus fishers operating. The EEZ was divided into 18 geographic locations that encompassed New Zealand and an additional $19^{\text {th }}$ location of the Chatham Islands. The three known spawning areas were re-sampled during spawning season in the hope of capturing any spawning aggregations composed of different regions that may occur. The Three Kings Islands were chosen as a $20^{\text {th }}$ sampling location to provide samples of $N$. $s p$. For all locations, 60 whole fish were caught. No more than 20 fish per single trawl, longline or charter trip were collected. This reduced the chance of $N$. macropterus samples being caught from the same school. 


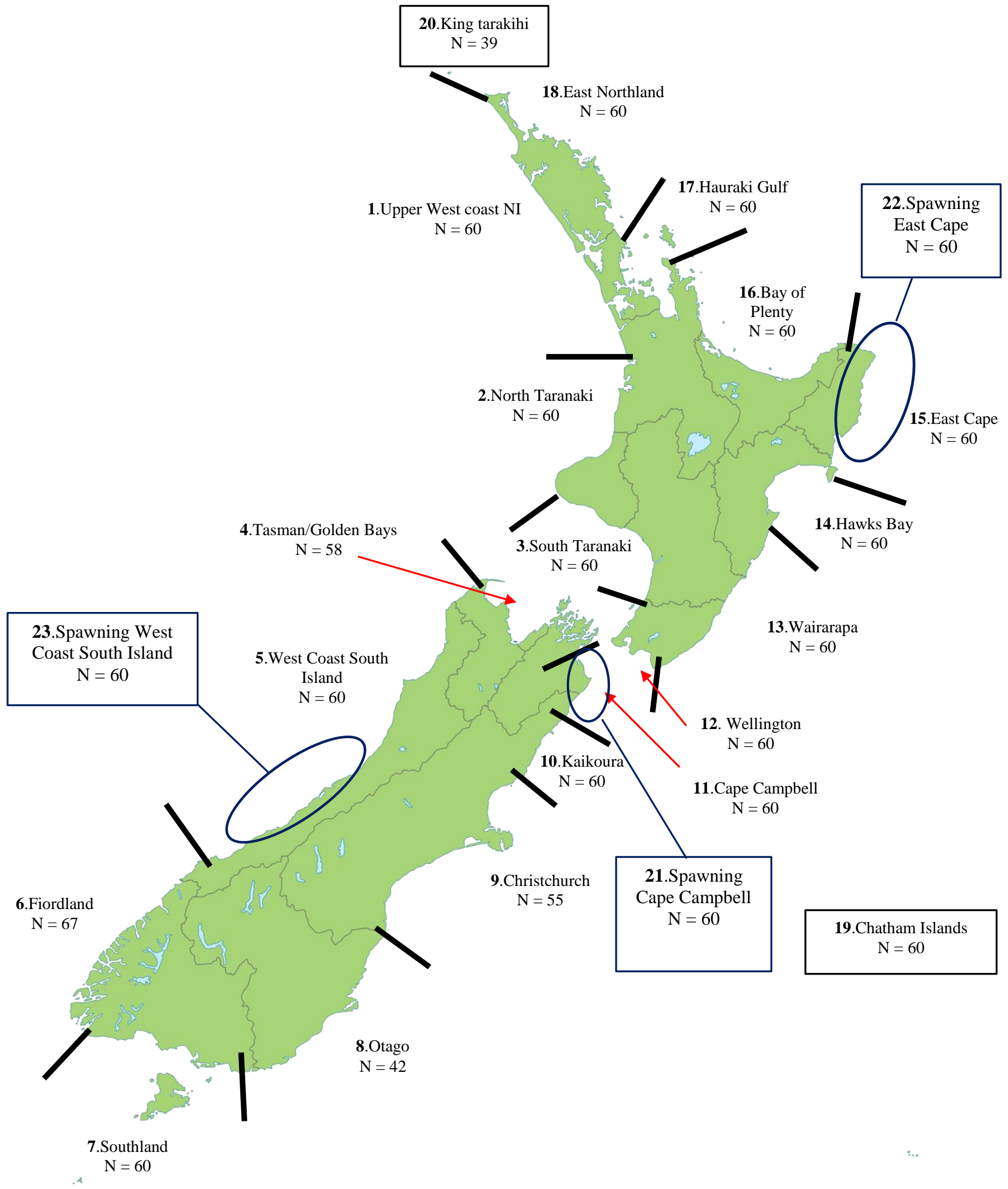

Figure 3.1: Map of New Zealand displaying sample locations of $N$. macropterus and $N$. $s p$. Total number of samples collected per location is displayed below the name of each location. 
In total a combined sample of $1302 N$. macropterus were caught from 22 regions and $39 N$. $s p$ were caught from the Three Kings Islands (Figure 3.1). Once samples were caught, they were shipped in three polystyrene boxes (one for each of the 3 collections) filled with salt ice and the following information recorded; date caught, vessel name, fisher, company, sample location, start/end latitude and longitude of each trawl or catch location, fishing method and depth caught. Once the samples were received, they were stored at $-20^{\circ} \mathrm{C}$ until they were ready to be processed. Each region was processed separately to avoid mistaking location identity and cross contamination. $N$. macropterus and $N$. $s p$ were thawed for processing using running sea water pumped directly from the ocean. Each fish had the following recorded; fork length $(\mathrm{mm})$, total weight (g), liver weight (g), gut weight (g), gonad sex, stage and weight (g). Gonads and guts were kept and placed in zip lock bags and frozen at $-20^{\circ} \mathrm{C}$ for future analysis. Furthermore, a pair of otoliths were extracted using carbon tweezers for future isotope and age analysis. Two sections of muscle tissue ( $5 \mathrm{~mm} \mathrm{~W}$ x $5 \mathrm{~mm} \mathrm{H}$ x $20 \mathrm{~mm} \mathrm{~L}$ ) were collected from either side of the vertebrate near the tail for genetic analysis. Muscle tissue was placed in $1.5 \mathrm{ml}$ o'ring sealed tubes filled with $99 \%$ ethanol and stored at $-20^{\circ} \mathrm{C}$.

\subsection{2: DNA Extraction}

Samples selected for DNA extraction were randomly chosen from each of the three collections for each region to prevent sampling the same school. Rapid Salt-extraction protocol adapted from Aljanabi and Martinez (1997) was used to extract DNA from muscle tissue samples. A $40 \mathrm{mg}$ piece of muscle tissue was pressed with a sterile kimwipe to remove ethanol. The pressed muscle tissue was further cut into thin slices and placed in a $1.5 \mathrm{ml}$ centrifuge tube on a heat block set to $30^{\circ} \mathrm{C}$ to allow the remaining ethanol to evaporate while preparing additional samples. $450 \mathrm{ul}$ of extraction buffer $(0.4 \mathrm{M} \mathrm{NaCl}, 10 \mathrm{mM}$ Tris-HCl pH 8.0, 2 mM EDTA pH 8.0), $50 \mathrm{ul}$ of $20 \%$ Sodium dodecyl sulfate and $10 \mathrm{ul}$ of $20 \mathrm{mg} / \mathrm{mL}$ proteinase K were added to each tube and placed in a rotating oven set to $300 \mathrm{rpm}$ at $55^{\circ} \mathrm{C}$ overnight or until tissue had digested. Tubes were centrifuged at 16,000 RCF for 5 minutes to remove any undigested material before transferring $450 \mathrm{ul}$ of supernatant to a new tube using wide bore pipette tips. To precipitate proteins from solution, $150 \mathrm{ul}$ of $5 \mathrm{M} \mathrm{NaCl}$ was added to the supernatant and then centrifuged at 16,000 RCF for 10 minutes. $500 \mathrm{ul}$ of supernatant was removed using a wide bore pipette tip and placed in a new tube with an additional $150 \mathrm{ul}$ of $5 \mathrm{M} \mathrm{NaCl}$ and centrifuged at 16,000 RCF for 30 minutes. $500 \mathrm{ul}$ of supernatant was removed with a wide bore 
pipette and placed in the final tube with $1 \mathrm{ml}$ of absolute (100\%) ethanol at room temperature. At this stage salt usually precipitated from solution, and in order to prevent salt contamination $150 \mathrm{ul}$ of $\mathrm{ddH}_{2} \mathrm{O}$ was added to the salty tubes so the salt dissolved back into solution. Tubes were left at $-20^{\circ} \mathrm{C}$ overnight. DNA was pelleted by centrifuging at $12,000 \mathrm{RCF}$ at $4^{\circ} \mathrm{C}$ for 30 minutes. The ethanol was poured off and the remaining pellet washed twice with $500 \mathrm{ul}$ of $70 \%$ ethanol centrifuges for 5 minutes at 16,000 RCF. The remaining ethanol was pipetted off the pallet and then the tubes were placed on a heat block with caps open and covered for 30 minutes at $40^{\circ} \mathrm{C} .30 \mathrm{ul}$ of TE was added to the DNA pellet to rehydrate it and left on the heat block at $40^{\circ} \mathrm{C}$ for a further 30 minutes then placed in the fridge at $4{ }^{\circ} \mathrm{C}$ overnight. DNA quality was assessed using a nanophotometer NP80 (Implen) to measure 260/280 and 260/230 wavelengths. $500 \mathrm{ng}$ of genomic DNA was added to a $1 \%$ electrophoresis agarose gel at $95 \mathrm{~V}$ for 30 minutes to assess how degraded it was and lambda hind III ladder was used to assess its molecular weight.

\subsection{3: $P C R$}

A 913 bp portion of the mitochondrial control region, tRNA-Thr and tRNA-Pro was amplified using polymerase chain reaction (PCR) in order to target HVR1. The following primers designed in chapter two were used, L-tRNA-Thr_Tar (5' GGTCTTGTAAACCGGATGTCG 3') and H-CCD_Tar (5' GGGGTCTTTTCTGTTTACGGG 3'). Each PCR was a total of 25 ul and included the following; buffer $\left(67 \mathrm{mM}\right.$ Tris- $\mathrm{HCl}, 16 \mathrm{mM}\left(\mathrm{NH}_{4}\right)_{2} \mathrm{SO}_{4}, 0.1 \%$ stabilizer), $\mathrm{MgCl}(3 \mathrm{mM}), \mathrm{BSA}(0.6 \mathrm{mg} / \mathrm{ml}), \mathrm{dNTPs}(0.4 \mathrm{mM}), 0.4 \mathrm{uM}$ of each primer, Taq polymerase $(0.05 \mathrm{U} / \mu \mathrm{l})$ and $50 \mathrm{ng}$ of template DNA. The thermocycler conditions were an initial denaturing of $95^{\circ} \mathrm{C}$ for 2 minutes, then 35 cycles of 1 minute at $95^{\circ} \mathrm{C}, 32$ seconds at $64^{\circ} \mathrm{C}, 30$ seconds at $71^{\circ} \mathrm{C}$, followed by a final extension of 10 minutes at $71^{\circ} \mathrm{C}$.

\subsection{4: DNA Sequencing}

To assess the PCR products, 2 ul was loaded in a 1.5\% agarose gel and electrophoresed for 30 minutes. Gels were stained with ethidium-bromide and visualized using UV light. Amplified products were purified by adding $0.5 \mu \mathrm{L}$ of EXO-SAP-IT to each tube and placed in the thermocycler on the following settings; $37^{\circ} \mathrm{C}$ for 30 minutes followed by $80^{\circ} \mathrm{C}$ for 15 minutes. 
Purified PCR products were loaded into a 96-well plate and sent to Macrogen Inc. (Seoul, South Korea) for sanger sequencing.

\subsection{5: Testing for Genetic Structure}

DNA sequences were aligned and edited with Geneious Prime v2019.0.4

(http://www.geneious.com) using the MUSCEL algorithm. Summary statistics such as the number of haplotypes $(\mathrm{Hn})$, haplotype diversity $(\mathrm{Hd})$, nucleotide diversity $(\pi)$, segregating sites (S) and shared haplotypes were calculated using DNAsp v6.12.03 (Rozas et al., 2017) and Arlequin 3.5.2.2 (Excoffier \& Lischer, 2010). A rarefaction analysis was performed using R packages pegas and spider to estimate how much of the total haplotype diversity was sampled in this study.

Population structure was analyzed using a pairwise fixation index calculated using Arlequin 3.5.2.2 and significance was assessed by permuting the data set 1000 times and applying a Bonferroni correction to the $\mathrm{p}$ values. A hierarchical Analysis of MOlecular VAriance (AMOVA) was conducted using Arlequin 3.5.2.2 to assess the levels of genetic differentiation within populations $\left(\Phi_{\mathrm{ST}}\right)$, among populations within groups $\left(\Phi_{\mathrm{SC}}\right)$ and among groups $\left(\Phi_{\mathrm{CT}}\right)$. Statistical significance was assessed using 1000 permutations of the data set. The AMOVA was run under ten different a priori grouping for population structure. The first a priori grouping included $N . s p$ and the remaining (2-10) excluded N. sp. A priori grouping: (1) one group; N. macropterus vs $N$. sp, (2) one group; containing all New Zealand locations, (3) one group; Fiordland vs Chatham Islands, (4) one group; Hawkes Bay vs east Northland, (5) two groups; all of New Zealand mainland locations vs Chatham Islands, (6) two groups; east vs west locations of mainland New Zealand excluding Wellington and Chatham Islands, (7) two groups; east vs west for all South Island locations, (8) two groups; east vs west for all North Island locations, (9) two groups; North vs South locations determined by $42^{\circ} \mathrm{S}$ latitude and (10) two groups; spawning locations vs the non-spawning locations. A principal component analysis (PCA) was conducted to analyze genetic structure by comparing samples without any a priori defined groups using R package adegenet, ape and MASS. Four PCA were conducted; (1) N. sp and N. macropterus samples, (2) non-spawning N. macropterus, (3) spawning $N$. macropterus and (4) size of spawning $N$. macropterus. N. macropterus were classified as small 
(S, $280-329 \mathrm{~mm})$ medium (M, $330-380 \mathrm{~mm}$ ) or large (L, $381-455 \mathrm{~mm})$. Sizes were determined by calculating the lower, median and upper quartile using Microsoft Excel v16.26. Isolation by distance (IBD) analysis was conducted using $\mathrm{R}$ package adegenet, ape and MASS to assess a matrix of genetic and geographic distances. Geographic distances were obtained by using the median start and stop trawl latitude and longitudes provided by the fishers. 1000 replicates were used, and a Mantels test was implemented in order to test the significance.

\subsection{6: Demographic Analysis}

Tajima D (Tajima, 1998) and Fu's $F s(F u, 1997)$ statistic were calculated using Arlequin 3.5.2.2 to assess sample neutrality. A negative value calculated by these statistics is indicative of a recent population expansion. Alternatively, a positive value is indicative of a recent population contraction. The mismatch distribution of pairwise nucleotide difference was calculated and plotted against the frequency of the haplotypes using DnaSP v6.12.03 to determine whether the populations have evidence of spatial range expansion or a stationary history. The data was fitted to a constant population model (1,000 simulations) and associated Harpending's raggedness index (Harpending, 1994) and sum of square deviations were calculated for all $N$. macropterus samples and $N$. sp. This measure quantifies the smoothness of the observed mismatch distribution and a non-significant result indicates an expanding population.

Arlequin 3.5.2.2 was used to calculate estimates of demographic parameter tau ( $t$ ), the demographic expansion factor, with $95 \%$ confidence intervals and the mutation parameters $\theta 0$, $\theta 1, \theta \mathrm{S}$. The number of generations since population expansion $(t)$ was estimated under the equation $t=\mathrm{t} / 2 \mu$ (Rogers \& Harpending 1992). The parameter $\mu$ is the mutation rate of the sequence (not the mutation rate of individual nucleotides), this can be measured using the formula $\mu=2 \mu k$ where $\mu$ is the mutation rate per nucleotide site, and $k$ is the number of analysed base pair nucleotides. To estimate times in years since population expansion, the estimated generations were multiplied by the number of years for a species to reach sexual maturity. Mutation rates of HVR1 are thought to be the highest out of the whole mitochondrial genome (Satoh et al., 2016), however, documented mutation rates have a large variability depending on the species biology (Liu et al., 2006). Small, short lived fish with high metabolic rates tend to have a higher mutation rate $(6.6$ - $8.8 \%$ per million years, McMillan \& Palumbi, 1997; 
Brunner et al., 2001) compared to larger fish that have a slower metabolic rate and greater longevity that tend to have lower mutation rates (1.8 - 4.5\% per million years, Zhu et al., 1994; Donaldson \& Wilson, 1999) and in some cases can be similar to the rest of the mitochondrial genome, such as in salmonids (Shedlock et al., 1992). N. macropterus are relatively long lived ( +30 years) and are considered to be relatively slow growing as once they reach sexual maturity at an average of six years of age, their growth rate decreases and most likely their metabolic rate as well (Annala, 1987). Given the absence of a mutation rate for HVR1 from a closely related species and taking into account $N$. macropterus biology, two mutation rate of $2 \%$ and $3.6 \%$ per million years were adopted (Bowen et al., 2006). Furthermore, because mitochondrial DNA is maternally inherited and does not undergo recombination (Satoh et al., 2016), Watterson's co-ancestry coefficient, theta $S(\theta S)$ can be used to provide an estimate of the female effective population size (Nef) under the equation $N e f=\theta \mathrm{s} / 2 \mu(2 \mu$ is calculated the same as above) (Watterson, 1975; Fu, 1994). In order to estimate the effective population size, the sex ratio of all tarakihi collected in this study was determined (Ardren \& Kapuscinski, 2003). No biological data was available for $N$. $s p$, so the parameters mentioned above for $N$. macropterus were used.

Popart v1.7 (http://popart.otago.ac.nz/index.shtml) was used to create a TCS network (Clement et al., 2002) of haplotypes to display the number of mutations occurring between individual haplotypes. In order to compare the historical demographic processes between New Zealand fishery species, average sequence divergence and haplotype diversity was plotted against one another in Microsoft Excel v16.26. The species compared all had a level of panmictic population structure and the control region was the molecular marker used. Bayesian skyline analysis was used to measure population size change through time for $N$. macropterus and N. sp implemented in BEAST v1.10.4 (Suchard et al., 2018). For $N$. macropterus, the Marko Chain Monte Carlo (MCMC) simulations were run for 100 million iterations with HKY G+I model as determined by Bayesian information criterion (BIC) using software MEGA X 10.1 (Kumar et al., 2018). For N. sp, the Marko Chain Monte Carlo (MCMC) simulations were run for 50 million iterations with HKY G+1 model as determined by MEGA BIC score. Gamma categories were set to 4 and a strict molecular clock using a mutation rate of $2 \times 10^{-7}$ was used for both $N$. macropterus and N. sp. Genealogies were sampled every 1000 iterations, and all other parameters remained in their default settings. Skyline plots of the tree file were generated using Tracer v1.5.1 with a 10\% burn-in. 


\section{3: Results}

\subsection{1: Genetic Structure}

DNA was successfully extracted, amplified and sequenced for 385 samples (Table 3.1). Of those, 15 were $N$. sp and 370 were $N$. macropterus caught from 14 locations around New Zealand. Due to the time constraints of this thesis all 1341 samples could not be utilized. The successful amplification of a $913 \mathrm{bp}$ control region fragment was edited, trimmed and aligned resulting in a $500 \mathrm{bp}$ fragments that covers hyper variable region 1 (HVR1). The resulting fragment is used for the population genetic and demographic analysis in this chapter - (Table $3.1)$.

Table 3.1: Summary information and estimates of nucleotide diversity for 15 locations. DNA of $N$. macropterus was extracted from 14 locations with a total of 370 sequences. DNA of $N$. $s p$ was extracted from 1 location with a total of 15 sequences. Key: sample size (n), number of haplotypes (Hn), haplotype diversity (Hd), private haplotypes (Hp), average number of nucleotide differences $(\mathrm{k})$, nucleotide diversity $(\pi)$ and segregation sites $(\mathrm{S})$.

\begin{tabular}{ccccccccccc}
\hline Map location & Sample location & Code & $\mathbf{n}$ & Hn & Hd & Hp & $\mathbf{k}$ & $\boldsymbol{\pi}$ & S & Indels \\
\hline 1 & Fiordland & FRDL & 15 & 14 & 0.99 & 2 & 14.38 & 0.029 & 57 & 1 \\
3 & Spawning West Coast South Island & SPWCSI & 59 & 57 & 0.999 & 5 & 14.38 & 0.029 & 91 & 4 \\
4 & Spawning Cape Campbell & SPCC & 60 & 58 & 0.999 & 2 & 13.05 & 0.026 & 81 & 2 \\
5 & Spawning East Cape & SPEC & 60 & 58 & 0.999 & 8 & 14.90 & 0.030 & 84 & 1 \\
6 & Wairarapa & WAI & 15 & 15 & 1 & 0 & 10.90 & 0.022 & 44 & 1 \\
7 & Otago & OTAG & 18 & 18 & 1 & 1 & 12.06 & 0.024 & 57 & 0 \\
8 & Kaikoura & KAIK & 24 & 23 & 0.996 & 0 & 10.91 & 0.022 & 56 & 2 \\
9 & Bay of Plenty & BPLE & 23 & 22 & 0.996 & 1 & 14.28 & 0.029 & 67 & 2 \\
10 & Wellington & WGNT & 15 & 15 & 0.99 & 2 & 16.00 & 0.032 & 57 & 1 \\
11 & Christchurch & CHCH & 16 & 16 & 1 & 3 & 12.44 & 0.025 & 51 & 1 \\
12 & Chatham Islands & CHAT & 15 & 15 & 1 & 1 & 15.07 & 0.030 & 57 & 1 \\
13 & East Northland & ENLD & 17 & 16 & 0.993 & 1 & 13.40 & 0.027 & 51 & 0 \\
14 & North Taranaki & NT & 15 & 15 & 1 & 0 & 14.63 & 0.029 & 55 & 1 \\
15 & Hawks Bay & HB & 18 & 17 & 0.993 & 0 & 11.32 & 0.023 & 60 & 2 \\
& All tarakihi locations & & 370 & 324 & 0.999 & & 13.25 & 0.027 & 130 \\
2 & King Tarakihi & KTAR & 15 & 12 & 0.971 & 3 & 6.73 & 0.014 & 37 & 1 \\
\hline
\end{tabular}

The aligned $15 N$. $s p$ sequences had asymmetric base frequencies of $\pi \mathrm{A}=0.321, \pi \mathrm{T}=0.292$, $\pi \mathrm{G}=0.208$ and $\pi \mathrm{C}=0.179$ with $96 \%$ of bases being identical between sequences. 12 haplotypes (Hp) were identified from 15 samples (n) with a total of three private haplotypes (Hp) resulting in a haplotype diversity $(\mathrm{Hd})$ of $0.971 . N$. $s p$ samples have a nucleotide diversity 
$(\pi)$ of 0.014 per site and an average number of nucleotide differences $(\mathrm{k})$ of 6.73 . Of the $500 \mathrm{bp}$ fragment, 37 loci were polymorphic (S) and one indel was present among the 15 samples (Table 3.1)

The 370 aligned $N$. macropterus sequences had asymmetric base frequencies of $\pi \mathrm{A}=0.318$, $\pi \mathrm{T}=0.291, \pi \mathrm{G}=0.212$ and $\pi \mathrm{C}=0.179$ with $73.7 \%$ of bases being identical between sequences. Sample size (n) varied between sampling locations, and spawning areas had the highest number of samples (59-60) compared to the rest of the sampling locations $(15-24)$. The number of haplotypes (Hn) detected matched the number of samples for some locations or were only 1-2 haplotypes less resulting in high haplotype diversity's (Hd) for all samples. All samples except Hawkes Bay, Kaikoura, North Taranaki and Wairarapa contained private haplotypes (Hp). Wairarapa samples had the lowest nucleotide diversity $(\pi=0.022)$ per site and average number of nucleotide differences $(k=10.9)$. In contrast, Wellington samples had the highest nucleotide diversity $(\pi=0.032)$ per site and average number of nucleotide differences $(k=16)$. Spawning west coast South Island samples had the highest number of polymorphic loci $(S=91)$ and indels (4) out of all the sampling locations. In contrast, east Northland had the lowest number of polymorphic sites $(\mathrm{S}=51)$ and no indels were present (Table 3.1).

The alignment of $370 \mathrm{~N}$. macropterus samples had 324 haplotypes in total of which 290 were unique and 34 were shared. Shared haplotypes varied from being exclusive to one sampling location or occurring in up to four sampling locations (Table 3.2). Shared haplotypes 3, 4, 8, 9, 27, 30, 32 and 34 were all exclusive to one sampling location. Shared haplotypes 1, 6, 7, 11, $15,16,20,23,32$ and 34 occurred in multiple sampling locations but were exclusive to the east coast of New Zealand. Shared haplotypes 25 and 22 occurred in multiple sampling locations but were exclusive to the west coast of New Zealand. Shared haplotypes 10, 24 and 25 occurred in multiple sampling locations along the east coast of New Zealand and Chatham Islands. Shared haplotypes 12, 13, 14, 17, 18, 19, 21, 26, 28, 29, 31 and 33 occurred in multiple sampling locations on the east and west coasts of New Zealand (Table 3.2). 
Table 3.2: Location of $N$. macropterus samples that have shared haplotypes.

\begin{tabular}{|c|c|c|c|}
\hline Shared haplotype & Map location & Sample location & Code \\
\hline \multirow[t]{2}{*}{1} & 15 & Hawks Bay & HB17026 \\
\hline & 5 & Spawning East Cape & SPGB021 \\
\hline \multirow[t]{2}{*}{2} & 1 & Fiordland & FRDL019 \\
\hline & 14 & North Taranaki & NT17058 \\
\hline \multirow[t]{2}{*}{3} & 15 & Hawks Bay & HB17039 \\
\hline & 15 & Hawks Bay & HB17051 \\
\hline \multirow[t]{2}{*}{4} & 13 & East Northland & ENLD005 \\
\hline & 13 & East Northland & ENLD051 \\
\hline \multirow[t]{2}{*}{5} & 14 & North Taranaki & NT17054 \\
\hline & 3 & Spawning West Coast South Island & SPWCSI020 \\
\hline \multirow[t]{3}{*}{6} & 8 & Kaikoura & KAIK003 \\
\hline & 8 & Kaikoura & KAIK039 \\
\hline & 4 & Spawning Cape Campbell & SPCC011 \\
\hline \multirow[t]{2}{*}{7} & 4 & Spawning Cape Campbell & SPCC050 \\
\hline & 5 & Spawning East Cape & SPEC004 \\
\hline \multirow[t]{2}{*}{8} & 3 & Spawning West Coast South Island & SPWCSI035 \\
\hline & 3 & Spawning West Coast South Island & SPWCSI040 \\
\hline \multirow[t]{2}{*}{9} & 10 & Wellington & WGTN025 \\
\hline & 10 & Wellington & WGTN026 \\
\hline \multirow[t]{2}{*}{10} & 12 & Chatham Islands & CHAT006 \\
\hline & 5 & Spawning East Cape & SPEC022 \\
\hline \multirow[t]{3}{*}{11} & 4 & Spawning Cape Campbell & SPCC027 \\
\hline & 5 & Spawning East Cape & SPEC019 \\
\hline & 5 & Spawning East Cape & SPGB019 \\
\hline \multirow[t]{2}{*}{12} & 7 & Otago & OTAG039 \\
\hline & 3 & Spawning West Coast South Island & SPWCSI028 \\
\hline \multirow[t]{4}{*}{13} & 8 & Kaikoura & KAIK041 \\
\hline & 7 & Otago & OTAG017 \\
\hline & 4 & Spawning Cape Campbell & SPCC024 \\
\hline & 3 & Spawning West Coast South Island & SPWCSI029 \\
\hline \multirow[t]{2}{*}{14} & 5 & Spawning East Cape & SPGB018 \\
\hline & 3 & Spawning West Coast South Island & SPWCSI031 \\
\hline \multirow[t]{2}{*}{15} & 11 & Christchurch & $\mathrm{CHCH} 028$ \\
\hline & 4 & Spawning Cape Campbell & SPCC025 \\
\hline \multirow[t]{2}{*}{16} & 7 & Otago & OTAG035 \\
\hline & 4 & Spawning Cape Campbell & SPCC059 \\
\hline \multirow[t]{4}{*}{17} & 1 & Fiordland & FRDL032 \\
\hline & 1 & Fiordland & FRDL056 \\
\hline & 4 & Spawning Cape Campbell & SPCC041 \\
\hline & 5 & Spawning East Cape & SPEC020 \\
\hline
\end{tabular}




\begin{tabular}{|c|c|c|c|}
\hline Shared haplotype & Map location & Sample location & Code \\
\hline \multirow[t]{3}{*}{18} & 15 & Hawks Bay & HB17002 \\
\hline & 14 & North Taranaki & NT17028 \\
\hline & 3 & Spawning West Coast South Island & SPWCSI055 \\
\hline \multirow[t]{2}{*}{19} & 8 & Kaikoura & KAIK015 \\
\hline & 3 & Spawning West Coast South Island & SPWCSI030 \\
\hline \multirow[t]{2}{*}{20} & 7 & Otago & OTAG027 \\
\hline & 4 & Spawning Cape Campbell & SPCC051 \\
\hline \multirow[t]{2}{*}{21} & 14 & North Taranaki & NT17033 \\
\hline & 10 & Wellington & WGTN035 \\
\hline \multirow[t]{2}{*}{22} & 1 & Fiordland & FRDL054 \\
\hline & 3 & Spawning West Coast South Island & SPWCSI049 \\
\hline \multirow[t]{2}{*}{23} & 9 & Bay of Plenty & BPLE012 \\
\hline & 8 & Kaikoura & KAIK006 \\
\hline \multirow[t]{4}{*}{24} & 12 & Chatham Islands & CHAT028 \\
\hline & 8 & Kaikoura & KAIK060 \\
\hline & 3 & Spawning West Coast South Island & SPWCSI008 \\
\hline & 6 & Wairarapa & WAI030 \\
\hline \multirow[t]{2}{*}{25} & 9 & Bay of Plenty & BPLE028 \\
\hline & 12 & Chatham Islands & CHAT053 \\
\hline \multirow[t]{3}{*}{26} & 9 & Bay of Plenty & BPLE024 \\
\hline & 15 & Hawks Bay & HB17023 \\
\hline & 3 & Spawning West Coast South Island & SPWCSI009 \\
\hline \multirow[t]{2}{*}{27} & 5 & Spawning East Cape & SPEC029 \\
\hline & 5 & Spawning East Cape & SPGB029 \\
\hline \multirow[t]{2}{*}{28} & 9 & Bay of Plenty & BPLE037 \\
\hline & 3 & Spawning West Coast South Island & SPWCSI002 \\
\hline \multirow[t]{2}{*}{29} & 1 & Fiordland & FRDL048 \\
\hline & 5 & Spawning East Cape & SPEC024 \\
\hline \multirow[t]{2}{*}{30} & 9 & Bay of Plenty & BPLE018 \\
\hline & 9 & Bay of Plenty & BPLE059 \\
\hline \multirow[t]{4}{*}{31} & 15 & Hawks Bay & HB17003 \\
\hline & 4 & Spawning Cape Campbell & SPCC043 \\
\hline & 3 & Spawning West Coast South Island & SPWCSI017 \\
\hline & 3 & Spawning West Coast South Island & SPWCSI047 \\
\hline \multirow[t]{2}{*}{32} & 4 & Spawning Cape Campbell & SPCC004 \\
\hline & 4 & Spawning Cape Campbell & SPCC047 \\
\hline \multirow[t]{2}{*}{33} & 4 & Spawning Cape Campbell & SPCC035 \\
\hline & 3 & Spawning West Coast South Island & SPWCSI015 \\
\hline \multirow[t]{2}{*}{34} & 4 & Spawning Cape Campbell & SPCC029 \\
\hline & 4 & Spawning Cape Campbell & SPCC046 \\
\hline
\end{tabular}




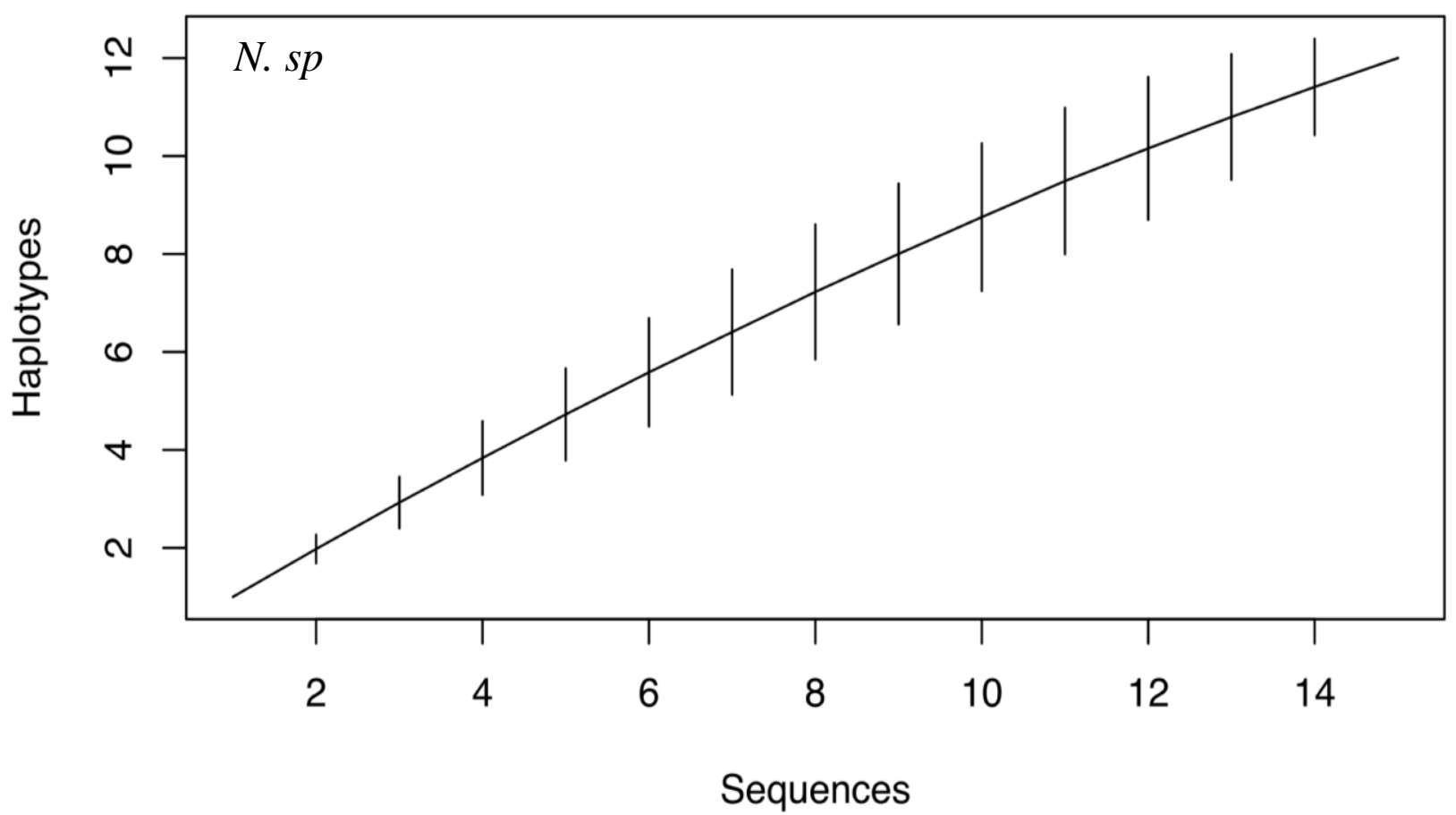

Figure 3.2: Rarefaction Curve of HVR1 haplotype frequency of $N$. $s p$. The solid black line represents the number of unique haplotypes discovered vs the number of individuals sampled; while the grey lines represent the upper and lower confidence intervals for this value.

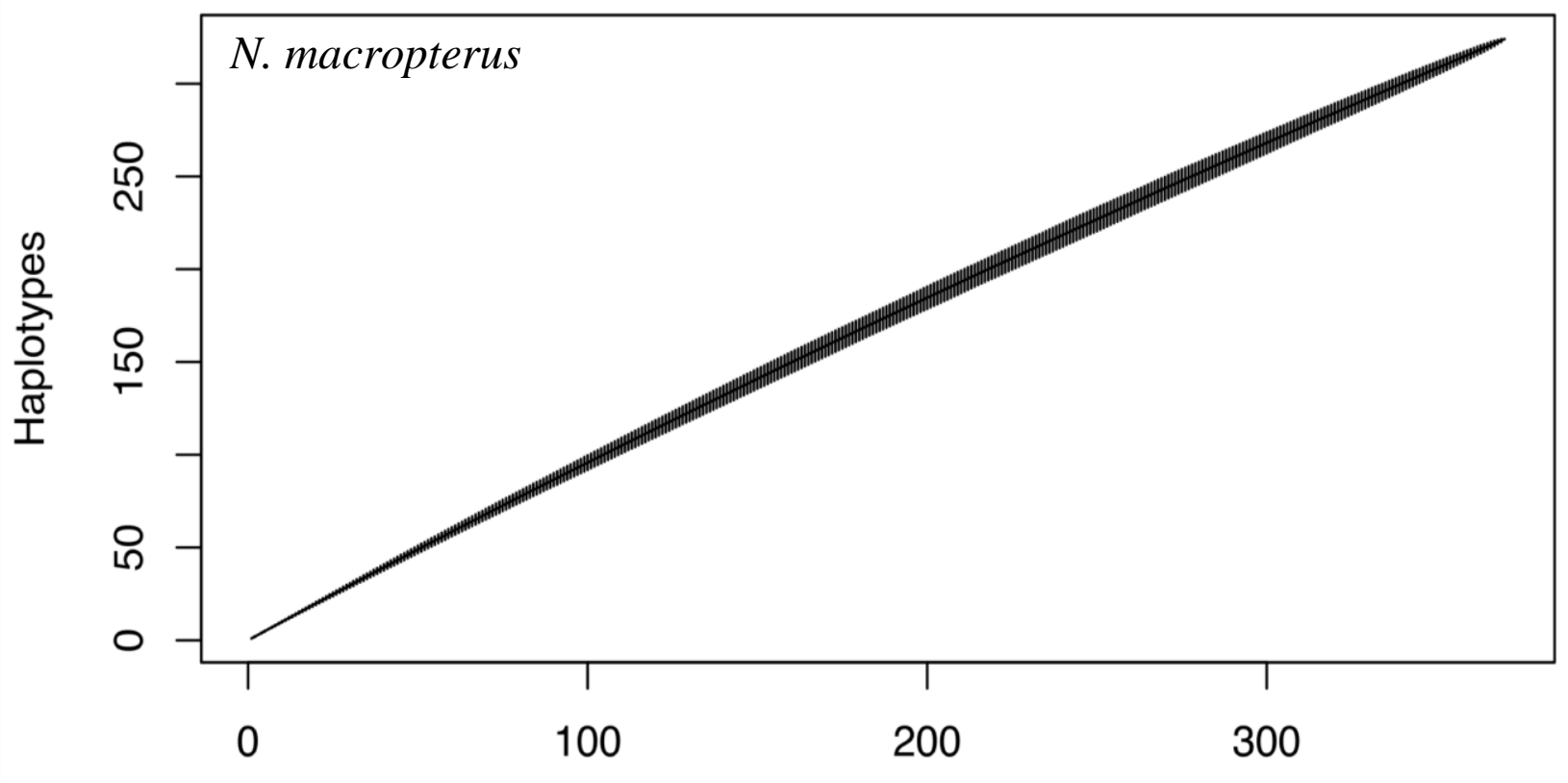

Sequences

Figure 3.3: Rarefaction Curve of HVR1 haplotype frequency of $N$. macropterus. The solid black line represents the number of unique haplotypes discovered vs the number of individuals sampled; while the grey lines represent the upper and lower confidence intervals for this value. 
The rarefaction curve for N. sp (Figure 3.2) and N. macropterus (Figure 3.3) generated using haplotype frequency data did not reach an asymptote. This suggests that a larger sample size is required to effectively capture haplotype diversity.

Pairwise $\Phi_{\mathrm{ST}}$ conducted between $N$. macropterus and $N$. $s p$ indicated that $N$. $s p$ are significantly different from all $N$. macropterus sampling locations $\left(\Phi_{\mathrm{ST}}=0.000, \mathrm{p}=0.000\right)$ (Table 3.3). Overall there was predominantly no significant differences among $N$. macropterus sampling locations, with the exception of a weak but significant difference found between Hawkes Bay $(\mathrm{HB})$ and east Northland $(\mathrm{ENLD})\left(\Phi_{\mathrm{ST}}=0.09728, \mathrm{p}=0.03052\right)$ after applying a Bonferroni correction to the p values (Table 3.3).

AMOVA analysis between $N$. $s p$ and $N$. macropterus detected a significant difference among groups $\left(\Phi_{\mathrm{CT}}=0.663, \mathrm{p}<0.001\right)$, among locations within groups $\left(\Phi_{\mathrm{SC}}=0.002, \mathrm{p}=0.002\right)$ and within locations $\left(\Phi_{\mathrm{ST}}=0.664 \mathrm{p}<0.001\right)$ (Table 3.4). 66.315\% of the genetic variation came from among $N . s p$ and $N$. macropterus as two individual groups. The majority of the remaining genetic variation came from individuals within sampling locations of $N$. $s p(\mathrm{n}=15)$ and $N$. macropterus $(\mathrm{n}=370)$. The remaining AMOVA analysis were conducted on a priori groupings of only $N$. macropterus and were predominantly statistically insignificant ( $\mathrm{p}=0.069-0.976)$ with very low $\Phi_{\mathrm{CT}}, \Phi_{\mathrm{SC}}$, and $\Phi_{\mathrm{ST}}$ implying low genetic structure. Furthermore, almost all genetic variation came from individuals within location $(91.935 \%-100 \%)$. There is however a significant difference $\left(\Phi_{\mathrm{ST}}=0.081, \mathrm{p}=0.005\right)$ detected within locations between Hawkes Bay (HB) and east Northland (ENLD). $8.065 \%$ of the genetic variation could be contributed among HB and ENLD, 91.935\% of the genetic variation was from individuals within HB and ENLD. Another significant difference $\left(\Phi_{\mathrm{SC}}=0.029, \mathrm{p}=0.024\right)$ was detected among locations within groups for east vs west North Island sampling locations. However, $1.646 \%$ of the genetic variation detected came from among locations within groups, compared to $98.354 \%$ of the genetic variation coming from within locations (Table 3.4). 


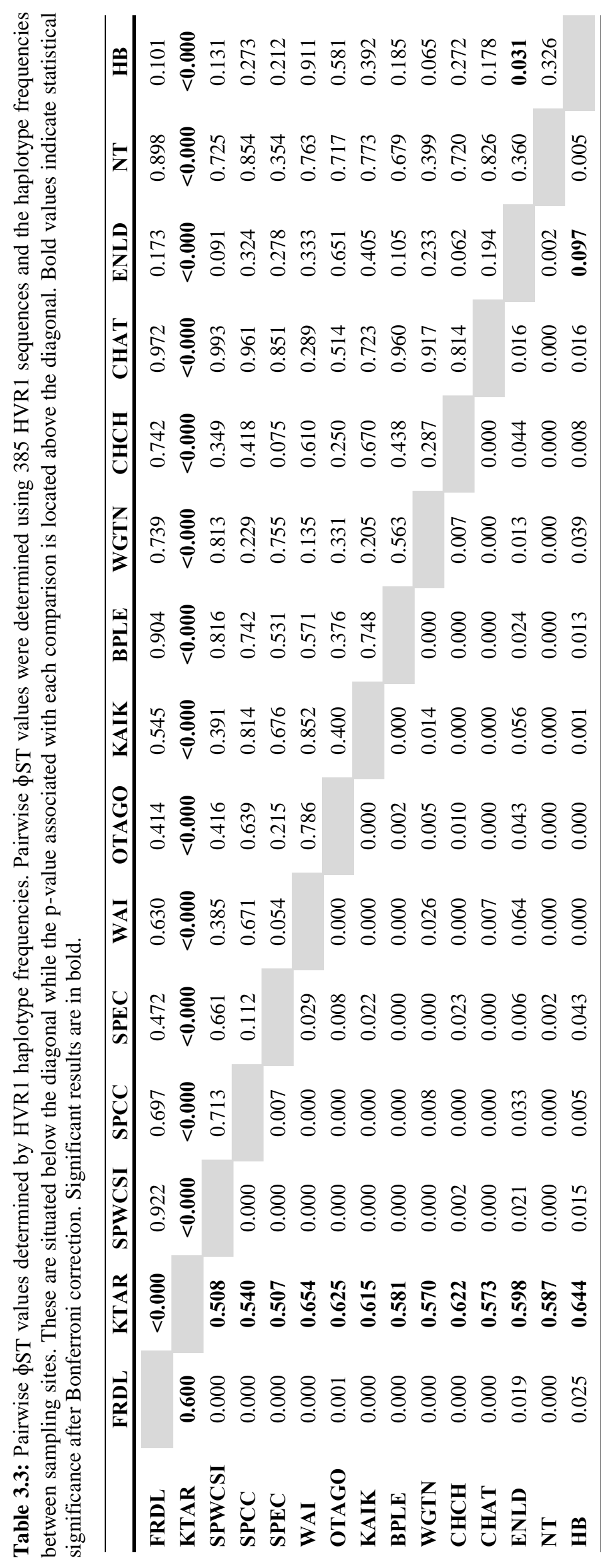




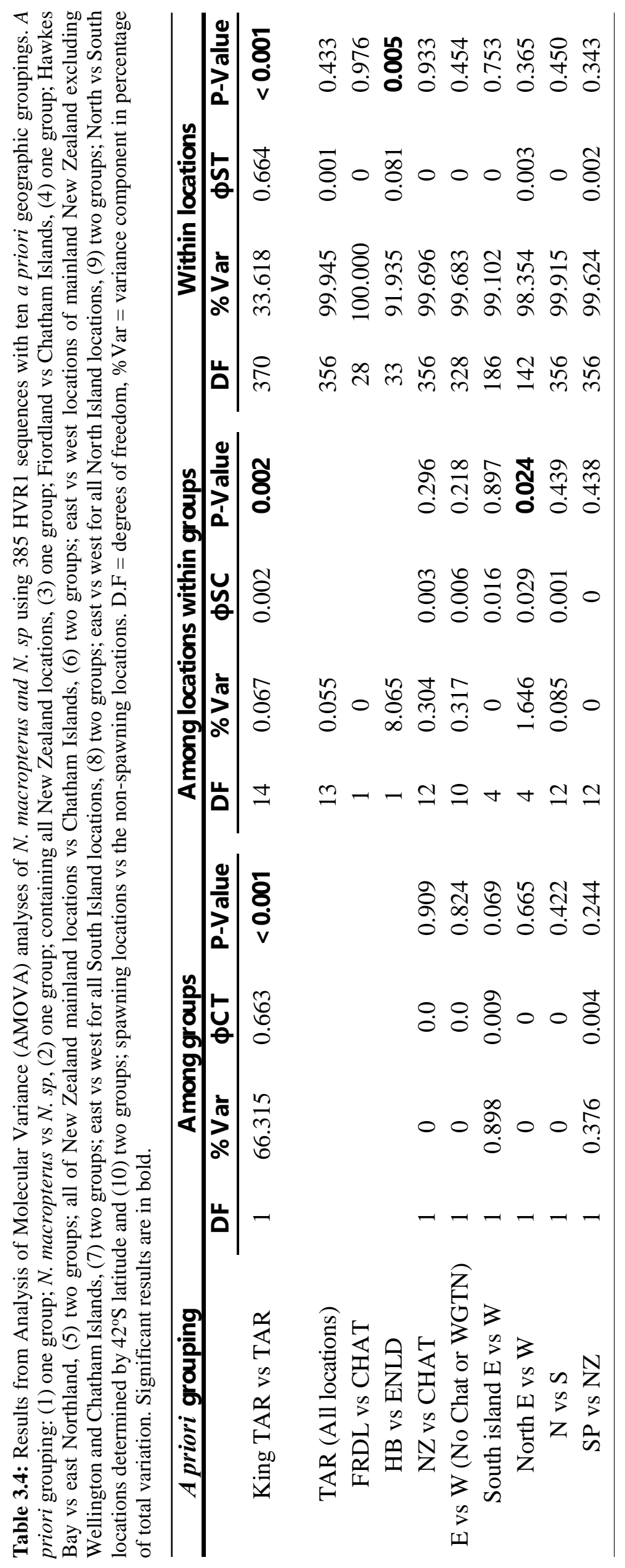




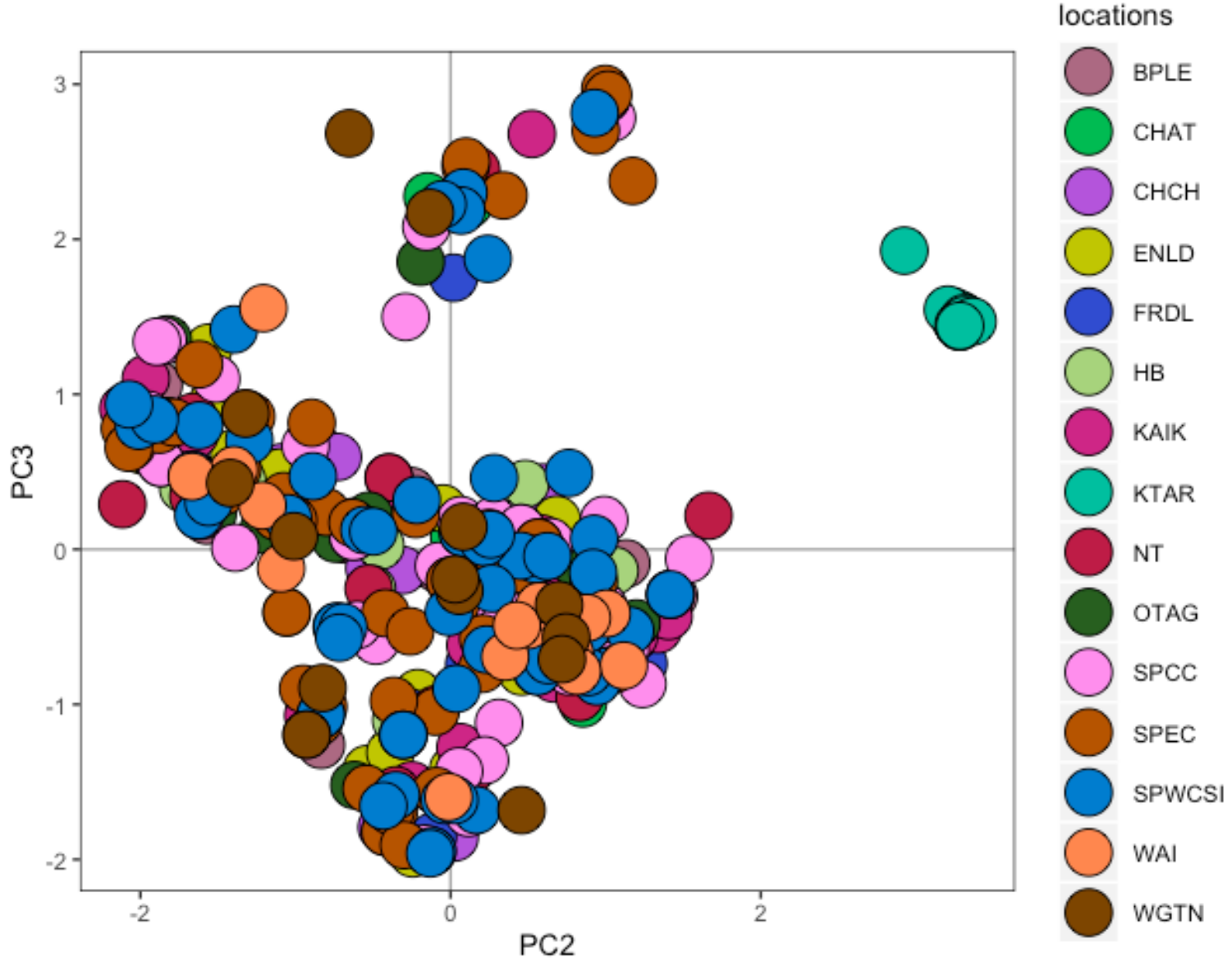

Figure 3.4: Principal Component Analysis of HVR1 for all N. macropterus $(\mathrm{n}=370)$ and $N . s p($ KTAR) samples $(\mathrm{n}=10)$.

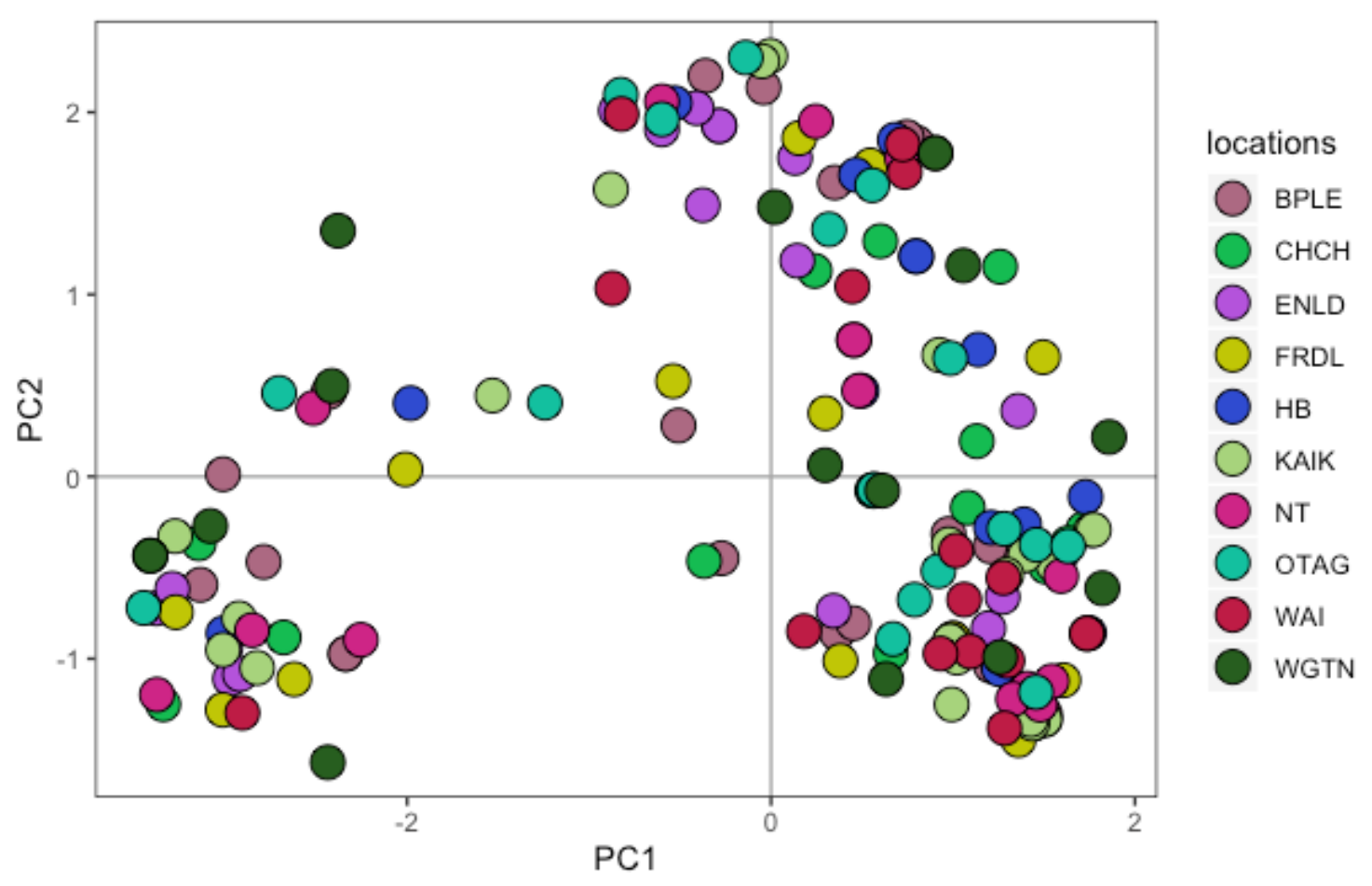

Figure 3.5: Principal Component Analysis of HVR1 of non-spawning N. macropterus $(\mathrm{n}=191)$. 


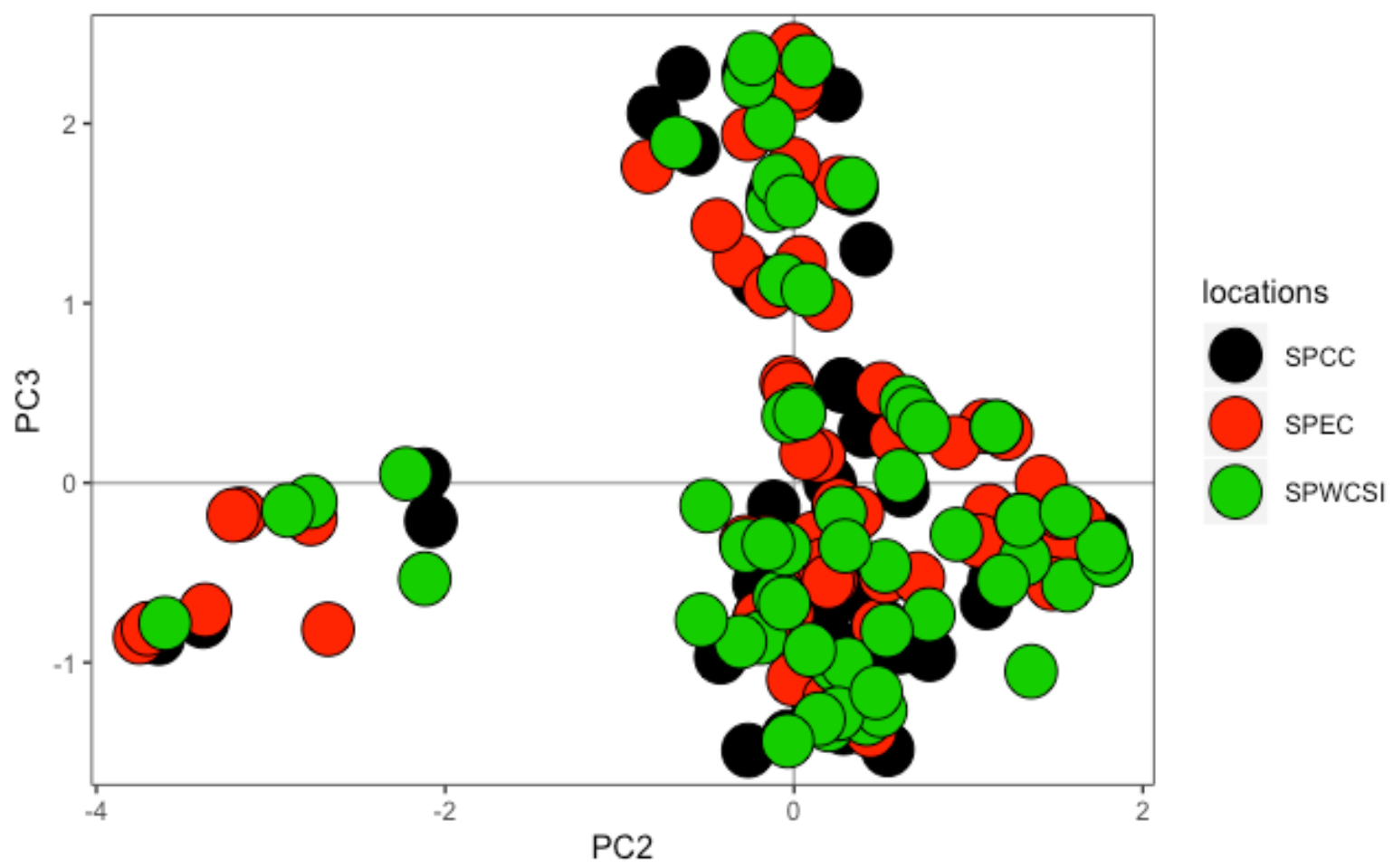

Figure 3.6: Principal Component Analysis of HVR1 of spawning N. macropterus $(\mathrm{n}=179)$.

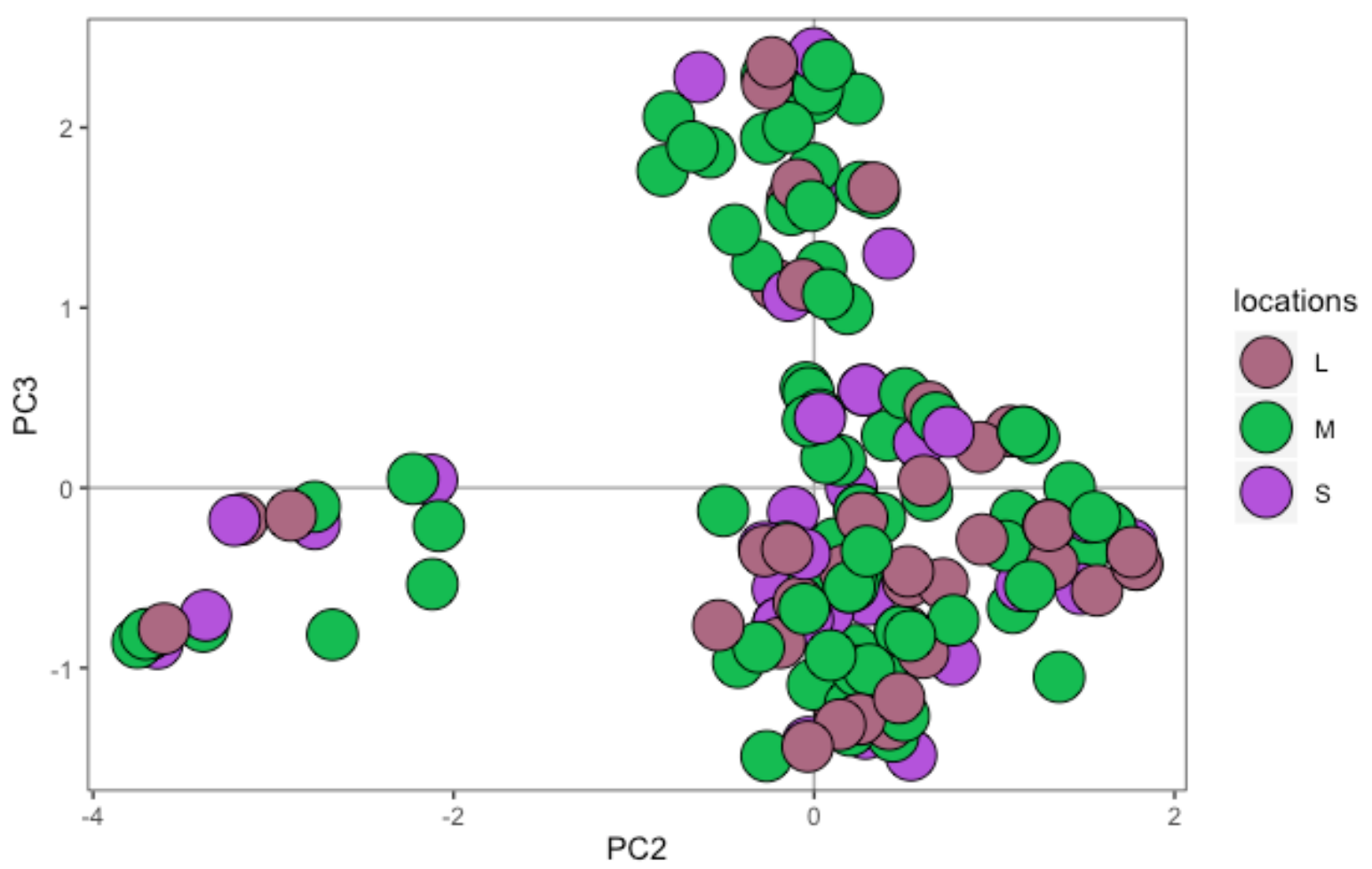

Figure 3.7: Principal Component Analysis of HVR1 of spawning N. macropterus displayed as sizes instead of locations $(\mathrm{n}=179)$. The samples were divided into small $(\mathrm{S}=280-329 \mathrm{~mm})$, medium $(\mathrm{M}=330-380 \mathrm{~mm})$ and large $(\mathrm{L}=381-455 \mathrm{~mm})$ using lower, median and upper quartiles calculated from fork length. 
The first PCA conducted (Figure 3.4) included all N. sp and N. macropterus samples comparing a total of 385 sequences. $N$. $s p$ group together forming a distinct cluster separate from $N$. macropterus. N. macropterus form one large cluster with a possible sub group. All $N$. macropterus sampling locations appear to be randomly distributed throughout the $N$. macropterus cluster indicating a lack of genetic structuring. The second PCA conducted (Figure 3.5) included only N. macropterus samples from non-spawning locations in order to exclude the likely grouping of multiple locations coming together to spawn. All samples appear to be randomly distributed forming one loose cluster indicating a lack of genetic structure. The third PCA conducted (Figure 3.6) included only N. macropterus samples from spawning locations in order to assess if spawning groups are genetically different from one another. Two or possibly three clusters formed, however, spawning location samples are randomly distributed among the clusters indicating that location is unlikely to be causing the separate clusters. The fourth PCA conducted (Figure 3.7) used the same spawning samples that were used in the previous PCA. The samples were divided into small $(\mathrm{S}=280-329 \mathrm{~mm})$, medium $(\mathrm{M}=330-380 \mathrm{~mm})$ and large $(\mathrm{L}=381-455 \mathrm{~mm})$ using lower, median and upper quartiles calculated from fork length and then projected over the PCA in order to assess if year class could be causing the clustering. Size classes appear to be randomly distributed among the clusters indicating that size is not causing the formation of the clusters.

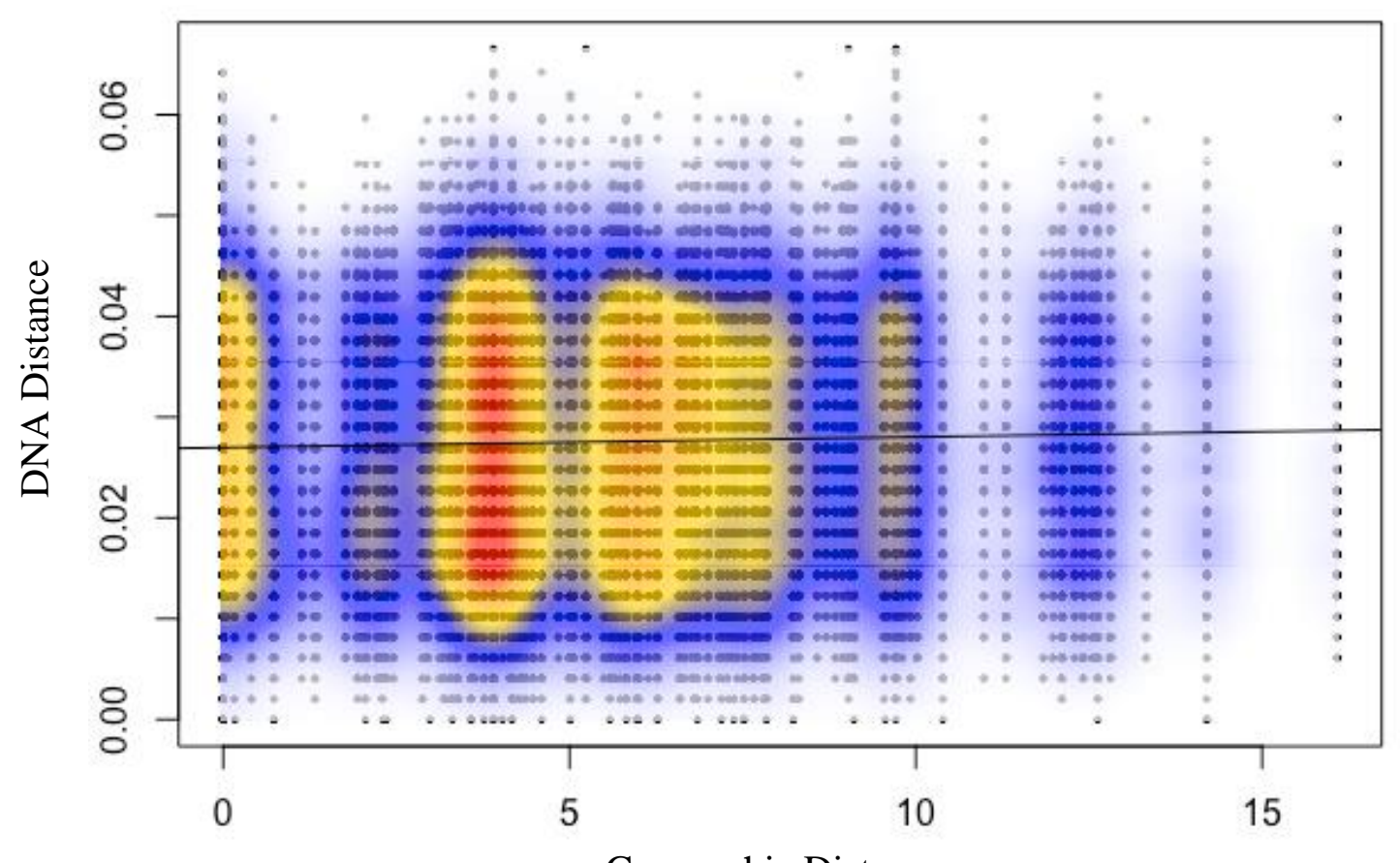

Geographic Distance

Figure 3.8: Isolation By Distance plot for all N. macropterus sampling locations. Geographic distances calculated by averaging the latitude and longitude coordinates from the start and end of a trawl. 
IBD was tested on four a priori groupings, however, after 1000 replicates and conducting a Mantel test, all groups were statistically insignificant indicating that IBD genetic structure is not present (Figure 3.8). The first group tested includes all N. macropterus samples from nonspawning locations in order to exclude possible groupings of different locations during spawning $(\mathrm{p}=0.225)$. The second group tested all $N$. macropterus samples $(\mathrm{p}=0.141)$ and the third group excluded Chatham Island samples to test if the geographic distance between the New Zealand mainland and Chatham Islands could be effecting IBD results $(p=0.111)$. The fourth IBD test included only spawning locations to determine if the geographic distance between locations could cause an IBD genetic structuring $(\mathrm{p}=0.067)$.

\subsection{2: Demographic Structure}

$N$. $s p$ neutrality tests were negative for Tajima's D and Fu's $F s$ statistics (Table 3.5). However, Tajima's D statistic was not statistically significant, so it cannot be accepted as significantly different from zero. Fu's $F$ s test returned a significant negative value (-6.487) implying a recent or current population expansion.

Table 3.5: Neutrality and Goodness of Fit tests for all sampling locations $(n=385)$. Significant results $(p=<0.05)$ are in bold with *.

\begin{tabular}{|c|c|c|c|c|}
\hline \multirow[b]{2}{*}{ Location } & \multicolumn{2}{|c|}{ Neutrality tests } & \multicolumn{2}{|c|}{ Goodness of fit } \\
\hline & Fu's Fs & Tajima's D & $\mathbf{H r}$ & SSD \\
\hline King Tarakihi & $-6.487 *$ & -1.433 & $0.077^{*}$ & $0.021 *$ \\
\hline All tarakihi locations & $-661.556^{*}$ & -1.415 & 0.001 & 0.003 \\
\hline Fiordland & -3.45 & -0.777 & & \\
\hline Spawning West Coast South Island & $-4.707 *$ & -1.234 & & \\
\hline Spawning Cape Campbell & $-24.25 *$ & -0.871 & & \\
\hline Spawning East Cape & $-24.337 *$ & -0.873 & & \\
\hline Wairarapa & $-24.252 *$ & -0.598 & & \\
\hline Otago & $-6.77 *$ & -0.735 & & \\
\hline Kaikoura & $-8.994 *$ & -1.127 & & \\
\hline Bay of Plenty & $-12.252 *$ & -1.012 & & \\
\hline Wellington & $-9.614 *$ & -0.836 & & \\
\hline Christchurch & -3.074 & -0.377 & & \\
\hline Chatham Islands & $-6.997 *$ & -0.807 & & \\
\hline East Northland & $-5.383 *$ & -0.608 & & \\
\hline North Taranaki & $-5.074 *$ & -0.467 & & \\
\hline Hawks Bay & $-5.511 *$ & -0.584 & & \\
\hline
\end{tabular}


All neutrality tests for $N$. macropterus returned negative Tajima's D and Fu's $F s$ statistics (Table 3.5). However, Tajima's D statistics were not statistically significant for all $N$. macropterus sampling locations and cannot be accepted as significantly different from zero. Fu's $F$ s test returned a significant negative value for all $N$. macropterus sampling locations with the exception of Christchurch and Fiordland. A negative Fu's Fs statistics implies recent or current population expansion.

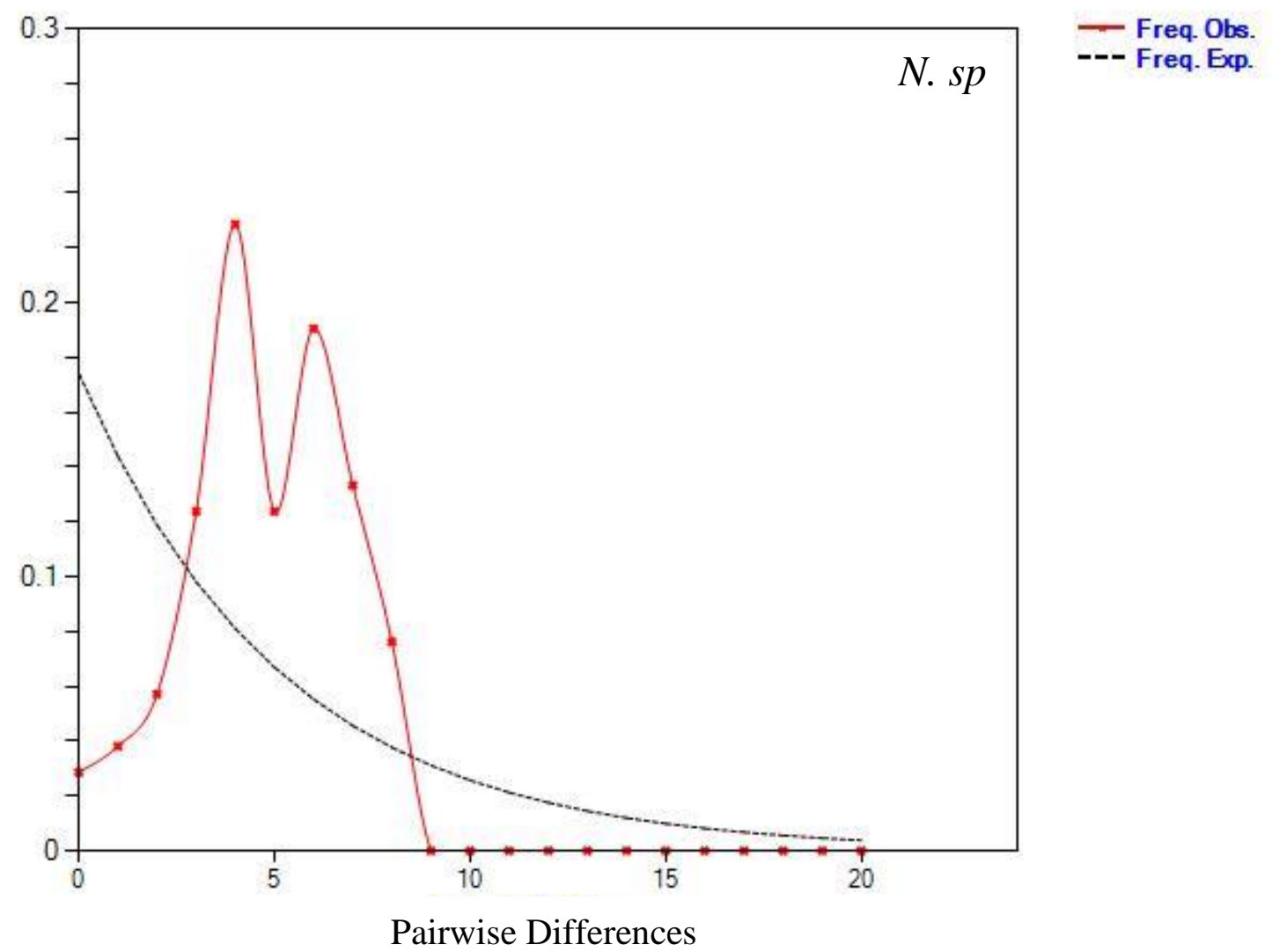

Figure 3.9: Mismatch distribution of the frequency of pairwise differences from 15 HVR1 $N$. $s p$ sequences. 


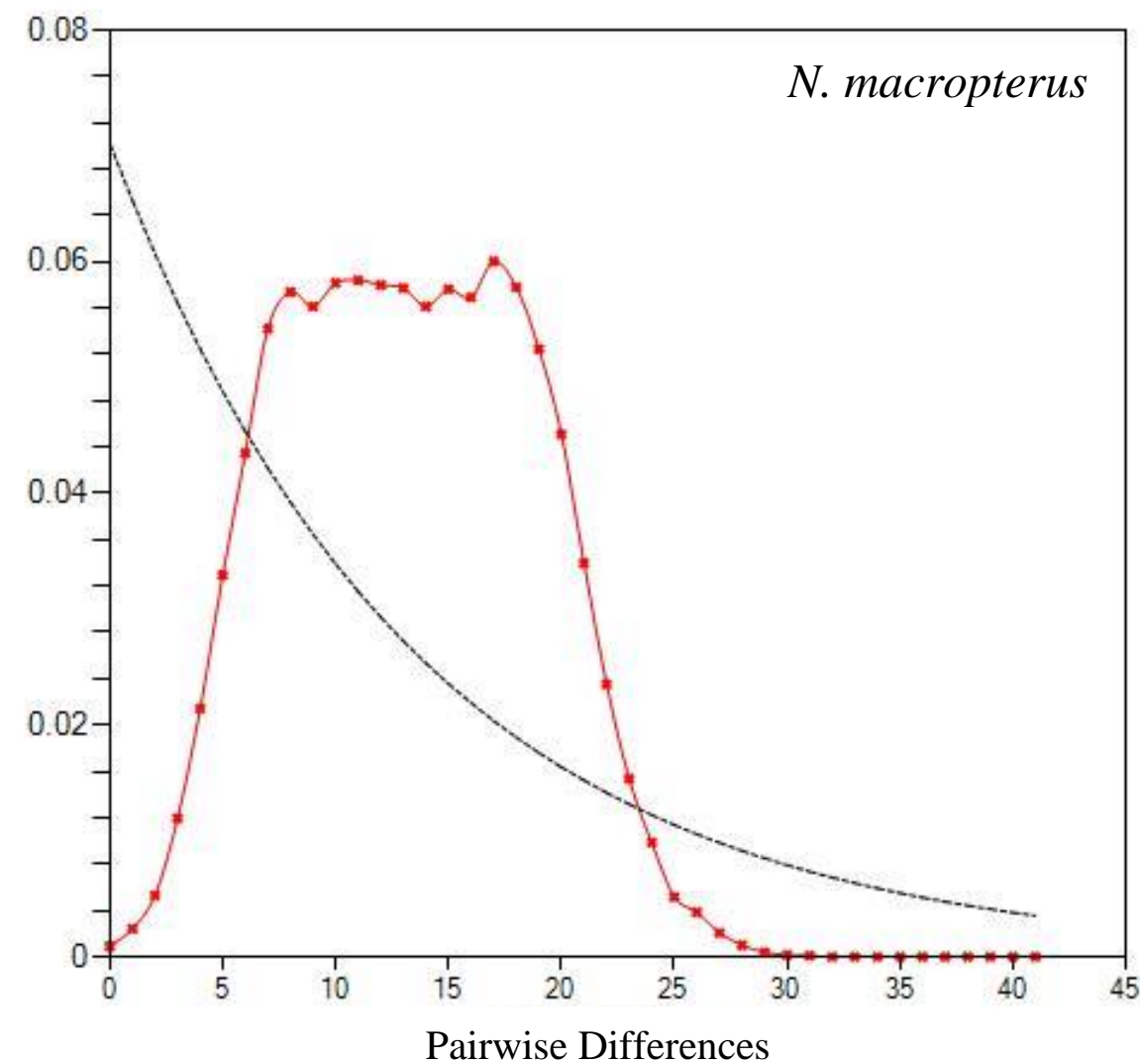

Figure 3.10: Mismatch distribution of the frequency of pairwise differences from 370 HVR1 N. macropterus sequences.

The mismatch distribution graph for $N$. $s p$ shows a possible twin peaked unimodal distribution peaking at 4 and 6 pairwise differences (Figure 3.9). The frequency observed is different from frequency expected and moving to the right of the graph due to increased pairwise differences among samples, indicating an expanding population. However, goodness of fit Harpending raggednesss $(\mathrm{Hr})$ and sum of squared deviation (SSD) statistics are both statistically significant $(\mathrm{Hr}=0.077, \mathrm{p}=0.03$ and $\mathrm{SSD}=0.021, \mathrm{p}=0.04)$ indicating that the mismatch distribution does not fit an expanding population model (Table 3.4).

The mismatch distribution graph for $N$. macropterus shows a unimodal distribution peaking between 8 and 18 pairwise differences (Figure 3.10). The frequency observed is different from frequency expected and moving to the right of the graph due to the high number of pairwise differences among samples, indicating a large expanding population. Goodness of fit $\mathrm{Hr}$ and SSD statistics are not statistically significant $(\mathrm{Hr}=0.001, \mathrm{p}=0.92$ and $\mathrm{SSD}=0.003, \mathrm{p}=0.54)$, which further supports population expansion (Table 3.4). 
Table 3.6: Demographic parameters from 370 N. macropterus and 15 N. sp HVR1 sequences; tau (t), population size before expansion $\left(\theta_{0}\right)$, population size after expansion $\left(\theta_{1}\right)$ and co-ancestry coefficient $(\theta s)$. Substitution rates of $2 \times 10^{-7}$ and $3.6 \times 10^{-7}$ were used to estimate time since population expansion occurred $(t)$, effective female population size $(\mathrm{Nef})$ and effective population size $(\mathrm{Ne})$.

\begin{tabular}{ccc}
\hline $\begin{array}{c}\text { Demographic } \\
\text { Parameters }\end{array}$ & N. macropterus & $\boldsymbol{N} . \boldsymbol{s} \boldsymbol{p}$ \\
\hline $\mathrm{t}$ & 8.646 & 4 \\
$\theta 0$ & 7.497 & 1.9 \\
$\theta 1$ & 189.539 & 3414.978 \\
$\theta \mathrm{S}$ & 20.495 & 6.766 \\
Subsitution rate & $3.6 \times 10^{-7} \quad 2 \times 10^{-7}$ & $3.6 \times 10^{-7} \quad 2 \times 10^{-7}$ \\
$t$ & $72,054-129,697$ & $33,333-60,000$ \\
$N e f$ & $28,465-51,237$ & $9,397-16,914$ \\
$N e$ & $39,566-71,219$ & $13,061-23,510$ \\
\hline
\end{tabular}

Estimations of demographic expansion parameters ( $t, \theta_{0}$, and $\left.\theta_{1}\right)$ were used to estimate the time since demographic expansion for N. macropterus and N. sp (Table 3.6). Estimates of time since population expansion for N. macropterus varied form 72,054 - 129,697 years before present depending on the mutation rate. Furthermore, the effective female population size was estimated to be $28,465-51,237$ individuals. The sex ratio between males $39 \%: 61 \%$ females was calculated from 1341 individuals sampled from 14 locations around New Zealand. Based on that sex ratio, the effective population size was estimated to be 39,566 - 71,219 individuals depending on the mutation rate. Estimates of time since population expansion for $N$. $s p$ varied form 33,333 - 60,000 years before present depending on the mutation rate (Table 3.6). Furthermore, the effective female population size was estimated to be 9,397 - 16,914 individuals. Sex ratios were assumed to be similar to $N$. macropterus, therefore, the effective population size was estimated to be 13,061 - 23,510 individuals depending on the mutation rate. 


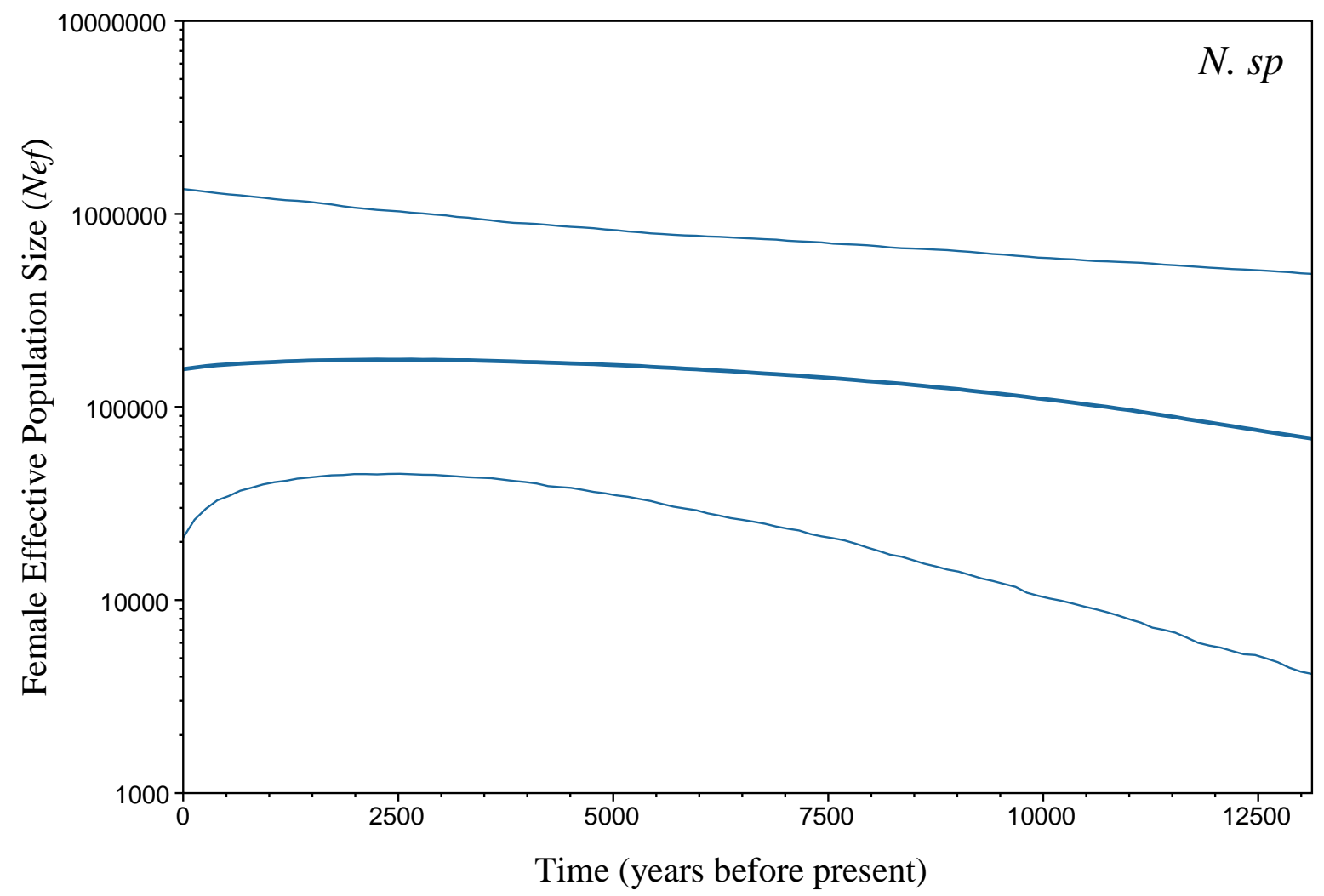

Figure 3.11: Bayesian Skyline Plot generated using HVR1 sequences illustrating estimated female effective population size through time in years before present for $N$. $s p$. The darker middle blue line represents mean female effective population size through time and the outer two blue lines represent the $95 \%$ confidence intervals.

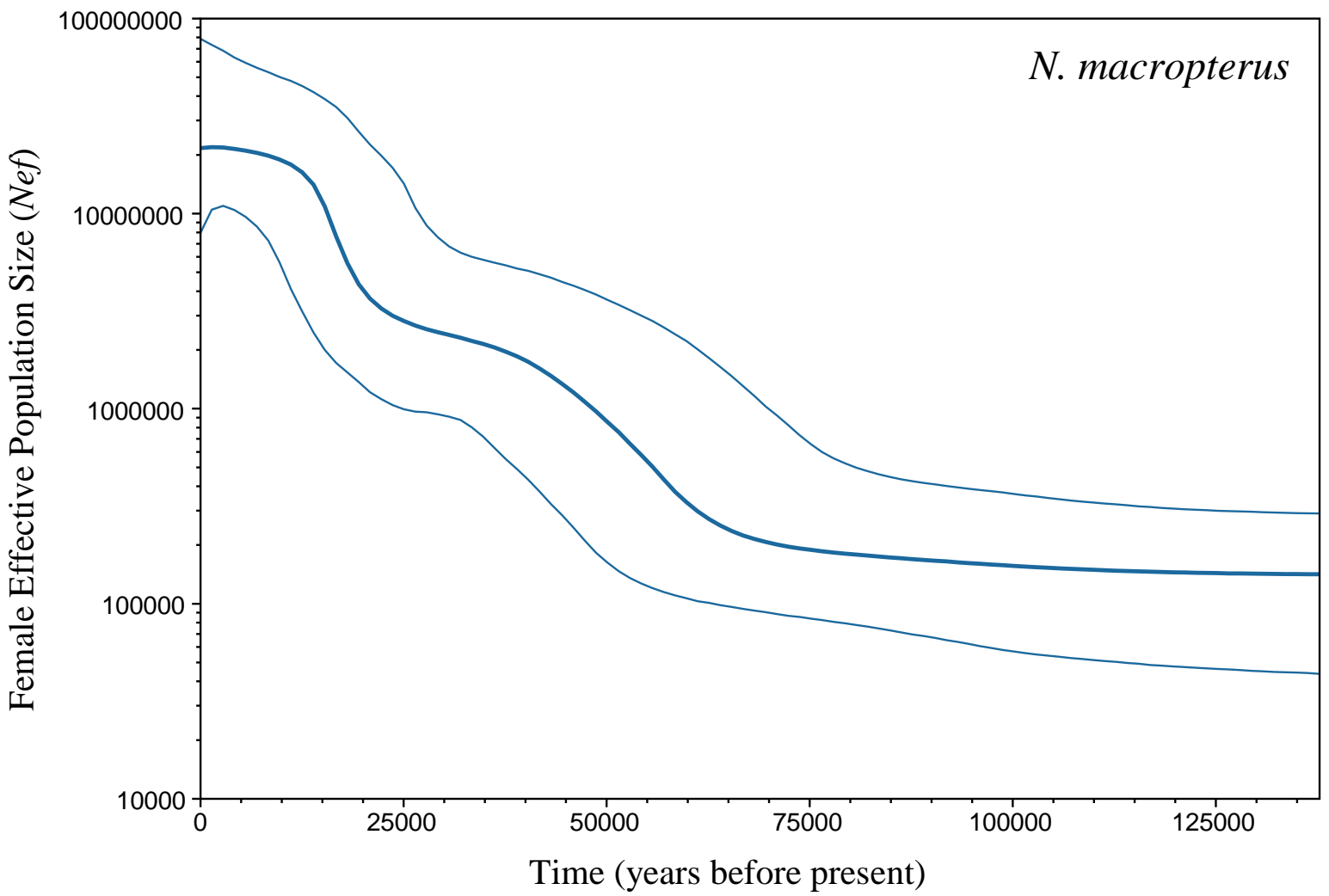

Figure 3.12: Bayesian Skyline Plot generated using HVR1 sequences illustrating estimated female effective population size through time in years before present for $N$. macropterus. The darker middle blue line represents mean female effective population size through time and the outer two blue lines represent the $95 \%$ confidence intervals. 
Bayesian skyline plots (BSP) were generated for $N$. $s p$ and $N$. macropterus to investigate historic changes to the effective population size (Figure 3.11 \& 3.12). N. $s p$ historic effective population appears to be relatively stable at approximately 200,000 for at least the past 13,000 years (Figure 3.11). However, N. macropterus historic effective population has undergone two possible expansion periods over the last 70,000 years. $N$. macropterus effective population size has increased from approximately 200,000 to 20,000,000 over this period (Figure 3.12). Based on these BSP, $N$. macropterus effective population size is 100 times larger than that of $N$. $s p$.

The historic demographic processes for some New Zealand marine populations are classified by comparing the average sequence divergence $(\pi)$ to haplotype diversity ( $h$ ) (Figure 3.13). Sector 1 is characterized by having shallow mtDNA divergence. Species that fall into this category have typically undergone a recent bottleneck or are a founding/recolonizing population. Atlantic cod was added to this graph as an example to demonstrate this class because Atlantic cod have undergone a recent bottleneck during the collapse of the Grand Banks cod fishery during the latter half of the $19^{\text {th }}$ century. Sector 2 is characterized by having a high haplotype diversity, but low nucleotide diversity. This is common for populations that have undergone rapid expansion but have not had the time for nucleotide diversity increase. Sector 3 is characterised by having high nucleotide and haplotype diversity typical for large stable populations. $N$. sp just fall into sector 3 of the graph compared to $N$. macropterus that is further to the right. Both $N$. sp and N. macropterus have high haplotypic diversity that is typical of an expanding population. However, N. macropterus have a higher nucleotide diversity compared to $N$. $s p$ indicating that $N$. macropterus have a larger population size and have been stable for a longer period of time.

Further evidence for this is demonstrated with the TCS haplotype network (Figure 3.14). Dashed lines across the branches of the network represent individual nucleotide differences between each haplotype. $N$. $s p$ represented as yellow on the TCS network have multiple nucleotide differences (14) separating them from $N$. macropterus. However, the nucleotide difference among the $N . s p$ samples is relatively low (1-2). In contrast, $N$. macropterus have a higher nucleotide diversity and is displayed by multiple nucleotide differences ranging from 1 to 9 marked between each haplotype (Figure 3.14). 


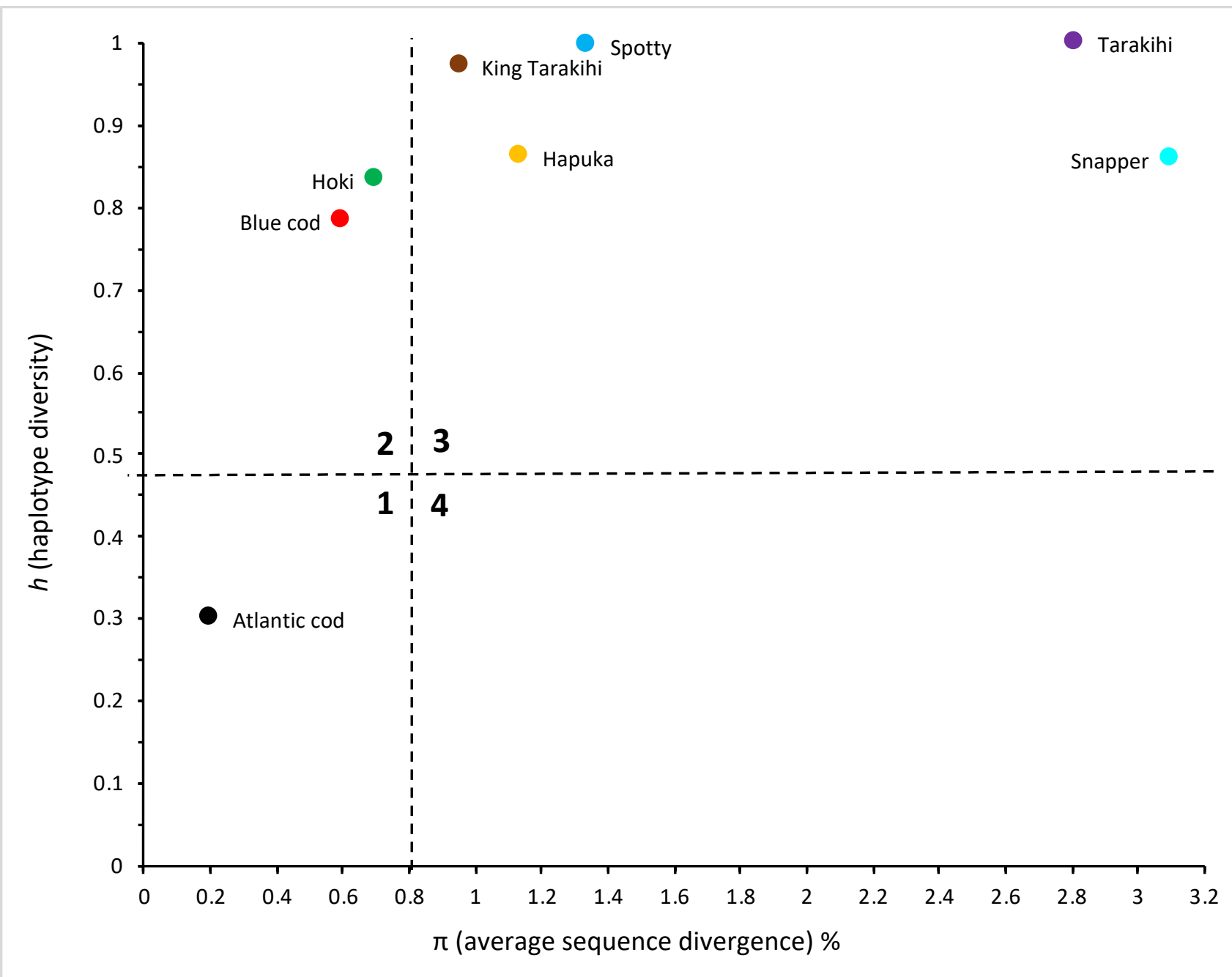

Figure 3.13: Classification of historical demographic processes in marine populations (adapted from Grant \& Bowen, 1998). Group 1 is characterised by low $\mathrm{h}$ and low $\pi$ and is representative of a population having undergone a recent bottleneck. Group 2 is characterised by high $\mathrm{h}$ and low $\pi$ and is representative of a recent expansion in the population size. Group 4 is characterised by high $\mathrm{h}$ and high $\pi$ and is representative of an older, historically stable population size. Group 3 is characterised by a low $\mathrm{h}$ and a high $\pi$ however there are few examples of this among fish species. Atlantic cod (Olsen et al., 2004), hoki (Takeshima et al., 2011), snapper (Ashton, 2013), hāpuka (Lane, 2013), spotty (Wilcox, 2015) and blue cod (Smith, 2012). 


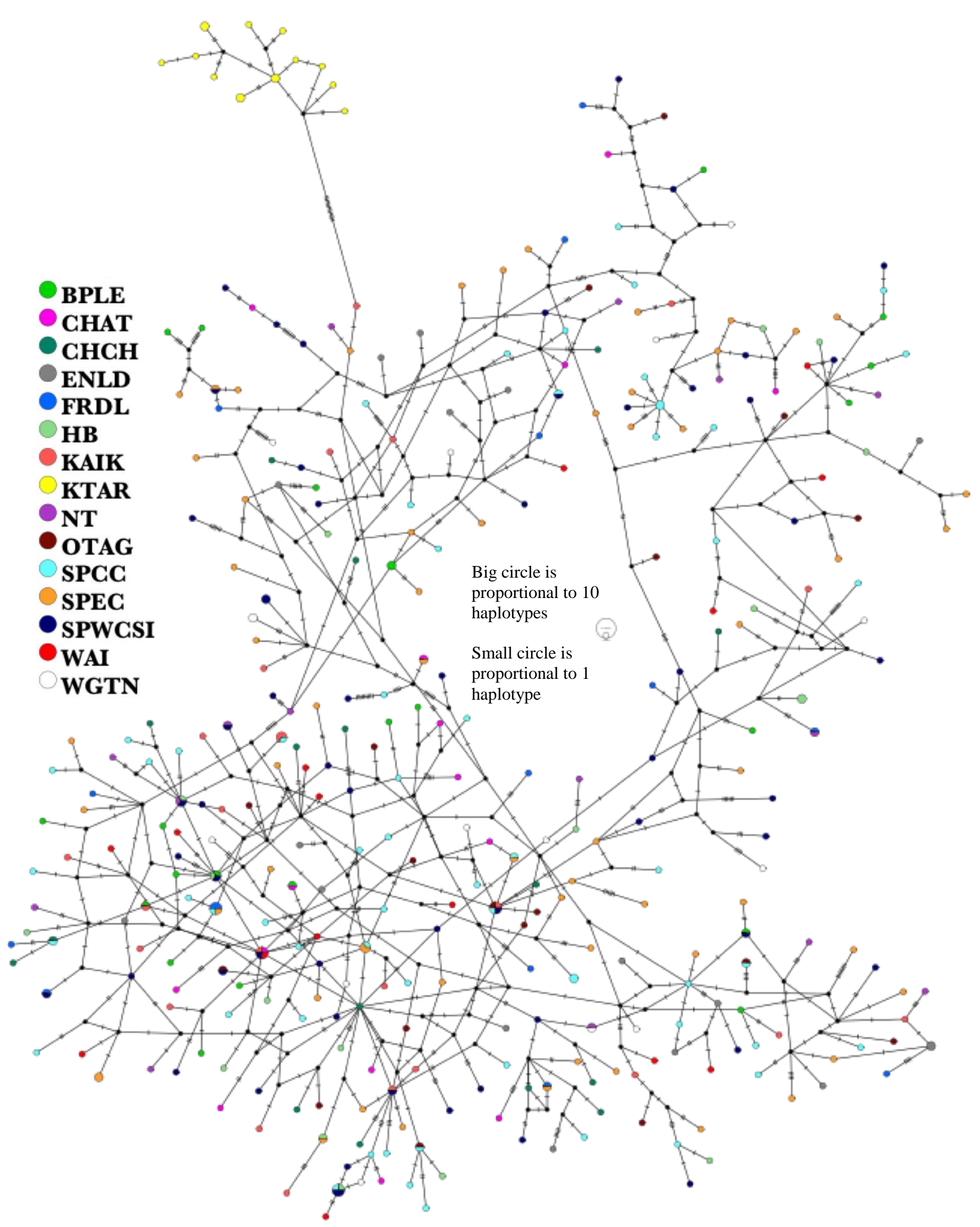

Figure 3.14: The TCS network depicts the relationships between 336 haplotypes present in the sample. The circle size is relative to the number of individuals who possess the haplotype, while individual substitutions between the two adjacent circles (haplotypes) is signified as a hatch mark across the connecting line. The smaller black circles represent the node between haplotypes. 


\section{4: Discussion}

The primary goal of this study is to investigate the genetic structure of $N$. macropterus populations throughout New Zealand. The secondary goal of this study is to investigate the genetic diversity and historic demography of $N$. $s p$. The third goal of this study is to investigate the genetic relationship between $N$. macropterus and $N$. $s p$. This is the first study to utilize DNA sequencing to investigate genetic diversity, structure, and demographic history of $N$. macropterus and N. sp around New Zealand. A 500 bp mtDNA control region fragment that covers HVR1 was used. The analysis of $N$. macropterus genetic structure revealed a panmictic genetic structure among all sampling locations, including the Chatham Islands. An analysis of demographic history, classified N. macropterus as having a large stable population size that has a high level of genetic variation. Genetic analysis between $N$. macropterus and $N$. $s p$ provides further evidence as separate species under the Nemadactylus genus.

\subsection{1: Nemadactylus. sp}

\subsubsection{1: Genetic Variation and Demographic History}

Measures of genetic variation can provide insight into the demographic history of a species. $N$. $s p$ display a low level of nucleotide diversity $(\pi=0.014)$ and a high level of haplotype diversity ( $h=0.971)$ within HVR1. Grant \& Bowen (1998) describe a population with these characteristics as one that has been affected by a population bottleneck followed by rapid population growth and accumulation of mutations. However a test for neutrality provided conflicting results as Fu's $F s$ was significant supporting population expansion but Tajima's D was not, rejecting population expansion. This is most likely a result of the sample size being to small. The rarefaction curve displays this as it has not reached an asymptote yet indicating that further sampling is required to capture the genetic diversity of the $N$. $s p$ population. Out of the fifteen samples, twelve haplotypes were identified causing the relatively high haplotype diversity. Increasing $N . s p$ sample size would most likely reduce the overall haplotype diversity moving $N$. sp into the lower portion of sector two. Having a low haplotype and nucleotide diversity are characteristics of a population that has been affected by a bottleneck or may be a founding population (Grant \& Bowen, 1998). This is somewhat supported by the mismatch distribution and goodness of fit Harpending raggednesss and sum of squared deviation statistics 
being significant, indicating that $N$. $s p$ do not fit the expanding population model. A Bayesian skyline analysis provides further evidence for this as the past effective population size appears to remain stable and has not undergone a recent expansion. However, larger sample sizes are required to gain a better understanding of their demographic history and capture the genetic diversity of $N$. sp.

\subsubsection{2: Evidence for Separate Species}

$N$. $s p$ have yet to be formally recognised as their own species within the Nemadactylus genus. However, previous studies have found distinct genetic differences between N. macropterus and $N$. $s p$ using methods such as allozymes, RAPD and mitochondrial CO1 barcoding (Smith et al., 1996). This led to Smith et al., (1996) to purpose a scientific species name of $N$. rex that has yet to be formally accepted. A $500 \mathrm{bp}$ mtDNA control region fragment that covers HVR1 was used to generate haplotype data for $N$. $s p$ and $N$. macropterus. The resulting haplotype data found shared haplotypes were exclusive among species and no haplotypes were shared between them indicating a lack of gene flow. Furthermore, $N$. $s p$ formed a separate cluster from $N$. macropterus in the PCA and TCS haplotype network and were separated from the closest $N$. macropterus haplotype by 14 nucleotide substitutions. A Pairwise $\Phi$ ST analysis provided very strong significance $\left(\Phi_{\mathrm{ST}}=0.507-0.654 \mathrm{p}=<0.001\right)$ between $N$. sp and all $N$. macropterus sampling locations, indicating a substantial genetic difference. AMOVA between $N$. $s p$ and $N$. macropterus also provided further evidence as the majority of the genetic variation $(66.315 \%$, $p<0.001)$ could be contributed to the difference between N. sp and N. macropterus.

\subsection{2: Nemadactylus macropterus}

\subsubsection{1: Genetic Structure}

N. macropterus inhabit much of New Zealand's continental shelf and can be found from the Three Kings Islands in the north to Stewart Island in the south and the Chatham Islands in the east (Annala, 1987). However, there is very little information regarding genetic structure of $N$. macropterus populations surrounding New Zealand. The current understanding is that the North and South Islands consist of a single population and Chatham Island are treated as a separate population due to geographic distance (Langley, 2018). The mtDNA data collected 
for this thesis indicates that $N$. macropterus have a panmictic population structure that encompasses mainland New Zealand and Chatham Islands.

The principal component analysis of all $N$. macropterus sampling locations indicate a panmictic population structure as all locations are randomly distributed across the graph forming one cluster. Chatham Island samples clustered with mainland locations and was found to also have shared haplotypes with spawning East Cape, Kaikoura, spawning west coast South Island, Wairarapa and Bay of Plenty. An isolation by distance test provided further evidence that Chatham Islands was not separate from mainland location. There was also no indication of an isolation by distance genetic structure among mainland sampling locations.

Pairwise $\Phi_{\text {ST }}$ and AMOVA result were not statistically significant for among almost all sampling locations. This indicates that the calculated genetic variation is not a result of population structure. However, there was a weak but significant difference detected between Hawkes Bay and east Northland with Pairwise $\Phi_{\mathrm{ST}}(0.097, \mathrm{p}=0.031)$ and AMOVA reporting $8.065 \%$ of the genetic variation could be attributed to between sampling locations. One possible explanation causing the slight genetic structuring could be reduced gene flow between the two location as a result of fishing (Pinsky \& Palumbi, 2014). A recent stock assessment of the eastern N. macropterus stock (TAR 1, TAR 2 and TAR 3) has estimated that the spawning biomass have been depleted below the fisheries soft limit of 20\% (Langley, 2018). Furthermore, it has been estimated that the spawning biomass has been reduced to this level since the 1970's as a result of high catches (5000-7000 t) during the 1950s and early 1960s (Langley, 2018). The current understanding is that once juvenile N. macropterus mature, they leave the nursery grounds of Canterbury Bight/Pegasus Bay area and migrate north up the east coast of New Zealand though the Hawkes Bay region, eventually making their way to east Northland as adults (Langley, 2018). Migrating fish make their way north through TAR $1(\sim 15$ $\%)$, TAR $2(\sim 46 \%)$ and TAR $3(\sim 33 \%)$ in which the majority of the commercial landings come from (Hanchet \& Field, n.d.). Additionally, the majority of historic N. macropterus commercial catches were landed from east Auckland to east cape, a region that lies between Hawkes Bay and east Northland (Hanchet \& Field, n.d.).

N. macropterus are long lived (30+ years), have a relatively long PLD ( 10 months) and are highly mobile as adults capable of dispersing/migrating hundreds of kilometres (Annala, 1987). These characteristics facilitate a high degree of gene flow among sampling locations resulting 
in a panmictic genetic structure (Laikre et al., 2005). Analysing shared haplotypes among sampling locations can start to provide information about connectivity of different sampling locations around New Zealand. Shared haplotypes 3, 4, 8, 9 ,27, 30, 32 and 34 came from single sampling locations on the east and west coast of the North and South Island indicating that schools may be made up of adults from the same cohort. Shared haplotypes 6, 7, 11, 15, 16, 20 and 23 occurred only on the east coast connecting locations such as Hawkes Bay to spawning East Cape, Bay of Plenty to Kaikoura and Otago, Christchurch, Kaikoura and spawning East Cape to spawning Cape Campbell. Shared haplotypes 2, 5 and 22 were exclusive to the west coast connecting Fiordland to north Taranaki, north Taranaki to spawning west coast South Island and spawning west coast South Island to Fiordland. Shared haplotypes 12, 13, 14, 17 , $18,19,21,26,28,29,31$ and 33 occurred on east and west coasts of the North and South Island in locations such as spawning Cape Campbell and spawning East Cape to Fiordland, north Taranaki to Wellington and spawning Cape Campbell, spawning East Cape, Hawkes Bay, Bay of Plenty, Kaikoura, North Taranaki, and Otago to spawning west coast South Island. The shared haplotype data cannot determine the mechanism causing the connectivity, however, it is likely a combination of migration as adults and dispersal as larvae (Shanks, 2009; Hogan et al., 2014).

The Chatham Islands shares haplotypes 10, 24 and 25 with mainland locations such as spawning East Cape, Wairarapa, Bay of Plenty, Kaikoura and spawning west coast South Island. The maximum known depth range that $N$. macropterus are known to occur is $250 \mathrm{~m}$ (Annala, 1987). However, the shallowest depth between Chatham Islands and the mainland is $500 \mathrm{~m}$ located on the Chatham rise (Chiswell et al., 2015). Since this is twice the known maximum depth of $N$. macropterus, adults migrating between the mainland and Chatham Islands is unlikely. The Chatham Islands are most likely a "sink" for larvae that are carried via ocean currents from several possible "source" spawning grounds. Furthermore, Chiswell (2009) used hydrographic models of the region to estimate that it would take 30-50 days for larvae to cover the $850 \mathrm{~km}$ stretch of water. $N$. macropterus have a relatively long PLD of approximately 10 months (Annala, 1987) making it possible to cover the $850 \mathrm{~km}$ stretch of water. The dominant water flow around New Zealand is from west to east (Chiswell et al., 2015). Larvae from the East Cape spawning ground would likely get caught in the East Cape current and then the Wairarapa coastal current that diverge along the Chatham rise transporting larvae to Chatham Islands (Chiswell et al., 2015). Larvae from the Cape Campbell spawning area would likely be transported to Chatham Island in the Southland current (Chiswell et al., 
2015). Larvae from west coast South Island spawning grounds would likely be transported via the Westland and d'Urville through the Cook Strait before being transported in either the Southland or Wairarapa coastal current to the Chatham Islands (Chiswell et al., 2015).

\subsubsection{2: Demographic History and Genetic Diversity}

Measures of genetic variation can provide insight into the demographic history of a species. $N$. macropterus display a high level of nucleotide $(\pi=0.027)$ and haplotype $(h=0.999)$ diversity within HVR1. In this study a total of 324 haplotypes were discovered from 370 N. macropterus samples. This is much larger than many other New Zealand marine species when comparing homologous control region fragment from similar sample sizes and life histories. For example a study on snapper (Pagrus auratus) had a sample size of 364 and detected 88 haplotypes.

High levels of nucleotide and haplotype diversity is suggested by Grant \& Bowen (1998) to be characteristics of a large stable population with long evolutionary history or secondary contact between previously isolated lineages. Approximately 20,000 years ago was the last glacial maximum and during this time sea levels were much lower (Golledge et al., 2012). Sea levels around New Zealand had dropped to a point in which land bridges connected the North, South and Stewart Island (Chiswell et al., 2015). This produced geological barriers to gene flow for some species such as blue cod, between east and western New Zealand (Smith, 2012). Soon after the end of the glaciation period, sea levels began to rise forming Cook Strait between the North and South Island (Chiswell et al., 2015). This was able to restore gene flow between eastern and western previously isolated blue cod lineages (Smith, 2012). However, these glaciation events are unlikely to have effected gene flow among $N$. macropterus populations due to the difference in life history and habitat preference between these two species. Blue cod have a short PLD (10 days) compared to N. macropterus ( 10 months) and have the tendency not to migrate large distances due to site fidelity (Smith, 2012). Furthermore, blue cod generally inhabit shallower reefs than $N$. macropterus, making their habitat more susceptible to the changes in sea level (Carbines, 2004). Lastly, blue cod are mostly found around the South Island so the closing of Cook Strait would leave the South and Stewart Islands as geological barrier to gene flow dividing the eastern and western populations (Carbines, 2004). In contrast, $N$. macropterus surround New Zealand waters in depths up to $250 \mathrm{~m}$ as adults forming schools that have the potential to migrate large distances (Annala, 1987). During the last glacial 
maximum, adult $N$. macropterus population would likely have been unaffected and gene flow maintained by relatively long PLD and the potential to migrate over a large distance. However, nursery habitats are relatively shallow and may have been affected if they could not adapt (Vooren, 1975). Because of this, it is unlikely that the nucleotide and haplotype diversity found in N. macropterus is a result of previously isolated lineages reconnecting.

The most likely cause is that $N$. macropterus have a large stable population with a long evolutionary history (Grant \& Bowen, 1998). The Bayesian skyline plot (BSP) is used to reconstruct historic effective population. The estimates of time since demographic expansion and female effective population size $\left(N_{e f}\right)$ are sensitive to different evolutionary rates implemented within each model. Without precise estimates of HVR1 mutation rates in $N$. macropterus, the interpretation of the trend from the BSP is more important. The trend of the BSP indicated that the $N$. macropterus past population has undergone two historic expansions. This "step-like" trend is most likely caused by a before, during and after glaciation. The initial population expansion occurred before the last glacial maximum (18-20kya). The expansion was not as rapid as the second due to a lower population size and/or lower ocean productivity due to the onset of a glaciation period (Wolff et al., 2006). During the glaciation, sea level was much lower potentially affecting nursery areas and the oceans were at their lowest productivity (Vooren, 1975; Wolff et al., 2006). This may have enforced a glaciation period carrying capacity on the $N$. macropterus population resulting in the decreased rate of expansion. Post glaciation, the ice begins to melt releasing nutrients into the ocean causing a boom in primary productivity (Wolff et al., 2006). Due to the abundance of food, N. macropterus populations begin to rapidly expand until they reach a carrying capacity and begin to asymptote at the current population size.

Further evidence is provided with the mismatch distribution supported by non-significant squared deviation (SSD) and Harpending's raggedness index values. The mismatch is unimodal indicating a population expansion. However, this pattern is likely an artifact of the historic rapid population expansion. The unimodal distribution is moving to the right of the graph due to the high nucleotide diversity shown as pairwise difference. This indicates that the population has undergone a rapid population expansion in the past but has since become a large stable population that has built up nucleotide diversity. The TCS haplotype network also displays this as there are multiple nucleotide segregations between haplotypes instead of only a few that which would characterise a recently expanding population. 


\subsection{3: Conclusion}

$N$. macropterus exhibit a panmictic population genetic structure maintained by their longevity, high migration/dispersal potential and long PLD. N. macropterus population have undergone at least two expansions leading to a large stable population with a long evolutionary history. As a result of this, $N$. macropterus have a high haplotype and nucleotide diversity. The rarefaction analysis and expansive PCA indicate that larger sample sizes are required to fully capture this. Furthermore, higher resolution markers such as microsatellites or whole genome sequencing are required to gain a better understanding surrounding the connectivity and evolution of $N$. macropterus. Genetic structure between $N$. macropterus and $N$. sp provide significant evidence for separate species. However, to gain more conclusive results of $N$. $s p$ genetic diversity and demographic history, a larger sample size is required. 


\section{Chapter Four: General Discussion}

The overall goal of this thesis research was to investigated the population genetic structure of N. macropterus using fish sampled from around New Zealand. In addition to that, the genetic diversity and demographic history of $N . s p$ was also studied using samples collected from around the Three Kings Islands of New Zealand. The complete mitochondrial genome of $N$. macropterus was reconstructed from bulk DNA sequencing data and a set of specific mtDNA primers were developed to amplify HVR1. The DNA sequencing data provided by these primers with the addition of published control region sequences was used to reconstruct the Nemadactylus phylogeny.

The complete DNA sequence of the whole mitochondrial genome of N. macropterus was for the first time determined and annotated. This new genetic resource was an invaluable source of information that was used to design specific primers to target and amplify HVR1. Furthermore, $N$. macropterus mitochondrial genome could be used to design additional primers to amplify other mitochondrial genes for future taxonomic or population structure analysis of species within Nemadactylus genus, and potentially the Cheilodactylidae family as well. The generation of HVR1 sequences formed the central data set for this thesis, which enabled analyses of the population genetic structure of $N$. macropterus, estimate of genetic diversity and demographic history of $N . s p$, and were used in the reconstruction of the Nemadactylus phylogeny. Furthermore, the comprehensive data set that was used to design the HVR1 primers demonstrated the broad success this approach has for amplifying sequences from two of the Nemadactylus species, and this would most likely be successful if applied to the other closely related species in the genus ( $N$. bergi, $N$. gayi and $N$. monodactylus). The HVR1 primers will be important for a future genetic population structure analysis of $N$. bergi because it is an important commercial and recreational fishery in Argentina (Venerus \& Cedrola, 2017). The reconstructed Nemadactylus phylogeny presented in this thesis is identical to the initial phylogeny presented by (Burridge, 1999). Both phylogenies complement one another supporting evidence of $N$. sp and N. gayi being transoceanic sister taxa (Burridge, 1999). 


\section{1: Demographic History}

N. macropterus appear to have a very high level of genetic and haplotype diversity. This implies $N$. macropterus have had a large stable population with a long evolutionary history (Grant \& Bowen, 1998). The results of the Bayesian skyline plot further support this, indicating that historic $N$. macropterus populations have undergone two significant expansions in a "steplike" trend. The last glacial maximum most likely occurred following the initial population expansion. During this period the rate of expansion was most likely limited due to reduced primary productivity. Following the glacial period, primary productivity increased resulting in the second population expansion (Wolff et al., 2006). This expansion continued up until approximately 10-15 thousand years ago as $N$. macropterus most likely reached its carrying capacity in the environment. Following this, $N$. macropterus appear to have remained large and stable for approximately the last ten thousand years. Furthermore, N. macropterus populations located around south Australia may be increasing the genetic diversity within the New Zealand gene pool. Microsatellite data collected by Burridge and Smolenski (2003) suggests transTasman dispersal from Australia may be occurring (Bruce et al., 2001). Connectivity between Australia and New Zealand populations would increase the effective population size and consequently the observed genetic and haplotype diversity of New Zealand's populations. Furthermore, Australian populations are thought to be one large panmictic population similar to New Zealand (Burridge \& Smolenski, 2003). Low levels of trans-Tasman gene flow may be enough to genetically homogenise New Zealand and Australian populations as only a few migrants are required to be exchanged and successfully reproduce per generation. However, the long distance and the hostility of the oceanic environment make it unlikely that exchanges among New Zealand and Australian populations are high enough to enable them to be considered demographically connected.

Determining the effect of climate change on fisheries is one area of concern that demographic history may be used to inform possible future distributions (Hollowed et al., 2013). Sea temperatures are predicted to increase by $1-4{ }^{\circ} \mathrm{C}$ by 2100 potentially changing species distributions and altering the flow of ocean currents (Alexander et al., 2018). N. macropterus have a relatively large temperature tolerance as they occur in subtropical and subantarctic oceans at depths of 10-400m around New Zealand and Australia (Annala, 1987; Jordan, 2001). However, sea temperature does appear to limit the northern extent of $N$. macropterus 
distribution around Australia (Jordan, 2001). Taking this into account, warming seas may eventually reduce $N$. macropterus distribution in northern areas of New Zealand. An extension to N. macropterus southward distribution would be hindered by the Southland and Subantarctic currents as they would prevent larvae from traveling south to the Auckland and Campbell Islands (Chiswell et al., 2015). Adults would most likely not have the ability to migrate there either as the Solander Trough $(+500 \mathrm{~m})$ and Campbell Plateau $(+600 \mathrm{~m})$ separates the Islands from Stewart Island (Chiswell et al., 2015). However, changes in ocean currents may be beneficial for $N$. macropterus due to their relatively long PLD. Furthermore, historic changes to ocean currents over the last 0.6-2.6 million years have been hypothesised to facilitate the radiation of Nemadactylus species throughout the world's southern oceans (Burridge, 1999).

\section{2: Genetic Structure and Fisheries Management}

Understanding the population genetic structure within a fishery can be useful for accurately defining stock boundaries and where a stock assessment model should be used. It also enables managers to develop long-term management strategies to preserve genetic variation and the evolutionary potential. If a single management unit contains two distinct populations there is usually a risk of overfishing one due to either uneven fishing pressure or uneven population distributions and sizes (Carvalho \& Hauser 1995). Alternatively, if one large panmictic population spans through multiple management units then fishing pressure is distributed across the population. As long as fishing mortality does not exceed recruitment then the likelihood of overfishing is relatively low (Pinsky \& Palumbi, 2014).

N. macropterus are currently fished from 7 QMA (TAR 1, TAR 2, TAR 3, TAR 4, TAR 5, TAR 7 and TAR 8) that support a national scale fishery averaging 4000-5000 tonnes per year, making it the third most valued inshore commercial finfish fishery (Langley, 2018). The main source of commercial $N$. macropterus catch comes from QMA TAR 1, 2, 3 and 7 via bottom trawling in depth ranges of 50-200m. $N$. macropterus are the target species for the majority of these catches, however, a portion are caught as bycatch from other fisheries such as snapper, john dory, gurnard and gemfish. Furthermore, there is a commercial set net fishery operating out of Kaikoura (Langley, 2017). According to the harvest strategy standard operational 
guidelines, $N$. macropterus are considered to be a low productive species that are less resilient to high levels of fishing pressure.

Prior to this study the stock structure of $N$. macropterus has been relatively uncertain. Although previous work to develop stock models suggested $N$. macropterus along the east coast of New Zealand may form one biological unit. The 2017 east coast $N$. macropterus stock assessment (east portion of TAR 1, TAR 2 and TAR 3) represented the first fully quantitative stock assessment analysing the east coast fisheries as one stock (Figure 4.1) (Langley, 2018). The assessment revealed that the spawning biomass of the east coast stock was estimated to be $15.9 \%$ SB0, significantly below the management target of $40 \%$ SB0 (Figure 4.2). That assessment put the stock size below the $20 \%$ SB0 soft limit since the early 2000s. In general terms, the spawning biomass of the stock has been on a downwards trend for approximately the last thirty years reaching its lowest point in 2014. Since then the spawning biomass has had a slight net increase. If this increase continues, then the stock is forecasted to meet the $40 \%$ SB0 target in approximately 35 years. However, the east coast $N$. macropterus stock has fallen below the soft limit, this means it is now considered to be overfished or depleted so a rebuild of the stock is required.

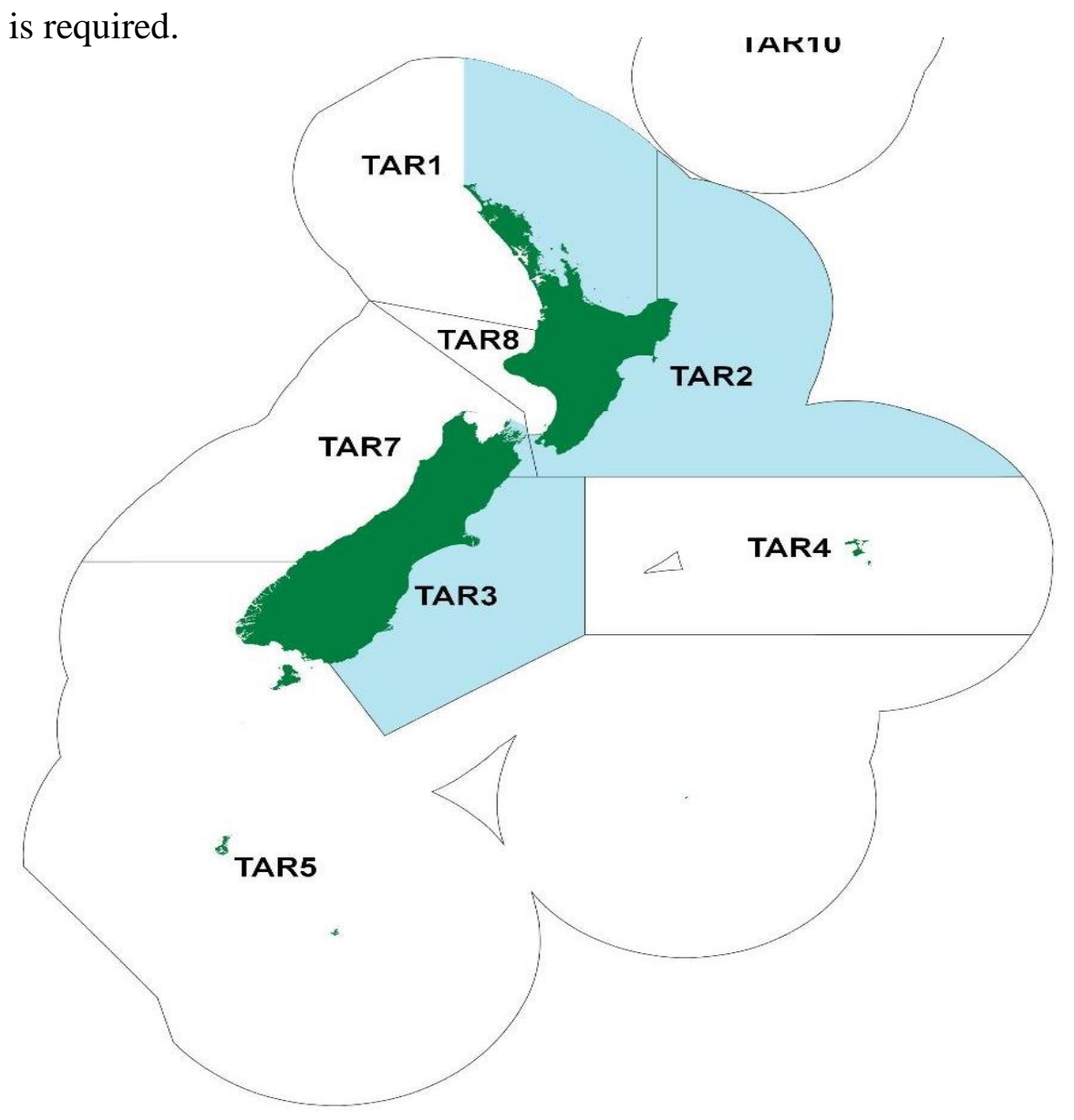

Figure 4.1: TAR quota management areas that were under review as part of the 2017 east coast $N$. macropterus stock assessment marked in blue. Retrieved from (Langley, 2018). 


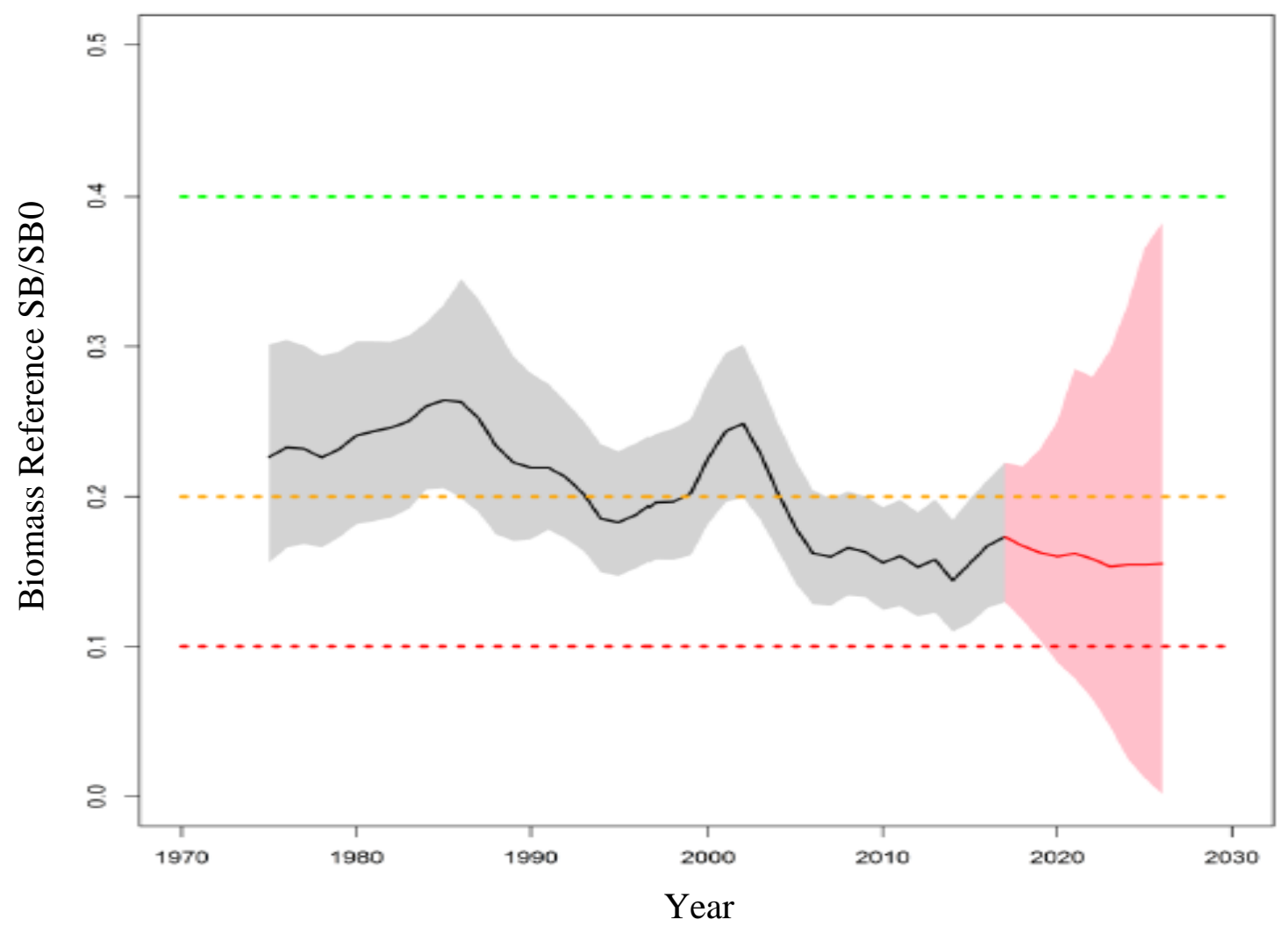

Figure 4.2: Annual trend in spawning biomass from 1975 to 2017 relative to $40 \%$ SB0 target biomass (green dashed line), the 20\% SB0 soft limit (orange dashed line) and the 10\% SB0 hard limit (red dashed line). The dark black line in the middle represents the mean spawning biomass and the grey outer areas represent the $95 \%$ confidence interval. The red area represents future projections form 2017. The variation in this projection is due to uncertainties in spawning success and recruitment (Langley, 2018). Retrieved from, Review of Sustainability Measures for 1 of October 2018.

Three proposals were put forward in order to rebuild the eastern stock, so it meets the $40 \%$ SB0 target (Langley, 2018). TAR 7 was not part of the 2017 eastern stock assessment, however, the majority of $N$. macropterus catches come from the eastern QMA and TAR 7. Because of this, TAR 7 has been added to the proposed rebuild plans. The first proposal suggests a 31\% reduction to TACC is required and the second proposal suggests a $35 \%$ reduction to TACC is required to allow the stock to rebuild to $40 \% \mathrm{SB} 0$, which is estimated to take 12 and 11 years respectively. The third proposal suggests no reductions to TACC is required and changes to fishing practice (avoid catching juveniles and better spreading the catch across the fisheries) can result in an increased stock size to $35 \%$ SB0 within approximately 27 years.

The Minister of Fisheries (Minister) announced as part of the October 2018 sustainability round, a two-staged plan to rebuild N. macropterus abundance back to a target level of $40 \%$ SB0. The staged approach has been chosen to provide the commercial fishing industry an opportunity to plan and adjust their operations accordingly with reductions to quota. The Minister announced a 20\% reduction to the combined TACC for TAR 1, TAR 2, TAR 3 and 
TAR 7 for the 2018/2019 fishing year as the first stage. The Minister is expected to announce the second stage of the rebuild plan for the 2019/2020 fishing season in October 2019. The harvest strategy standard operational guidelines recommend the rebuild of $N$. macropterus stocks to $40 \%$ SB0 should take ten years. Because of this, the most likely option chosen will be for rebuild proposal one or two in order to align the rebuild to a ten-year period.

This thesis has provided the first description of the population genetic structure of $N$. macropterus from around New Zealand based on HVR1 of the mitochondrial genome. The results suggest $N$. macropterus have a panmictic pattern of genetic diversity that encompasses all of the sampled sites around New Zealand, including the Chatham Islands. This finding might be beneficial to the rebuild strategy of the $N$. macropterus east coast fisheries, as a panmictic population structure is the most desirable because of the high levels of gene flow among populations, therefore preventing a potential genetic bottleneck (Laikre et al., 2005). $N$. macropterus populations occupying the surrounding QMA have not been as extensively fished. These populations may act as reservoirs of genetic diversity. Gene flow among areas will assist in maintaining genetic diversity, which is vital in the successful recovery and long-term management of the east coast N. macropterus fisheries. However, high levels of genetic diversity suggests a relatively large historic effective population size and most likely the census population size was also high (Grant \& Bowen, 1998). As the population size is reduced, genetic diversity is lost. The commercial $N$. macropterus fishery targets east coast QMA and TAR7 because this is where N. macropterus have the highest abundance (Langley, 2018). Historically the populations inhabiting these areas were most likely very large. Extensive fishing pressure that eventually lead to these QMA becoming overfished likely reduced the genetic diversity. As a result of this, lower levels of genetic diversity may become the new norm for $N$. macropterus populations, reducing their evolutionary potential.

To ensure the successful long term management, further research needs to be done to understand the demographic connectivity between QMA. Until demographic connectivity is better understood, it would be prudent to retain the placement of the current QMA. However, once the east coast $N$. macropterus has recovered, it is vital to have a better informed understanding of the level of fishing pressure so it does not exceed recruitment. Furthermore, fishing pressure should be distributed across multiple QMA to prevent overfishing a portion of the $N$. macropterus population. This further prevents the potential for a local reduction in gene flow to occur as a result of intensively fishing one area. This may have already occurred as a 
slight genetic difference was detected between Hawkes Bay and East Northland sampling locations. Fortunately, the 2017 east coast $N$. macropterus stock assessment recognised the need to rebuild this fishery, likely mitigating any detrimental effects caused by a reduction in gene flow between these areas.

\section{3: Future Research}

In order to improve the understanding of $N$. macropterus population genetic structure, larger samples sizes will be required to better describe the patterns of diversity. In addition, further research is required to determine the level and direction of demographic connectivity between N. macropterus populations. If two populations are genetically distinct then demographic connectivity is unlikely (Lowe \& Allendorf, 2010). However, genetically connected populations can be demographically disconnected (Ovenden, 2013). This is because genetic connectivity is measured in absolute numbers of dispersers and demographic connectivity is a function of the proportion of migrants moving between populations (Lowe \& Allendorf, 2010). One migrant per generation can maintain genetic connectivity, however, an exchange of up to $10 \%$ between populations may justify their treatment as separate stocks (Hauser and Ward, 1998). Because of this, a holistic approach is required that encompasses both demographic connectivity and genetic connectivity to completely understand population connectivity.

Future directions to help address this issue might include otolith microchemistry analysis, oceanographic modelling and mark-recapture research. Population genomic is an emerging field that uses next generation sequencing technologies to sub-sample the genome or sequence it entirely. Genomics provides the highest genetic resolution available and can estimate the rate and direction of connectivity between populations. A genomics approach would be a 'stepchange' level of progress for understanding the population genetic structure of the $N$. macropterus fishery. Further research is also required to identify nursery habitats and align fishing practice in order to prevent these critical areas from being degraded and juvenile $N$. macropterus being caught unintentionally. In addition, the minimum legal size may need to be increased from a fork length of $25 \mathrm{~cm}$ to over $33 \mathrm{~cm}$ as $N$. macropterus are thought to reach sexual maturity at an age of 6 years and $33 \mathrm{~cm}$. 
In conclusion, while mtDNA marker were suitable for the scope of this current study, future work requires higher resolution genetic techniques and direct measures of dispersal to gain a full understanding of $N$. macropterus population connectivity. It is hoped that this research will contribute to the growing body of data that can be successfully applied to future management decisions of the treasured New Zealand N. macropterus fishery. 


\section{$\underline{\text { References: }}$}

Abbott, J. A., Francklyn, C. S., \& Robey-Bond, S. M. (2014). Transfer RNA and human disease. Frontiers in genetics, 5, 158.

Aboim, M. A., Menezes, G. M., Schlitt, T., \& Rogers, A. D. (2005). Genetic structure and history of populations of the deep-sea fish Helicolenus dactylopterus (Delaroche, 1809) inferred from mtDNA sequence analysis. Molecular ecology, 14(5), 13431354.

Alexander, M. A., Scott, J. D., Friedland, K. D., Mills, K. E., Nye, J. A., Pershing, A. J., \& Thomas, A. C. (2018). Projected sea surface temperatures over the 21 st century: Changes in the mean, variability and extremes for large marine ecosystem regions of Northern Oceans. Elem Sci Anth, 6(1).

Aljanabi, S. M., \& Martinez, I. (1997). Universal and rapid salt-extraction of high quality genomic DNA for PCR-based techniques. Nucleic acids research, 25(22), 46924693.

Allendorf, F. W. (2017). Genetics and the conservation of natural populations: allozymes to genomes. Molecular Ecology, 26(2), 420-430.

Andrew, T. G., Hecht, T., Heemstra, P. C., and Lutjeharms, J. R. E. (1995). Fishes of the Tristan da Cunha group and Gough Island, South Atlantic Ocean. Ichthyol. Bull. J. L. B. Smith Inst. Ichthyol. 63: 1-43.

Annala, J. H. (1987). The biology and fishery of tarakihi, Nemadactylus macropterus. New Zealand waters. New Zealand Fisheries Research Division Occasional Publication, 51, 1-12.

Apte, S., \& Gardner, J. P. A. (2002). Population genetic subdivision in the New Zealand greenshell mussel (Perna canaliculus) inferred from single-strand conformation polymorphism analysis of mitochondrial DNA. Molecular Ecology, 11(9), 16171628.

Ardren, W. R., \& Kapuscinski, A. R. (2003). Demographic and genetic estimates of effective population size $(\mathrm{Ne})$ reveals genetic compensation in steelhead trout. Molecular Ecology, 12(1), 35-49.

Ashton, D. T. (2013). Population Genetics of New Zealand Pagrus auratus and Genetic Variation of an Aquaculture Broodstock. 100.

Avise, J. C., Giblin-Davidson, C., Laerm, J., Patton, J. C., \& Lansman, R. A. (1979). Mitochondrial DNA clones and matriarchal phylogeny within and among geographic populations of the pocket gopher, Geomys pinetis. Proceedings of the National Academy of Sciences, 76(12), 6694-6698.

Ayers, K. L., \& Waters, J. M. (2005). Marine biogeographic disjunction in central New Zealand. Marine Biology, 147(4), 1045-1052. 
Ayling, T., \& Cox, G. J. (1982). Collins guide to the sea fishes of New Zealand. International Specialized Book Service Incorporated.

Baker, C. S., MacCarthy, M., Smith, P. J., Perry, A. P., \& Chambers, G. K. (1992). DNA fingerprints of orange roughy, Hoplostethus atlanticus: a population comparison. Marine Biology, 113(4), 561-567.

Baker, C. S., Perry, A., Chambers, G. K., \& Smith, P. J. (1995). Population variation in the mitochondrial cytochrome $\mathrm{b}$ gene of the orange roughy Hoplostethus atlanticus and the hoki Macruronus novaezelandiae. Marine Biology, 122(4), 503-509.

Ballard, J. W. O., \& Kreitman, M. (1995). Is mitochondrial DNA a strictly neutral marker?. Trends in Ecology \& Evolution, 10(12), 485-488.

Batstone, C. J., \& Sharp, B. M. (1999). New Zealand's quota management system: the first ten years. Marine Policy, 23(2), 177-190.

Beentjes, M.P.; Parker, S.; Fu, D. (2012). Characterisation of TAR 2 \& TAR 3 fisheries and age composition of landings 2010/11. New Zealand Fisheries Assessment Report $2012 / 25$.

Bernatchez, L., Wellenreuther, M., Araneda, C., Ashton, D. T., Barth, J. M., Beacham, T. D. \& Ovenden, J. R. (2017). Harnessing the power of genomics to secure the future of seafood. Trends in Ecology \& Evolution, 32(9), 665-680.

Bhargava, A., \& Fuentes, F. F. (2010). Mutational dynamics of microsatellites. Molecular biotechnology, 44(3), 250-266.

Billington, N., \& Hebert, P. D. (1991). Mitochondrial DNA diversity in fishes and its implications for introductions. Canadian Journal of Fisheries and Aquatic Sciences, 48(S1), 80-94.

Birky, C. W., Fuerst, P., \& Maruyama, T. (1989). Organelle gene diversity under migration, mutation, and drift: equilibrium expectations, approach to equilibrium, effects of heteroplasmic cells, and comparison to nuclear genes. Genetics, 121(3), 613-627.

Bohonak, A. J. (1999). Dispersal, gene flow, and population structure. The Quarterly Review of Biology, 74(1), 21-45.

Bors, E. K., Rowden, A. A., Maas, E. W., Clark, M. R., \& Shank, T. M. (2012). Patterns of deep-sea genetic connectivity in the New Zealand region: implications for management of benthic ecosystems. PLoS One, 7(11), e49474.

Botsford, L. W., Castilla, J. C., \& Peterson, C. H. (1997). The management of fisheries and marine ecosystems. Science, 277(5325), 509-515.

Bradbury, I. R., Laurel, B., Snelgrove, P. V., Bentzen, P., \& Campana, S. E. (2008). Global patterns in marine dispersal estimates: the influence of geography, taxonomic category and life history. Proceedings of the Royal Society B: Biological Sciences, 275(1644), 1803-1809. 
Bowen, B. W., A. Muss, L. A. Rocha, and W. S. Grant, 2006, Shallow mtDNA coalescence in atlantic pygmy angelfishes (Genus Centropyge) indicates a recent invasion from the Indian Ocean: Journal of Heredity, v. 97, p. 1-12.

Bray, D.J. 2019 a, Nemadactylus sp. in Fishes of Australia, accessed 05 Sep 2019, http://fishesofaustralia.net.au/home/species/5492

Bray, D.J. 2019 b, Nemadactylus valenciennesi in Fishes of Australia, accessed 05 Sep 2019, http://fishesofaustralia.net.au/home/species/434

Brown, K. H. (2008). Fish mitochondrial genomics: sequence, inheritance and functional variation. Journal of Fish Biology, 72(2), 355-374.

Brown, W. M., \& Wright, J. W. (1979). Mitochondrial DNA analyses and the origin and relative age of parthenogenetic lizards (genus Cnemidophorus). Science, 203(4386), 1247-1249.

Bruce, B. D., Evans, K., Sutton, C. A., Young, J. W., \& Furlani, D. M. (2001). Influence of mesoscale oceanographic processes on larval distribution and stock structure in jackass morwong (Nemadactylus macropterus: Cheilodactylidae). ICES Journal of Marine Science, 58(5), 1072-1080.

Brunner, P.C., Douglas, M.R., Osinov, A., Wilson, C.C., Bernatchez, L., 2001. Holarctic phylogeography of arctic charr (Salvelinus alpinus L.) inferred from mitochondrial DNA sequences. Evolution 55 (3), 573- 586.

Burridge, C. P. (1999). Molecular phylogeny of Nemadactylus and Acantholatris (Perciformes: Cirrhitoidea: Cheilodactylidae), with implications for taxonomy and biogeography. Molecular Phylogenetics and Evolution, 13(1), 93-109.

Burridge, C. P., \& Smolenski, A. J. (2003). Lack of genetic divergence found with microsatellite DNA markers in the tarakihi Nemadactylus macropterus. New Zealand Journal of Marine and Freshwater Research, 37(2), 223-230.

Cape Town Museum (1891) Annals of the South African Museum. Annale van die SuidAfrikaanse Museum. Pg, 690.

Carbines, G. D. (2004). Age, growth, movement and reproductive biology of blue cod (Parapercis colias-Pinguipedidae): implications for fisheries management in the South Island of New Zealand (Doctoral dissertation, University of Otago).

Carson, H. S., Cook, G. S., López-Duarte, P. C., \& Levin, L. A. (2011). Evaluating the importance of demographic connectivity in a marine metapopulation. Ecology, 92(10), 1972-1984.

Carvalho, G. R., \& Hauser, L. (1995). Molecular genetics and the stock concept in fisheries. In Molecular genetics in fisheries (pp. 55-79). Springer, Dordrecht.

Chakraborty, R. (1992). Sample size requirements for addressing the population genetic issues of forensic use of DNA typing. Hum Biol, 64(2), 141-159. 
Chambers, G. K., \& MacAvoy, E. S. (2000). Microsatellites: consensus and controversy. Comparative Biochemistry and Physiology Part B: Biochemistry and Molecular Biology, 126(4), 455-476.

Charlesworth, B. (2009). Effective population size and patterns of molecular evolution and variation. Nature Reviews Genetics, 10(3), 195.

Chiang, H. C., Hsu, C. C., Wu, G. C. C., Chang, S. K., \& Yang, H. Y. (2008). Population structure of bigeye tuna (Thunnus obesus) in the Indian Ocean inferred from mitochondrial DNA. Fisheries Research, 90(1-3), 305-312.

Chiswell, S. M. (2009). Colonisation and connectivity by intertidal limpets among New Zealand, Chatham and Sub-Antarctic Islands. II. Oceanographic connections. Marine Ecology Progress Series, 388, 121-135.

Chiswell, S. M., Bostock, H. C., Sutton, P. J., \& Williams, M. J. (2015). Physical oceanography of the deep seas around New Zealand: a review. New Zealand Journal of Marine and Freshwater Research, 49(2), 286-317.

Clement M, Snell Q, Walke P, Posada D, Crandall, K (2002). TCS: estimating gene genealogies. Proc 16th Int Parallel Distrib Process Symp 2:184.

Cooper, R. A., \& Millener, P. R. (1993). The New Zealand biota: historical background and new research. Trends in Ecology \& Evolution, 8(12), 429-433.

Cowen, R. K., \& Sponaugle, S. (2009). Larval dispersal and marine population connectivity. Annual review of marine science, 1, 443-466.

Cowen, R. K., Gawarkiewicz, G., Pineda, J., Thorrold, S. R., \& Werner, F. E. (2007). Population connectivity in marine systems an overview. Oceanography, 20(3), 1421.

Cowen, R. K., Paris, C. B., \& Srinivasan, A. (2006). Scaling of connectivity in marine populations. Science, 311(5760), 522-527.

Cuéllar-Pinzón, J., Presa, P., Hawkins, S. J., \& Pita, A. (2016). Genetic markers in marine fisheries: Types, tasks and trends. Fisheries Research, 173, 194-205.

Dammannagoda, S. T., Hurwood, D. A., \& Mather, P. B. (2011). Genetic analysis reveals two stocks of skipjack tuna (Katsuwonus pelamis) in the northwestern Indian Ocean. Canadian Journal of Fisheries and Aquatic Sciences, 68(2), 210-223.

Donaldson, K.A., Wilson, R.R., 1999. Amphi-Panamic geminates of snook (Percoidei: Centropomidae) provide a calibration of the divergence rate in the mitochondrial DNA control region of Wshes. Mol. Phyloge- net. Evol. 13, 208-213.

Dieffenbach, C. W., Lowe, T. M., \& Dveksler, G. S. (1993). General concepts for PCR primer design. PCR methods appl, 3(3), S30-S37. 
Elliott, N. G., \& Ward, R. D. (1994). Enzyme variation in jackass morwong, Nemadactylus macropterus (Schneider, 1801)(Teleostei: Cheilodactylidae), from Australian and New Zealand waters. Marine and Freshwater Research, 45(1), 51-67.

Elliott, N. G., Haskard, K., \& Koslow, J. A. (1995). Morphometric analysis of orange roughy (Hoplostethus atlanticus) off the continental slope of southern Australia. Journal of Fish Biology, 46(2), 202-220.

Elshire, R. J., Glaubitz, J. C., Sun, Q., Poland, J. A., Kawamoto, K., Buckler, E. S., \& Mitchell, S. E. (2011). A robust, simple genotyping-by-sequencing (GBS) approach for high diversity species. PloS one, 6(5), e19379.

Enberg, K., Jørgensen, C., Dunlop, E. S., Varpe, Ø., Boukal, D. S., Baulier, L., ... \& Heino, M. (2012). Fishing-induced evolution of growth: concepts, mechanisms and the empirical evidence. Marine Ecology, 33(1), 1-25.

Endler, J. A. (1979). Gene flow and life history patterns. Genetics, 93(1), 263-284.

Excoffier, L. and H.E. L. Lischer (2010) Arlequin suite ver 3.5: A new series of programs to perform population genetics analyses under Linux and Windows. Molecular Ecology Resources. 10 564-567.

Fisheries (Commercial Fishing) Regulations 2001. Retrieved form http://www.legislation.govt.nz/regulation/public/2001/0253/latest/whole.html on the 23rd of August, 2019.

Fisheries

Act

(1996).

Retrieved from http://www.legislation.govt.nz/act/public/1996/0088/latest/DLM394192.html?search= ta_act_F_ac\%40ainf\%40anif_an\%40bn\%40rn_25_a\&p=4 on the $20^{\text {th }}$ of August, 2019.

Francis, R. I. C. C., \& Clark, M. R. (1998). Inferring spawning migrations of orange roughy (Hoplostethus atlanticus) from spawning ogives. Marine and Freshwater Research, 49(2), 103-108.

fs.fish. (2019). Retrieved from https://fs.fish.govt.nz/Page.aspx?sc=TAR\&pk=7 on the $23^{\text {rd }}$ of August, 2019.

Fu, Y. X. (1994). Estimating effective population size or mutation rate using the frequencies of mutations of various classes in a sample of DNA sequences. Genetics, 138(4), $1375-1386$.

$\mathrm{Fu}$, Y. X. (1997). Statistical tests of neutrality of mutations against population growth, hitchhiking and background selection. Genetics, 147(2), 915-925.

Funk, W. C., McKay, J. K., Hohenlohe, P. A., \& Allendorf, F. W. (2012). Harnessing genomics for delineating conservation units. Trends in ecology \& evolution, 27(9), 489-496.

Gaines, S. D., \& Bertness, M. D. (1992). Dispersal of juveniles and variable recruitment in sessile marine species. Nature, 360(6404), 579-580. 
Gauldie, R. W., \& Nathan, A. (1977). Iron content of the otoliths of tarakihi (Teleostei: Cheilodactylidae). New Zealand Journal of Marine and Freshwater Research, 11(2), 179-191.

Gauldie, R.W.; Graynoth, E.J.; Illingworth, J. (1980). The relationship of the iron content of some fish otoliths to temperature. Comparative Biochemistry and Physiology 66A: $19-24$.

Gauldie, R.W.; Johnston, A.J. (1980). The geographical distribution of phosphoglucomutase and glucose phosphate isomerase alleles of some New Zealand fishes. Comparative Biochemistry and Physiology 66B: 171-183.

Gibbs, M. T. (2008). The historical development of fisheries in New Zealand with respect to sustainable development principles. The Electronic Journal of Sustainable Development, 1(2), 23-33.

Golledge, N. R., Mackintosh, A. N., Anderson, B. M., Buckley, K. M., Doughty, A. M., Barrell, D. J., ... \& Schaefer, J. M. (2012). Last Glacial Maximum climate in New Zealand inferred from a modelled Southern Alps icefield. Quaternary Science Reviews, 46, 30-45.

Grant, W. A. S., \& Bowen, B. W. (1998). Shallow population histories in deep evolutionary lineages of marine fishes: insights from sardines and anchovies and lessons for conservation. Journal of Heredity, 89(5), 415-426.

Grewe, P. M., Smolenski, A. J., \& Ward, R. D. (1994). Mitochondrial DNA diversity in jackass morwong (Nemadactylus macropterus: Teleostei) from Australian and New Zealand waters. Canadian journal of fisheries and aquatic sciences, 51(5), 11011109.

Hadrys, H., Balick, M., \& Schierwater, B. (1992). Applications of random amplified polymorphic DNA (RAPD) in molecular ecology. Molecular ecology, 1(1), 55-63.

Hamner, R. M., Constantine, R., Oremus, M., Stanley, M., Brown, P., \& Scott Baker, C. (2014). Long-range movement by Hector's dolphins provides potential genetic enhancement for critically endangered Maui's dolphin. Marine Mammal Science, 30(1), 139-153.

Hann, T. A .2013,a, Image of tarakihi. Retrieved from:

http://www.fishphotos.co.nz/stockbox/index.php? module=media\&pId=102\&id=9504 on the $26^{\text {th }}$ of August, 2019.

Hann, T. A .2013,b, Image of porae. Retrieved from:

http://www.fishphotos.co.nz/stockbox/index.php? module=media\&pId=102\&id=9472 on the $26^{\text {th }}$ of August, 2019.

Harmon, L. J., \& Braude, S. (2010). Conservation of small populations: effective population sizes, inbreeding, and the 50/500 rule. An introduction to methods and models in 
ecology, evolution, and conservation biology. Princeton University Press, Princeton, 125-138.

Harpending, H. C. (1994). Signature of ancient population growth in a low-resolution mitochondrial DNA mismatch distribution. Human biology, 591-600.

Harris, H. (1966). C. Genetics of Man Enzyme polymorphisms in man. Proceedings of the Royal Society of London. Series B. Biological Sciences, 164(995), 298-310.

Harvest strategy standard operational guideline, 2011. Retrieved from https://fs.fish.govt.nz/Page.aspx?pk=113\&dk=23081 on the 30 ${ }^{\text {th }}$ of August, 2019.

Hauser, L., \& Ward, R. D. (1998). Population identification in pelagic fish: the limits of molecular markers. NATO ASI Series a Life Sciences, 306, 191-224.

Hendry, R. (2004). An assessment of the spatial extent and relative importance of nurseries and of the genetic structure among nurseries of rig (Mustelus lenticulatus), an endemic New Zealand shark. MSc University of Victoria, Wellington, Wellington, $210 \mathrm{p}$.

Hickey, A.J.R.; Lavery, S.D.; Hannan, D.A.; Baker, C.S.; Clements, K.D. (2009). New Zealand triplefin fishes (family Tripterygiidae): contrasting population structure and mtDNA diversity within a marine species flock. Molecular Ecology 18: 680-696.

Hilborn, R., \& Walters, C. J. (1992). Quantitative fisheries stock assessment: choice, dynamics and uncertainty. Reviews in Fish Biology and Fisheries, 2(2), 177-178.

Hixon, M. A., \& Jones, G. P. (2005). Competition, predation, and density-dependent mortality in demersal marine fishes. Ecology, 86(11), 2847-2859.

Hogan, J. D., Blum, M. J., Gilliam, J. F., Bickford, N., \& McIntyre, P. B. (2014). Consequences of alternative dispersal strategies in a putatively amphidromous fish. Ecology, 95(9), 2397-2408.

Hollowed, A. B., Barange, M., Beamish, R. J., Brander, K., Cochrane, K., Drinkwater, K \& Kim, S. (2013). Projected impacts of climate change on marine fish and fisheries. ICES Journal of Marine Science, 70(5), 1023-1037.

Hsieh, C. H., Yamauchi, A., Nakazawa, T., \& Wang, W. F. (2010). Fishing effects on age and spatial structures undermine population stability of fishes. Aquatic Sciences, 72(2), 165-178.

Hurst, R.J.; Stevenson, M.L.; Bagley, N.W.; Griggs, L.H.; Morrison, M.A.; Francis, M.P. (2000). Areas of importance for spawning, pupping or egglaying, and juveniles of New Zealand coastal fish. Unpublished document held by the Ministry for Primary Industries, Wellington, N.Z.

HUTCHISON III, C. A., Newbold, J. E., Potter, S. S., \& Edgell, M. H. (1974). Maternal inheritance of mammalian mitochondrial DNA. Nature, 251(5475), 536. 
Huxley, T.H. 1884. Inaugural address. Fisheries Exhibition Literature 4, 1-22.

Ivanova, N. V., Zemlak, T. S., Hanner, R. H., \& Hebert, P. D. (2007). Universal primer cocktails for fish DNA barcoding. Molecular Ecology Notes, 7(4), 544-548.

Iwasaki, W., Fukunaga, T., Isagozawa, R., Yamada, K., Maeda, Y., Satoh, T. P., ... \& Nishida, M. (2013). MitoFish and MitoAnnotator: a mitochondrial genome database of fish with an accurate and automatic annotation pipeline. Molecular biology and evolution, 30(11), 2531-2540.

Jones, F. C., Grabherr, M. G., Chan, Y. F., Russell, P., Mauceli, E., Johnson, J., ... \& Birney, E. (2012). The genomic basis of adaptive evolution in threespine sticklebacks. Nature, 484(7392), 55.

Jones, G. P., Planes, S., \& Thorrold, S. R. (2005). Coral reef fish larvae settle close to home. Current Biology, 15(14), 1314-1318.

Jordan, A. R. (2001). Spatial and temporal variations in abundance and distribution of juvenile and adult jackass morwong, Nemadactylus macropterus, in south-eastern Tasmania. Marine and Freshwater Research, 52(4), 661-670.

Kong, X., Dong, X., Zhang, Y., Shi, W., Wang, Z., \& Yu, Z. (2009). A novel rearrangement in the mitochondrial genome of tongue sole, Cynoglossus semilaevis: control region translocation and a tRNA gene inversion. Genome, 52(12), 975-984.

Kumar S, Stecher G, Li M, Knyaz C, and Tamura K ( 2018) Molecular Biology and Evolution 35:1547-1549.

Laikre, L., Palm, S., \& Ryman, N. (2005). Genetic population structure of fishes: implications for coastal zone management. AMBIO: A Journal of the Human Environment, 34(2), 111-120.

Lamb, T. D. (1990). "The Taxonomy and Phylogeny of Cheilodactylid and Latrid Fishes," B.Sc.(Hons) thesis, Univ. of Tasmania, Hobart, Australia.

Lane, H. S., Symonds, J. E., \& Ritchie, P. A. (2016). The phylogeography and population genetics of Polyprion oxygeneios based on mitochondrial DNA sequences and microsatellite DNA markers. Fisheries research, 174, 19-29.

Langley, A. D. (2018). Stock assessment of tarakihi off the east coast of mainland New Zealand. New Zealand Fisheries Assessment Report, 5.

Langley, A.D. (2017). Fishery characterisation and Catch-Per-Unit-Effort indices for tarakihi in TAR 1, TAR 2 and TAR 3. New Zealand Fisheries Assessment Report 2017/44. $122 \mathrm{p}$.

Lee, W. J., Conroy, J., Howell, W. H., \& Kocher, T. D. (1995). Structure and evolution of teleost mitochondrial control regions. Journal of Molecular Evolution, 41(1), 54-66. 
Leis, J. M. (2006). Are larvae of demersal fishes plankton or nekton?. Advances in marine biology, 51, 57-141.

Lench, N., Stanier, P., \& Williamson, R. (1988). Simple non-invasive method to obtain DNA for gene analysis. The Lancet, 331(8599), 1356-1358.

Lenormand, T. (2002). Gene flow and the limits to natural selection. Trends in Ecology \& Evolution, 17(4), 183-189.

Lewontin, R. C., \& Hubby, J. L. (1966). A molecular approach to the study of genic heterozygosity in natural populations. II. Amount of variation and degree of heterozygosity in natural populations of Drosophila pseudoobscura. Genetics, 54(2), 595.

Lidgard, C.W. (2001). Evaluating the population genetic structure of the New Zealand cockle Austrovenus stutchburyi using allozyme electrophoresis. MSc University of Waikato, Hamilton, $45 \mathrm{p}$.

Liu, J. X., Gao, T. X., Zhuang, Z. M., Jin, X. S., Yokogawa, K., \& Zhang, Y. P. (2006). Late Pleistocene divergence and subsequent population expansion of two closely related fish species, Japanese anchovy (Engraulis japonicus) and Australian anchovy (Engraulis australis). Molecular Phylogenetics and Evolution, 40(3), 712-723.

Lowe, W. H., \& Allendorf, F. W. (2010). What can genetics tell us about population connectivity?. Molecular ecology, 19(15), 3038-3051.

Luck, G. W., Daily, G. C., \& Ehrlich, P. R. (2003). Population diversity and ecosystem services. Trends in Ecology \& Evolution, 18(7), 331-336.

Mascher, M., Muehlbauer, G. J., Rokhsar, D. S., Chapman, J., Schmutz, J., Barry, K., ... \& Himmelbach, A. (2013). Anchoring and ordering NGS contig assemblies by population sequencing (POPSEQ). The Plant Journal, 76(4), 718-727.

Maunder, M. N. (2002). The relationship between fishing methods, fisheries management and the estimation of maximum sustainable yield. Fish and Fisheries, 3(4), 251-260.

McKenzie, J.R.; Beentjes, M.P.; Parker, S.; Parsons, D.M.; Armiger, H.; Wilson, O.; Middleton, D.; Langley, A.; Buckthought, D.; Walsh, C.; Bian, R.; Maolagáin, C.Ó.; Stevenson, M.; Sutton, C.; Spong, K.; Rush, N.; Smith, M. (2017). Fishery characterisation and age composition of tarakihi in TAR 1, 2 and 3 for 2013/14 and 2014/15. New Zealand Fisheries Assessment Report 2017/36. 80 p.

McKenzie, M.K. (1961). Fisheries Research in the East Cape area. Fisheries Technical Report, New Zealand Marine Department No 3. 9 p.

McMillan, W.O., Palumbi, S.R., 1997. Rapid rate of control-region evolution in PaciWc ButterXyWshes (Chaetodontidae). J. Mol. Evol. 45, 473-484. 
Methot Jr, R. D., \& Wetzel, C. R. (2013). Stock synthesis: a biological and statistical framework for fish stock assessment and fishery management. Fisheries Research, 142, 86-99.

mfe.govt. (2019). Retrieved from https://www.mfe.govt.nz/marine/kermadec-oceansanctuary on the 23rd of August, 2019.

Miller, K. (1997). Genetic structure of black coral populations in New Zealand's fiords. Marine Ecology Progress Series 161: 123-132.

Miller, K. (1998). Short-distance dispersal of black coral larvae: inference from spatial analysis of colony genotypes. Marine Ecology Progress Series 163: 225-233.

Miller, K.; Mundy, C.; Chadderton, W. (2004). Ecological and genetic evidence of the vulnerability of shallow-water populations of the stylasterid hydrocoral Errina novaezelandiae in New Zealand's fjords. Aquatic Conservation-Marine and Freshwater Ecosystems 14: 75-94.

Miller, M. R., Dunham, J. P., Amores, A., Cresko, W. A., \& Johnson, E. A. (2007). Rapid and cost-effective polymorphism identification and genotyping using restriction site associated DNA (RAD) markers. Genome research, 17(2), 240-248.

Miller, P. A., Fitch, A. J., Gardner, M., Hutson, K. S., \& Mair, G. (2011). Genetic population structure of Yellowtail Kingfish (Seriola lalandi) in temperate Australasian waters inferred from microsatellite markers and mitochondrial DNA. Aquaculture, 319(3-4), 328-336.

Mladenov, P.V.; Allibone, R.M.; Wallis, G.P. (1997). Genetic differentiation in the New Zealand sea urchin Evechinus chloroticus (Echinodermata: Echinoidea). New Zealand Journal of Marine and Freshwater Research 31: 261-269.

Morjan, C. L., \& Rieseberg, L. H. (2004). How species evolve collectively: implications of gene flow and selection for the spread of advantageous alleles. Molecular ecology, 13(6), 1341-1356.

Morrison, M., Jones, E. G., Consalvey, M., \& Berkenbusch, K. (2014). Linking marine fisheries species to biogenic habitats in New Zealand: a review and synthesis of knowledge. Ministry for Primary Industries.

Mullis, K. B. (1994). The polymerase chain reaction (Nobel Lecture). Angewandte Chemie International Edition in English, 33(12), 1209-1213.

Mullon, C., Fréon, P., \& Cury, P. (2005). The dynamics of collapse in world fisheries. Fish and fisheries, 6(2), 111-120.

Nevo, E., Beiles, A., \& Ben-Shlomo, R. (1984). The evolutionary significance of genetic diversity: ecological, demographic and life history correlates. In Evolutionary dynamics of genetic diversity (pp. 13-213). Springer, Berlin, Heidelberg. 
Nielsen, E. E., Cariani, A., Mac Aoidh, E., Maes, G. E., Milano, I., Ogden, R., ... \& Bekkevold, D. (2012). Gene-associated markers provide tools for tackling illegal fishing and false eco-certification. Nature communications, 3, 851.

Nielsen, E. E., HEMMER-HANSEN, J. A. K. O. B., Larsen, P. F., \& Bekkevold, D. (2009). Population genomics of marine fishes: identifying adaptive variation in space and time. Molecular ecology, 18(15), 3128-3150.

Norman, J. (1937). Coast fishes part II. The Patagonia region. Disc. Rep. 16: 1-150.

Olsen, E. M., Heino, M., Lilly, G. R., Morgan, M. J., Brattey, J., Ernande, B., \& Dieckmann, U. (2004). Maturation trends indicative of rapid evolution preceded the collapse of northern cod. Nature, 428(6986), 932.

Openseas (2019). Retrieved from https://openseas.org.nz/fish/tarakihi/ on the $28^{\text {th }}$ of August, 2019.

Orita, M., Iwahana, H., Kanazawa, H., Hayashi, K., \& Sekiya, T. (1989). Detection of polymorphisms of human DNA by gel electrophoresis as single-strand conformation polymorphisms. Proceedings of the National Academy of Sciences, 86(8), 27662770.

Ovenden, J. R. (2013). Crinkles in connectivity: combining genetics and other types of biological data to estimate movement and interbreeding between populations. Marine and Freshwater Research, 64(3), 201-207.

Ovenden, J. R., Lloyd, J., Newman, S. J., Keenan, C. P., \& Slater, L. S. (2002). Spatial genetic subdivision between northern Australian and southeast Asian populations of Pristipomoides multidens: a tropical marine reef fish species. Fisheries Research, 59(1-2), 57-69.

Palsbøll, P. J., Berube, M., \& Allendorf, F. W. (2007). Identification of management units using population genetic data. Trends in ecology \& evolution, 22(1), 11-16.

Pauly, D., Christensen, V., Guénette, S., Pitcher, T. J., Sumaila, U. R., Walters, C. J., ... \& Zeller, D. (2002). Towards sustainability in world fisheries. Nature, 418(6898), 689.

Penrith, M. J. (1967). Ceratioid angler-fishes from South Africa. Journal of Natural History, 1(2), 185-188.

Pereira, S. L. (2000). Mitochondrial genome organization and vertebrate phylogenetics. Genetics and Molecular biology, 23(4), 745-752.

Petit, R. J., \& Excoffier, L. (2009). Gene flow and species delimitation. Trends in Ecology \& evolution, 24(7), 386-393.

Pinsky, M. L., \& Palumbi, S. R. (2014). Meta-analysis reveals lower genetic diversity in overfished populations. Molecular Ecology, 23(1), 29-39. 
Pourkazemi, M., Skibinski, D. F., \& A. Beardmore, J. (1999). Application of mtDNA d-loop region for the study of Russian sturgeon population structure from Iranian coastline of the Caspian Sea. Journal of Applied Ichthyology, 15(4-5), 23-28.

Prakash, S., Lewontin, R. C., \& Hubby, J. L. (1969). A molecular approach to the study of genic heterozygosity in natural populations IV. Patterns of genic variation in central, marginal and isolated populations of Drosophila pseudoobscura. Genetics, 61(4), 841.

Pulliam, H. R. (1988). Sources, sinks, and population regulation. The American Naturalist, 132(5), 652-661.

Quota Management System (QMS). Retrieved from https://www.mpi.govt.nz/law-andpolicy/legal-overviews/fisheries/quota-management-system/ on the $20^{\text {th }}$ of August, 2019.

Reed, D. H., O'Grady, J. J., Brook, B. W., Ballou, J. D., \& Frankham, R. (2003). Estimates of minimum viable population sizes for vertebrates and factors influencing those estimates. Biological Conservation, 113(1), 23-34.

Reef Life Survey. 2019, Image of N. bergi. Retrieved from: https://reeflifesurvey.com/species/nemadactylus-bergi/ on the $26^{\text {th }}$ of August, 2019.

Reisser, C. M., Bell, J. J., \& Gardner, J. P. A. (2014). Correlation between pelagic larval duration and realised dispersal: long-distance genetic connectivity between northern New Zealand and the Kermadec Islands archipelago. Marine biology, 161(2), 297312.

Review of sustainability measures for of 1 October 2018. Retrieved from https://www.mpi.govt.nz/news-and-resources/consultations/review-of-sustainabilitymeasures-for-1-october-2018/ on the $30^{\text {th }}$ of August, 2019.

Richardson, B. J. (1982). Geographical distribution of electrophoretically detected protein variation in Australian commercial fishes. II. Jackass morwong, Cheilodactylus macropterus Bloch \& Schneider. Marine and Freshwater Research, 33(5), 927-931.

RNZ 2018. Retrieved from https://www.rnz.co.nz/national/programmes/afternoons/audio/2018633058/kapiti-smystery-fish on 26th of August, 2019.

Robertson, D. A. (1978). Spawning of tarakihi (Pisces: Cheilodaetylidae) in New Zealand waters. New Zealand journal of marine and freshwater research, 12(3), 277-286.

Ross, P. M., Hogg, I. D., Pilditch, C. A., \& Lundquist, C. J. (2009). Phylogeography of New Zealand's coastal benthos. New Zealand Journal of Marine and Freshwater Research, 43(5), 1009-1027.

Rogers, A. R., \& Harpending, H. (1992). Population growth makes waves in the distribution of pairwise genetic differences. Molecular biology and evolution, 9(3), 552-569. 
Roughgarden, J., Iwasa, Y., \& Baxter, C. (1985). Demographic theory for an open marine population with space-limited recruitment. Ecology, 66(1), 54-67.

Rozas, J., Ferrer-Mata, A., Sánchez-DelBarrio, J.C., Guirao-Rico, S., Librado, P., RamosOnsins, S.E., Sánchez-Gracia, A. (2017). DnaSP 6: DNA Sequence Polymorphism Analysis of Large Datasets. Mol. Biol. Evol. 34: 3299-3302. DOI:

$10.1093 / \mathrm{molbev} / \mathrm{msx} 248$

Sandoval-Castillo, J., Robinson, N. A., Hart, A. M., Strain, L. W., \& Beheregaray, L. B. (2018). Seascape genomics reveals adaptive divergence in a connected and commercially important mollusc, the greenlip abalone (Haliotis laevigata), along a longitudinal environmental gradient. Molecular ecology, 27(7), 1603-1620.

Sanger, F., Nicklen, S., \& Coulson, A. R. (1977). DNA sequencing with chain-terminating inhibitors. Proceedings of the national academy of sciences, 74(12), 5463-5467.

Satoh, T. P., Miya, M., Mabuchi, K., \& Nishida, M. (2016). Structure and variation of the mitochondrial genome of fishes. Bmc Genomics, 17(1), 719.

Scheffer, M., Carpenter, S., \& de Young, B. (2005). Cascading effects of overfishing marine systems. Trends in Ecology \& Evolution, 20(11), 579-581.

Seafood New Zealand. Retrieved from https://www.seafoodnewzealand.org.nz/industry/keyfacts/ on the $20^{\text {th }}$ of August, 2019.

Selkoe, K. A., \& Toonen, R. J. (2006). Microsatellites for ecologists: a practical guide to using and evaluating microsatellite markers. Ecology letters, 9(5), 615-629.

Selkoe, K. A., \& Toonen, R. J. (2011). Marine connectivity: a new look at pelagic larval duration and genetic metrics of dispersal. Marine Ecology Progress Series, 436, 291305.

Selkoe, K. A., Aloia, C. C., Crandall, E. D., Iacchei, M., Liggins, L., Puritz, J. B., ... \& Toonen, R. J. (2016). A decade of seascape genetics: contributions to basic and applied marine connectivity. Marine Ecology Progress Series, 554, 1-19.

Shanks, A. L. (2009). Pelagic larval duration and dispersal distance revisited. The biological bulletin, 216(3), 373-385.

Shanks, A. L. (2009). Pelagic larval duration and dispersal distance revisited. The biological bulletin, 216(3), 373-385.

Shedlock, A.M., Parker, J.D., Crispin, D.A., Pietsch, T.W., Burmer, G.C., 1992. Evolution of the salmonid mitochondrial control region. Mol. Phylogenet. Evol. 1, 179-192.

Shen, K. N., Yen, T. C., Chen, C. H., Li, H. Y., Chen, P. L., \& Hsiao, C. D. (2016). Next generation sequencing yields the complete mitochondrial genome of the flathead mullet, Mugil cephalus cryptic species NWP2 (Teleostei: Mugilidae). Mitochondrial DNA Part A, 27(3), 1758-1759. 
Silva, C. N., \& Gardner, J. P. (2015). Identifying environmental factors associated with the genetic structure of the New Zealand scallop: linking seascape genetics and ecophysiological tolerance. ICES Journal of marine Science, 73(7), 1925-1934.

Slatkin, M. (1987). Gene flow and the geographic structure of natural populations. Science, 236(4803), 787-792.

Smith, D. C., Robertson, S. G., Fenton, G. E., \& Short, S. A. (1995). Age determination and growth of orange roughy (Hoplostethus atlanticus): a comparison of annulus counts with radiometric ageing. Canadian Journal of Fisheries and Aquatic Sciences, 52(2), 391-401.

Smith, H. M. (2012). CHARACTERISATION OF THE MITOCHONDRIAL GENOME AND THE PHYLOGEOGRAPHIC STRUCTURE OF BLUE COD (PARAPERCIS COLIAS). 89.

Smith, P. J. (1986). Genetic similarity between samples of the orange roughyHoplostethus atlanticus from the Tasman Sea, South-west Pacific Ocean and North-east Atlantic Ocean. Marine biology, 91(2), 173-180.

Smith, P. J., \& Benson, P. G. (1997). Genetic diversity in orange roughy from the east of New Zealand. Fisheries research, 31(3), 197-213.

Smith, P. J., \& Paulin, C. D. (2003). Genetic and morphological evidence for a single species of pink ling (Genypterus blacodes) in New Zealand waters. New Zealand Journal of Marine and Freshwater Research, 37(1), 183-194.

Smith, P. J., Benson, P. G., \& McVeagh, S. M. (1997). A comparison of three genetic methods used for stock discrimination of orange roughy, Hoplostethus atlanticus: allozymes, mitochondriat DNA, and random amplified polymorphic DNA. FISHERY BULLETIN-NATIONAL OCEANIC AND ATMOSPHERIC ADMINISTRATION, 95, 800-811.

Smith, P. J., Roberts, C. D., McVeagh, S. M., \& Benson, P. G. (1996). Genetic evidence for two species of tarakihi (Teleostei: Cheilodactylidae: Nemadactylus) in New Zealand waters. New Zealand Journal of Marine and Freshwater Research, 30(2), 209-220.

Smith, P. J., Robertson, S. G., Horn, P. L., Bull, B., Anderson, O. F., Stanton, B. R., \& Oke, C. S. (2002). Multiple techniques for determining stock relationships between orange roughy, Hoplostethus atlanticus, fisheries in the eastern Tasman Sea. Fisheries Research, 58(2), 119-140.

Smith, P. J., Steinke, D., McMillan, P., McVeagh, S. M., Stewart, A. L., \& Struthers, C. D. (2008). DNA database for commercial marine fish. New Zealand Aquatic Environment and Biodiversity Report, 22, 1-62.

Stanton, B. R. (1986). Winter oceanographic observations in some New Zealand fiords. New Zealand Journal of Marine and Freshwater Research, 20(2), 299-314. 
Stephens, S. A., Broekhuizen, N., Macdiarmid, A. B., Lundquist, C. J., McLeod, L., \& Haskew, R. (2006). Modelling transport of larval New Zealand abalone (Haliotis iris) along an open coast. Marine and Freshwater Research, 57(5), 519-532.

Stevens, C. L., O’Callaghan, J. M., Chiswell, S. M., \& Hadfield, M. G. (2019). Physical oceanography of New Zealand/Aotearoa shelf seas-a review. New Zealand Journal of Marine and Freshwater Research, 1-40.

Stevens, M.I.; Hogg, I.D. (2004). Population genetic structure of New Zealand's endemic corophiid amphipods: evidence for allopatric speciation. Biological Journal of the Linnean Society 81: 119-133.

Stevens, P.M. (1991). A genetic analysis of the pea crabs (Decapoda: Pinnotheridae) of New Zealand: II. Patterns and intensity of spatial population structure in Pinnotheres atrinicola. Marine Biology 108: 403-410.

Stock Status. Retrieved from https://www.fisheries.govt.nz/growing-andharvesting/fisheries/fisheries-management/fish-stock-status/ on the $20^{\text {th }}$ of August, 2019.

Strüder-Kypke, M. C., \& Lynn, D. H. (2010). Comparative analysis of the mitochondrial cytochrome c oxidase subunit I (COI) gene in ciliates (Alveolata, Ciliophora) and evaluation of its suitability as a biodiversity marker. Systematics and Biodiversity, 8(1), 131-148.

Suchard MA, Lemey P, Baele G, Ayres DL, Drummond AJ \& Rambaut A (2018) Bayesian phylogenetic and phylodynamic data integration using BEAST 1.10 Virus Evolution 4, vey016. DOI:10.1093/ve/vey016

Sunday, J. M., Bates, A. E., \& Dulvy, N. K. (2012). Thermal tolerance and the global redistribution of animals. Nature Climate Change, 2(9), 686.

Takeshima, H., Hatanaka, A., Yamada, S. I., Yamazaki, Y., Kimura, I., \& Nishida, M. (2011). Low genetic differentiation between two geographically separated populations of demersal gadiform fishes in the Southern Hemisphere. Genes \& genetic systems, 86(5), 339-349.

Thomas, L., \& Bell, J. J. (2013). Testing the consistency of connectivity patterns for a widely dispersing marine species. Heredity, 111(4), 345.

Thurstan, R. H., Brockington, S., \& Roberts, C. M. (2010). The effects of 118 years of industrial fishing on UK bottom trawl fisheries. Nature communications, 1, 15.

Tajima, F. (1989). Statistical method for testing the neutral mutation hypothesis by DNA polymorphism. Genetics, 123(3), 585-595.

Tong, L. J., \& Vooren, C. M. (1972). The biology of the New Zealand tarakihi, Cheilodactylus macropterus (Bloch and Schneider). New Zealand Ministry of Agriculture and Fisheries. 
Traill, L. W., Bradshaw, C. J., \& Brook, B. W. (2007). Minimum viable population size: a meta-analysis of 30 years of published estimates. Biological conservation, 139(1-2), 159-166.

Treaty of Waitangi Settlement Act. Retrieved from http://www.legislation.govt.nz/act/public/1992/0121/latest/DLM281433.html on the $20^{\text {th }}$ of August, 2019.

Two Oceans Aquarium. 2019, Image of Nemadactylus monodactylus. Retrieved from: https://www.aquarium.co.za/species/entry/tristan_five_fingers on the 26th of August, 2019.

Tzeng, C. S., Hui, C. F., Shen, S. C., \& Huang, P. C. (1992). The complete nucleotide sequence of the Crossostoma lacustre mitochondrial genome: conservation and variations among vertebrates. Nucleic Acids Research, 20(18), 4853-4858.

Varela, A. I., Ritchie, P. A., \& Smith, P. J. (2012). Low levels of global genetic differentiation and population expansion in the deep-sea teleost Hoplostethus atlanticus revealed by mitochondrial DNA sequences. Marine biology, 159(5), 10491060 .

Varela, A. I., Ritchie, P. A., \& Smith, P. J. (2013). Global genetic population structure in the commercially exploited deep-sea teleost orange roughy (Hoplostethus atlanticus) based on microsatellite DNA analyses. Fisheries research, 140, 83-90.

Veale, A. (2007). Phylogeography of two intertidal benthic marine invertebrates around New Zealand: the waratah anemone (Actinia tenebrosa) and the snakeskin chiton (Sypharochiton pelliserpentis). MSc University of Auckland, Auckland, 147 p.

Venerus, L. A., \& Cedrola, P. V. (2017). Review of marine recreational fisheries regulations in Argentina. Marine Policy, 81, 202-210.

Vision Oceanica. 2019, Image of $N$. gayi. Retrieved from: http://www.visionoceanica.com/gleria/nemadactylus-gayi.html on the $26^{\text {th }}$ of August, 2019.

Vooren, C. M. (1972). Postlarvae and juveniles of the tarakihi (Teleostei: Cheilodactylidae) in New Zealand. New Zealand Journal of Marine and Freshwater Research, 6(4), 602-618.

Vooren, C. M. (1975). Nursery grounds of tarakihi (Teleostei: Cheilodactylidae) around New Zealand. New Zealand journal of marine and freshwater research, 9(2), 121-158.

Vos, P., Hogers, R., Bleeker, M., Reijans, M., Lee, T. V. D., Hornes, M., ... \& Zabeau, M. (1995). AFLP: a new technique for DNA fingerprinting. Nucleic acids research, 23(21), 4407-4414.

Vrijenhoek, R. C. (1997). Gene flow and genetic diversity in naturally fragmented metapopulations of deep-sea hydrothermal vent animals. Journal of Heredity, 88(4), 285-293. 
Vrooman, A. M. (1964). Serologically differentiated subpopulations of the Pacific sardine, Sardinops caerulea. Journal of the Fisheries Board of Canada, 21(4), 691-701.

Waples, R. S., \& Gaggiotti, O. (2006). INVITED REVIEW: What is a population? An empirical evaluation of some genetic methods for identifying the number of gene pools and their degree of connectivity. Molecular ecology, 15(6), 1419-1439.

Ward, R. D. (2000). Genetics in fisheries management. Hydrobiologia, 420(1), 191-201.

Ward, R. D., Hanner, R., \& Hebert, P. D. (2009). The campaign to DNA barcode all fishes, FISH-BOL. Journal of fish biology, 74(2), 329-356.

Waters, J.M.; Roy, M.S. (2003). Marine biogeography of southern Australia: phylogeographical structure in a temperate sea-star. Journal of Biogeography 30: 1787-1796.

Watson, J. R., Kendall, B. E., Siegel, D. A., \& Mitarai, S. (2012). Changing seascapes, stochastic connectivity, and marine metapopulation dynamics. The American Naturalist, 180(1), 99-112.

Watterson, G. A (1975). On the number of segregation sites. Theor. Popul. Biol. 7: 256-276.

Willi, Y., Fracassetti, M., Zoller, S., \& Van Buskirk, J. (2018). Accumulation of mutational load at the edges of a species range. Molecular biology and evolution, 35(4), 781791.

Wolff, E. W., Fischer, H., Fundel, F., Ruth, U., Twarloh, B., Littot, G. C., ... \& Hansson, M. (2006). Southern Ocean sea-ice extent, productivity and iron flux over the past eight glacial cycles. Nature, 440(7083), 491.

Wright, S. (1943). Isolation by distance. Genetics, 28(2), 114.

Wright, S. (1949). The genetical structure of populations. Annals of eugenics, 15(1), 323-354.

Xiao, Y., Zhang, Y., Gao, T., Yanagimoto, T., Yabe, M., \& Sakurai, Y. (2009). Genetic diversity in the mtDNA control region and population structure in the small yellow croaker Larimichthys polyactis. Environmental biology of fishes, 85(4), 303-314.

Xinhong, G. U. O., Shaojun, L. I. U., \& Qiao, L. I. U. (2004). New progresses on mitochondrial DNA in fish. Acta Genetica Sinica, 31(9), 983-1000.

Zeng, C., Rowden, A. A., Clark, M. R., \& Gardner, J. P. (2017). Population genetic structure and connectivity of deep-sea stony corals (Order Scleractinia) in the New Zealand region: Implications for the conservation and management of vulnerable marine ecosystems. Evolutionary applications, 10(10), 1040-1054.

Zhu, D., Jamieson, B. G., Hugall, A., \& Moritz, C. (1994). Sequence evolution and phylogenetic signal in control-region and cytochrome $\mathrm{b}$ sequences of rainbow fishes (Melanotaeniidae). Molecular Biology and Evolution, 11(4), 672-683. 
Appendix A: List of samples and accession numbers used to re-construct the Nemadactylus phylogeny.

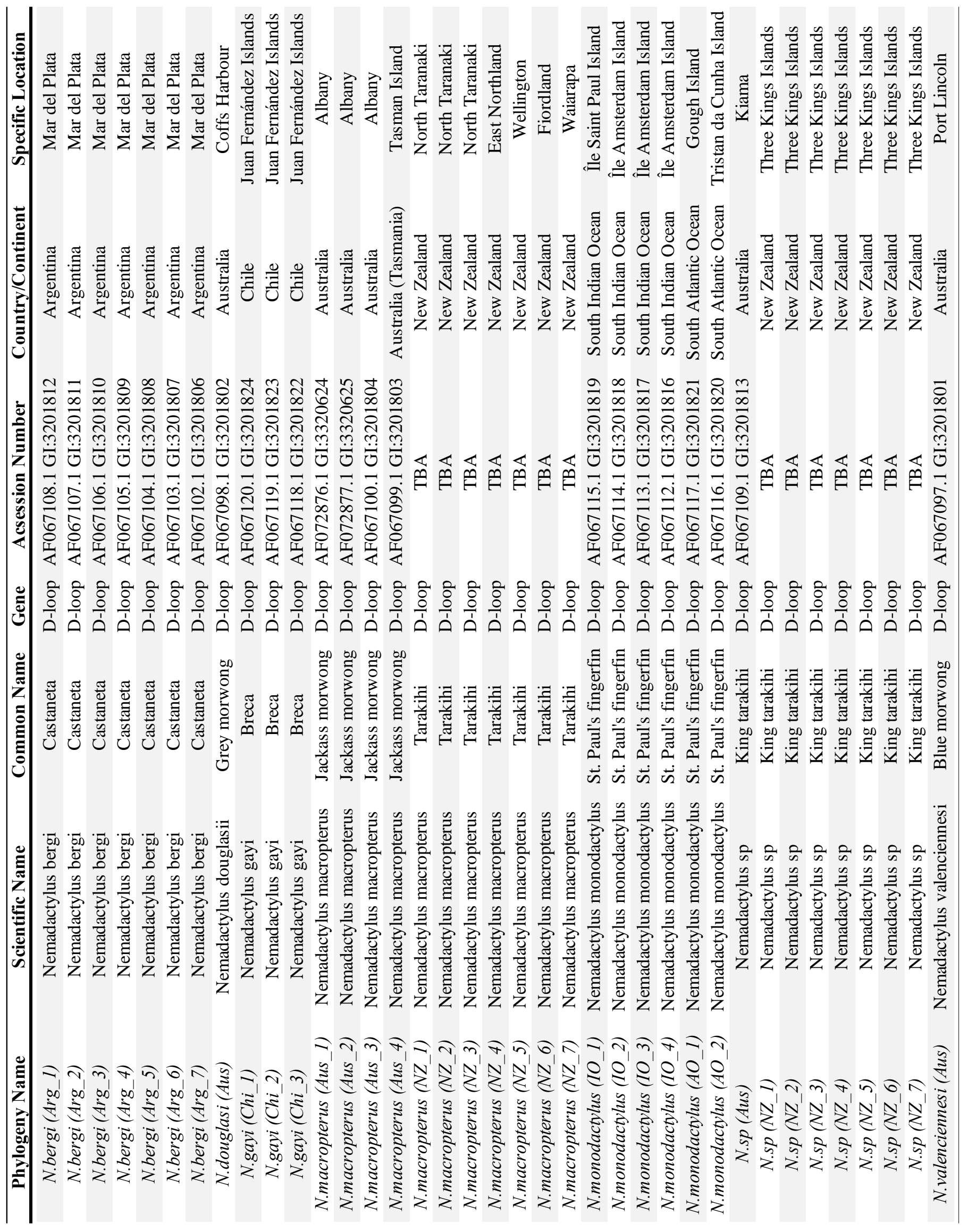




\section{Appendix B: Nemadactylus macropterus mitochondrial genome.}

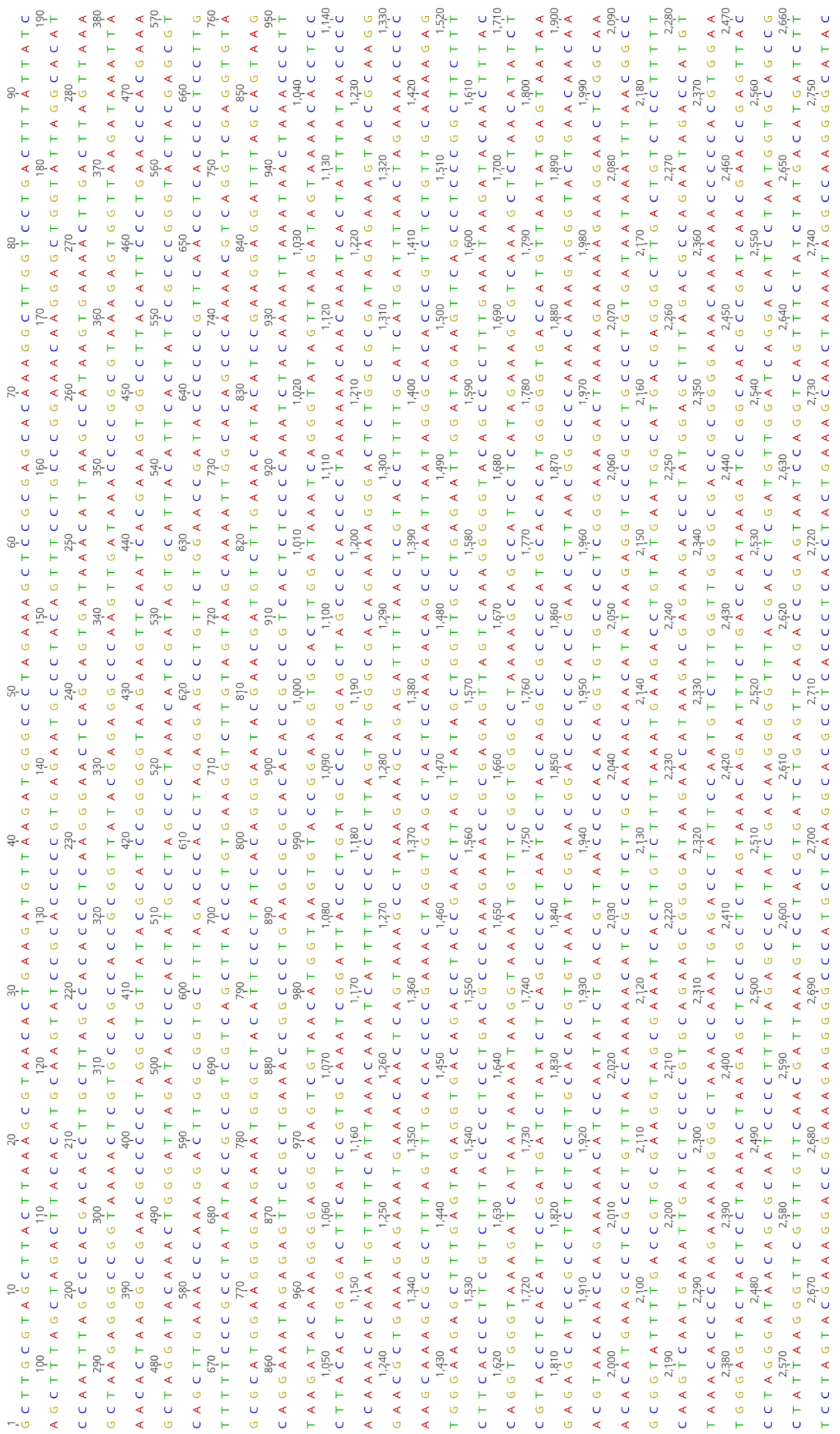




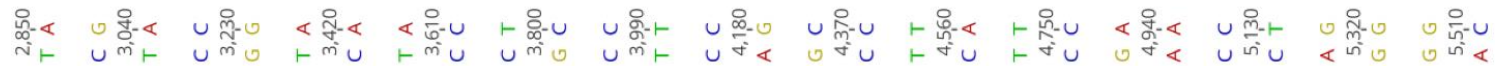

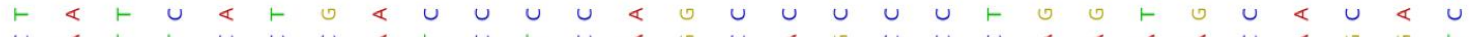

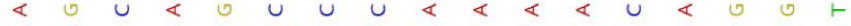

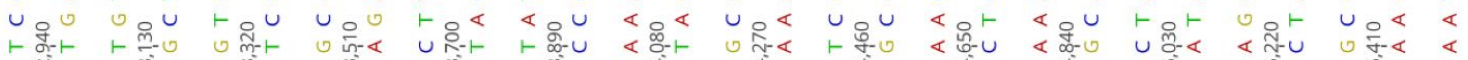
Unt

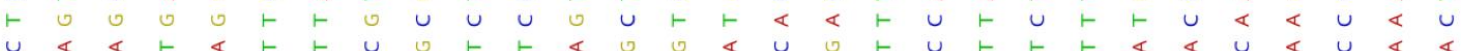

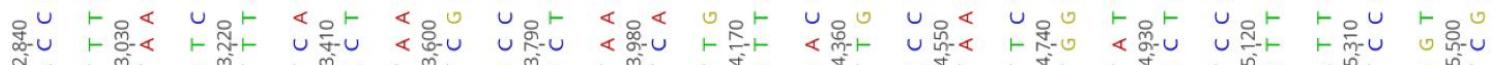

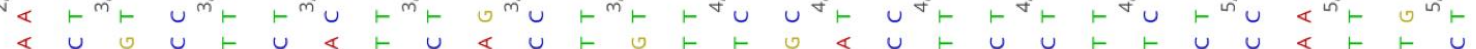

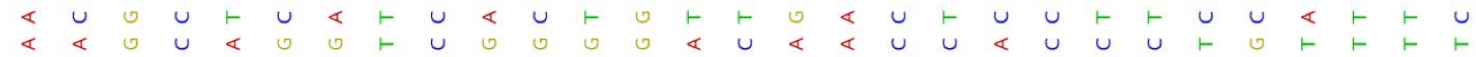

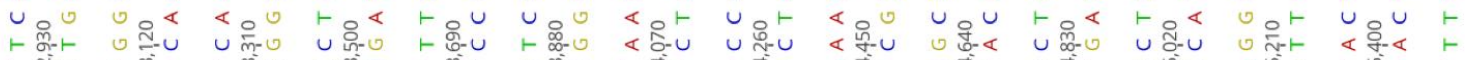
$\vdash$ Nu

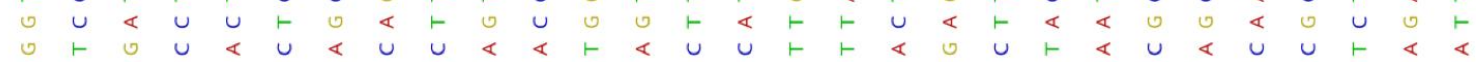

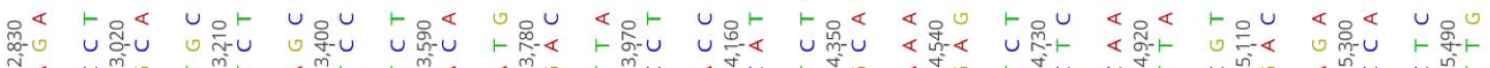

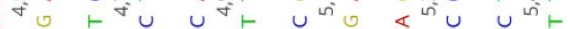
u u u

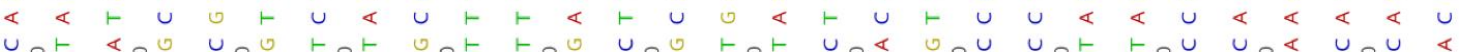

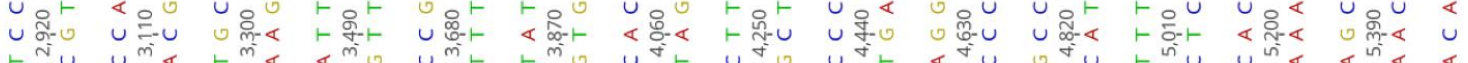

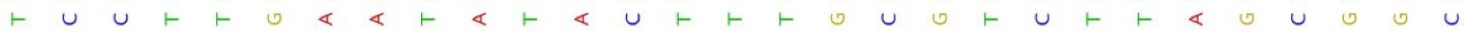

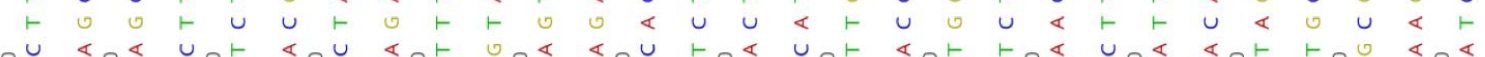

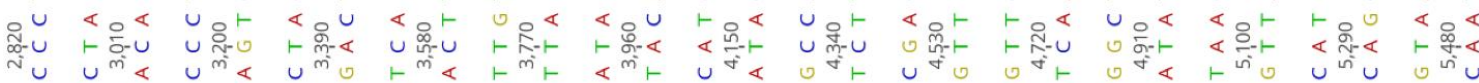

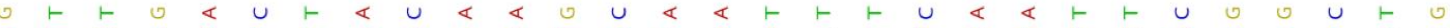

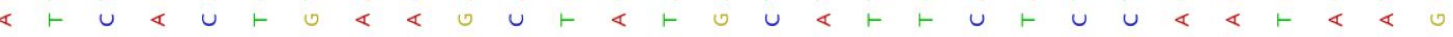

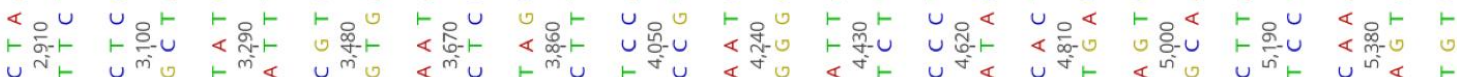

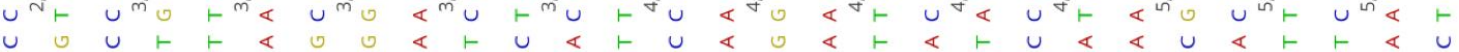

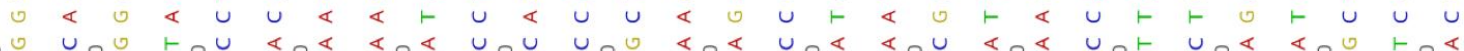

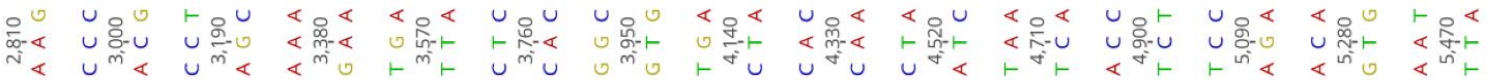

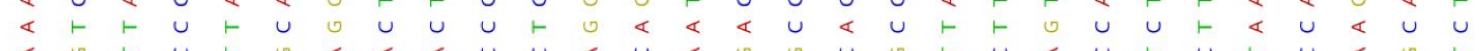

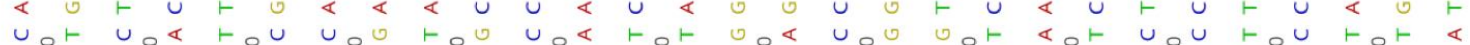

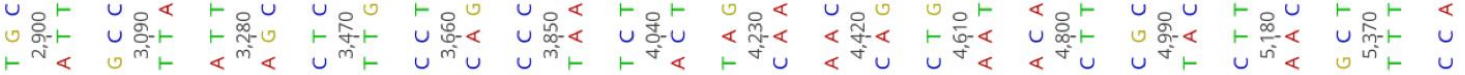

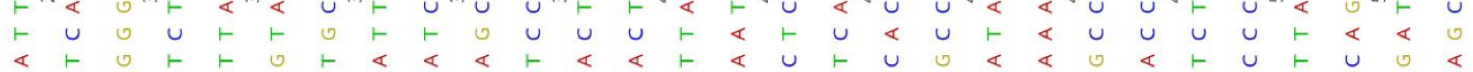

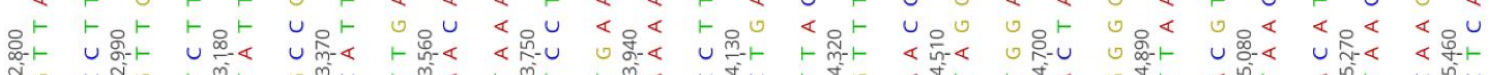

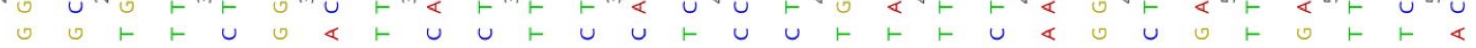

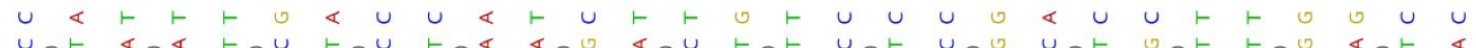

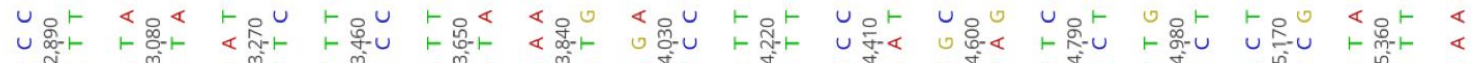

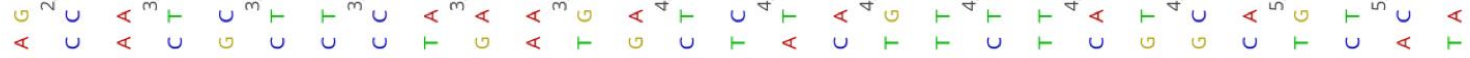

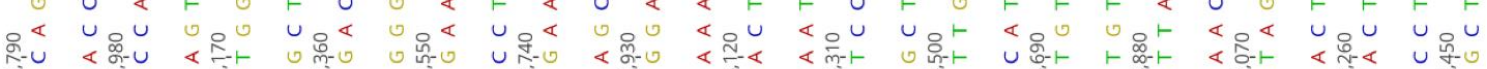

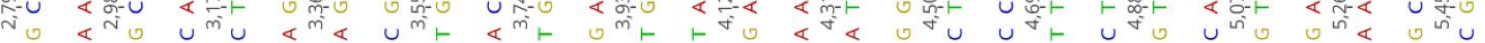

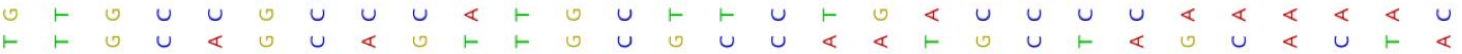

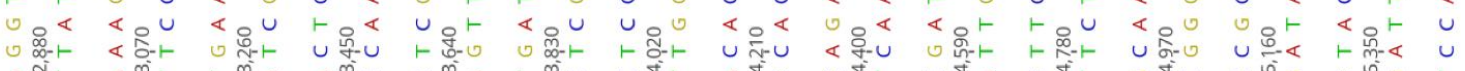

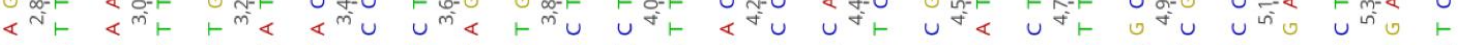

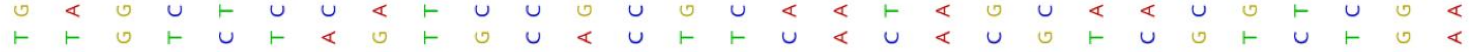

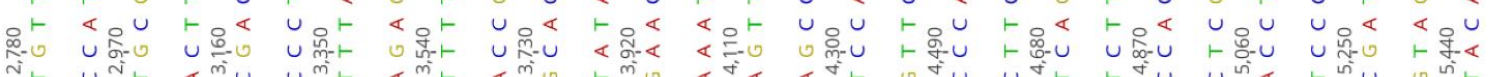

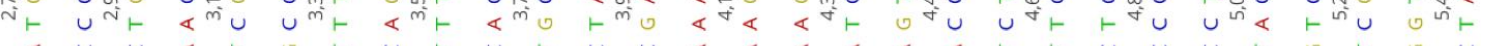

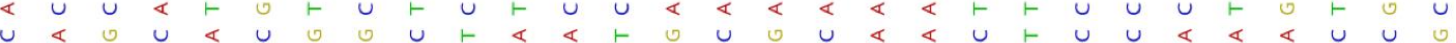

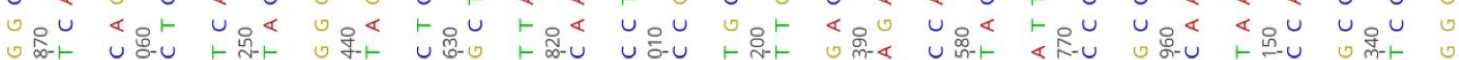

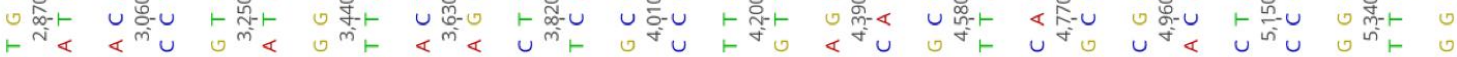

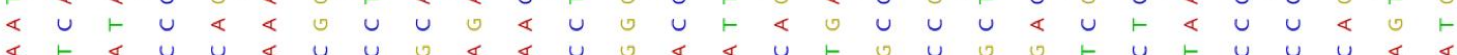

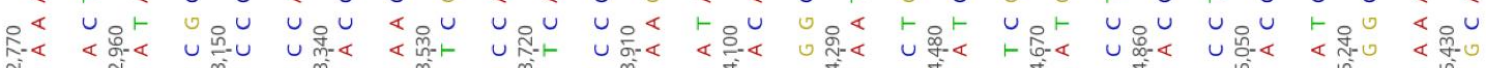

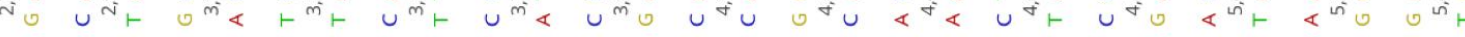

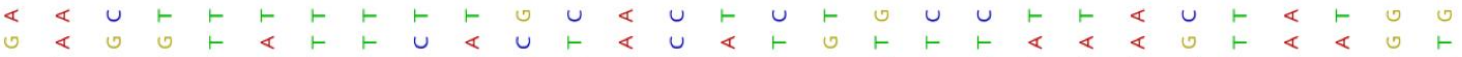

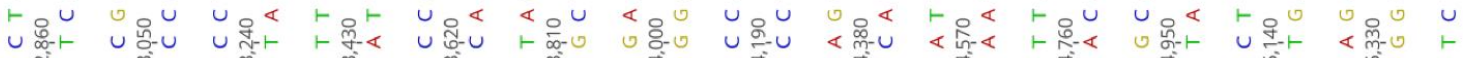
$u$ in

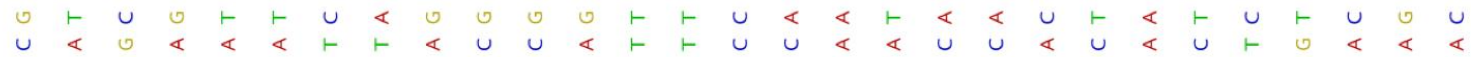
管

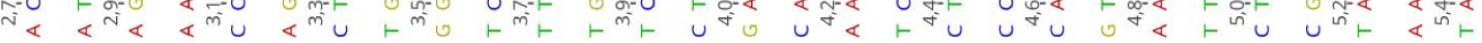

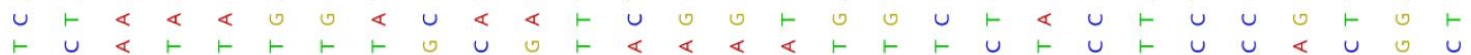

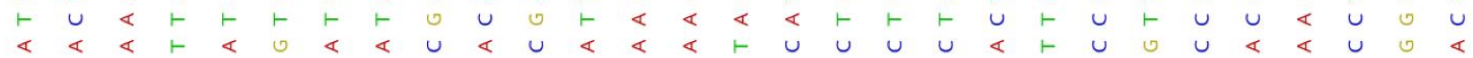




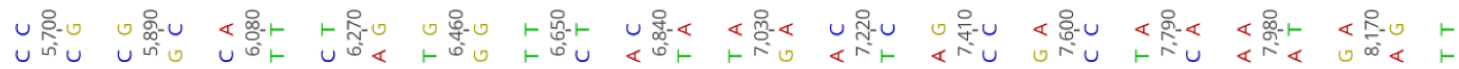

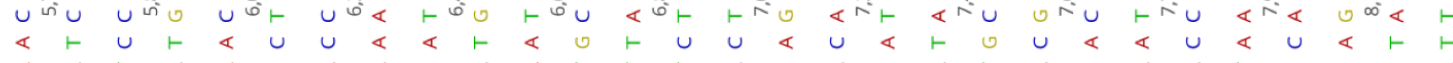

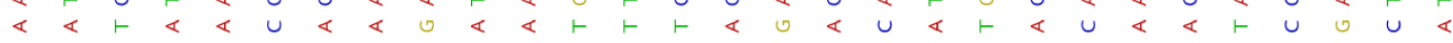

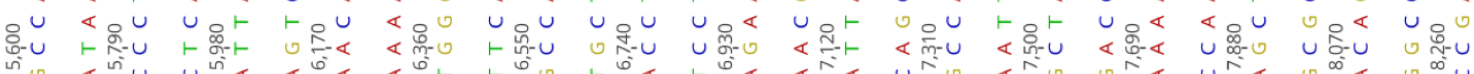

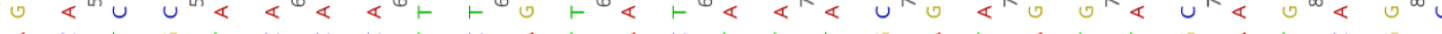

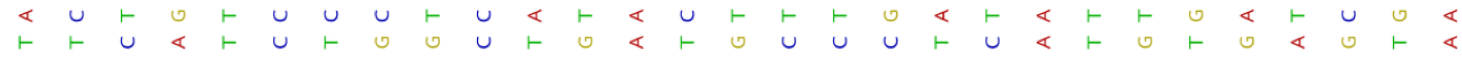

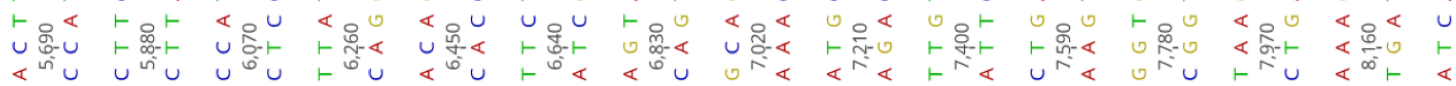

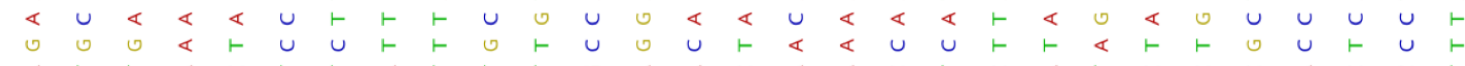

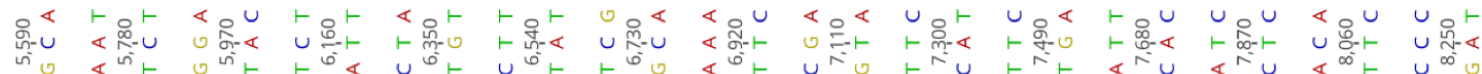

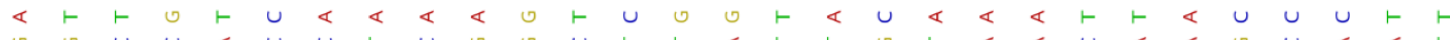

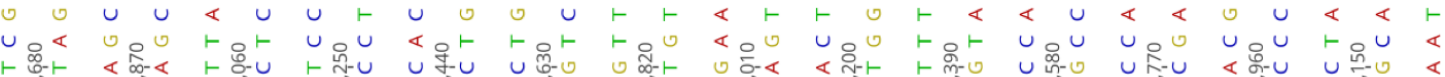

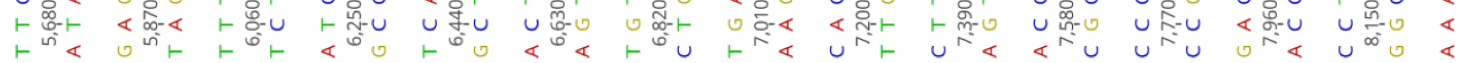

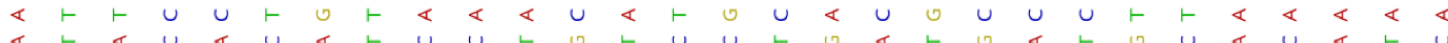

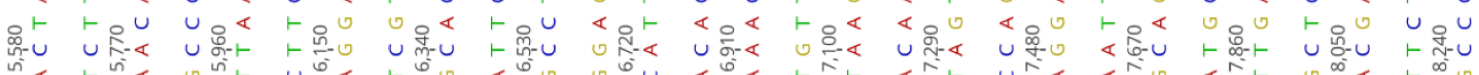

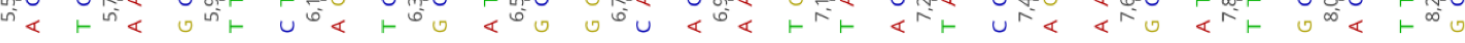

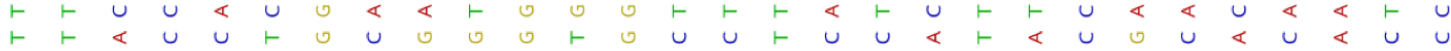

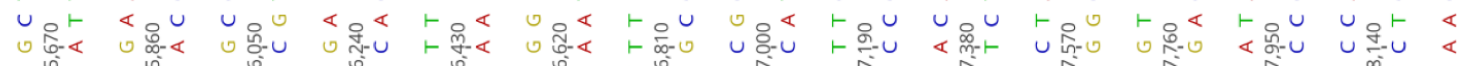

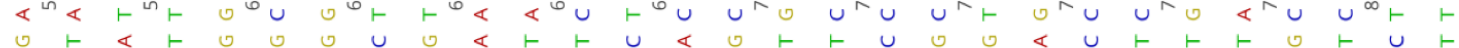

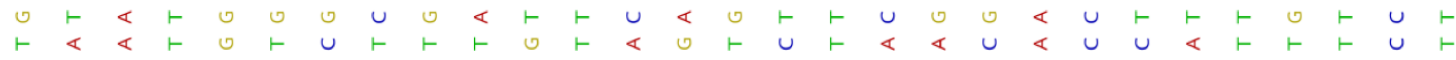

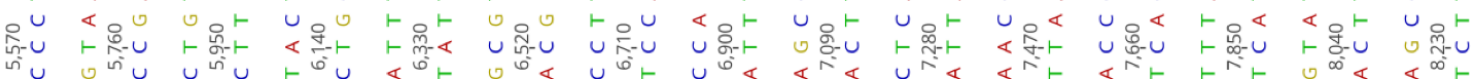

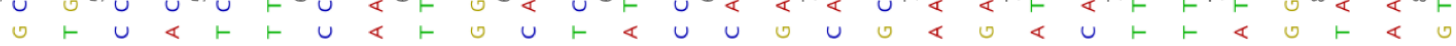

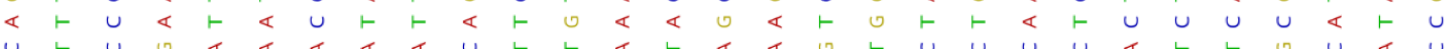

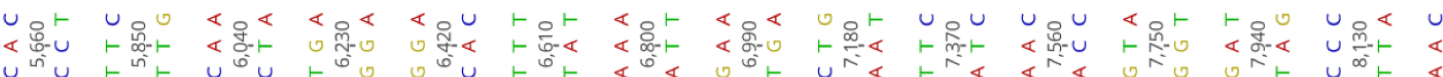

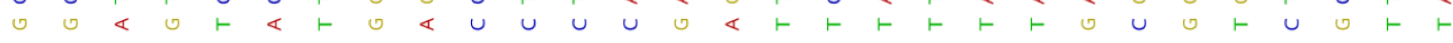

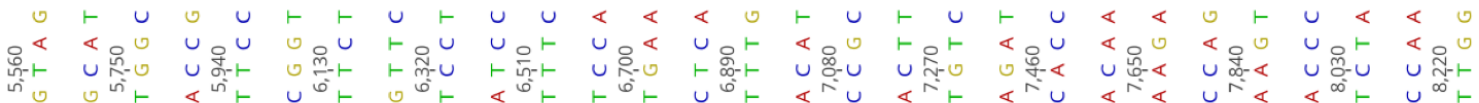

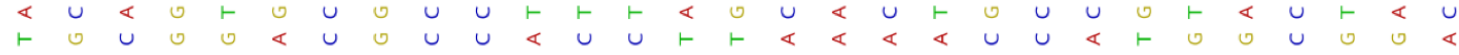

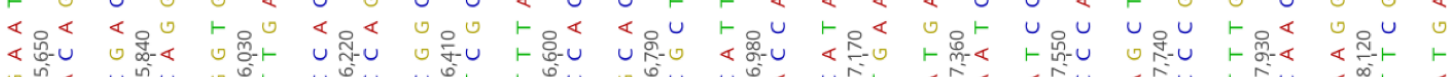
0 ind $\begin{array}{lll}0 \\ 0\end{array}$

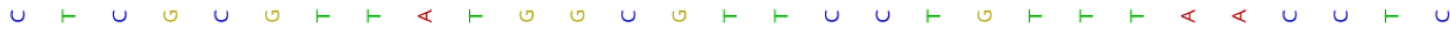

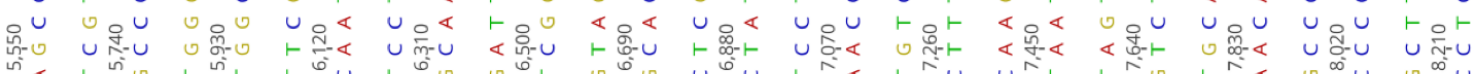

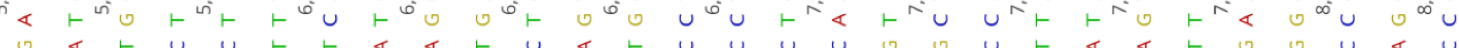

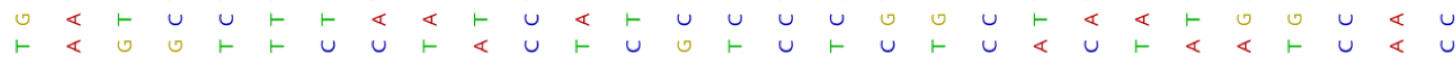

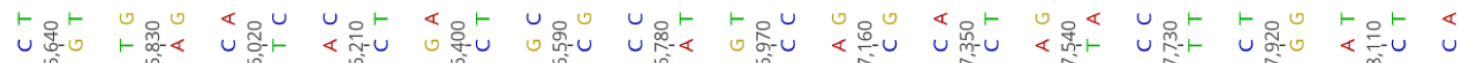

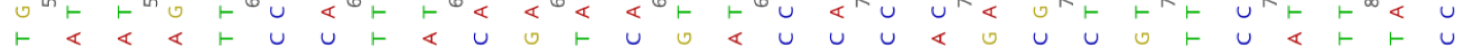

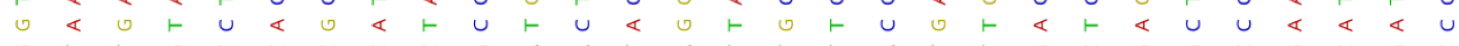

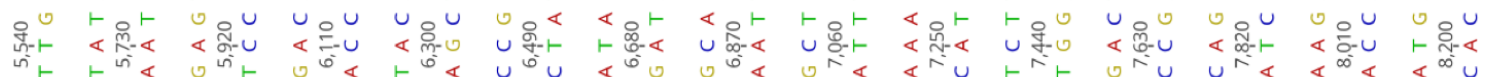

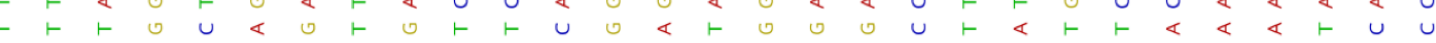

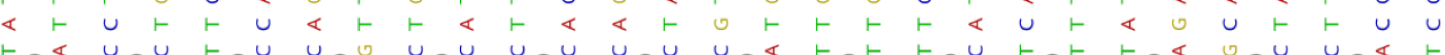

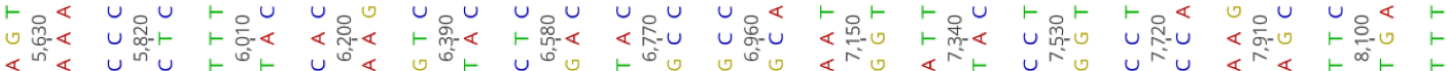
$-u \in u \& \& \vdash 0$ u

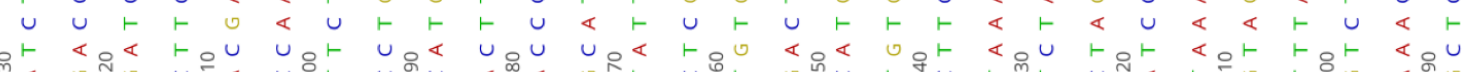

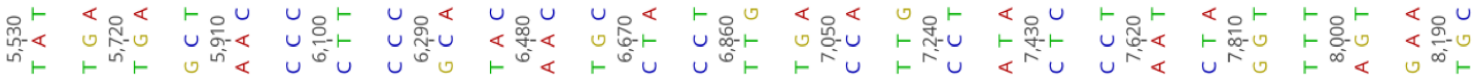

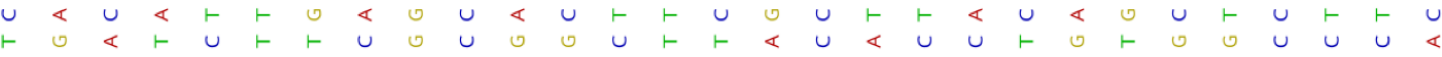

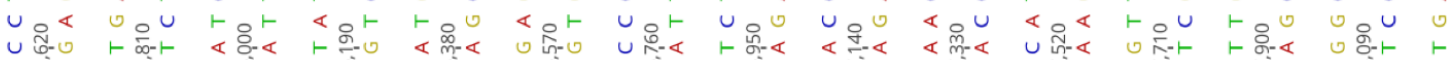

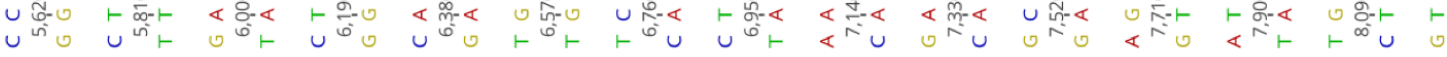

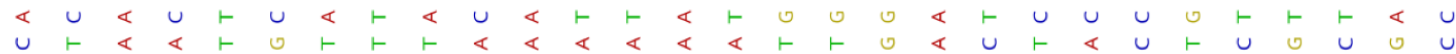

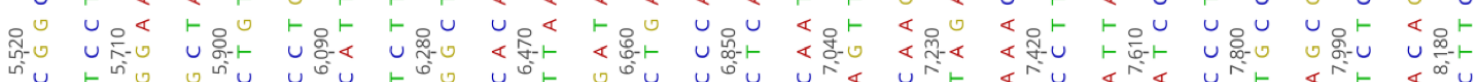

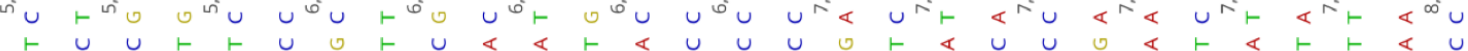

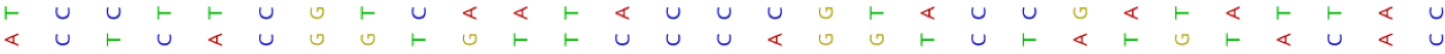

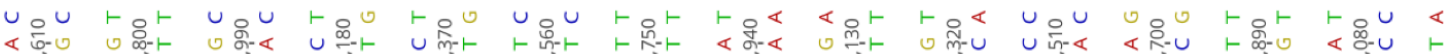
un on un un u

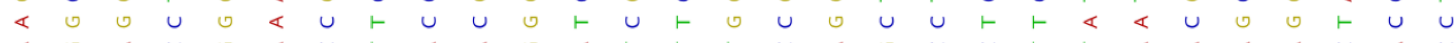

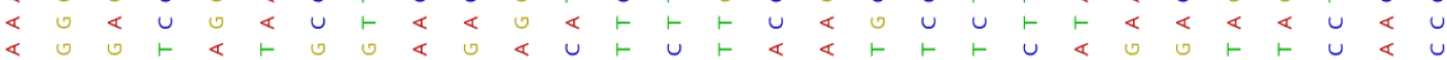




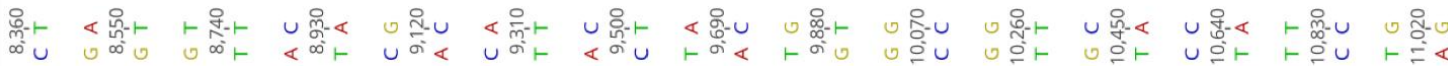
$\begin{gathered}0 \\ 0\end{gathered}<\begin{aligned} & 0 \\ & 0\end{aligned}$

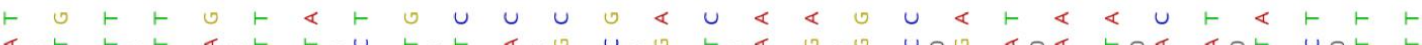

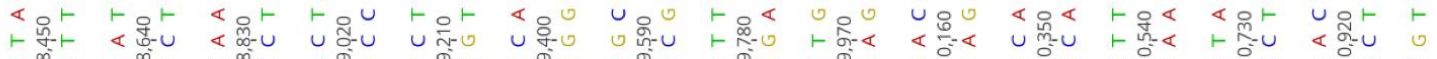

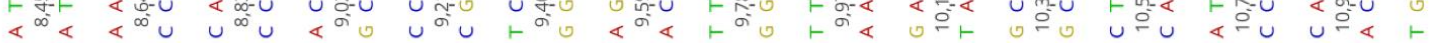

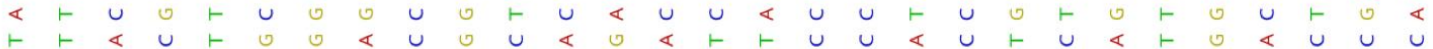

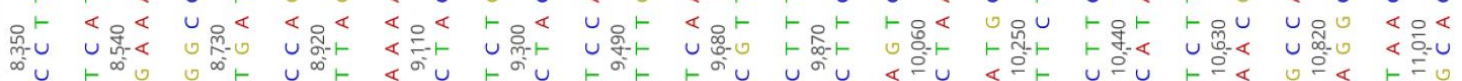

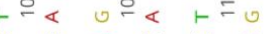
$\varangle \vdash \vdash \& \& u$ u u $<u \in u$ u

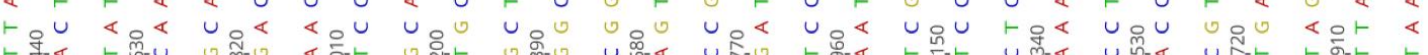

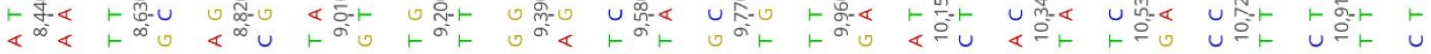

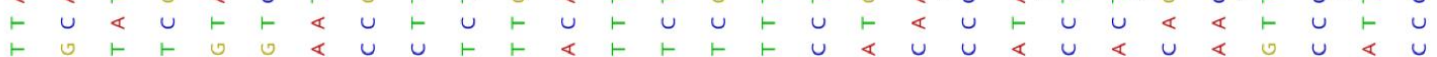

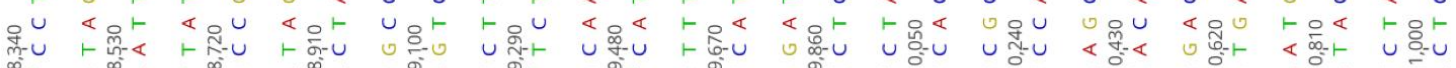

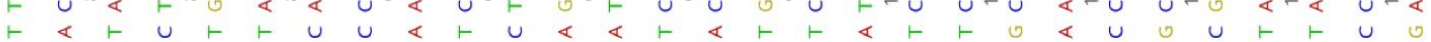

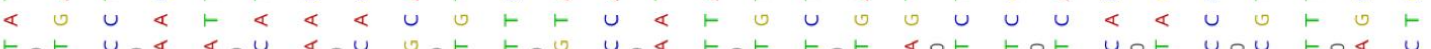

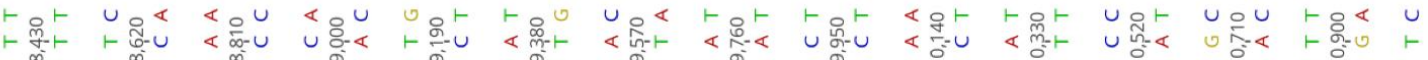
u

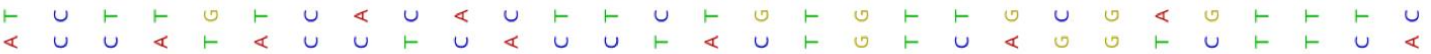

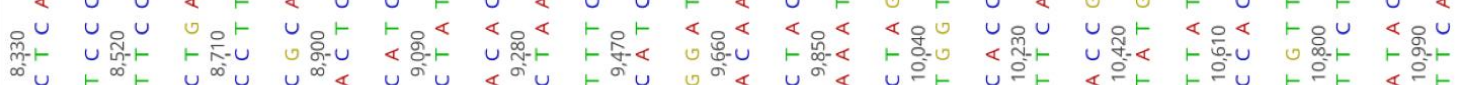
$u$ b u u

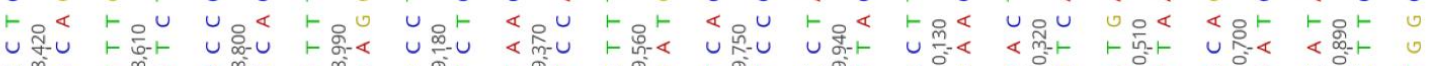

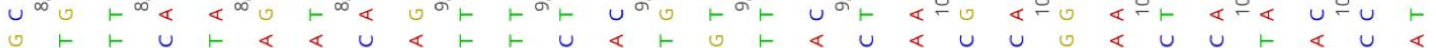

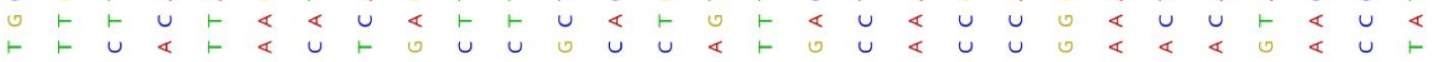

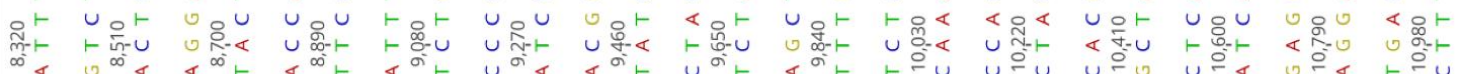
\& u u u $\vdash \& u$ u

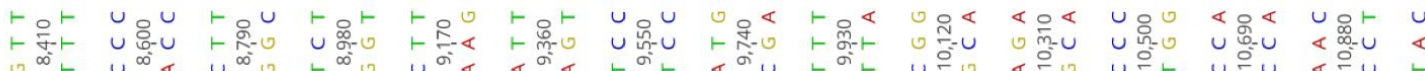

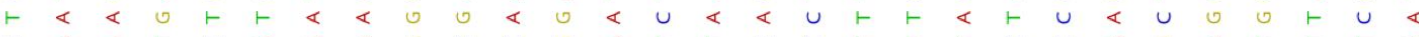

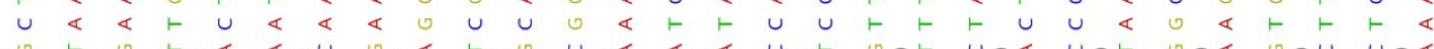

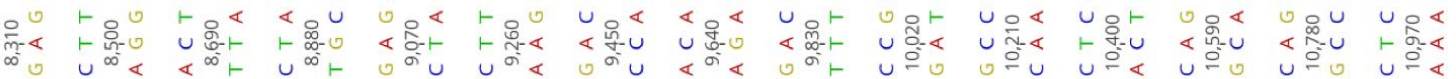

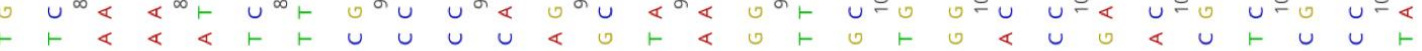

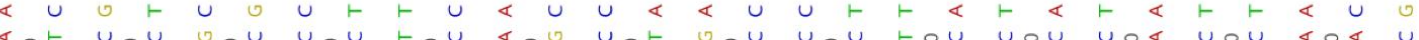

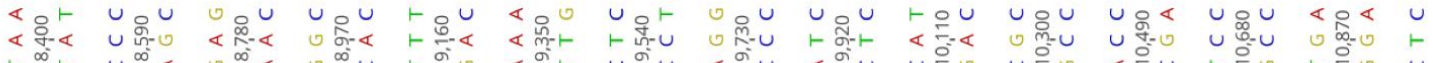

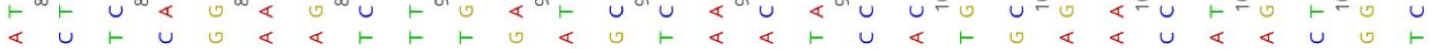

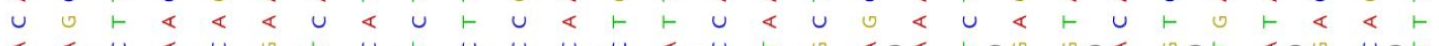

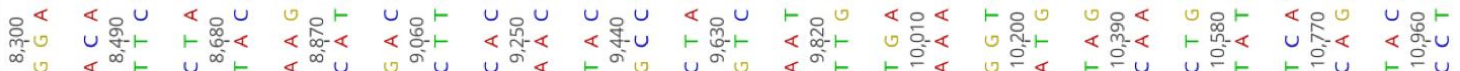
0
0

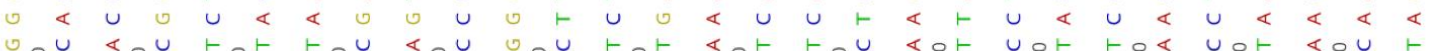

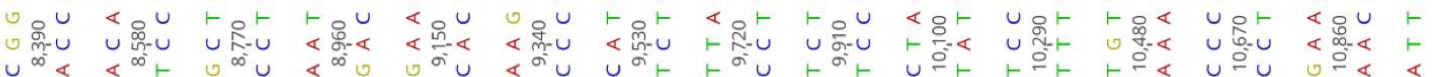
u u v c e \& \& u u u

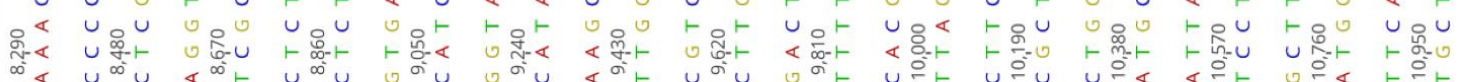

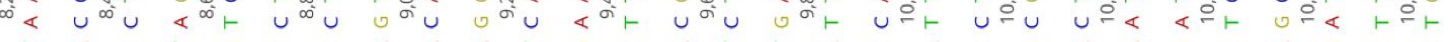

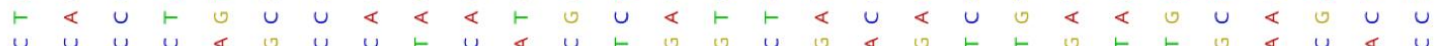

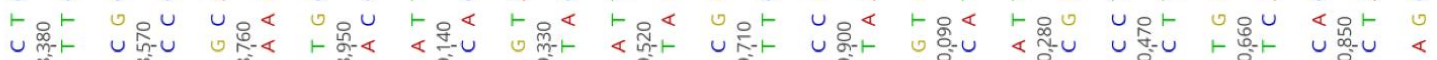

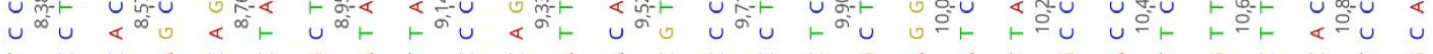

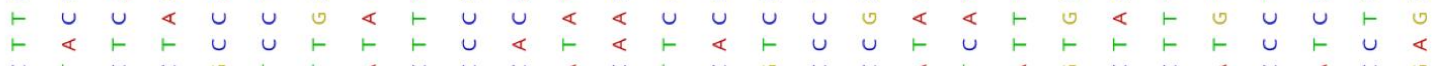

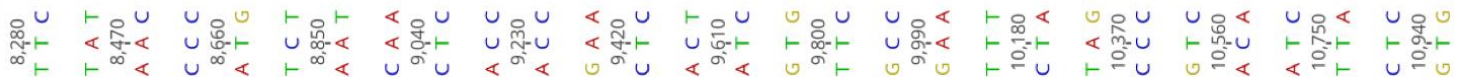

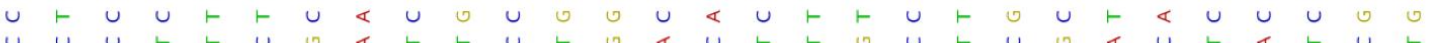

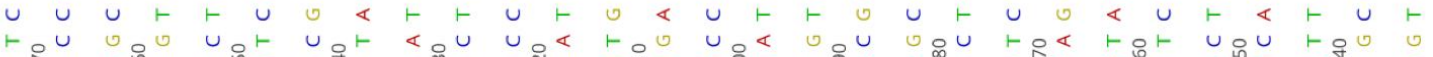

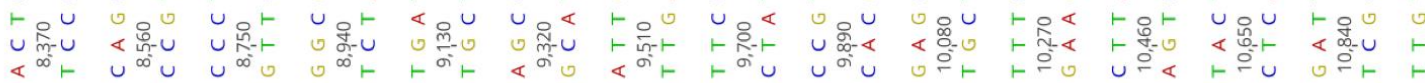

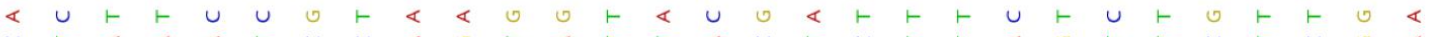

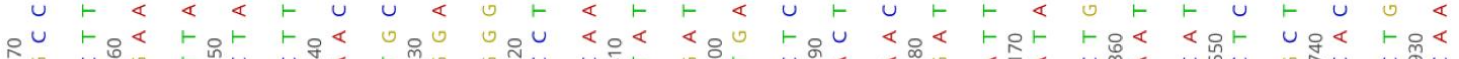

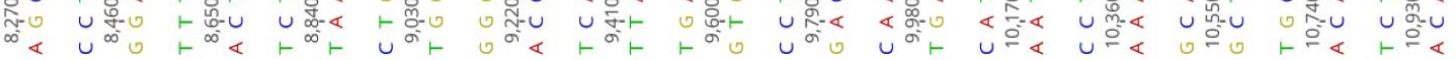
$\vdash 0 u \& b u$

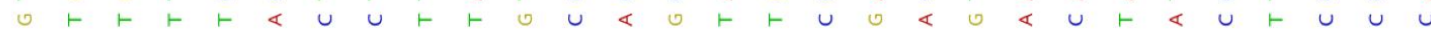




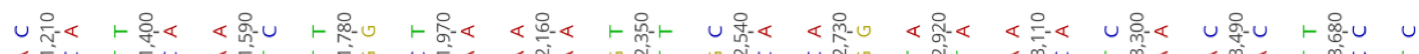

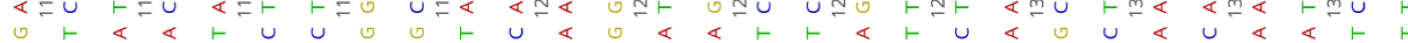

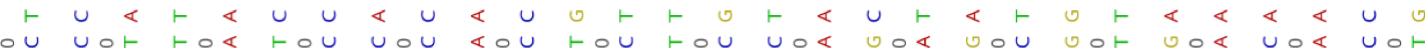

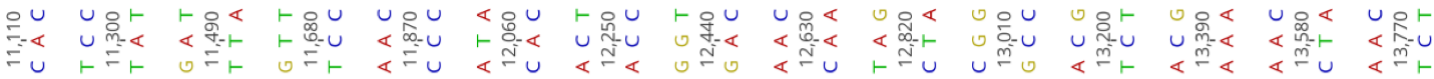

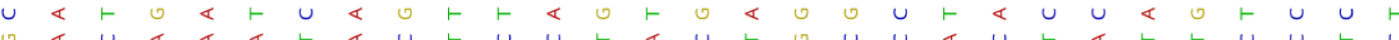

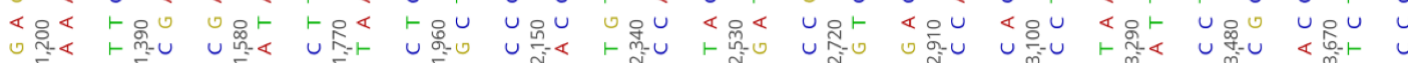

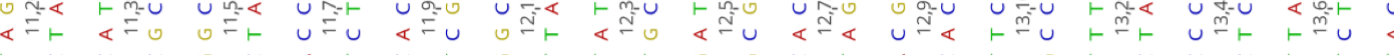

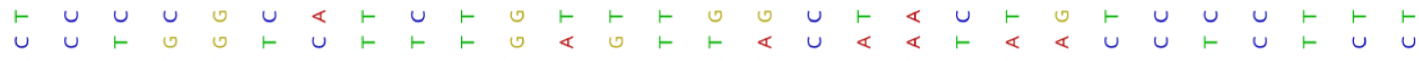

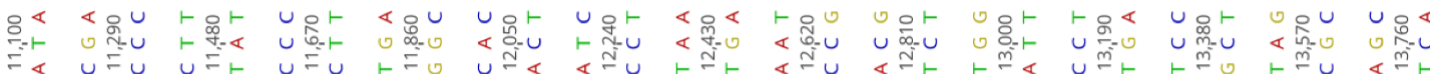

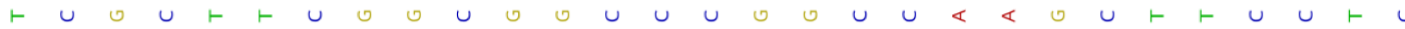

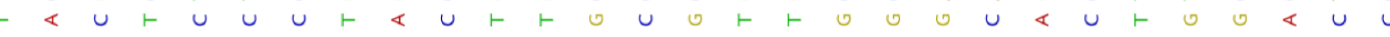

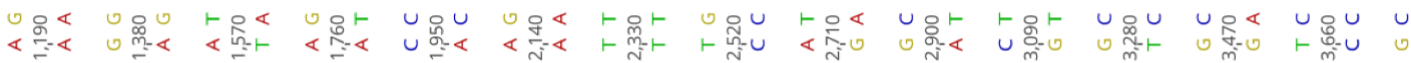

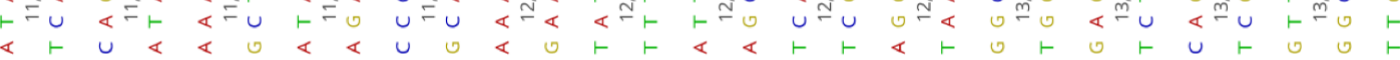

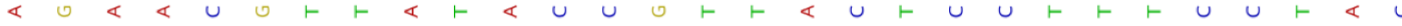

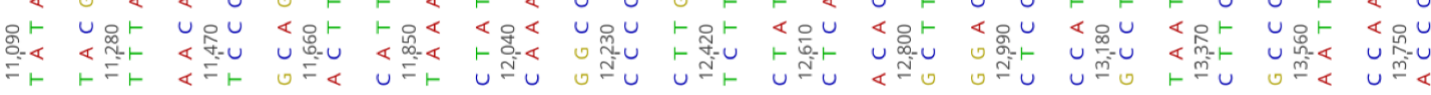

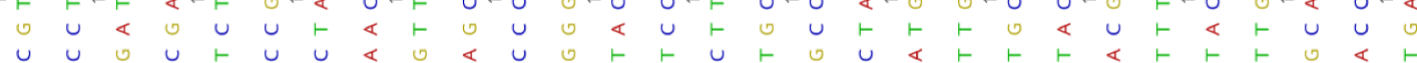

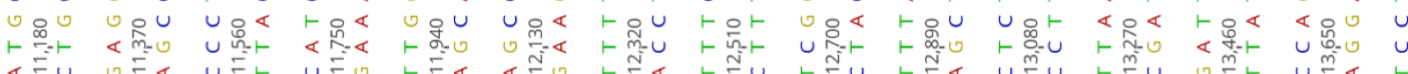

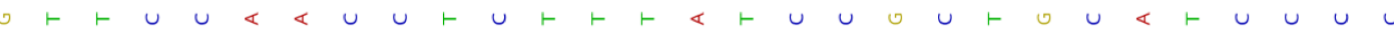
$r$
$a$

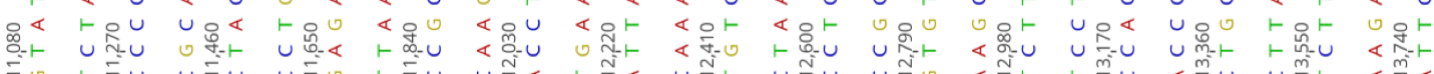

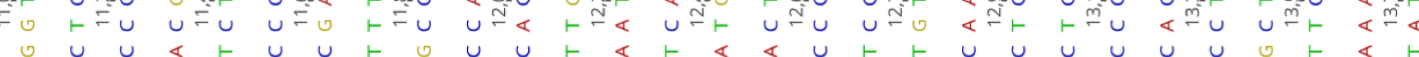

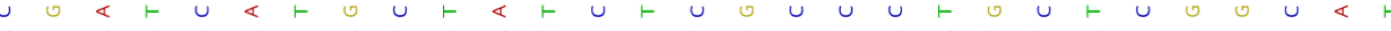

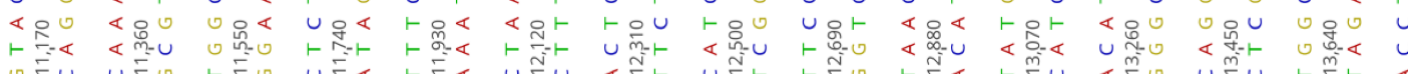

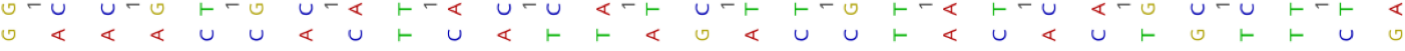

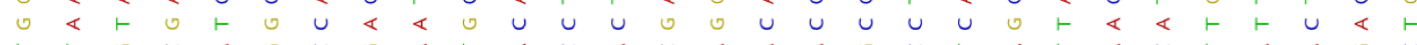

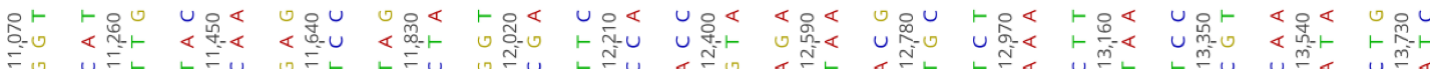
$\varangle \vdash u$ u u v u

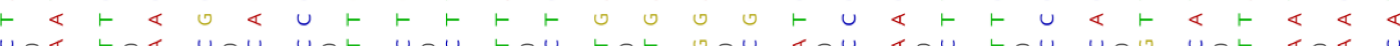

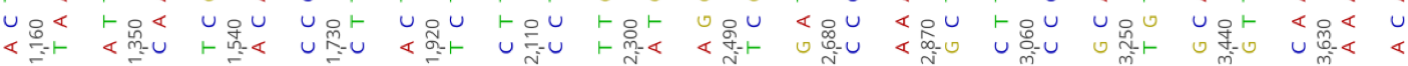

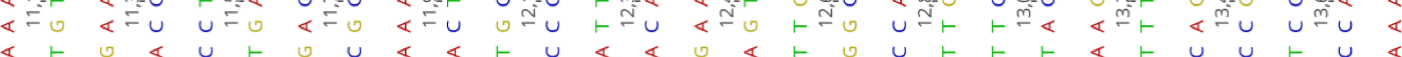

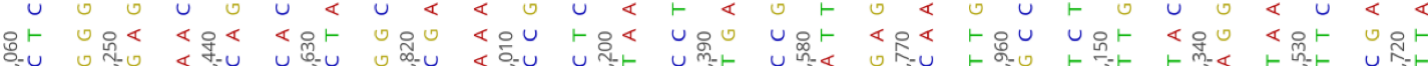

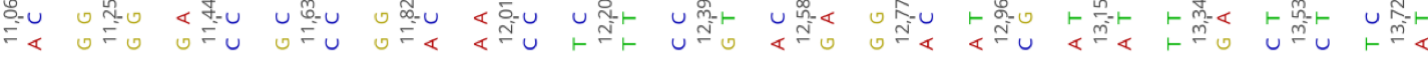

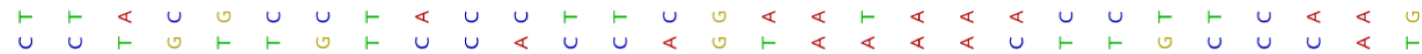

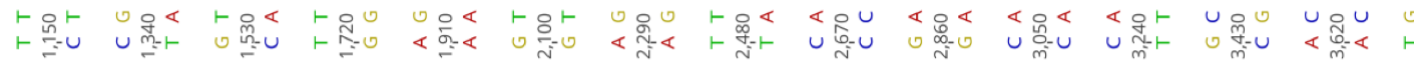

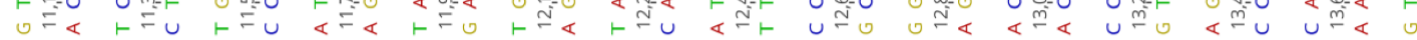

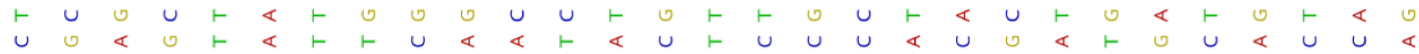

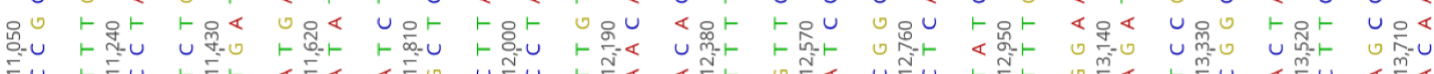

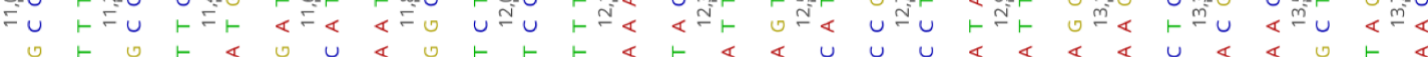

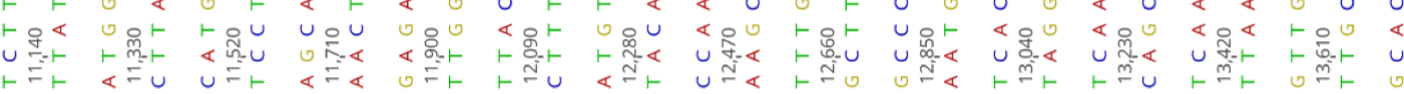

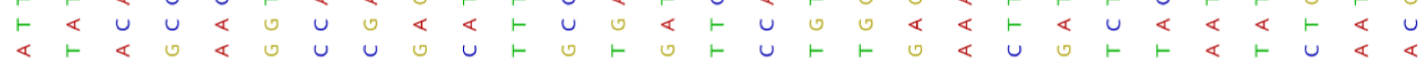

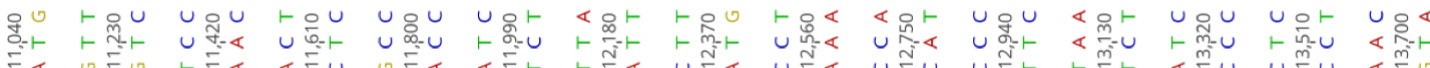

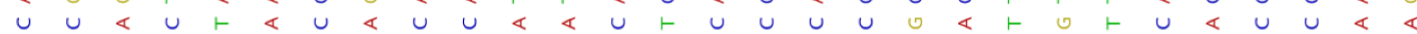

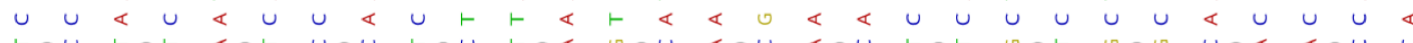

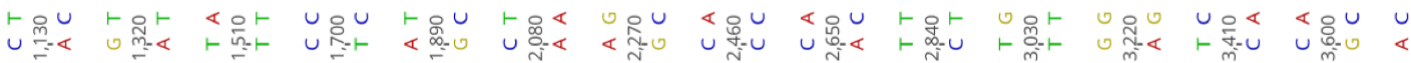

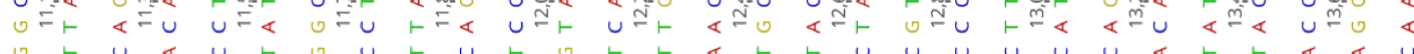

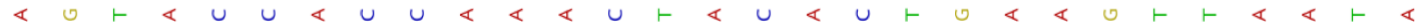

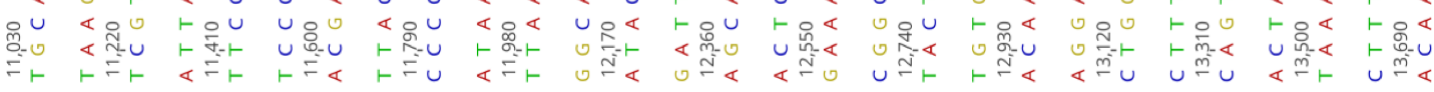

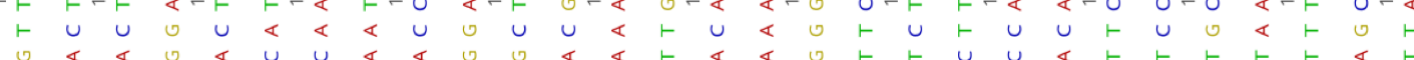

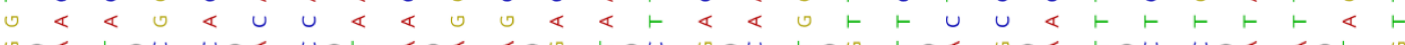

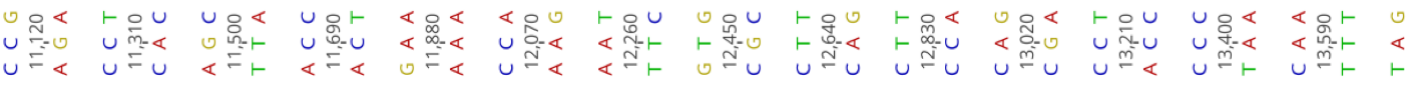

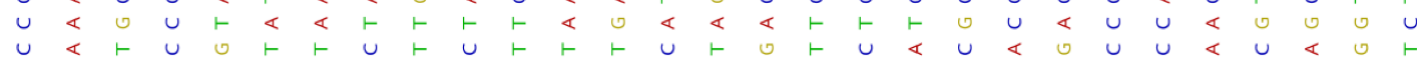

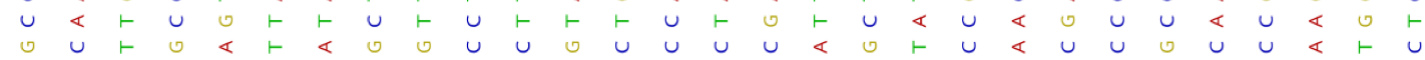




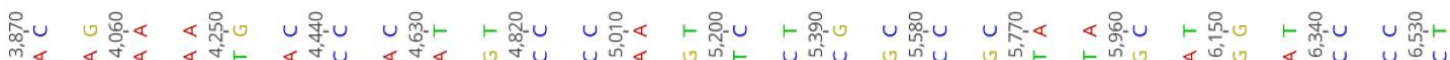

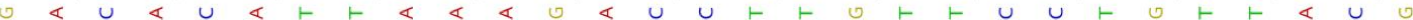

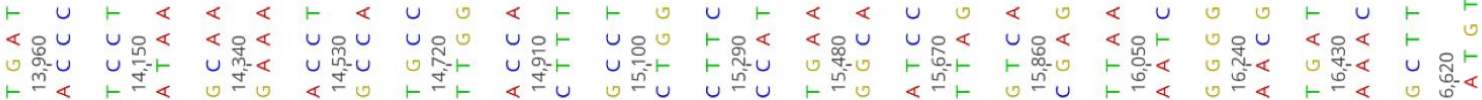

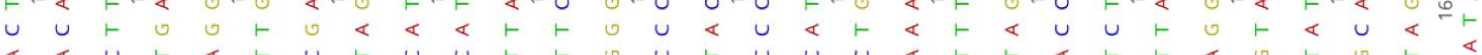

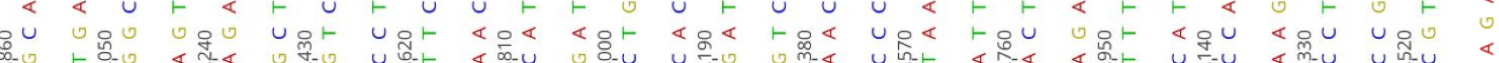

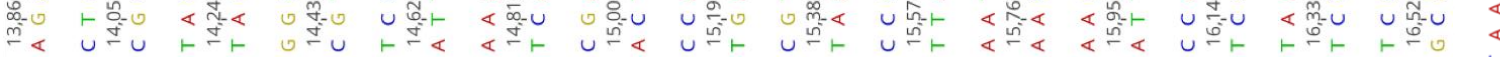

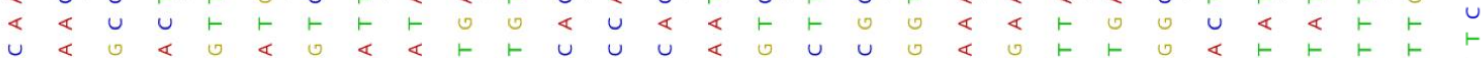

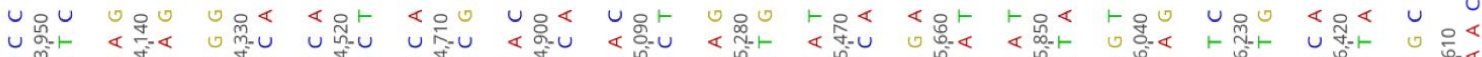

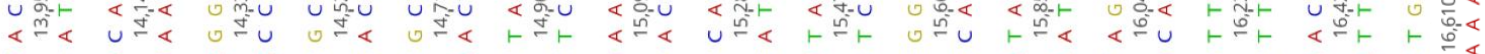

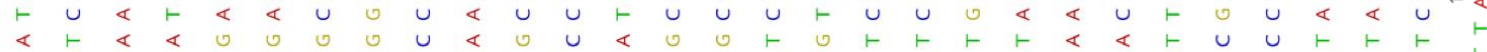

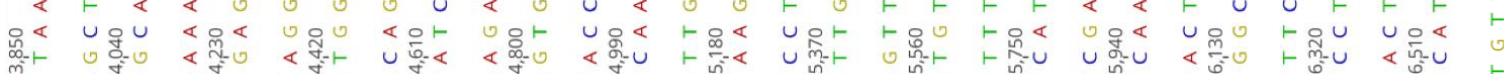

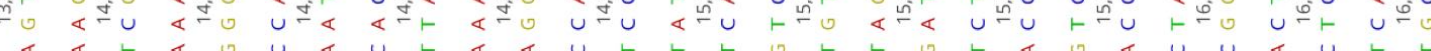

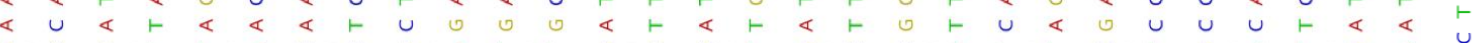

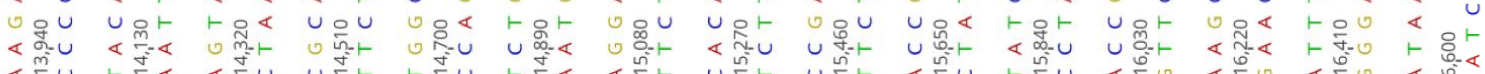

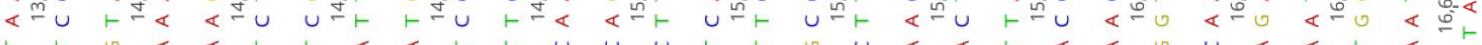

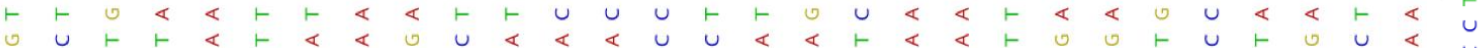

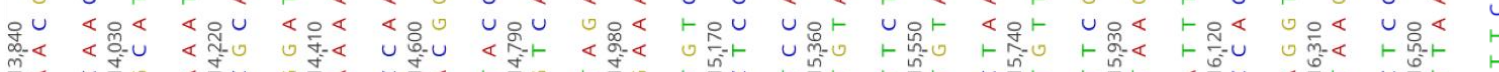

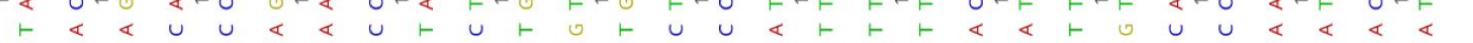

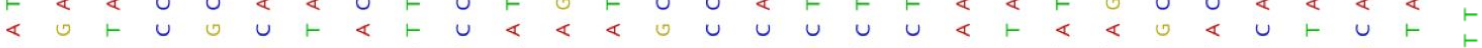

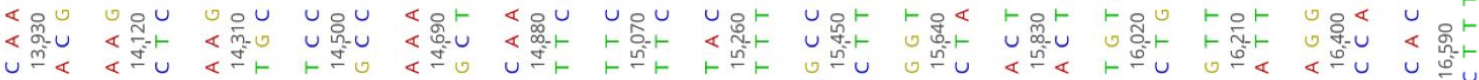

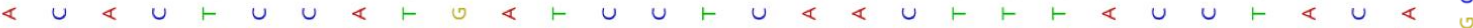

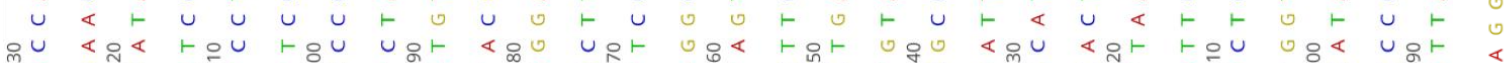

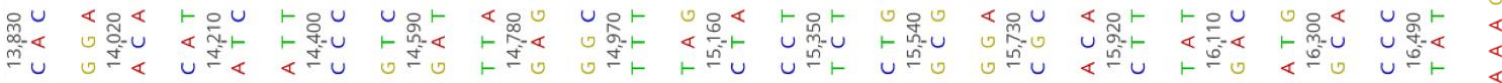

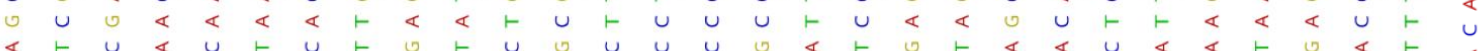

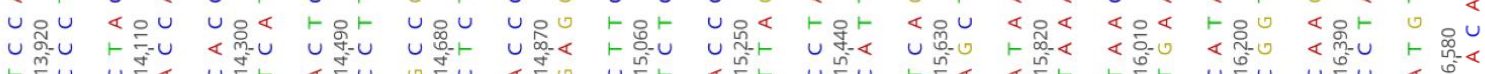
$u$
0

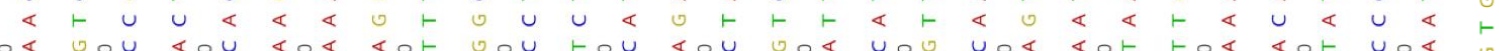

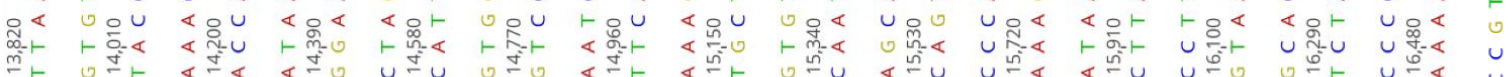

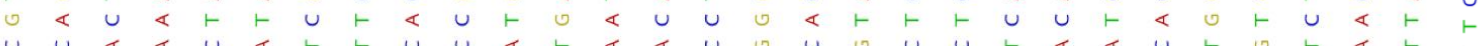

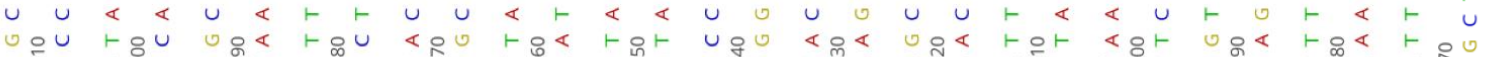

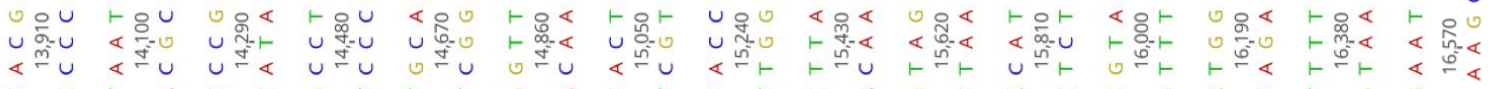

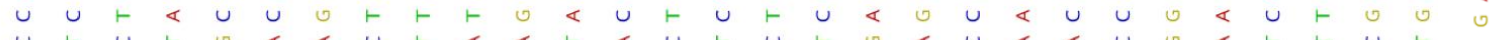

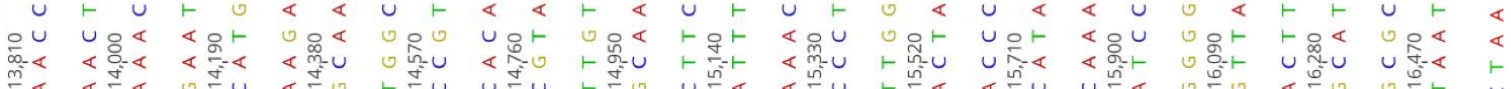

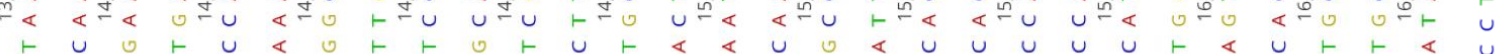

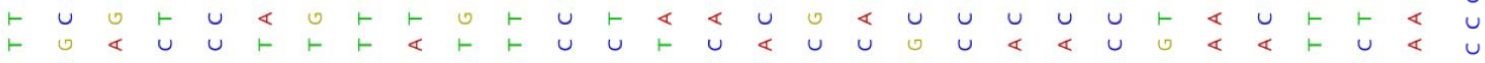

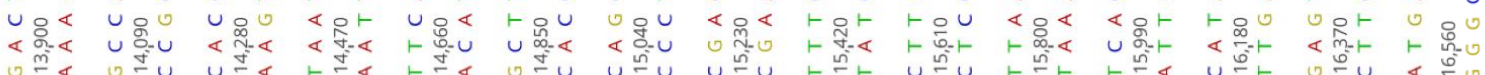
$u$
0

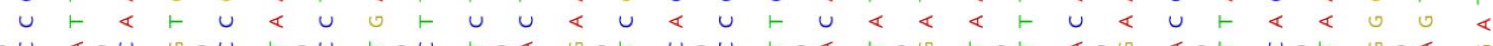

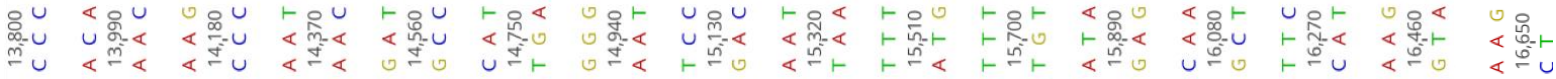

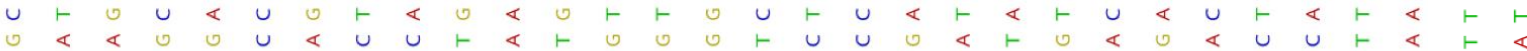

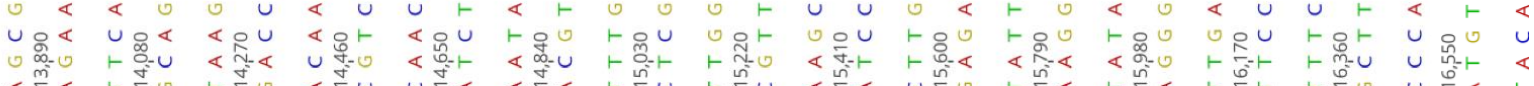

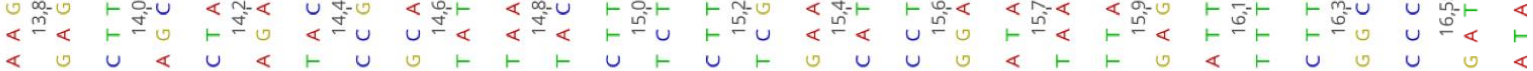

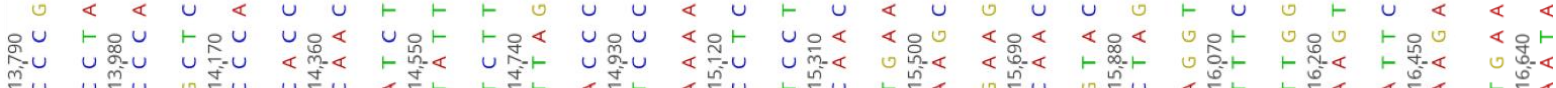

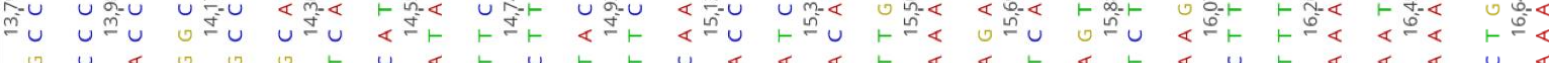

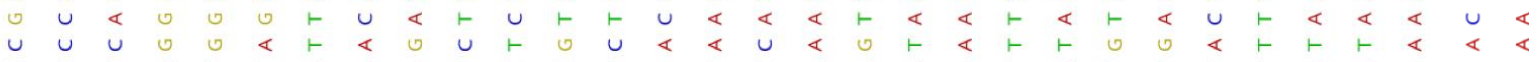

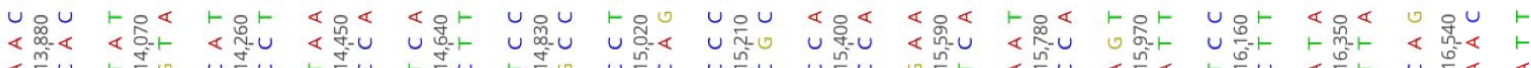
$\& u \& u$ u u o $\vdash u$ u u

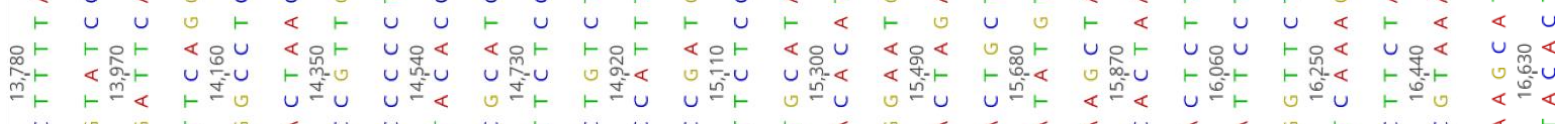

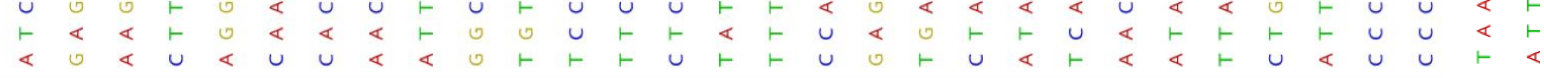

